\title{
Quantitative assessment of sustainable development and growth in sub-Saharan Africa
}

Citation for published version (APA):

Wiebe, K. S. (2012). Quantitative assessment of sustainable development and growth in sub-Saharan Africa. [Doctoral Thesis, Maastricht University]. Datawyse / Universitaire Pers Maastricht. https://doi.org/10.26481/dis.20120615kw

Document status and date:

Published: 01/01/2012

DOI:

$10.26481 /$ dis.20120615kw

Document Version:

Publisher's PDF, also known as Version of record

\section{Please check the document version of this publication:}

- A submitted manuscript is the version of the article upon submission and before peer-review. There can be important differences between the submitted version and the official published version of record.

People interested in the research are advised to contact the author for the final version of the publication, or visit the DOI to the publisher's website.

- The final author version and the galley proof are versions of the publication after peer review.

- The final published version features the final layout of the paper including the volume, issue and page numbers.

Link to publication

\footnotetext{
General rights rights.

- You may freely distribute the URL identifying the publication in the public portal. please follow below link for the End User Agreement:

www.umlib.nl/taverne-license

Take down policy

If you believe that this document breaches copyright please contact us at:

repository@maastrichtuniversity.nl

providing details and we will investigate your claim.
}

Copyright and moral rights for the publications made accessible in the public portal are retained by the authors and/or other copyright owners and it is a condition of accessing publications that users recognise and abide by the legal requirements associated with these

- Users may download and print one copy of any publication from the public portal for the purpose of private study or research.

- You may not further distribute the material or use it for any profit-making activity or commercial gain

If the publication is distributed under the terms of Article $25 \mathrm{fa}$ of the Dutch Copyright Act, indicated by the "Taverne" license above, 


\section{Quantitative Assessment of Sustainable Development and Growth IN SUb-SAHARAN AFricA}


(c) 2012 K. S. Wiebe

All rights reserved.

Cover prepared with R by K. S. Wiebe

Prepared with $\mathrm{LT}_{\mathrm{E}} \mathrm{X}$

UNU-MERIT Dissertation series \# 74

Printed in the Netherlands by Datawyse Maastricht Published by Universitaire Pers Maastricht

ISBN 9789461591555 


\title{
Quantitative Assessment of Sustainable Development and Growth in Sub-Saharan Africa
}

\author{
PROEFSCHRIFT
}

ter verkrijging van de graad van doctor aan de Universiteit Maastricht, op gezag van de Rector Magnificus, Prof. Mr. G.P.M.F. Mols, volgens het besluit van het College van Decanen, in het openbaar te verdedigen op vrijdag 15 juni 2012 om 10.00 uur

door

Kirsten Svenja Wiebe

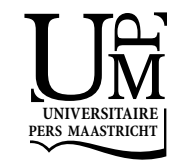




\section{Promotor:}

Prof. Dr. P. Mohnen

Co-promotor:

Dr. A. van Zon

Beoordelingscommissie:

Prof. Dr. T.T. Azomahou, voorzitter

Prof. Dr. K.J. Koch, Universität Siegen

Prof. Dr. J. Muysken

Dr. T. Ziesemer

This research is financed by United Nations University Maastricht Economic and Social Research and Training Center on Innovation and Technology (UNU-MERIT). 


\section{Contents}

1 Introduction 1

1.1 Economic growth in Sub-Saharan Africa . . . . . . . . . . . 1

1.2 Sustainable development in Sub-Saharan Africa . . . . . . . . . 2

1.3 Quantitative assessment .................. 4

2 Measuring and assessing sustainable development $\quad 7$

2.1 Political approaches to sustainable development . . . . . . . . 8

2.2 Measuring with indicators . . . . . . . . . . . . . 9

2.2 .1 Indicators . . . . . . . . . . . . . . . . . . . 10

2.2 .2 Indicator systems . . . . . . . . . . . . . . . . . . . 11

2.2 .3 Composite indicators . . . . . . . . . . . . . . . 11

2.3 SDIs and SD indicator systems . . . . . . . . . . . . 12

2.3.1 The Millennium Development Goals . . . . . . . . . . . 13

2.3.2 The Human Development Index . . . . . . . . . . . . . . 15

2.3.3 Alternative composite development indicators . . . . . . . . 17

2.4 When is development sustainable? . . . . . . . . . . . . . 18

2.4.1 Environmental sustainability . . . . . . . . . . . . . . 19

2.4 .2 Economic sustainability . . . . . . . . . . . . . . . 20

2.4 .3 Social sustainability . . . . . . . . . . . . . . . . 21

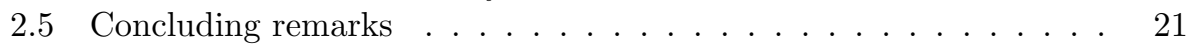

3 Development progress in Sub-Saharan Africa 23

3.1 Sub-Saharan Africa in the World . . . . . . . . . . . . . 24

3.2 Economic development and standard-of-living . . . . . . . . 27

3.3 Educational attainment . . . . . . . . . . . . . . . . . . 31

3.4 Health status . . . . . . . . . . . . . . . . . . . . . 33

3.5 Integrated development . . . . . . . . . . . . 36

3.6 Is development progress in SSA sustainable? . . . . . . . . . . 37

4 Complementarities in development 41

4.1 Empirical analysis of development . . . . . . . . . . . . 42

4.2 Complementarity analysis . . . . . . . . . . . . 45

4.3 Modeling development complementarities . . . . . . . . . 48

4.4 Results . . . . . . . . . . . . . . . . . 50

4.4.1 Structural form equations . . . . . . . . . . . . 52

4.4.2 Complementarity and partial adjustment coefficients . . . 56 


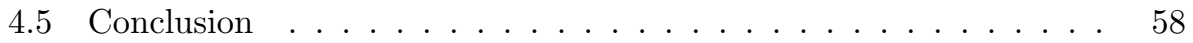

5 Public spending for development $\quad \mathbf{6 1}$

5.1 Public spending in developing countries . . . . . . . . . . . . . . 62

5.2 Optimum Portfolio Theory . . . . . . . . . . . . . . 65

5.3 Portfolio theory, public spending and the HDI . . . . . . . . . 68

5.3 .1 Data........................ 68

5.3.2 Efficient development portfolio design . . . . . . . . . . . 71

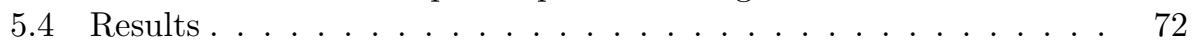

5.4.1 Estimation results ................ . . . . 72

5.4.2 Portfolio application results . . . . . . . . . . . . 75

5.4 .3 Performance measurement . . . . . . . . . . . . . . . 78

5.4.4 Allocation inefficiencies . . . . . . . . . . . . 81

5.4 Sensitivity analysis . . . . . . . . . . . . . . . . 86

5.5 Policy implications ................... 88

6 A growth model for development $\quad 91$

6.1 Growth theory and sustainable development . . . . . . . . . . . . 94

6.1.1 Theoretical relations between sustainable development issues 94

6.1.2 Developing countries and transitional dynamics . . . . . . . 97

6.2 The Lucas model, education and health . . . . . . . . . . . . . . . 101

6.2.1 Modeling the HDI . . . . . . . . . . . . . . . 103

6.2.2 Long-run balanced growth path . . . . . . . . . . . . 106

6.2.3 Transitional dynamics . . . . . . . . . . . . . . . . . . 117

6.3 Model implications and future research . . . . . . . . . . . . 120

7 Concluding remarks $\quad 123$

7.1 Summary of the main findings . . . . . . . . . . . . . . . . 123

7.2 Suggestions for future research . . . . . . . . . . . . . 125

A Mathematical appendix to Chapter 5 127

A.1 Derivation of the EDP FOC's . . . . . . . . . . . . . . . . . 127

A.2 The estimated variance-covariance matrix . . . . . . . . . . . . 129

B Mathematical appendix to Chapter 6 133

B.1 First order conditions . . . . . . . . . . . . . . . . . . 133

B.2 Differential equations of co-state variables . . . . . . . . . . . 135

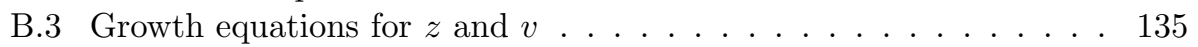

B.4 Transversality conditions in the long run equilibrium . . . . . . . . 136

B.5 Transition paths of individual shocks . . . . . . . . . . . . 136

$\begin{array}{ll}\text { Bibliography } & 140\end{array}$

$\begin{array}{ll}\text { Samenvatting } & 149\end{array}$

$\begin{array}{ll}\text { Curriculum Vitae } & 151\end{array}$ 


\section{List of Tables}

3.1 Data sources . . . . . . . . . . . . . . . . 24

3.2 Descriptive Statistics . . . . . . . . . . . . . . . . 25

3.3 Spearman correlations between standard-of-living indicators . . . . 30

3.4 Spearman correlations between education indicators . . . . . . . 33

3.5 Spearman correlations between health indicators . . . . . . . . 34

3.6 Intertemporal Spearman correlations between outcome indicators . 36

4.1 Estimation results Model I . . . . . . . . . . . . . . . . . . . . 53

4.2 Estimation results Model II . . . . . . . . . . . . . . . . . . . 54

4.3 Estimation results Model III . . . . . . . . . . . . . . . . 55

4.4 Complementarity and partial adjustment coefficients . . . . . . 57

5.1 Data sources and descriptive statistics $\ldots \ldots \ldots \ldots$

5.2 Country coverage . . . . . . . . . . . . . . 70

5.3 EDP estimation results $\ldots \ldots \ldots \ldots$. . . . . . . . . . 90

5.4 Governance correlations . . . . . . . . . . . . . . 90

6.1 Set of parameter values . . . . . . . . . . . . . . . . . 112

6.2 Responses to parameter changes . . . . . . . . . . . . . 115

6.3 Relative valuation of consumption, education and health . . . . 116

A.1 Variance-covariance matrix . . . . . . . . . . . . . . . 131 



\section{List of Figures}

2.1 Millennium Development Goals in Sub-Saharan Africa . . . . . . 14

3.1 Global development . . . . . . . . . . . . . . . 26

3.2 Standard of living over time . . . . . . . . . . . . . . . . . 28

3.3 Education over time . . . . . . . . . . . . . . . . 32

3.4 Health over time . . . . . . . . . . . . . . . . . . . 35

3.5 Contemporaneous correlations between outcome indicators . . . . 37

3.6 Development in SSA . . . . . . . . . . . . . . . . . . . . 39

4.1 Complementarities . . . . . . . . . . . . . . . . 52

5.1 The optimum portfolio selection problem $\ldots \ldots \ldots \ldots 6$

5.2 Efficient portfolio frontiers . . . . . . . . . . . . 77

5.3 Extended efficiency measurement . . . . . . . . . . . . . . . 79

5.4 Extended efficiency surpluses and deficits . . . . . . . . . . 80

5.5 Improvement in HDI with efficient spending . . . . . . . . . . . . 83

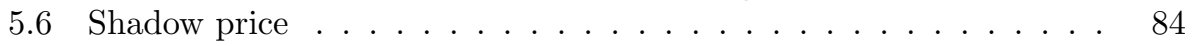

5.7 Actual budget shares . . . . . . . . . . . . . . . . 85

5.8 Difference between efficient and actual budget distribution . . . . 86

5.9 Sensitivity results . . . . . . . . . . . . . . . . . 87

6.1 Stylized facts of economic growth in developing countries: SubSaharan Africa . . . . . . . . . . . . . . . . . . 92

6.2 Theoretically modeled relations $\ldots \ldots \ldots \ldots \ldots$

6.3 Changing $\rho$ and $\theta \ldots \ldots \ldots$. . . . . . . . . . . . . 109

6.4 Changing $\alpha$ and $\delta$ or $\phi \ldots \ldots \ldots \ldots \ldots \ldots \ldots$

6.5 Changing $\beta$ and $\sigma$ or $\zeta \ldots \ldots \ldots \ldots \ldots \ldots \ldots \ldots \ldots$

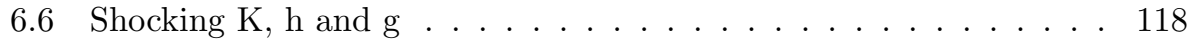

6.7 Shocking K, h and g: Transition paths . . . . . . . . . . 121

A.1 Variance-covariance matrix partitions . . . . . . . . . . 128

B.1 Shocking capital K . . . . . . . . . . . . . . . . 137

B.2 Shocking human capital h . . . . . . . . . . . . . . . . . 138

B.3 Shocking health level g . . . . . . . . . . . . . . . . 139 

Injustice anywhere is a threat to justice everywhere.

In a real sense all life is inter-related. All men are caught in an inescapable network of mutuality, tied in a single garment of destiny.

Whatever affects one directly affects all indirectly. I can never be what I ought to be until you are what you ought to be, and you can never be what you ought to be until I am what I ought to be. This is the inter-related structure of reality.

Martin Luther King Jr. 



\section{Acknowledgements}

During the past four and a half years I have lived in three very different worlds: the international academic world of MERIT and Maastricht, the world of Icelandic horses in Germany and the applied economic research world in Osnabrück, which made it possible to easily combine the other two worlds. But, in all of these worlds I was a PhD student, and I liked being a $\mathrm{PhD}$ student and I could not have done it without the support of the people in these different worlds.

First of all, I thank my supervisors Adriaan van Zon and Pierre Mohnen, who willingly substituted quite a few personal meetings by Skype conferences. Thank you, Eveline in de Braek and Wilma Coenegracht, for always promptly replying to all my non-research-related questions. Furthermore, I appreciate the constructive and detailed criticism during the PhD seminars by Luc Soete, Eddy Szirmai, Robin Cowan, Thomas Ziesemer and Théophile Azomahou. I would like to thank the latter two together with Joan Muysken and Karl-Josef Koch for forming the degree committee and reading and commenting on the complete dissertation. A special thanks goes to Shuan and Iman for making me feel welcome every time I came to MERIT.

The basis for doing a $\mathrm{PhD}$ was already given to me by my teachers during the Bachelor and Master studies at the Department of Quantitative Economics: Stan van Hoesel, Rudolf Müller, Jean-Pierre Urbain, Tjark Vredeveld, Dennis de Crombrugge, and many others, especially my fellow students, the Dutch guys Bart, Bas and Bram - and the German girls - Barbara and Kathrin.

My colleagues and friends at GWS in Osnabrück, thank you for providing a stimulating research atmosphere, which made me come to the office to work on my thesis on many days that I could have spent at home or in Maastricht. I would like to thank Christian Lutz for making it possible to combine working in Osnabrück and following the $\mathrm{PhD}$ programme $300 \mathrm{~km}$ away, Ingo Wolter and Mark Meyer for pushing me to put all the Greek and Latin letters into words and Thomas Drosdowski and Britta Stöver for listening to my confused thoughts over and over again. But most of all, I thank Ulrike Lehr for constantly sharing her problem solving skills, weekdays, weekends, and from all around the globe, especially during the last year.

This acknowledgment is not complete without appreciating the help of my Canadian cousins Christine and Karen, who proofread the entire thesis, and of Jacob Kikkert, who willingly shared his knowledge of the Dutch language to translate the summary.

And last, but not least, I have to express my gratitude to my closest friends 
and family: Dani and Basti, you really made living and studying in Maastricht fun. Birte, our long lasting friendship makes you more my sister than my very best friend. Silja and Berit, you are simply the best sisters I can wish for. Thank you for always listening to my - you call it - crazy talk ;-) My parents Conny and Rainer, thank you for always supporting my decisions, always making me think that I can do anything and for showing me, already very early in my life, that working hard is easier when you are able to take your mind off it for some time and let 'das Leben ist ein Ponyhof' be reality. 


\section{Chapter 1}

\section{Introduction}

In $201012.5 \%$ of the World's population, producing $1.8 \%$ of global GDP were living in Sub-Saharan Africa on 18.2\% of the earth's land area (WDI, 2011).

"Although Africa is a continent of great diversity, African states have much in common, not only their origins as colonial territories, but the similar hazards and difficulties they have faced. Indeed, what is so striking about the fifty-year period since independence is the extent to which African states have suffered so many of the same misfortunes." Martin Meredith in his book 'The state of Africa' (2005, p. 14)

Africa's misfortunes over the past five decades are numerous ranging from natural hazards, such as droughts, to exploitation of resources and political difficulties including corruption, despotisms and even war. Their consequences are high social disparities regarding income, access to basic necessities such as food and health care as well as education. Much has been written about the causes and consequences of these problems in Africa. This thesis takes a purely quantitative approach to analyzing development in Sub-Saharan Africa over the past three decades.

The title of this work, read from back to front, provides an outline for this introductory chapter and gives an overview of this thesis: Sub-Saharan Africa has just been characterized, the next two sections shortly introduce economic growth and sustainable development. Bringing these two concepts together gives the motivation and research questions, which will be tackled using quantitative assessment methods.

\subsection{Economic growth in Sub-Saharan Africa}

Recently, the African countries have been called the 'lion economies' (The Economist, 2011), which is a reference to the 'Asian tigers', reflecting the fact that the African economies have grown with almost 5\% (GDP in constant prices) on average between 2005 and 2010 (WDI, 2011). Even though this recent economic growth performance is applaudable, one has to keep in mind that the average per capita GDP in Africa still is only about 1300 USD (in current prices) and, thus, far below 
the World average of almost 10000 USD (in current prices). In addition, 5\% GDP growth result in only $2.4 \%$ per capita GDP growth, which is - based on an income of 1000 USD - only a total additional 24 USD per capita annually, while the average global growth of slightly more than $1 \%$ per capita makes a difference of 100 USD for a current per capita income of 10000 USD. Looking at percentage growth rates alone might overstate the actual development progress in the short run, as the relative absolute growth shows that the African countries are still lagging behind the rest of the world. Still, high growth rates are a necessary condition for long term economic development.

Economic growth has been subject of intense research over the past centuries, resulting in a variety of theoretical models ranging from the first formal growth models such as the Harrod-Domar model (Harrod, 1939), neo-classical growth models, e.g. the Solow-Swan model (Solow, 1956) or the Ramsey-Cass-Koopmans model (Ramsey, 1928; Cass, 1965, 1966), and new Keynesian growth theory (Kaldor, 1961), to new neo-classical growth theory (Romer, 1989) that emerged from explicitly considering knowledge as a production input (Arrow et al., 1961, Uzawa, 1962) and evolutionary growth models (Nelson and Winter, 1982). Many of the older theoretical growth models, however, are not capable of explaining the long run low growth performance of the African countries. Still, there are some theoretical economists that have explicitly analyzed growth in developing countries, as for example Agénor et al. (2004, 2005) or Steger (2000), who, following Kaldor (1961) and Romer (1989), developed four stylized facts of economic growth in developing countries. But, ...

\subsection{Sustainable development in Sub-Saharan Africa}

... economic growth alone is not sufficient for development in any country, especially in the Sub-Saharan African countries, because of two main reasons: First, economic growth is often unequally distributed across the population; and, second, growth of the economy in monetary terms does not necessarily imply development in the non-monetary aspects such as education or health, both of which are of major concern in Sub-Saharan Africa. This issue has been recognized a long time ago and different programs such as the United Nations (UN) campaigns 'Health for All' or 'Education for All' have been implemented.

"The main thing was to have people realize the centrality of health in human development and therefore in any nations development." Dr. Gro Harlem Brundtland, Former WHO Director General, in a promotion video for the global health fund in January $2012 .^{1}$

"Education needs to maintain a central position in the global development architecture beyond 2015. Equitable learning supports sustainable development in a variety of ways. It improves health and livelihoods, empowers women and other vulnerable groups, promotes democracy, boosts economic growth and reduces poverty, and helps to

\footnotetext{
${ }^{1}$ UN DESA: Video 'The Global Fund: 10 Years of Impact', http://youtu.be/OA-31xD0log, at 02:07 $\mathrm{min}$.
} 
lock in these gains for generations to come." Pauline Rose, Director of the Education for All Global Monitoring Report, in January 2012. ${ }^{2}$

Not only should non-monetary aspects be considered in development, but also should development achievements be sustainable. Development achievements are sustainable if they do not only affect short-run development, but contribute to a positive long-run development. Sustainable development targets not only for Africa, but for all developing and emerging economies world wide, are for example stated in the Millennium Development Goals (McGillivray, 2008).

"We need to chart a new, more sustainable course for the future, one that strengthens equality and economic growth while protecting our planet. (...) Sustainable development offers our best chance to change course." Ban Ki-Moon, Secretary-General of the United Nations, in January $2012^{3}$.

The term 'sustainable development' is known from the famous Brundtland Report from 1987. Chapter 2 will introduce the concept of sustainable development in more detail and illustrate its multi-dimensional nature. These dimensions are time (past, present and future), location (all countries world wide) and aspects of development (economic, social, environmental). Over the past decades development progress in Sub-Saharan Africa in terms of all these aspects has been slow. The Deputy Secretary-General Asha-Rose Migiro of the New Partnership for Africa's Development (NEPAD) describes the current situation as $^{4}$

"The African child who gets an education still may not find a decent job. The African woman who enjoys greater gender equality still may die in childbirth. The African patient receiving anti-retroviral drugs still may fall victim to bacteria from poor sanitation."

This relatively bad performance of African countries compared to countries in other world regions in all development aspects (economic, social and environmental) suggests that these aspects are not independent. The central research question of this work is

\section{How are the different aspects of sustainable development inter-related?}

To answer this question, Chapter 2 gives the foundation for the quantitative analysis in the remaining chapters by summarizing how sustainable development is measured, theoretically and in practice, and by defining when development can be considered to be sustainable.

\footnotetext{
${ }^{2}$ World Education Blog (Jan 26, 2012): 'The future we want' post-2015: Sustainable development goals. https://efareport.wordpress.com/2012/01/26/the-future-we-want-post-2015sustainable-development-goals / .

${ }^{3}$ UN News Centre, Jan 30, 2012: With new blueprint in hand, Ban calls for action to chart more sustainable future. http://www.un.org/apps/news/story.asp?NewsID $=41077$ $\& \mathrm{Cr}=$ sustainable+development\&Cr $1=$.

${ }^{4}$ UN News Centre, Oct 7, 2011: Top UN officials praise gains of African development partnership. http://www.un.org/apps/news/story.asp?NewsID $=39973 \& \mathrm{Cr}=$ mdgs $\& \mathrm{Cr} 1=\& \mathrm{Kw} 1=\mathrm{Top}+$ $\mathrm{UN}+$ officials + praise+gains+of+African+development+partnership $\& \mathrm{Kw} 2=\& \mathrm{Kw} 3=$
} 


\subsection{Quantitative assessment}

The central research question will be comprehensively analyzed by using different quantitative economic methods: descriptive statistical analysis in Chapter 3, econometric complementarity analysis in Chapter 4, portfolio theory in Chapter 5 and endogenous growth theory in Chapter 6.

According to Professor Paul Cheung, Director of the United Nations Statistics Division (UNSD), Department of Economic and Social Affairs, in February 2012 "statistics are crucial to economic and social development." The quantitative analysis in this thesis begins with a statistical description of the development progress in Sub-Saharan Africa over the past three decades in Chapter 3. Input and outcome indicators of different development aspects and their development over time and across countries are analyzed, starting with economy-related indicators in Section 3.2 and followed with educational and health aspects in Sections 3.3 and 3.4, respectively. The chapter closes with a simple correlation analysis, which provides a first indication on the nature of the interdependencies between the different development aspects.

Chapter 4 builds on the results of Chapter 3 and applies econometric analysis to empirically identify complementarities between the development aspects. The method of econometric complementarity analysis is known from firm productivity analysis and has to be extended here to additionally include a partial adjustment model. This is necessary because a country's development is not necessarily planned as a profit maximizing optimality problem, which is a common assumption in economic analyses at the firm level. The partial adjustment model allows for the fact that development progress is not on its optimal path. The analysis in Chapter 4, which uses data on economic, education and health aspects in Sub-Saharan Africa over the past three decades, shows that development in this region has not only been off its optimum path, but even further diverged during the 1990s. The empirical results in Chapters 3 and 4 clearly show that education and health are mutually reinforcing and, hence, are very important for the overall development of African countries.

Chapter 5 answers the question of what local policy makers' possibilities are to optimize overall development using the existing complementarities, that were found in Chapter 4. Overall development in this chapter is measured by the Human Development Index (HDI), a composite index of an education, a health and a standard-of-living indicator. One of the responsibilities of local policy makers is the allocation of public expenditures across the different budget items. Based on Markowitz' optimum portfolio theory, this chapter introduces the concept of efficient development portfolios, an approach to calculating the optimal allocation of a government budget across different budget items that relate to the development aspects. The main result is that far too little government money is spent on health and education, while the share of remaining government expenditures in the total budget generally is too high. An increase in total public spending is expected to increase the overall development, but for most countries the variance of the expected outcomes increase as well.

Sustainable development is a long run issue. The most common way of analyzing the long run development of an economy is by using theoretical growth 
models. As shortly discussed in the section on economic growth in Sub-Saharan Africa, there only exist very few growth models for developing countries. Chapter 6 develops an endogenous growth model that explicitly takes into account the non-monetary aspects of development. To this end, the model not only includes a final output production sector, but also a health and an education sector. Furthermore, health and education are considered as contributing factors to welfare, thus acknowledging the importance of these two factors.

Chapter 7 summarizes the main findings of this thesis and suggests some topics for future research. 



\section{Chapter 2}

\section{Measuring and assessing sustainable development}

The report by the Commission on the Measurement of Economic Performance and Social Progress (Stiglitz et al., 2009) and the OECD "Better Life Initiative" (ibid, 2011) has shifted the attention of policy makers and researchers back to the shortcomings of measuring a country's development solely on the basis of GDP or GDP per capita. In their recommendations Stiglitz et al. clearly point out that this production based measure is not adequate for measuring society's well-being. Their first recommendation is to "...look at income and consumption rather than production, (...) when evaluating material well-being..." (p.12). Further, social development as well as environmental conditions should be considered as these also have strong impacts on living conditions now and in the future. Both social and environmental factors, though, are often hard to capture in one indicator. Possible indicators such as school enrollment rates or $\mathrm{CO}_{2}$ emissions are available for long time periods for at least the developed countries. What these indicators do not measure is the quality of education or the impact of $\mathrm{CO}_{2}$ on the environment. Nevertheless, according to Stiglitz et al. (2009) these should be measured. In this context the notion of sustainable development has gained importance in the past decade.

The concept of sustainable development is long known and recognized as important. The most famous definition of sustainable development is given in the 1987 Brundtland Report: "Sustainable development is development that meets the needs of the present without compromising the ability of future generations to meet their own needs." Sustainable development encompasses various aspects of human life, explicitly laid out in the key objectives of the renewed EU Sustainable Development Strategy (European Council, 2006): environmental protection, social equity and cohesion, economic prosperity, and meeting our international responsibilities. These four objectives are also reflected in the United Nations Millennium Development Goals (MDGs).

Using these description alone, we are able to grasp the concept behind sustainable development: it is multi-dimensional in multiple dimensions. First, from the Brundtland Report, we have the reference to the presence and the future. That 
means that we are not only looking at one point in time, but also consider future consequences of our actions today. Sustainable development is an inter-temporal issue.

Second, from the EU Sustainable Development Strategy (EU SDS) we learn that we may not only concentrate a single subject, i.e. the economy or economic growth, but also take into account other aspects of development: the environment and also social issues. These three aspects of development are often referred to as the three pillars of sustainable development: the economic, the social, and the environmental pillar.

The last key objective of the EU SDS and MDG 8, reflect the third and last multi-dimensional dimension of sustainable development. It does not concern one person, one group of people, one city, or one country only. In times of increasing globalization, be it economic, social, or environmental aspects, sustainable development cannot be achieved in one country alone. Development has to be sustainable globally.

In this chapter, a short overview of existing approaches to measuring sustainable development will be given. First, some political sustainable development agendas will be reviewed, followed by a short discussion on the use of indicators when measuring development. Then some existing indicators and indicator systems will be introduced. The chapter concludes with a discussion of the question when development is sustainable.

\subsection{Political approaches to sustainable develop- ment}

There are different international agreements dealing with sustainable development, e.g. the UN Agenda 21 agreed upon at the UNCED meeting in 1992 in Rio de Janeiro, the Johannesburg Plan of Implementation (JPOI) developed at the UNCED meeting in 2002 or the Lisbon Strategy of the European Commission from 2000 and its environmental extension agreed upon at the 2001 Gothenburg meeting. Advancements in the implementation of sustainable development strategies vary in different parts of the world with some countries having national sustainable development strategies. In Europe, additional to these national sustainable development strategies, the European Commission agreed on an European sustainable development strategy, based upon the Lisbon and Gothenburg strategies.

The Sustainable Development Report on Africa (UNECA, 2008) was issued by UNECA, the United Nations Economic Commission for Africa. This report mainly refers to the program of the African Union (AU) called "New partnership for Africa's Development" (NEPAD), which is recognized as "providing a framework for sustainable development on the continent" (UNECA, 2008, p. xiii) by the Johannesburg Plan of Implementation (JPOI, 2002). Chapter 8 of JPOI explicitly deals with sustainable development in Africa and its targets mainly coincide with the Millennium Development Goals (MDGs). To this date, national sustainable development strategies relating to NEPAD are not yet implemented in most African countries.

While sustainable development targets for the EU are defined in national SDS 
and the EU SDS, the AU does not have such precise targets. The Millennium Development Goals can be understood as more detailed sustainable development targets for this region (Dalal-Clayton, 2003). On a general level, the understanding of sustainable development for Europe and Africa does not differ substantially. It is rather the details that differ and the emphasis put onto each of the three pillars. Out of ten themes of sustainable development described in the EUROSTAT (2009) report, four themes directly relate to environmental protection and are rather detailed, while only MDG 7 deals with environmental protection. The MDGs are more detailed with respect to the specification of the social pillar of sustainable development.

Sustainable development targets in the EU SDS relating to the environment are, for example, a decrease of greenhouse gas (GHG) emissions, an increase in resource productivity, a decrease in energy intensity and energy dependency. Socially relevant sustainable development targets are inter alia a reduction of health inequalities and a decrease of the number of jobless households. The MDGs specify the targets more clearly. MDG 1 for example calls for "halving global poverty" until 2015 (compared to 1990 levels), and MDG 4 states that child mortality should be reduced by two thirds. Regarding sustainable environmental development, the MDGs are just as vague as the EU SDS, stating that international environmental principles should be integrated into national policies.

For the MDGs as well as for the EU SDS indicators were defined that are used to monitor and measure progress toward the targets. Next to these indicators, other internationally accepted measures of (sustainable) development exist, such as the Human Development Index (HDI). Before Section 2.3 introduces some existing indicators and indicator systems used for monitoring countries' development, the next section gives a short overview of indicators and indicator systems, and why and how they are used.

\section{$2.2 \quad$ Measuring with indicators}

In its recent report on the quality of life, the $\operatorname{OECD}(2011$, p.4) emphasizes the importance of measuring development using statistical methods: "Developing better measures is not an end in itself but a means to enhance policies that improve people's lives. Statistics on critical aspects of people's lives are important, as what we measure shapes what we, collectively, strive to pursue. But statistics are obviously not enough. They need to be combined with a robust understanding and analysis of how the outcomes that these indicators measure respond to policy interventions."

Examples for politically relevant indicator systems that measure the development of a country or region are indicators of the Millennium Development Goals, the Human Development Index the European Structural Indicators and the European Sustainable Development Indicators, or Canada's and Australia's key national indicator systems. Before describing these indicators and indicator systems in detail, this section shortly discusses the methodological aspects of using indicators. 


\subsubsection{Indicators}

"An indicator is a quantitative measure that describes an economic, environmental, or social and cultural condition." GAO (2004)

"Indicators are generally understood as quantitative measures that are specified using several mathematical constructs (e.g., ordinal or cardinal scale) for different types of reference objects and on various levels of abstractions..." Frank et al. (2008) based on Grüning (2002)

A search for the word 'indicator' at the OCED Glossary of Statistical Terms (OECD, 2007) returned 296 results, including

\section{- statistical indicator}

"A data element that represents statistical data for a specified time, place, and other characteristics."

- sustainable development indicator

"A statistical measure that gives an indication on the sustainability of social, environmental and economic development."

- environmental indicator

"An environmental indicator is a parameter, or a value derived from parameters, that points to, provides information about and/or describes the state of the environment, and has a significance extending beyond that directly associated with any given parametric value. The term may encompass indicators of environmental pressures, conditions and responses."

Indicators are used in different fields, not only economic, social, or environmental development, but also in management, finance, or other realms of science. The intended purpose of indicators is performance measurement, i.e. measuring progress itself or progress toward a specific target. According to Noll (2004), social indicators have different potential uses: they can be used for comparative research,which is done in this work, for measuring and monitoring well-being and social progress, and as a tool for policy making. The use of economic, social, and environmental indicators by politicians is similar to that in management or finance, where managers use the indicators to follow progress toward pre-set targets or benchmarks (Frank et al., 2008), and possibly adapt their strategies if the indicator development shows that the set target will not be reached or that the performance is too low compared to the benchmark. Indicators can also be used to compare performance across departments or firms, in case of management or finance indicators, or across regions or countries, in case of policy driven indicators. Policy driven indicators emerge when policy objectives are formulated that are to be measured. Noll (2004) further distinguishes between data driven and concept driven indicators. Data driven indicators are those that emerge from data collected in databases; he mentions Eurostat's List of Social Indicators as an example. Concept driven indicators on the other hand originate from concepts that define different dimensions that should be measured. An example for this is the "proportion of people living on less than 1 dollar a day'. This is a very important indicator to measure poverty, but data is hardly available. 
Indicators can further be classified as direct and indirect or proxy indicators. Direct indicators directly measure an issue of interest for policy makers or economists, whereas indirect indicators are only an approximation of what they measure. The best known proxy indicator is GDP per capita as measure for welfare. It does not directly measure the quality of life; it rather measures per capita production, i.e. the value of all goods and services produced in the country divided by the size of its population. Both direct and indirect indicators can be measured over time, used to assess progress toward a goal associated with the indicator, or used for comparison to a benchmark or to other performance units, i.e. other countries or regions. Furthermore, indicators should be analytically sound, measurable, and relevant to the subject they are intended to measure.

As pointed out in the previous sections, sustainable development is not unidimensional; therefore it cannot be represented by a single indicator. There are two possibilities to capture the multi-dimensional concept of sustainable development: composite indicators and indicator systems.

\subsubsection{Indicator systems}

Indicator systems are collections of individual indicators, that are organized in such a way that they are easily accessible, understandable, and interpretable. The individual indicators in an indicator system should be based on the same data collection process, that is, they should be measured on common grounds. If that is the case, they can be set in relation to each other and compared to each other. One indicator system can cover a variety of subjects that are relevant to the overall measurement target. In case of sustainable development these include economic, social, cultural, political, and environmental issues.

\subsubsection{Composite indicators}

Composite indicators are indicators that are calculated from two or more individual indicators, with the intention to capture multi-dimensional concepts using just one number. They can therefore be seen as aggregates of indicator systems. "Ideally, a composite indicator should be based on a theoretical framework / definition, which allows individual indicators / variables to be selected, combined and weighted in a manner which reflects the dimensions or structure of the phenomena being measured." (OECD, 2007, Context of 'composite indicator').

Composite indicators are heavily criticized, but they also have their merits. In this thesis, composite indicators are used to measure a country's development in multiple dimensions to be able to compare development across countries and over time. When using a single index instead of different individual indicators, it is straight forward to rank countries, analyze complex matters efficiently, and policy makers and the public can easily interpret the outcome. But they can just as easily misinterpret the outcome or come to "simplistic policy conclusions" (p.13, OECD and JRC, 2008), because information embodied in the individual components of the composite indicator gets lost.

The construction of a composite indicator is a complex task, where errors can be made at each step. Possible flaws are the decision which indicators to 
include, disregarding that measurement and definition of the indicators in different countries may vary, as well as the fact that there may be different data collection procedures in different countries, or different methods of filling data gaps, et cetera.

One of the most sensible tasks when constructing a composite indicator is the design of the model which aggregates the different indicators. Saltelli et al. (2004) present three basic types of these models: linear aggregation, geometric aggregation, and multi-criteria analysis. Linear aggregation is used most frequently, but it has the drawback of "compensation". This refers to the possibility of leveling out the effect of bad scores on some variables by good scores in other variables, depending on the relative weights. This effect also occurs for geometric aggregation, but to a lesser extent as the penalty of scoring bad in one of the components is higher. The compensation effect is smaller, the higher the correlation between the input variables, but "the interaction among indicators, ..., is often ignored" (Mairesse and Mohnen, 2010, p.1140). The interaction between the different indicators is subject of Chapter 4 .

Compensation, however, is not necessarily bad, if the aim is to compare countries despite their differences. For a more extensive review on possible aggregation methods, including their (dis-)advantages, the reader is referred to OECD and JRC (2008). Finding the correct weights for combining different indicators is crucial, as these reflect the relative importance of the individual indicators in the final number. The weighting system is often seen as being arbitrarily chosen (Mairesse and Mohnen, 2010) and therefore tends to be criticized the most when a composite indicator is constructed.

Multi-criteria analysis does not impose a specific weighting scheme, rather the importance of the single indicators and their weighting and aggregation are based upon experts' opinions and discussed within the group of experts that are to make the decision.

Probably, the best known composite indicators for development is the Human Development Index (HDI). From a variety of indicators relevant to a country's development, one single indicator using basic mathematical operations (addition, subtraction, multiplication, division) is calculated. The HDI will be introduced in the next section and explained in more detail later.

\subsection{SDIs and SD indicator systems}

The discussion in the previous section shows that development can be measured by single indicators, composite indicators, or indicator systems. This section will introduce one indicator system and a composite indicator, which are developed by the United Nations Development Program (UNDP) and that are used globally for measuring development and development progress: the Millennium Development Goals (MDGs) and the Human Development Index (HDI). These indicators are available for almost all countries, including the Sub-Saharan African countries.

Some of the industrialized countries have additionally developed their own indicator systems, which capture national/regional sustainable development strategies in more detail. Examples are the Sustainable Development Indicators in the EU and sets of structural indicators in the EU and other OECD countries. In accordance with the Lisbon Strategy a set of 35 structural indicators plus eight 
background indicators was developed for measuring development in the EU countries (Keuning and Verbruggen, 2003a). The structural indicators mainly refer to economic development and aim at measuring the progress EU countries make in order "to become the most competitive and dynamic knowledge-based economy in the world" (European Council, 2000). The European structural indicators cover employment, innovation and research, economic reform, social cohesion and environment (Keuning and Verbruggen, 2003b). Australia and Canada also have national structural indicator systems that are similar to the set of European structural indicators.

Additionally, the European Commission developed indicators to monitor the progress toward a more sustainable development in Europe, the sustainable development indicators (SDIs). These indicators cover ten themes: Socio-economic development, sustainable consumption and production, social inclusion, demographic changes, public health, climate change and energy, sustainable transport, natural resources, global partnership, and good governance. The progress that is measured with these indicators is analyzed in biannual reports, e.g. EUROSTAT (2007) and (2009).

\subsubsection{The Millennium Development Goals}

The Millennium Development Goals (MDGs) are an outcome of the United Nations Millennium Declaration from 2000 (UN, 2000) and were phrased as the MDGs for the first time in the "Road map toward the implementation of the United Nations Millennium Declaration" (UN, 2001). They were further described in the "Implementation of the United Nations Millennium Declaration" (UN, 2002). The MDGs cover a variety of subjects disaggregated into eight goals (UN, 2007, 2008a, 2008b): Eradicate extreme poverty and hunger, achieve universal primary education, promote gender equality and empower women, reduce child mortality, improve maternal health, combat HIV/AIDS, malaria and other diseases, ensure environmental sustainability and develop a global partnership for development.

Progress toward each of these goals and sub-targets is measured by different indicators. The base year relative to which progress is measured is 1990. By now, data until 2007 are available. We can therefore analyze the progress until the "midpoint" between setting the goals and 2015, the year in which they should be reached. A detailed analysis of the development of the MDGs is given in Bourguignon et al. (2008a) and its technical counterpart (Bourguignon et al., 2008b). In general, progress toward the goals is slow at the country level, especially in Sub-Saharan African countries, as can be seen in Figure $2.1^{1}$.

The goals themselves do not specify whether they should be reached in each country individually, continent wide or world wide. Progress in all least developed countries is driven by progress made in Asian countries, especially in East Asia, where poverty rates decreased from about $28 \%$ to $15 \%$ in the 1990 s already (Devarajan et al., 2002; Besley and Burgess, 2003). Vandemoortele (2007), who

\footnotetext{
${ }^{1}$ This figure was displayed at http://go.worldbank.org/WO8BCF0HG0 in 2007 when the Global Monitoring Report 2007 (Sundberg et al., 2007) was published. The "September 2008 update" however replaced this figure with more recent figures. The individual graphs within this figure can be found in the corresponding sections of the Global Monitoring Report 2007. It is also used by Easterly (2009) as Figure 1 on p. 27.
} 


\section{Sub-Saharan Africa}
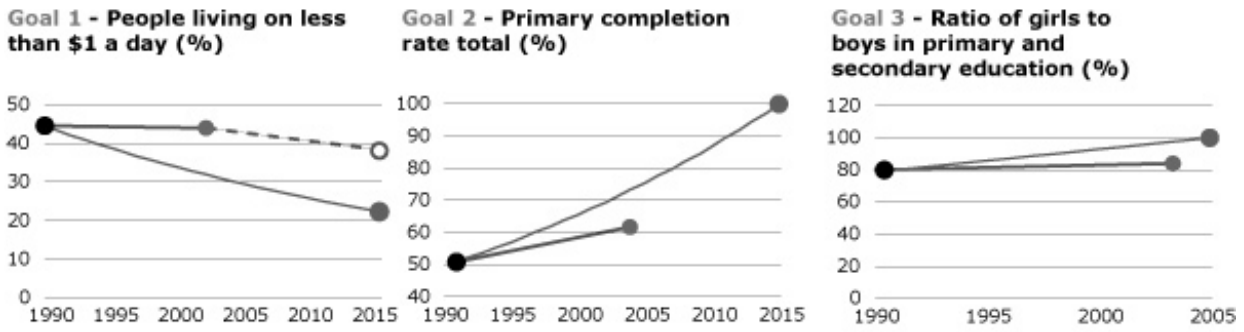

Goal 4 - Under 5 mortality (deaths per 1,000)
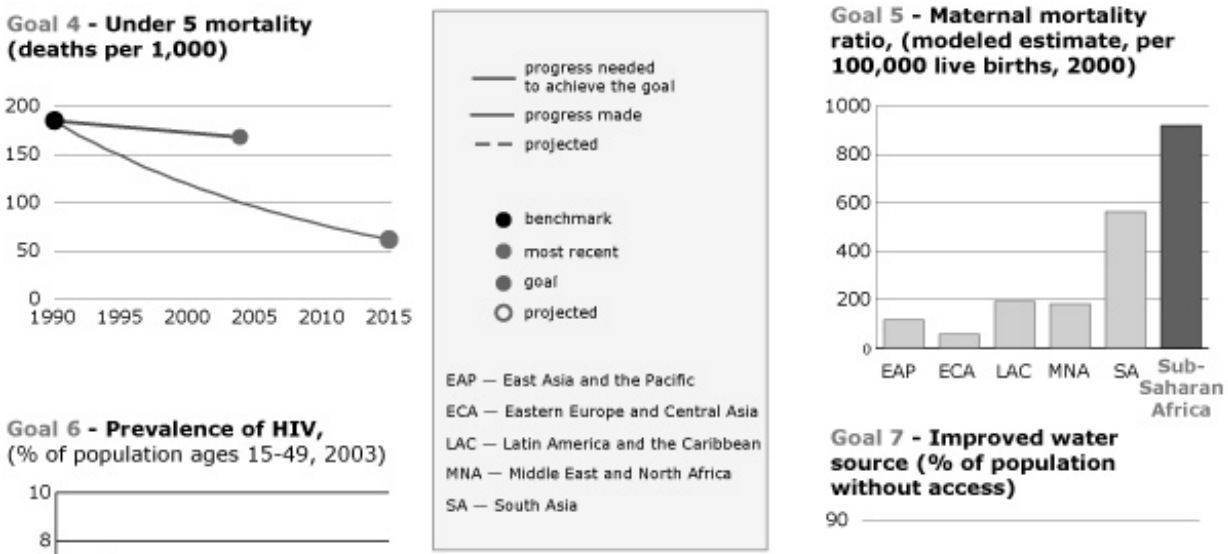

Goal 6 - Prevalence of HIV, (\% of population ages $15-49,2003$ )
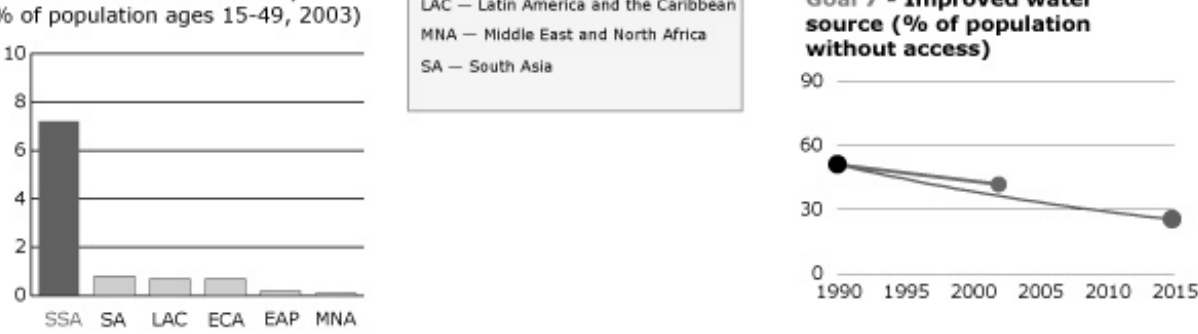

Source: Global Monitoring Report website

Figure 2.1: Millennium Development Goals in Sub-Saharan Africa

was involved in the formulation of the MDGs, clearly states that the goals should be reached at the global level. They are not intended for particular regions or countries. With this statement he clarifies a major misunderstanding of the goals, which led to a harsh discussion about the fairness of the goals.

Easterly (2009) quotes several development reports, commission declarations, and statements of policy makers that all draw the same conclusion: Africa as a whole and most of its countries are not making enough progress toward the MDGs and will therefore fail to attain them. Easterly (2009) shows that Africa is not able to attain these goals, because the MDGs are designed in a way that makes it impossible for most African countries to attain them. The first point of criticism is the - according to Easterly (2009) - arbitrarily chosen benchmark year of 1990 . While the Asian countries already made good progress in the 1990s the situation 
worsened during that decade in many African countries $^{2}$, or if there was some progress, this was too little, due to missing policies directed at the goals. Using Figure 2.1 he shows that Africa was already off the optimal path toward the goals when they were set in 2000. Easterly (2009) and Clemens et al. (2007) conclude that the goals are too ambitious, especially for African countries and therefore are rather discouraging.

The second major criticism is that the goals' targets seem to be arbitrarily picked. Some are relative to the current level, while others are absolute targets. Examples for the former are Target 1a Reduce by half the proportion of people living on less than a dollar a day or Target 4 a Reduce by two thirds the mortality rate among children under five, and for the latter Target 2a Ensure that all boys and girls complete a full course of primary schooling. Additionally, some targets are measured with positively-valued indicators, others with negatively-valued indicators $^{3}$, which leads to different relative improvements, especially when looking at ratio or level changes. Easterly (2009) and Clemens et al. (2007) discuss these criticisms in more detail.

Even though the criticism is valid, it can be weakened if the goals are to be seen as targets that indicate the direction in which all countries should develop, but progress should only be measured globally. According to Clemens and Moss (2005) p.3 "this view takes the MDGs as a tool, not a practical target". The MDGs will not be achieved globally, but progress toward the goals is visible. The South-East Asian countries have made substantial development improvements over the past two decades, hence compensating for the slow development progress in Sub-Saharan Africa, which - according to the MDG critical literature - is mainly due to their disadvantaged starting situation. Measuring the MDGs at the global level however makes regional compensation possible and this can be just as heavily criticized as the compensation that occurs in composite indicators.

This work uses the MDG indicators as given measures for development targets, but with a different angle on the discussion by dealing with the question whether the development dimensions reflected in the MDGs in Africa can actually be reached at the same time, that is whether the individual targets are complements or substitutes, which will be analyzed in Chapter 4 .

\subsubsection{The Human Development Index}

If well-being is to be captured in a single measure, this has to be a composite measure including different aspects such as income, health, education, environment, freedom, or equality. The biggest drawback to actually establishing such a measure is data availability, especially concerning quality of education, health, and the environment on a macroeconomic level as well as inequality. One measure of inequality is the GINI-coefficient ${ }^{4}$, but data on this coefficient is only sporadically available for most countries. Aside from the Gini coefficient there are only few

\footnotetext{
${ }^{2}$ Also see Chapter 3.

${ }^{3}$ Positively-valued indicators are those for which an increase is seen as development progress, negatively-valued indicators on the other hand are those for which a decrease is seen as development progress. An example for a negatively-valued indicator is the under- 5 mortality rate.

4 "The Gini coefficient is computed as the average difference between all pairs of incomes in a country, normalized by the mean." IMF (2007), p. 139
} 
other inequality measures as for example explained by Litchfield $(1999)^{5}$. Overall, very few composite development indicators exist that include some of these aspects for a wide range of countries over a longer time period.

A multidimensional indicator for human development that has been around for more than 20 years is the Human Development Index (HDI) developed by the United Nations Development Program (UNDP) and that was first published in the UNDP (1990) Human Development Report. The HDI measures "the average achievements in a country in three basic dimensions of human development: a long and healthy life, knowledge and a decent standard of living. It is calculated for 177 countries and areas for which data are available. In addition, human development indicators are presented for another $17 \mathrm{UN}$ member countries for which complete data was not available" 6 .

The HDI is an arithmetic (old, until 2010) or geometric (new, since 2010) average of three indices corresponding to the three basic dimensions: income $Y$, education $H$, and health $G$. Both the content of these components as well as their calculation methods changed over time. The basic calculation method for the index of component $X$ is

$$
X_{i}=\frac{x_{i}-\min _{c}\left\{x_{c}\right\}}{\max _{c}\left\{x_{c}\right\}-\min _{c}\left\{x_{c}\right\}}
$$

for country $i$. It follows that all components as well as the HDI itself take values between 0 and 1 . The calculation method that has been used until 2010 was:

$$
H D I=\frac{1}{3} Y+\frac{1}{3} H+\frac{1}{3} G
$$

This will be explained for the 'old' HDI in further detail in Chapter 5, where data from UNDP (2009) is used. The new method was introduced in the 20-year anniversary Human Development Report (UNDP, 2010). For the 'new' HDI not only the aggregation method (geometric average) of the three components, but also the indicators used to calculate the education index ${ }^{7}$ changed. The growth model developed in Chapter 6 is based on the multiplicative nature of the new HDI.

Both calculation methods and indicators included in the HDI changed over time. The first set of components included in the index for the 1990 report was life expectancy, adult literacy and log GDP, with the respective maxima and minima to calculate each index taken from the data. This was heavily criticized since changing values of the HDI from year to year were only relative and not absolute. This could lead to an increased index for a country even though its performance worsened if the minima decreased. Still, this calculation method was not changed until 1994. From 1991 through 1994 the education indicator was a combination of adult literacy and years of schooling. After 1994 it was calculated by adding two thirds of the adult literacy rate and one third of the combined primary, secondary, and tertiary enrollment rate. From 1995 on, the maxima for the calculation of all

\footnotetext{
${ }^{5}$ on http://www.worldbank.org/poverty/inequal/index.htm

${ }^{6}$ http://hdr.undp.org/en/statistics/indices/

${ }^{7}$ Until 2010 these indicators used to be literacy rate and the school enrollment rate. Since 2010, the education indicators are calculated from the expected and actual mean years of schooling.
} 
indexes were defined as constants. The minimum of GDP per capita, taken from the Atkinson formula, was still changing over the years, until this was abandoned in 1999 (Morse, 2003). Then, until 2010, the calculation method shown in Equation (2.2) was used.

Criticisms of the HDI relate to the weighting scheme of the three different dimensions, the additive and hence linear nature of the composite final indicator, and the included or excluded aspects of human development. Aspects often recorded missing are (in)equality, human rights, freedom and institutions, and the environment. According to Bérenger and Verdier-Chouchane (2007) the HDI "reflects well the basic dimensions of human development". They support this empirically by showing that their two alternative indicators (standard of living, SL, and quality of life, QL) give high importance to the education indicators, adult literacy rate and school enrollment rate. This view is also supported by McGillivray (2005). Dasgupta and Weale (1992) and Rahman et al. (2005) find that life expectancy at birth well captures the non-monetary aspects of development. The final set of components of the HDI (income, health and education), which has been around since 1997, is classified as "universal", "basic to life", and "measurable" by Bérenger and Verdier-Chouchane (2007).

\subsubsection{Alternative composite development indicators}

In light of the criticisms, alternative calculation methods for the HDI were suggested. Sagar and Najam (1998) argue that adding up the different components reflects perfect substitutability between the individual components. They suggest a multiplication of the three components to more heavily penalize those countries with very bad performance in one dimension and call the resulting index reformed HDI (RHDI). This concept has been picked up by the HDR Office in Human Development Reports Research Paper published in 2010 (Herrero et al.) and in its 20-year anniversary report from September 2010. Noorbakhsh (1998) suggests to change the transformation of GDP into an index, such that decreasing marginal returns of income are better reflected, and to also introduce decreasing marginal returns in the education index. He calls this index the modified HDI (MHDI).

Bérenger and Verdier-Chouchane (2007) develop two new indices that follow the thought of Amartya Sen's capability approach. The standard of living (SL) indicator refers to "commodities" and includes three indicators for each of standard of health (public health expenditure, improved water sources, number of physicians), standard of education (age dependency ratio, public spending on education, net primary enrollment rate), and material well-being (number of vehicles, paved roads, television sets). Quality of life (QL) on the other hand refers to "functionings" or "capabilities" and includes three indicators for each of quality of health (under-weight or under-height children, life expectancy at birth, maternal mortality ratio), quality of education (adult literacy rate, children and women in labor force), and quality of the environment, where the environmental indicators are trade openness, CO2 emissions and a combination of the Freedom House property rights and civil liberty scores. For a short overview on other alternative indicators, see Bérenger and Verdier-Chouchane (2007), p.1261.

Other composite indicators that can be seen as complementary to the HDI are 
for example the Happy Planet Index by Abdallah et al. (2009), including happy life years and the ecological footprint, or the Human Poverty Index and the Gender Related Development Index developed by UNDP. The Physical Quality of Life Index (PQLI) combines three single indicators: life expectancy at birth, infant mortality and literacy rates (Morris, 1978). The Human Suffering Index (HSI) ranks people according to the level of human suffering based on 10 measures: Life expectancy, daily calorie supply, access to clean water, infant immunization, secondary school enrollment, per capita GDP, rate of inflation, communications, technology, political freedom, and civil rights (Camp and Speidel, 1987).

Considering that the third pillar of sustainable development, the environment, is disregarded in the HDI, several scholars developed "green" extensions of the HDI. There are three possible ways to factor in the environmental pillar in the HDI: First, include an additional component, the environmental component, so that the HDI exists not only of three but of four indices. Second, use a sustainable development index next to the HDI, e.g. the Environmental Sustainability Index (ESI) of the World Economic Forum. And third, identify countries that cannot sustain their current HDI because of possible environmental damage. Neumayer (2010) later brings together the literature on human development and this approach to sustainability. In line with this is the idea of Constantini and Monni (2005) to discount the different capital types (natural capital, manufacturing capital, human capital, social capital) in order to identify non-sustainable development levels of countries. This understanding is based on the Hicksian definition of income that states that 'income' is the amount of capital that can be consumed while keeping the total capital stock constant, where the capital stock does not only consists of manufacturing capital, but also natural capital ((Farzin, 2004, 2006)).

\subsection{When is development sustainable?}

According to the Brundtland Report from 1987, development is sustainable when the 'needs of the present are met without compromising the ability to meet the needs of future generations'. This concerns people worldwide and all pillars of sustainable development. Though this statement is very coherent, it is also rather vague; at least when putting it into the context of the quantitative indicators that have just been introduced. This section can by no means give quantitative answers to the question "When is development sustainable?", that is giving exact values or value ranges in which the indicators should be. It can however summarize the most important qualitative preconditions for development to be sustainable. This does not mean that collecting and analyzing quantitative data is useless because it is not possible to exactly quantify sustainability targets. This has already been recognized by W.E. Demin in his famous quote "If you can't measure it, you can't manage it" and recently also been emphasized by OECD (2011) as quoted in Section 2.2 on p. 9. Setting targets is essential for policy makers to formulate policies in such a way that they are easily publishable and comprehensive. For example, this has been done for the Millennium Development Goals. Also, quantitative targets - whether or not they are easily achievable or overly ambitious - point into the direction of development. 


\subsubsection{Environmental sustainability}

Defining environmentally sustainable development is comparably easy for some aspects. With respect to the environment we have to consider both ways in which humans interact with nature. On the one hand we extract raw materials, be it water, mineral resources, timber, crops, et cetera. On the other hand we emit pollution into nature. This does not only include greenhouse gas (GHG) emissions, but also all other kinds of pollution, such as garbage, including non-decomposable substances and chemical waste. The most recent destructions of nature that received huge media attention are the oil spill in the Gulf of Mexico in April 2010 and the nuclear emergency following the earthquake and tsunami in Japan in March 2011.

Originally the notion of sustainable development comes from forest management and was first written down in 1713 by Johann Carl von Carlowitz in Sylvicultura Oeconomica. The main essence of his statement on p. 105-106 is that extraction of raw material is sustainable only if it is extracted at most at the pace at which nature, with the help of humans, is able to replace $i t^{8}$ :

Wird derhalben die größte Kunst/Wissenschaft/Fleiß und Einrichtung hiesiger Lande darinnen beruhen / wie eine sothane Conservation und Anbau des Holtzes anzustellen / daß es eine continuierliche beständige und nachhaltende Nutzung gebe / weiln es eine unentberliche Sache ist / ohne welche das Land in seinem Esse nicht bleiben mag.

With regard to emitted air pollutants emitted the 2007 Stern Review (p. 284) states that ${ }^{9}$

The current evidence suggests aiming for stabilization somewhere within the range 450 - 550ppm CO2e. Anything higher would substantially increase risks of very harmful impacts but would only reduce the expected costs of mitigation by comparatively little. Anything lower would impose very high adjustment costs in the near term for relatively small gains and might not even be feasible, not least because of past delays in taking strong action.

These two examples show that it is possible to estimate extraction and pollution thresholds beyond which neither of these two are sustainable. Data for both $\mathrm{CO}_{2}$ emissions and material extraction are readily available for most countries world wide, see for example IEA (2010a) for emission data and SERI and WI (2011) for material extraction data.

The pressing environmental problems in developing countries in Sub-Saharan Africa on the other hand are not well covered by any statistics. In addition, the problems are very different for the individual countries depending on the climate

\footnotetext{
${ }^{8} \mathrm{~A}$ translation of this 1713-German text into nowadays English could be: For that the highest art/science/effort and arrangement of this land will be / to engage in such a conservation and cultivation of timber / so that a continuous firm and sustainable extraction is possible / because it (forest) is an essential part / without which the land is not able to remain.

${ }^{9} \mathrm{CO} 2 \mathrm{e}=\mathrm{CO}_{2}$ equivalents, that is emissions including not only carbon dioxide but also other greenhouse gases, but converted into the same units as $\mathrm{CO}_{2}$ regarding their global warming potential.
} 
zone, their geographical location and natural resource deposits: deforestation of the rain forest in the Central African countries or increasing desertification in the Saharan region and Kalahari desert in Botswana and Namibia, the destruction of the environment by mining activities, contaminated water or garbage disposal ${ }^{10}$. All of these problems are on the one hand hard to capture in one measure and on the other hand differ across the countries. Hence, to be able to compare environmental sustainability across countries one or two standardized indicators should exist. Due to the very different nature of the problems, developing such general environmental indicators is not easy. An example for an indicator that could be comparable across countries is the Sustainable Budget Index (SBI) in Botswana (Lange and Wright, 2004). The SBI is a rule which requires that all mineral revenues are reinvested into,for example, health and education. The SBI is equal to the ratio of non-investment public spending to recurrent mineral revenues, where a value of 1.0 or less reflects sustainable public consumption. If this ratio is higher than one, consumption relies partly on mineral revenues, which is not sustainable in the long run.

The only indicators that are readily available for the Sub-Saharan African countries are $\mathrm{CO}_{2}$ emissions and resource extraction data. Emissions however relate to a relatively unimportant environmental issue faced by SSA countries: as industrial production in the SSA countries is very low, $\mathrm{CO}_{2}$ emissions per capita in SSA in 2005 are between 0.02 metric tonnes (t) in Burundi and $8.6 \mathrm{t}$ in South Africa and on average only $0.8 \mathrm{t}$ per capita, which is only $10 \%$ of the EU per capita average of $8 \mathrm{t}$ and less than $5 \%$ of the US average of almost $20 \% \mathrm{t}^{11}$. Resource extraction differs between the countries because of different resource endowments and the environmental effect of the extraction is not included in the data. As this data does not provide sufficient background for a quantitative analysis, the environmental dimension is not covered the subsequent empirical analyses in Chapters 4 and 5 .

To conclude, for environmental problem sustainability thresholds could be found, but these problems, at least those the SSA countries are facing, are hard to capture in quantitative indicators that are comparable across countries. Social and economic progress, in contrast, can be measured quantitatively, at least for some part, but the definition of sustainability thresholds is not easily possible.

\subsubsection{Economic sustainability}

In the renewed EU Sustainable Development Strategy (European Council, 2006) sustainable economic development is understood as achieving a "prosperous, innovative, knowledge-rich, competitive and eco-efficient economy which provides high living standards and full and high-quality employment" (p.4). This does not put an emphasis on physical economic growth, but rather on qualitative improvements of the standard-of-living. This understanding is in line with the thoughts of Herman E. Daly, expressed in a number of his works, inter alia Daly (1990; 1991; 1996).

\footnotetext{
${ }^{10}$ See for example Volk and Lippelt (2011) for a short discussion on garbage problems in developing countries and their consequences.

${ }^{11}$ The averages only changed slightly over the past two decades, see indicator EN.ATM.CO2E.PC 'CO2 emissions (metric tons per capita)' of WDI (2011).
} 
The resource view from environmental sustainability can also be employed in the economic context of investment and debt. The economic crises of 2008/2009 and the debt crisis of Greece, Portugal, Ireland and also the United States of America in 2011 show that also the developed economies did not follow a sustainable budget plan, by taking up more debt than the market is prepared to believe they can ever repay.

\subsubsection{Social sustainability}

Sustainable social development is by far the hardest to quantify. Sustainable social development means that there is no social exclusion, everyone has access to good health care and is able to get a decent education (UN, 2000, 2001, 2000, or the Education for All campaign ${ }^{12}$ ). As long as there is social exclusion, exclusion from health care and education, this has negative consequences for human capital accumulation $^{13}$, and hence for the economy. Low educated people and those with low health have a lower productivity. An additional risk is that the excluded groups feel left out. This feeling gives rise to conflicts, political instability, or even civil wars. The living conditions in such situations get worse, health and education of the respective group decreases even further, entering a vicious circle.

But when is social development sustainable? How good does accessible health care need to be? When is education decent? The Millennium Development Goals do quantify these social targets and according to Dalal-Clayton (2003) "achieving progress toward the MDGs is at the core of operationalizing sustainable development, ..." (p.3). The three most important words in this sentence are "achieving progress toward" because on the one hand they do not claim that the targets have to be reached and hence soften the criticism of Easterly (2009), while on the other hand they clearly state that for development to be sustainable it has to go into the direction of the targets.

\subsection{Concluding remarks}

Sustainable development is multi-dimensional in more than one dimension: in terms of time (now and in the future), geography (worldwide), and for the various aspects of development itself. Measuring sustainable development therefore is not straightforward. Setting goals is important to move into the right direction, even if the goals are too ambitious. Since actions today influence the future, it is important to act now. And the sooner we follow a more sustainable development path, the easier it is for future generations to continue that path. Even if some goals seem to be too ambitious to be reached within the next few years, any action taken now is worth the effort. If there are no targets, there is no clear direction for future development. If the targets are not sufficiently ambitious, we might end up on a non-sustainable development path.

The indicator systems above aim at monitoring progress toward a more sustainable development and set targets that - when attaining them - should ensure

\footnotetext{
12 http://www.unesco.org/en/efa/

${ }^{13}$ This is a term from economic theory, not from the discussion on sustainable development.
} 
that the world is on a sustainable development path. Quantitative indicators can well be used for comparative research, for which they provide descriptive background information, and a database for analyzing progress and testing hypothesis (Noll, 2004). The indicators used for the empirical analysis in Chapter 4 are introduced in Chapter 3, which empirically describes development progress made in Sub-Saharan Africa over the past three decades. 


\section{Chapter 3}

\section{Development progress in Sub-Saharan Africa}

Szirmai (2010) emphasizes the importance of distinguishing between ultimate, intermediate and proximate sources of development and growth, and socio-economic outcomes when analyzing development. Ultimate sources of growth and development are mainly geographic, demographic and institutional factors, while intermediate sources are policies and demand structures, and proximate sources are interactions of economic actors. In Chapter 2 indicators and indicator systems that can be used to assess development were introduced. Most of the indicators and indicator systems described there belong to the fourth category, that is socioeconomic outcomes. We will refer to indicators belonging to this group as outcome indicators, while those relating to sources of growth and development will be called input indicators.

This chapter describes the development progress measured with selected output indicators made in Sub-Saharan Africa (SSA) between 1980 and 2005. To this end, it introduces data on the Millennium Development (MDG) indicators and the aspects covered by the Human Development Index (HDI) that are used in the subsequent analyses. The data are time series for 47 Sub-Saharan African countries extracted from different international databases, such as the World Development Indicators provided by the World Bank, the World Health Organization's statistics center, and the Human Development Report Office statistics. The depiction of each indicator includes the exact data source in Table 3.1, descriptive statistics in Table 3.2 and a description of the development of the indicator across countries and across time. If the indicator was not readily available in the data sources and had to be constructed, the calculation method is explained in detail. Due to frequent data gaps, 5-year average data is used for the empirical analyses. The average for year $t$ is taken from all available years in the period from $t$ - 2 to $t+2$, that is for example the average of all available years between 1978 and 1982 for the data point labeled 1980. This method has been applied in the literature before and proven to be useful, see for example Adler et al. (2009).

While for most indicators an increase in their value is perceived as a positive development, the opposite is true for some - mainly health related - indicators, 
Table 3.1: Data sources

\begin{tabular}{|c|c|c|}
\hline \multirow{2}{*}{\multicolumn{3}{|c|}{$\begin{array}{l}\text { Name Variable description } \\
\text { Standard of living }\end{array}$}} \\
\hline & & \\
\hline GDPC GDP per capita (constant 2000 US\$) & WDI & NY.GDP.PCAP.KD \\
\hline $\begin{array}{l}\text { HCEH Household final consumption expenditure per capita } \\
\text { (constant } 2000 \text { US } \$ \text { ) }\end{array}$ & WDI & NE.CON.PRVT.PC.KD \\
\hline EMPR Employment to population ratio, $15+$, total $(\%)$ & WDI & SL.EMP.TOTL.SP.ZS \\
\hline ATSS Improved sanitation facilities (\% of population with access) & WDI & SH.STA.ACSN \\
\hline ATSW Improved water source (\% of population with access) & WDI & SH.H2O.SAFE.ZS \\
\hline TPEC Total primary energy consumption (Mill. Btu per person) & EIA & $\begin{array}{l}\text { International Energy } \\
\text { Statistics }\end{array}$ \\
\hline \multicolumn{3}{|l|}{ Education } \\
\hline LITR Adult literacy rate (\% of population aged 15 years and over) & HDRO & \\
\hline PSCR Primary completion rate, total (\% of relevant age group) & WDI & SE.PRM.CMPT.ZS \\
\hline $\begin{array}{l}\text { GSER Combined gross enrollment ratio (\% of the population of the } \\
\text { theoretical age group for education) }\end{array}$ & HDRO & \\
\hline $\begin{array}{l}\text { SEPN School enrollment, primary (\% net) } \\
\text { Health }\end{array}$ & WDI & SE.PRM.NENR \\
\hline LIFE Life expectancy at birth, total (years) & WDI & SP.DYN.LE00.IN \\
\hline U5MR Mortality rate, under-5 (per 1000) & WDI & SH.DYN.MORT \\
\hline U5SR $=1000-\mathrm{U} 5 \mathrm{MR}$, children surviving until the age of 5 & WDI & own calculation \\
\hline IMMU Immunization, measles (\% of children ages $12-23$ months) & WDI & SH.IMM.MEAS \\
\hline DPTI Immunization, DPT (\% of children ages $12-23$ months) & WDI & SH.IMM.IDPT \\
\hline PUND Prevalence of undernourishment (\% of population) & WDI & SN.ITK.DEFC.ZS \\
\hline HIVT Prevalence of HIV, total (\% of population ages 15-49) & WDI & SH.DYN.AIDS.ZS \\
\hline
\end{tabular}

HDRO: Human Development Report Office (UNDP, 2009)

WDI: World Development Indicators (WDI, 2011)

EIA: U.S. Energy Information Administration (EIA, 2011)

such as the under-5 mortality rate. We will refer to the former as positively-valued indicators and to the latter as negatively-valued indicators. For the statistical and econometric analyses in the subsequent chapter the reciprocal value (here defined as the total scale minus the original value) of the negatively-valued indicators is used. For the under-5 mortality rate that is the number of children (per thousand) that survive until the age of five (compare U5SR in Table 3.1).

This chapter is organized according to the different aspects of development: economic development and standard-of-living, education and health (leaving environmental issues aside for the moment). It first starts by putting development progress made in Sub-Saharan Africa into the context of global development.

\subsection{Sub-Saharan Africa in the World}

The region Sub-Saharan Africa consists of all African countries except those bordering the Mediterranean Sea, that is all countries on the African continent except Morocco, Algeria, Tunisia, Lybia and Egypt. Sub-Saharan Africa therefore includes about 50 countries that are very different in their geographical conditions and climate zone. It ranges from groups of very small islands, e.g. Sao Tome and Principe or Mauritius, or small land-locked countries, like Rwanda or Burundi, to countries that have a land area which would cover most of Central Europe like the Democratic Republic of the Congo or Sudan. Climate in the North and South is very dry with hardly any vegetation, while large parts of the Central African countries are covered by tropical rain forests. Even though many of the countries are officially democracies, the political reality is different. According to Freedom House (2011), only nine of the countries can be considered as politically free, 
Table 3.2: Descriptive Statistics

\begin{tabular}{lrrrrrrrrrrrr}
\hline \multicolumn{1}{c}{ Number of Observations } & \multicolumn{1}{c}{ Min Med Max Mean } & SD \\
\hline Standard of living & Total 1980 & 1985 & 1990 & 1995 & 2000 & 2005 & & & & & \\
GDPC & 264 & 41 & 43 & 45 & 45 & 45 & 45 & 81 & 337 & 7385 & 848 & 1303 \\
HCEH & 196 & 26 & 30 & 32 & 33 & 42 & 33 & 79 & 310 & 4629 & 581 & 744 \\
TPEC & 277 & 47 & 47 & 47 & 47 & 47 & 47 & 0.3 & 3.5 & 156 & 11 & 21 \\
EMPR & 180 & 0 & 0 & 45 & 45 & 45 & 45 & 38 & 66 & 87 & 66 & 12 \\
ATSS & 173 & 0 & 0 & 36 & 45 & 46 & 46 & 4 & 27 & 91 & 30 & 19 \\
ATSW & 174 & 0 & 0 & 37 & 45 & 46 & 46 & 17 & 58 & 99 & 60 & 18 \\
Education & & & & & & & & & & & \\
LITR & 188 & 18 & 20 & 29 & 32 & 43 & 46 & 9 & 58 & 92 & 54 & 23 \\
PSCR & 193 & 25 & 24 & 33 & 29 & 39 & 43 & 0 & 47 & 116 & 50 & 25 \\
GSER & 258 & 40 & 41 & 43 & 44 & 44 & 46 & 7 & 43 & 88 & 44 & 18 \\
SEPN & 163 & 16 & 17 & 27 & 28 & 39 & 36 & 14 & 64 & 100 & 63 & 22 \\
Health & & & & & & & & & & & & \\
LIFE & 282 & 47 & 47 & 47 & 47 & 47 & 47 & 30 & 51 & 73 & 52 & 8 \\
U5MR & 278 & 44 & 46 & 47 & 47 & 47 & 47 & 13 & 153 & 322 & 153 & 64 \\
IMMU & 251 & 25 & 43 & 44 & 45 & 47 & 47 & 1 & 61 & 99 & 58 & 22 \\
DPTI & 253 & 27 & 43 & 44 & 45 & 47 & 47 & 1 & 59 & 99 & 57 & 26 \\
PUND & 180 & 0 & 0 & 45 & 45 & 45 & 45 & 5 & 26 & 70 & 28 & 17 \\
HIVT & 166 & 0 & 0 & 40 & 42 & 42 & 42 & 0 & 2 & 27 & 5 & 6 \\
\hline
\end{tabular}

mainly countries in the South such as Botswana, Namibia or South Africa, and in the West like Ghana, Benin or Mali; 17 are classified as not free, e.g. Somalia, Guinea, Gabon or Zimbabwe, and the remaining countries as partly free.

Many of the Sub-Saharan African countries are among the poorest and least developed countries in the world. Figure 3.1 shows the development of GDP per capita, household consumption expenditures, life expectancy at birth and the under-5 mortality rate in Sub-Saharan Africa compared to the Euro area ${ }^{1}$ and the world average. While GDP per capita in the Euro area substantially increased over the past three decades by more than $50 \%$ in constant prices and the world average almost doubled as well, GDP per capita in Sub-Sahran Africa increased by only $5.5 \%$ during that period. GDP per capita was already slightly decreasing in the beginning of the Eighties, reaching its minimum of about $490 \mathrm{USD}^{2}$ in the MidNineties due to the African debt crises. Only in 2006 had the average per-capita GDP in Sub-Saharan Africa returned to its 1980-level of about 600 USD.

Development of household consumption expenditures (HCE) per capita was similar, though it only started decreasing in the second half of the Eighties and then reaching its 1980-level in 2002 already. Also, as HCE makes up only one of the consumption side components of GDP, it is naturally on a lower level; increasing from $58 \%$ of GDP to about $65 \%$ of GDP since the late Nineties. Total per capita household consumption expenditures increased by almost 15\% between 1980 and 2009 and by 30\% between the Mid-Nineties and 2009. Household consumption expenditures per capita also stagnated in the Euro area and globally in the beginning of the Nineties. Still, overall they increased by more than $50 \%$ in the Euro area and globally. Due to the low level of both GDP and household consumption

\footnotetext{
${ }^{1}$ Region as defined by WDI (2011).

${ }^{2}$ All of the indicators in monetary terms are measured in constant 2000 US dollars, for matters of simplification the notation used in the remainder of this work is USD, if not noted otherwise.
} 

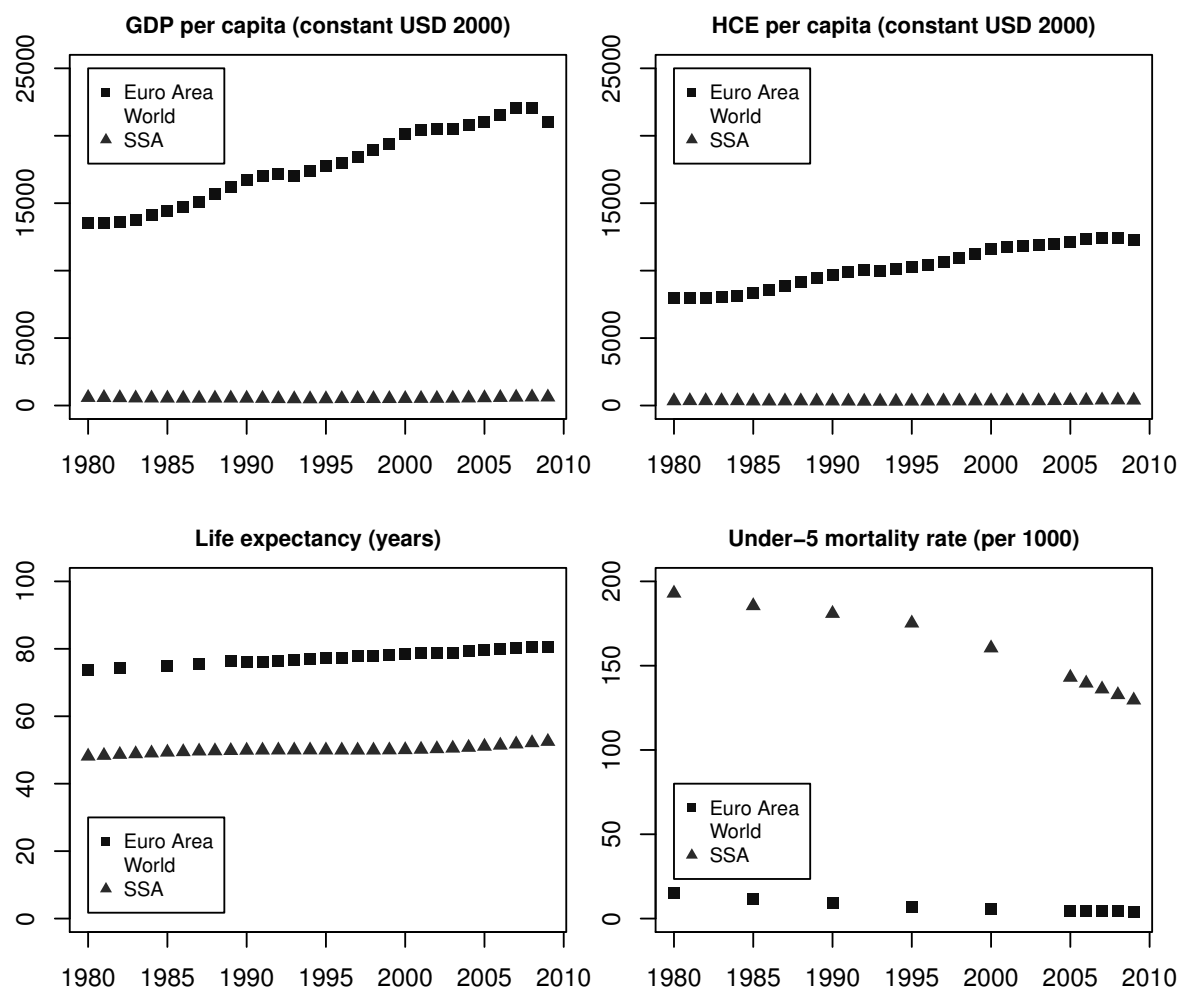

Data source: World Development Indicators Online (2011)

Figure 3.1: Global development

expenditures per capita compared to the Euro countries and also globally and the little change in these indicators, the fluctuations in SSA described above can hardly be seen from the top two graphs of Figure 3.1.

The lower two graphs in this figure show that some progress in global health level has been made; life expectancy rose by $11 \%$ or 6.6 years globally. Both the Euro area as well as Sub-Saharan Africa experienced lower than average growth rates in life expectancy over the past three decades. While it steadily grew in the Euro area from 74 years in 1980 to 80 years today, it stagnated in Sub-Saharan Africa in the 1990s at about 50 years. After 2000 the progress in health improvement accelerated, life expectancy rose by two and a half years. This is partly due to a significantly decreasing average under-5 mortality rate from 160 to 130 children per thousand live births. Still, this value is more than twice the world average of 60 children per thousand live births and not comparable to levels in the industrialized countries of the Euro area where this rate is almost zero with four per 1000 life births. The corresponding Millennium Development Goal is Target $4 \mathrm{~A}$ "reduce by two thirds the mortality rate among children under five". This 
goal should be attained in 2015 and is defined relative to its 1990 level. Progress toward this goal is significant and it will be reached at the global level, especially because of improvements in health in Asia and Eastern Europe. In Sub-Saharan Africa the relative reduction is insufficient, despite a high absolute reduction in the child mortality rate of more than 50 per thousand since 1990 . Mortality rates might even increase again in 2011 due to the current drought in East Africa.

\subsection{Economic development and standard-of-living}

Economic development is generally measured using GDP, GDP growth, GDP per capita or GDP per capita growth. From these, GDP per capita can well be used for country comparisons as it has a common denominator. As was just mentioned, the Nineties were a decade of slow or even negative economic growth in SubSaharan Africa. The maps on the left hand side of Figure 3.2 show GDP per capita levels in 1985, 1995 and 2005. The darker red the shading of the country, the lower per capita GDP. Here as well as for subsequent maps in Figures 3.3 and 3.4 , a red colored country on the map indicates that the corresponding indicator in that country is low for positively-valued indicators and high for negatively-valued indicators, such as the under-5 mortality rate. If a country is colored green, it performs good with respect to that indicator. The GDP per capita map for 1995 has more red and orange shaded areas than the map for 1985, reflecting the low growth decade, e.g. in the Central African Republic or Angola. This is especially visible for the DR Congo toward the end of the Mobuto-regime with GDP per capita being cut in half from about 250 USD in the Eighties to less than 125 USD by the Mid-Nineties and even further to less than 100 USD in the subsequent periods.

GDP per capita is a measure of production. To assess living standards more adequately Stiglitz et al. (2009) suggest to use a consumption rather than a production measure. Therefore, household consumption expenditure per capita (HCEH) will also be used in the subsequent analyses next to GDP per capita as a measure for the standard-of-living. As can be seen in the boxplots in Figure 3.6 (at the end of this chapter on p. 39) median per capita household consumption expenditures decreased more strongly during the Nineties than median GDP per capita. Starting around the turn of the Millennium, household consumption expenditures increased significantly, at least in some countries, e.g. Botswana $+63 \%$ or Cape Verde $+75 \%$ both having slightly more than 1400 USD in 2005 . The highest percentage increase between 1995 and 2005 took place in Lesotho with $+77.5 \%$, though the level in 1995 was average, so that the increase in absolute terms was only about 300 USD. The highest absolute and percentage drop during that time period was in Eritrea with -157 USD, where household consumption expenditure was cut in half. The overall development can also be seen from the maps in Figure 3.2, where the one for 1995 is slightly more red than the one for 1985, while the map for 2005 shows more green shaded areas, which means that household consumption expenditures are higher than before in the corresponding countries.

According to the World Energy Outlook (IEA, 2009, p. 110) "energy poverty is already a major problem in the world's least developed regions, holding back much-needed improvements in productivity, employment, communication, health 
GDP per capita (USD 2000)

- 75 - 150 USD

口 $150-300$ USD

$\square 300-600$ USD

$\square 00-1000$ USD

$\square 1000$ and more USD

$\square$ not available
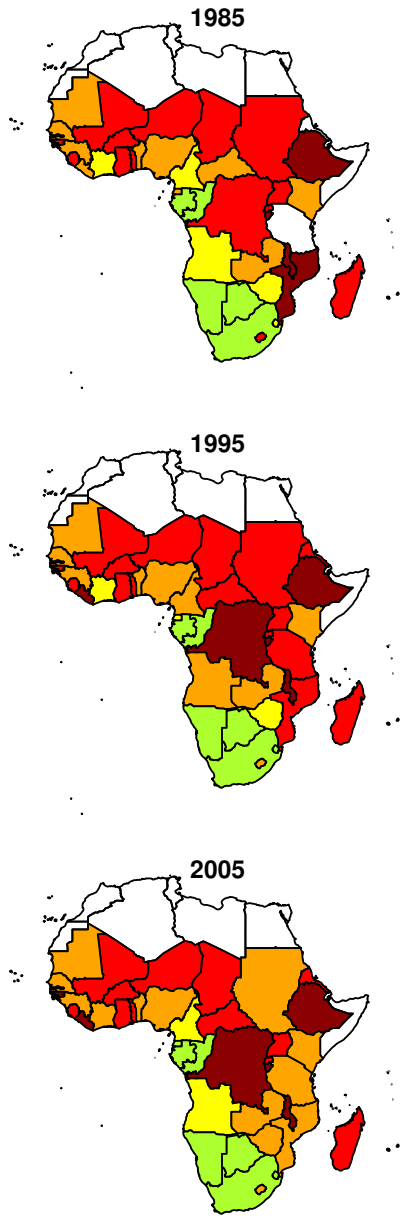

Household consumption exp. per capita

$\begin{array}{ll}\square & 75-150 \text { USD } \\ \square & 150-300 \text { USD }\end{array}$

$\square 300-600$ USD

$\square 600-1000$ USD

$\square \quad 1000$ and more USD

$\square$ not available
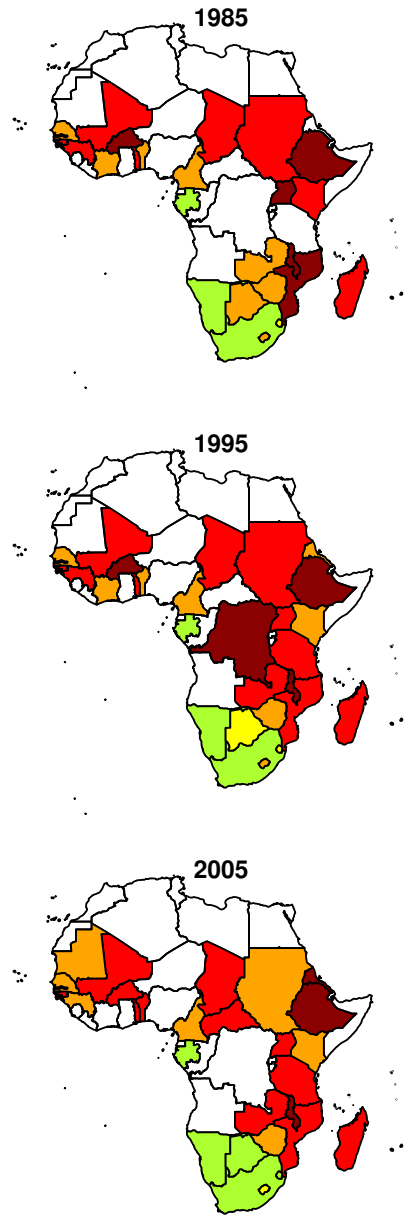

Figure 3.2: Standard of living over time 
care and education". Energy consumption is both an input as well as an outcome indicator: it is an input into production, but it can also indicate living standards via households energy consumption for lighting, cooking, heating, and also using a radio or TV. Total primary energy consumption per capita (TPEC) is therefore included as a third standard-of-living outcome indicator in the subsequent analyses. As can be seen in the top right box plot in Figure 3.6, TPEC developed similarly to GDPC and HCEH: it was lower during the Nineties than during the Eighties and only increased again toward the year 2000. Note that this plot excludes all outliers with energy consumption higher than 50 million Btu per person. The only two countries with a per capita energy consumption higher than this are the Seychelles and South Africa.

Other indicators for standard-of-living can be found among the Millennium Development Goals (MDG) indicators. Data for these indicators is however only available from 1990 on. Substantial progress in living conditions has been made with regard to access to safe sanitation facilities (ATSS) and access to improved water sources (ATSW). Improving ATSS and ATSW are subtargets of MDG 7, which relates to environmental sustainability. Still, here they are classified as standard-of-living indicators, because they have a direct influence on every-day living conditions of the people. The proportion of the population that has access to improved drinking water sources largely varies between the different SSA countries: While in Mauritius everybody has access to safe water, on average this is the case for only $60 \%$ of the population. Ethiopia was able to significantly increase the proportion from $13 \%$ in 1995 to $42 \%$ in 2005. Other countries with a significant increase during this time span are Mali (33\% to 60\%) and Burkina Faso (34\% to $72 \%)$. Generally, the values of this indicator increased over time, for some countries no improvement is visible.

This also holds for ATSS. Mauritius has the highest rate (94\%), which remains constant during the past three decades. All other countries have rates below $60 \%$, going as far down as 3\% in Eritrea and Niger in 1995. Other countries starting with rates below 10\% in 1995 are Ethiopia, Chad, Burkina Faso, Ghana, and Madagascar. In South Africa, Malawi, Equatorial Guinea, Swaziland, and Zambia more than half of the population can access improved sanitation facilities. For most countries we can observe a slight increase over time, but the rate was decreasing in Burundi and Liberia. Compared to ATSW, progress made here is slower, while the actual level is even lower. There is some progress toward MDG Target 7.C "halve, by 2015, the proportion of people without sustainable access to save drinking water and basic sanitation", but not enough in all countries.

Still, the development in these indicators is more favorable than the development of the employment rate, which decreases over time. Also, the employment rate tends to be higher in those countries that, according to other indicators, are lower developed and vice versa: The employment rate in South Africa is about $40 \%$, and in Botswana and Namibia around 45\%. The employment rate is below $50 \%$ for three more countries: Mauritania, Sudan, and Mali. An employment rate of more than $80 \%$ on the other hand can be found in Burundi, Uganda, Madagascar, Guinea, Burkina Faso, and Rwanda.

This gives rise to the question of how the employment rate is measured. The official definition is "the employment-to-population ratio is the proportion of a 
Table 3.3: Spearman correlations between standard-of-living indicators

\begin{tabular}{lrrrrrr}
\hline & $\mathrm{GDPC}_{t}$ & $\mathrm{HCEH}_{t}$ & $\mathrm{TPEC}_{t}$ & $\mathrm{EMPR}_{t}$ & $\mathrm{ATSS}_{t}$ & $\mathrm{ATSW}_{t}$ \\
\hline $\mathrm{GDPC}_{t}$ & 1 & & & & & \\
$\mathrm{HCEH}_{t}$ & 0.97 & 1 & & & & \\
$\mathrm{TPEC}_{t}$ & 0.82 & 0.82 & 1 & & & \\
EMPR $_{t}$ & -0.62 & -0.64 & -0.6 & 1 & & \\
$\mathrm{ATSS}_{t}$ & 0.6 & 0.58 & 0.57 & -0.51 & 1 & \\
$\mathrm{ATSW}_{t}$ & 0.73 & 0.76 & 0.61 & -0.44 & 0.59 & 1 \\
$\mathrm{GDPC}_{t-1}$ & 0.98 & 0.97 & 0.84 & -0.61 & 0.59 & 0.74 \\
$\mathrm{HCEH}_{t-1}$ & 0.96 & 0.98 & 0.84 & -0.67 & 0.56 & 0.74 \\
$\mathrm{TPEC}_{t-1}$ & 0.8 & 0.81 & 0.97 & -0.6 & 0.59 & 0.61 \\
EMPR $_{t-1}$ & -0.59 & -0.62 & -0.56 & 0.99 & -0.5 & -0.44 \\
$\mathrm{ATSS}_{t-1}$ & 0.6 & 0.59 & 0.59 & -0.53 & 0.99 & 0.58 \\
$\mathrm{ATSW}_{t-1}$ & 0.75 & 0.77 & 0.63 & -0.46 & 0.58 & 0.98 \\
\hline
\end{tabular}

country's working-age population that is employed. Employment is defined as persons above a specified age who performed any work at all, in the reference period, for pay or profit (or pay in kind), or were temporarily absent from a job for such reasons as illness, maternity or parental leave, holiday, training or industrial dispute. Unpaid family workers who work for at least one hour should be included in the count of employment, although many countries use a higher hour limit in their definition." (MDG, 2010 Goal 1, Target 1B). Measurement differences mainly stem from differences in the definition of the age group considered as being in 'working age'. The range of EMPR narrows over time, but the median and the second and third quartiles remain about constant, see the top right plot in Figure 3.6. On average no progress toward full employment is made.

It is also possible that these counter-intuitive numbers are due to the economic structure considering that lower developed countries with a larger share of the population employed in the primary (agricultural) sector have a more laborintensive production than more developed countries. In the steady state analysis of the growth model developed in Chapter 6 this case is reflected by a high value of $\alpha$. Still, a high employment rate is desirable, but it is negatively correlated with other development indicators (Table 3.3), hence not straight forward interpretable in quantitative analyses and therefore discarded from the subsequent analysis.

ATSS and ATSW are strongly positively correlated with GDPC, HCEH and TPEC with contemporaneous correlation coefficients ${ }^{3}$ between 0.6 and 0.75 . The intertemporal correlation coefficients for ATSS and ATSW at $t-1$ and GDPC, $\mathrm{HCEH}$ and TPEC at $t$ are slightly higher than the contemporaneous correlations, and for GDPC, HCEH and TPEC at $t-1$ and ATSS and ATSW at $t$ slightly lower than the contemporaneous coefficients. This confirms the assumption of ATSS and ATSW being development inputs, whereas GDP per capita, household consumption expenditures and primary energy consumption can be seen as development outcomes.

\footnotetext{
${ }^{3}$ The tables in this chapter present the Spearman rank correlation coefficients. Kendall's Tau coefficients give the same qualitative results. In addition, both contemporaneous and intertemporal correlations have been calculated. Intertemporal correlations are correlations between one indicator in period $t$ and the other indicator in the previous period $t-1$.
} 


\subsection{Educational attainment}

Educational attainment is hard to measure. High school enrollment rates do not necessarily ensure a good quality of education. If enrollment rates are increased without providing more teachers and sufficient teaching material, the quality of education will suffer. MDG 2 is to "achieve universal primary education". Progress toward this goal is measured by three different indicators: the net enrollment rate in primary schools, the proportion of pupils starting grade 1, who reach the last grade of primary school, and the literacy rate of young adults. The education index in the Human Development Index ${ }^{4}$ is composed of the combined (primary, secondary an tertiary) school enrollment rate (GSER) and the adult literacy rate (LITR). The primary school completion rate (PSCR), which is used for the subsequent analysis is a proxy for the MDG indicator "proportion of pupils starting grade 1, who reach the last grade of primary school" for which data availability was rather low, is taken from the WDI database, as is the primary school enrollment rate (SEPN). Data availability was also a problem for the literacy rate of young adults, so that in the following the literacy rate (LITR) from the HDR statistics is used. Data on the combined school enrollment rate (GSER) also stems from the HDR statistics.

School enrollment rates can be directly influenced by policies or policy makers, e.g. by enacting a law that all children have to go to school as is done in most industrialized countries, or by reducing school fees and providing sufficient capacity at state schools. Therefore school enrollment rates can rather be seen as an input into development than as an output. The development output in education can be measured by the literacy rate, though this is of course only a proxy indicator of what the actual education level of a country is. Changes in the literacy rate due to specific policies or socio-economic factors might take a long time to become visible; changes in the primary school completion rate become visible much faster.

The two education outcome indicators literacy rate (LITR) and primary school completion rate (PSCR) are displayed in Figure 3.3. These maps show that not only education itself but also data availability, displayed in Table 3.2, of education indicators significantly increased over time. The boxplots in Figure 3.6 (at the end of this chapter) of LITR, PSCR, GSER (total school enrollment rate) and SEPN (primary school enrollment rate) confirm the increase in education levels. The fluctuations of minimum, maximum and median are mainly due to data availability for additional countries. Significant progress in school enrollment rates (GSER, SEPN) and the percentage of students that finished primary school (PSCR) was made since the declaration of the Millennium Development Goals in 2000. While the minimum of the share of children attending primary school (SEPN) in 1980 was as low as 14\% in South Africa and Burkina Faso, and the minimum in 1995 was $24 \%$ in Nigeria, this number increased to more than $40 \%$ in 2005 (Nigeria still having the lowest primary school enrollment rates of those SSA countries for which data is available). The three countries with highest primary school enrollment rates are Cape Verde, Mauritius and Senegal, all having rates of more than $90 \%$ for almost all of the three decades. Still in about one quarter of the

\footnotetext{
${ }^{4}$ Here the HDI is based on data and methodology used before 2010, in contrast to the 'new HDI' which was introduced in the 20-year anniversary report in 2010.
} 


\section{Literacy rate}

- < 30 percent

$30-50$ percent

$\square 50-65$ percent

$\square \quad 65-80$ percent

$\square \quad>80$ percent

$\square$ not available
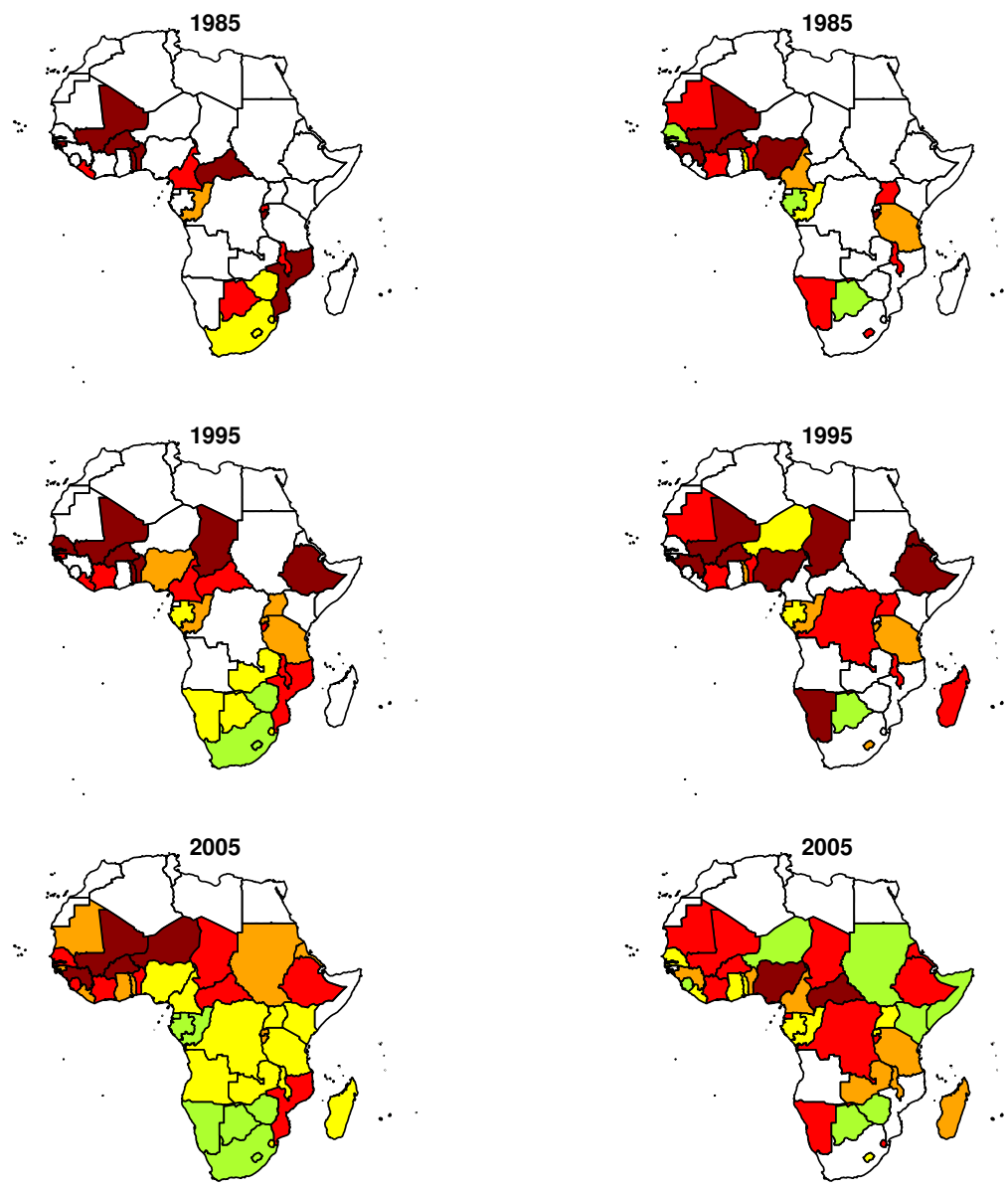

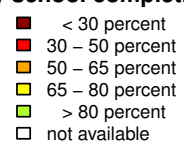

$\square$ not available 
Table 3.4: Spearman correlations between education indicators

\begin{tabular}{lrrrc}
\hline & LITR $_{t}$ & PSCR $_{t}$ & SEPN $_{t}$ & GSER $_{t}$ \\
LITR $_{t}$ & 1.00 & & & \\
PSCR $_{t}$ & 0.51 & 1.00 & & \\
SEPN $_{t}$ & 0.63 & 0.87 & 1.00 & \\
GSER $_{t}$ & 0.81 & 0.57 & 0.61 & 1.00 \\
LITR $_{t-1}$ & 0.97 & 0.49 & 0.62 & 0.80 \\
PSCR $_{t-1}$ & 0.47 & 0.92 & 0.76 & 0.51 \\
SEPN $_{t-1}$ & 0.61 & 0.90 & 0.94 & 0.61 \\
GSER $_{t-1}$ & 0.82 & 0.52 & 0.55 & 0.95 \\
\hline
\end{tabular}

countries less than $60 \%$ of the children attend primary school.

The development of the primary school completion rate (PSCR) is similar to the one of SEPN: it is generally increasing. An exception is Zimbabwe, which rate of $95 \%$ in 1990 decreased to $80 \%$ in 2005 . The rate is above $75 \%$ in less than one quarter of the countries. In 2005, most countries have primary school completion rates between $45 \%$ and $75 \%$. The lowest rates are in Niger and Burkina Faso, both about 30\%. The highest school completion rates can be found in the Seychelles, Mauritius, South Africa, Botswana, and Cape Verde. There has been some improvement of primary school completion rates; still, the level is very low. Progress in both SEPN and PSCR is not sufficient to reach MDG target 2.A "Ensure that, by 2015, children everywhere, boys and girls alike, will be able to complete a full course of primary schooling".

The high intertemporal correlations (lower part in Table 3.4) between the total school enrollment rate (GSER) at time $t-1$ and the literacy rate (LITR) at time $t$ as well as between the primary school enrollment rate (SEPN) at $t-1$ and the primary school completion rate (PSCR) at $t$, show that both indicators are indeed outcome indicators, while school enrollment can rather be seen as an input indicator.

\subsection{Health status}

Life expectancy at birth well summarizes the health status of a population and additionally is an indicator for which data is readily available for many countries. Life expectancy is also used to calculate the health index for the HDI. The three MDGs that explicitly deal with health are more detailed: MDG 4 "reduce child mortality", MDG 5 "improve maternal health" and MDG 6 "combat HIV/AIDS, malaria and other diseases". All of these goals are equally important, but progress toward these goals is not easily measured. In total, 18 different indicators are used to measure progress toward these goals, some of which are displayed in the lower two rows of Figure 3.6 (at the end of this chapter). Life expectancy and the under-five mortality rate are chosen because they are not directly influenceable by policy measures and can therefore be seen as health outcomes. Immunization against measles (IMMU) and diphtheria (DPTI) rather are development input indicators. The percentage of population that is undernourished (PUND) or the HIV prevalence rate (HIVT) cannot not be classified as either inputs or outputs of the development process. 
Table 3.5: Spearman correlations between health indicators

\begin{tabular}{lrrrrrr}
\hline & LIFE $_{t}$ & U5MR $_{t}$ & IMMU $_{t}$ & DPTI $_{t}$ & PUND $_{t}$ & HIVT $_{t}$ \\
LIFE $_{t}$ & 1.00 & & & & & \\
U5MR $_{t}$ & -0.73 & 1.00 & & & & \\
IMMU $_{t}$ & 0.17 & -0.47 & 1.00 & & & \\
DPTI $_{t}$ & 0.27 & -0.55 & 0.93 & 1.00 & & \\
PUND $_{t}$ & -0.37 & 0.35 & -0.05 & -0.03 & 1.00 & \\
HIVT $_{t}$ & -0.26 & -0.13 & 0.26 & 0.27 & 0.07 & 1.00 \\
LIFE $_{t-1}$ & 0.90 & -0.81 & 0.24 & 0.34 & -0.39 & 0.00 \\
U5MR $_{t-1}$ & -0.70 & 0.95 & -0.42 & -0.51 & 0.33 & -0.21 \\
IMMU $_{t-1}$ & 0.18 & -0.50 & 0.79 & 0.77 & -0.06 & 0.39 \\
DPTI $_{t-1}$ & 0.24 & -0.56 & 0.78 & 0.83 & -0.02 & 0.38 \\
PUND $_{t-1}$ & -0.37 & 0.36 & -0.12 & -0.09 & 0.95 & 0.04 \\
HIVT $_{t-1}$ & -0.33 & -0.12 & 0.27 & 0.29 & 0.10 & 0.94 \\
\hline
\end{tabular}

All of the indicators show slow progress toward the corresponding targets. Immunizing children within the first years of their lives against measles and diphtheria goes hand in hand with a reduction in the under-5 mortality rate (U5MR) as is confirmed by the negative contemporaneous correlation coefficients of -0.60 and 0.66 respectively ${ }^{5}$. In the Eighties the highest under- 5 mortality rates (over 300 per 1000 live births) were found in Niger and Sierra Leone. These rates dropped significantly until 2005, but still remained among the highest in Sub-Saharan Africa. While in 1995 still more than one quarter of the countries had rates above 200, all but three out of 47 countries reduced these rates to less than 200 by 2005 .

The strongly increasing HIV rate in the 1990s is the main cause of the stagnating life expectancy. In some countries very high HIV rates even caused life expectancy to drop significantly. Examples are Botswana, where life expectancy dropped from almost 60 years in the Mid-Nineties to 50.5 years around 2000, and Lesotho and Swaziland, where life expectancy was slightly over 50 years in the Mid-Nineties and below 45 years in 2000, or Zimbabwe, where life expectancy dropped by 10 years during the late Nineties from 53 to 43 years. In 2000, HIV rates in these countries were about $25 \%$, that is one quarter of the population was affected by HIV. MDG Target 6 .A is to "have halted by 2015 and begun to reverse the spread of HIV/AIDS". The median rate in 2005 is lower than in 2000, but there are more higher rates. The rate in Zimbabwe of $27 \%$ in 2000 , which is the overall maximum throughout the last 30 years declined to 19\%, leaving Swaziland with the highest HIV rate in 2005 of $26 \%$.

The correlation coefficients displayed in Table 3.5 are quite low compared to the contemporaneous and intertemporal correlations of the standard-of-living and education indicators. Still, the intertemporal correlations of the input indicators at time $t-1$ and the under- 5 mortality rate at time $t$ are higher than the contemporaneous correlations or the intertemporal correlations in the other direction. For life expectancy it is the opposite, but this could be due to more intensive health programs in those countries, where life expectancy is lower.

\footnotetext{
${ }^{5}$ For an easier interpretation of the econometric results in later chapters, the under-5 survival rate (U5SR) is calculated from the negative indicator U5MR as $1000-U 5 M R$. That is, U5SR, which is a positive indicator, is the number of children born within one year that survive at least until the age of five.
} 


\section{Life expectancy at birth}

口 $29-45$ years

口 $45-50$ years

50 - 55 years

$\square 55-60$ years

$\square 60-73$ years

$\square$ not available
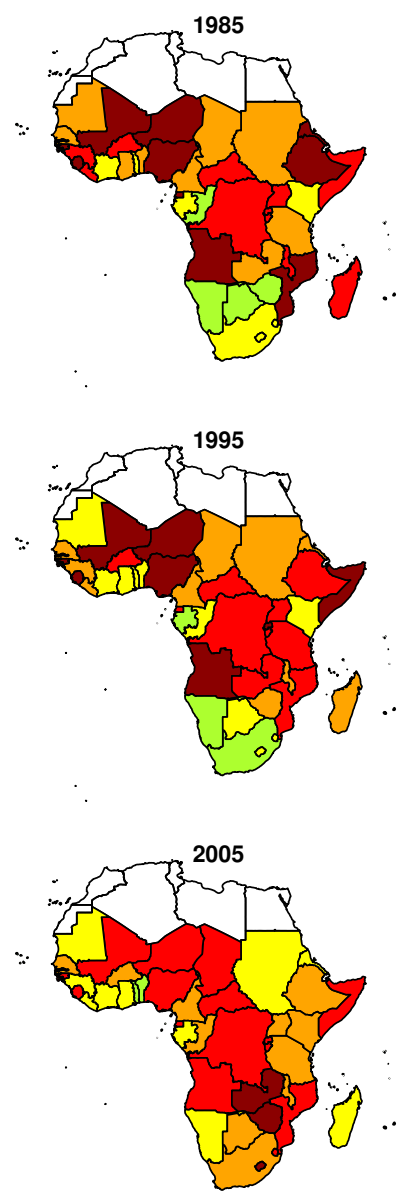

Under-5 mortality rate

ㅁ $12-100$ per 1000

ㅁ $100-150$ per 1000

$\square \quad 150-175$ per 1000

口 $175-200$ per 1000

- 200 - 350 per 1000

$\square$ not available
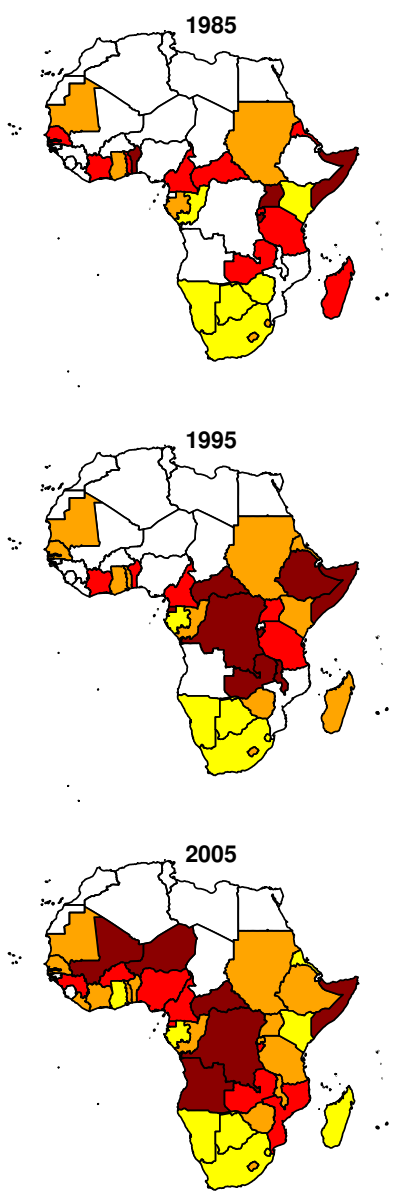

Figure 3.4: Health over time 
Table 3.6: Intertemporal Spearman correlations between outcome indicators

\begin{tabular}{lrrrrrrr}
\hline & $\mathrm{GDPC}_{t}$ & $\mathrm{HCEH}_{t}$ & $\mathrm{TPEC}_{t}$ & LITR $_{t}$ & $\mathrm{PSCR}_{t}$ & LIFE $_{t}$ & U5SR $_{t}$ \\
$\mathrm{GDPC}_{t-1}$ & 0.99 & 0.98 & 0.91 & 0.68 & 0.48 & 0.58 & 0.77 \\
$\mathrm{HCEH}_{t-1}$ & 0.97 & 0.99 & 0.90 & 0.67 & 0.44 & 0.60 & 0.77 \\
LITR $_{t-1}$ & 0.89 & 0.88 & 0.99 & 0.70 & 0.52 & 0.57 & 0.81 \\
$\mathrm{TPEC}_{t-1}$ & 0.69 & 0.70 & 0.71 & 0.97 & 0.57 & 0.40 & 0.79 \\
$\mathrm{PSCR}_{t-1}$ & 0.52 & 0.51 & 0.59 & 0.58 & 0.93 & 0.41 & 0.62 \\
LIFE $_{t-1}$ & 0.69 & 0.72 & 0.72 & 0.54 & 0.46 & 0.95 & 0.81 \\
$\mathrm{USSR}_{t-1}$ & 0.81 & 0.82 & 0.85 & 0.81 & 0.63 & 0.75 & 0.99 \\
\hline
\end{tabular}

\subsection{Integrated development}

The main goal of this work is to investigate the relations and interdependencies between the different dimensions of development, i.e. standard-of-living, health and education. The descriptive statistics and data analyses of the different aspects of development therefore have to be brought together. A first indication of whether or not there are relations between the development aspects can be given by a simple correlation analysis. Here, the displayed correlation coefficients are Spearman coefficients (because of their small sample properties), but the results are also confirmed by Kendall's $\tau$ and the usual Pearson correlation coefficients.

Figure 3.5 shows pairwise contemporaneous correlations and corresponding scatter plots of the outcome indicators. Table 3.6 shows intertemporal correlations. Looking at both contemporaneous and intertemporal correlations is important, because development is not static and high intertemporal correlations could indicate a causality relation over time.

All contemporaneous correlation coefficients are positive and larger than 0.5 with few exceptions. The highest correlations are found between the indicators within each dimension. Still, the under-5 survival rate (U5SR) is highly correlated with household consumption expenditures $(\mathrm{HCEH})$ and the literacy rate. The correlation coefficients of the primary school completion rate (PSCR) are lower than 0.5 with values between 0.3 (with life expectancy at birth, LIFE) and 0.42 (with U5SR and HCEH).

The scatter plots in Figure 3.5 show that there is hardly any linear relation ${ }^{6}$ between the different indicators, with the exception of the relation between life expectancy at birth (LIFE) and household consumption expenditures (HCEH). The relation between $\mathrm{HCEH}$ and the under-5 survival rate (U5SR) could be exponential, as could be the relation between GDPC and U5SR. This shows that a simple correlation analysis is not sufficient to infer about nature of the relations between the different dimensions of development.

The intertemporal correlations, that is correlations between the variables at time $t$ and all other variables at time $t$-1, i.e. the previous five-year average, are also positive and not necessarily lower than the contemporaneous correlations. The highest correlations can naturally be found on the diagonal of Table 3.6, but also the correlation coefficients of GDP per capita (GDPC) and lagged household consumption expenditures $(\mathrm{HCEH})$ and $\mathrm{HCEH}$ and lagged GDPC are higher than

\footnotetext{
6 indicated by the lowess lines in the plots. In the statistical software R, the LOWESS smoother uses locally-weighted polynomial regression.
} 


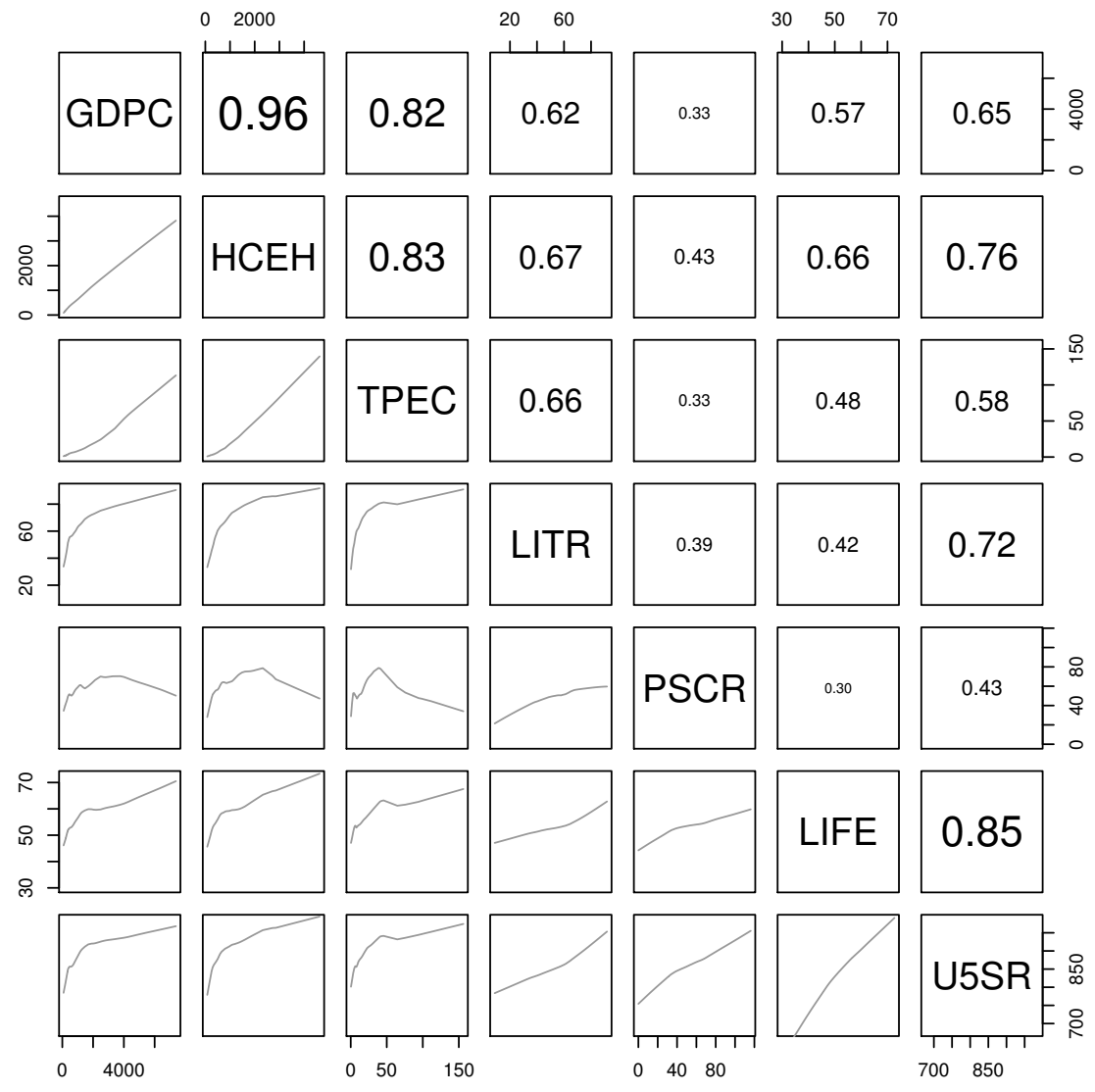

Figure 3.5: Contemporaneous correlations between outcome indicators

0.9. The lowest intertemporal correlations can be found between life expectancy at birth at time $t$ and the two education indicators at time $t$ - 1 . In general, the intertemporal correlations are quite close to the contemporaneous correlations. Exceptions are the correlations between the health indicators and the primary school enrollment rate at $t-1$ and the standard-of-living indicators at time $t$. A possible interpretation is that a good health level in previous years and a higher share of people that have completed primary school have a positive influence on both GDP and HCE per capita in later years.

\subsection{Is development progress in SSA sustainable?}

There is sufficient data available to monitor the long term development progress in Sub-Saharan Africa (SSA). The data relating to the more specific development targets that are laid down in the Millennium Development Goals (MDG) is available 
for at least every fifth year since 1990. This, however, only holds for the data presented in this chapter. In general, there are large data gaps in the MDG database, especially for the Sub-Saharan African countries. The indicator measuring, for example, the overall prevalence of poverty, that is the number of person living on less than 1 or 2 USD per day, is only available sporadically. The same is true for the Gini-coefficient, an internationally comparable measure of inequality. For the purpose of purely econometric analysis, as conducted in the next chapter, most of the data series available for the Sub-Saharan African countries in the MDG database do not contain a sufficient number of observations. The correlation analysis in the previous section together with the description of the development before shows that the outcome indicators of the three aspects standard-of-living, education and health are highly correlated with the other indicators of the respective dimension, and hence well represent development in that dimension.

The outcome indicators for standard-of-living are GDP per capita (GDPC), household consumption expenditures per capita ( $\mathrm{HCEH})$ and total primary energy consumption expenditures (TPEC). Development progress in Sub-Saharan Africa with respect to these indicators stagnated or was even negative during the Nineties. Economic growth, and with this household consumption expenditures and primary energy consumption, only started increasing again from $2000 \mathrm{on}$. Still, while both GDP and household consumption expenditures increased by $50 \%$ over the past three decades globally, these only increased by $5.5 \%$ on average in the SSA countries, which already had the lowest absolute GDP and HCE per capita. The increases in health and education outcomes, measured by the literacy rate (LITR) and primary school completion rate (PSCR) and life expectancy at birth (LIFE) and under-5 mortality rate (U5MR), over the past three decades were stronger, but also stagnated during the Nineties. Again, development progress in the SSA countries was well below average, so that the gap to the industrialized countries even widened.

This situation cannot be called sustainable. The SSA countries were hit hardest by the World Food Crisis in 2008, because it was the prices for the basic food supplies such as rice, wheat and corn that rose most. Due to the very low income, the poor could no longer afford to buy a sufficient amount of food, which in turn led to undernourishment and increasing mortality rates. Children that are too weak to walk, cannot attend school, so drop-out rates increased. This shows that there are interdependencies between the different aspects of development, which gives rise to the question: Does a low performance in one development dimension hold back the development in the other dimensions of a country?

The results of a quick correlation analysis between the outcome indicators of the three dimensions show that there are positive relations between living standards, education and health. This means that development progresses similarly in these dimensions. Positive correlation coefficients can, however, be induced by third variables, that is exogenous variables that simultaneously influence all the outcome indicators. Further, correlation coefficients are not sufficient to make inferences about the nature of the causal relations between the three aspects of development. The model developed in Chapter 4 uses econometric complementarity analysis to shed some light on the relation between the development outcome indicators introduced in this chapter. 

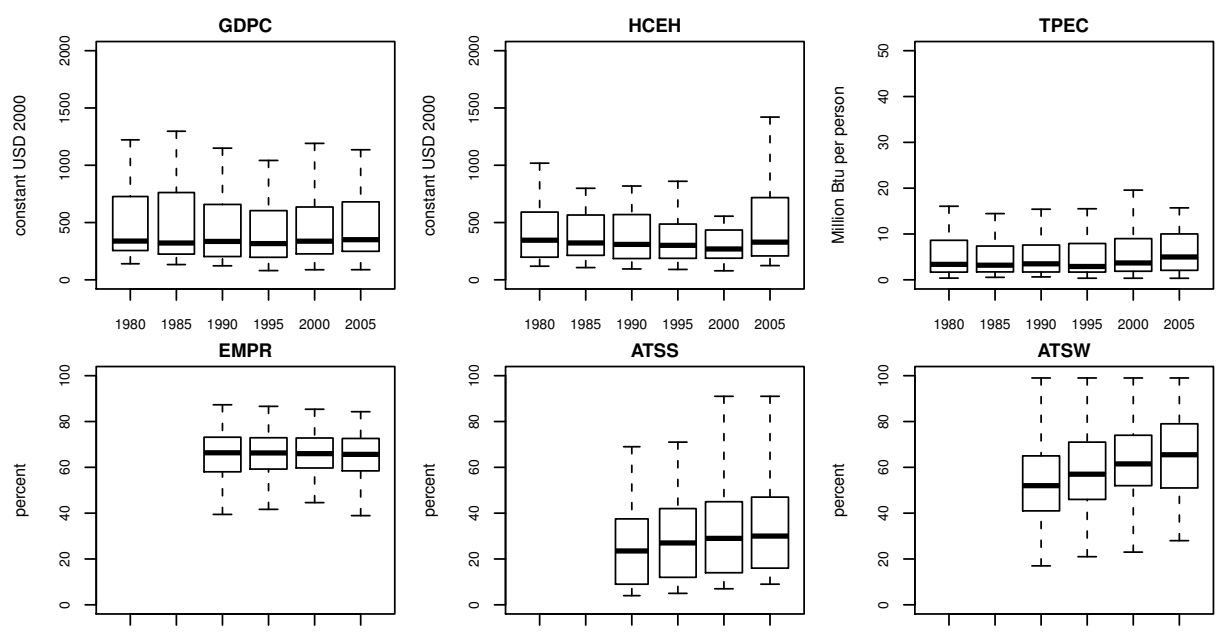

$\begin{array}{llllll}1980 & 1985 & 1990 & 1995 & 2000 & 2005\end{array}$ ATSS
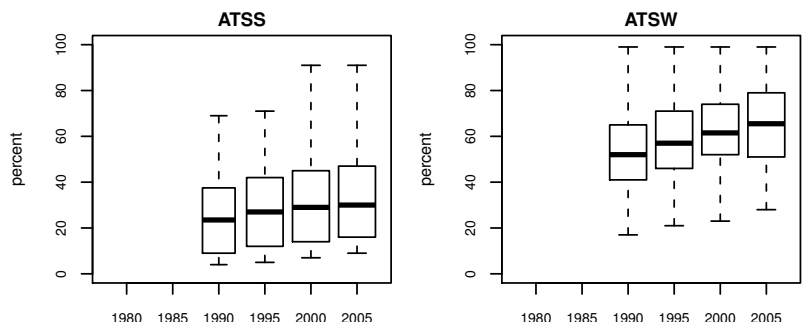

LITR

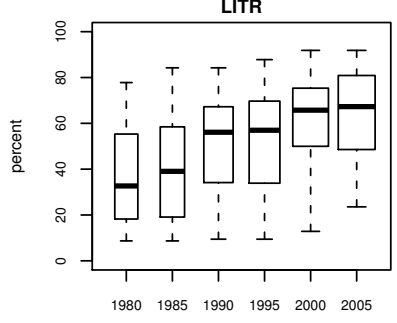

$\begin{array}{llllll}1980 & 1985 & 1990 & 1995 & 2000 & 2005\end{array}$

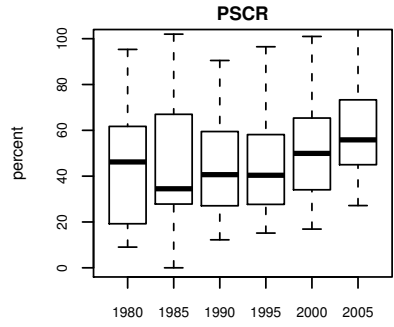

GSER

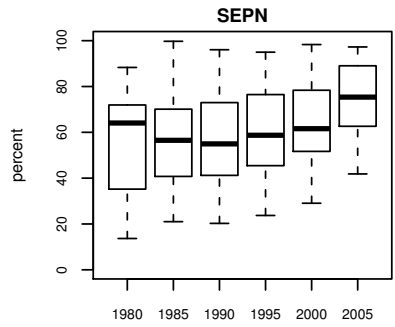
LIFE
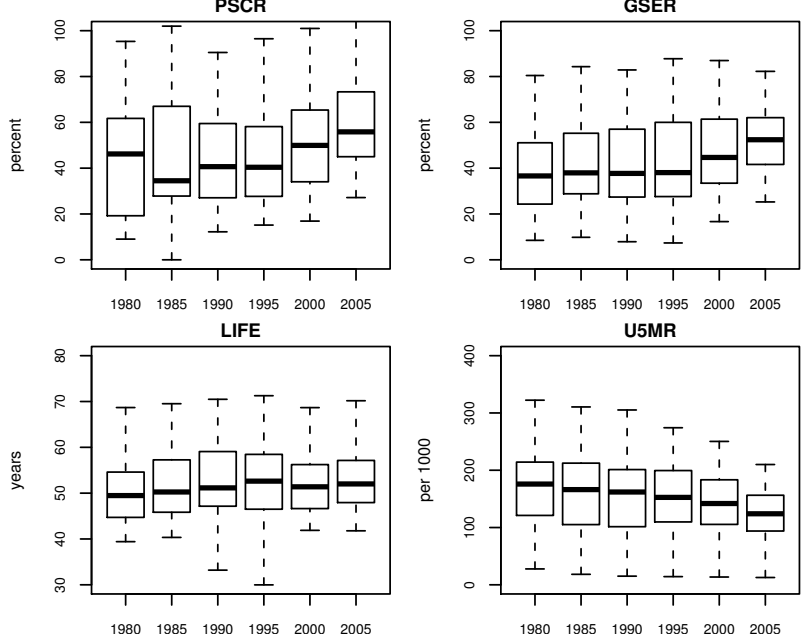

U5MR

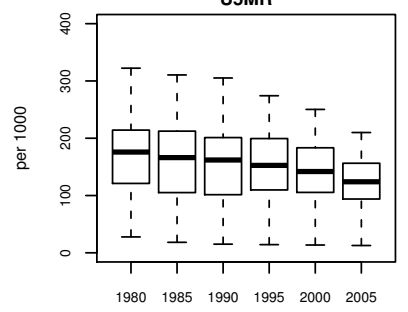

IMMU

DPT

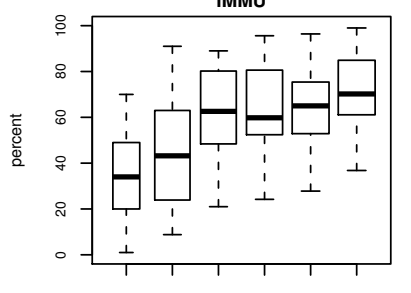

$19801985 \quad 1990 \quad 1995 \quad 2000 \quad 2005$

The circles on the upper/lower ends of the plots are outhiers, which are calch

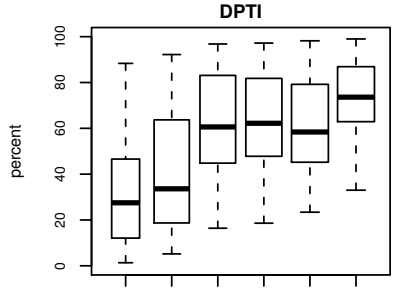

PUND

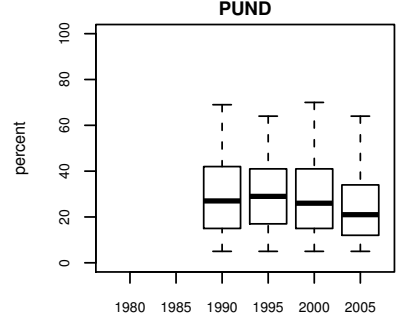

compared to the size of the box. Here it is a factor of 1.5. For more information, see Rhelp on boxplot.stats.

Figure 3.6: Development in SSA 



\section{Chapter 4}

\section{Complementarities in development}

Development progress in Sub-Saharan African countries over the past three decades has been slow; in fact - as shown in Chapter 3 - on average development progress in these countries was slower than the world average, which led to a further widening of the gap to not only the industrialized countries, but to many other developing countries and emerging economies, too. Out of the 30 lowest ranked countries with regard to the Human Development Index (HDI) in the 2011 Human Development Report (UNDP, 2011), 28 are from Sub-Saharan Africa, with the lowest 15 being exclusively Sub-Saharan African countries. By now, more than two thirds of the time span to achieve the Millennium Development Goals (MDGs) has passed and only very few countries seem to be on track in reaching the targets set by the UN General Assembly in 2000. The natural question to ask is 'Why?'. There are most probably many different reasons and hence also many different answers as well as possibilities to deduce answers. A very basic question that should be answered first is: Can all MDGs actually be achieved simultaneously? Are the different dimensions of development compatible? Or can only progress in one dimension be achieved at a time? Or, to pose a more positive question: Are the three dimensions of development introduced in the previous chapter, i.e. living standards, education and health, complementary to each other, or, in other words, does a positive development in one of these dimensions have positive externalities on enhancing development progress in the other dimensions? According to Mairesse and Mohnen (2010) the idea behind the notion of complementarity is the interaction among different indicators or different policies. In the introduction to their book on the MDGs (p. 2) McGillivray et al. (2008) state that

No one goal can be looked at in isolation from the others, nor from key macroeconomic outcomes not built directly into or recognized within the MDGs. Central to achieving the MDGs is a recognition of these interdependencies, and any robust and insightful analysis of them must take this into account. 
The literature on possible interdependencies between the indicators of the different dimensions of development is not conclusive. The European Report on Development (Bourguignon et al., 2008a), which was published in September 2008, for example, notes (on p. 9) that:

The correlation between GDP per capita growth and the non-income MDGs is practically zero, thus confirming the limited linkage found between these indicators and poverty reduction.

The Stern Review (Stern, 2007) says (on p. 125) that

There is also a close relationship between growth and many non-income indicators of development, ranging from under-5 mortality to educational attainment and peace and security.

The MDGs as well as the HDI cover very different aspects of living: poverty, health, education and environmental sustainability. In Chapter 3 the development in Sub-Saharan Africa over the past three decades with respect to the different aspects of development was described. The objective of this chapter is to find complementarities between three aspects of development: standard-of-living, health and education, using both the HDI and the MDG indicators.

According to McGillivray et al. (2008) not many structural econometric models have been applied to this issue before. The authors use simultaneous equation modeling to analyze interdependencies between some MDG related indicators, aid and material well-being. The approach applied here is similar regarding the general problem setting, but differs because it uses methods from firm productivity analysis to find complementarities. There are two main types of this complementarity/substitutability analysis, productivity analysis (PROD) and correlation analysis (CORR), as described by Mohnen and Röller (2003). While the former method compares the productivity of following two strategies ${ }^{1}$ simultaneously versus following each of the strategies individually, the latter identifies the correlation between outcomes of following different strategies after controlling for other variables.

This chapter applies the PROD approach, testing whether the three dimensions of development, standard-of-living, education and health, are complementary to each other. The chapter is organized as follows: the next section will shortly summarize some of the relevant literature on development indicators and econometric analyses of their interdependencies. Section 4.2 introduces econometric complementarity analysis. The model applied here is developed in Section 4.3. After presenting results, Section 4.5 gives some conclusions.

\subsection{Empirical analysis of development}

There exists a broad literature relating income, health and education measured by different indicators, but, as also noted by Fielding and Torres (2009), most of the empirical literature focuses on analyzing relations between two indicators only.

\footnotetext{
${ }^{1}$ The term strategy will be defined in Section 4.2 .
} 
According to McGillivray et al. (2008) a comprehensive view on the interdependencies between different dimensions of development should involve a model that looks at more than one relationship simultaneously. Some of the papers, referred to by Fielding and Torres (2009, p. 39), do not even consider a two-way relation between pairs of indicators, but rather only the effect of education on income (e.g. Teulings and van Rens, 2003) or of income on education (e.g. Fernandez and Rogerson, 1997), the effect of health on income (e.g. Bloom et al., 2004) or of income on health (e.g. Pritchett and Summers, 1993).

One example for the investigation of the two-way relation between GDP per capita growth and life expectancy at birth is Azomahou et al. (2008a), who observed, for 18 different countries between 1820 and 2005, a co-evolution of per capita income and life-expectancy at birth. The estimation results confirm their assumption of a non-linear relationship between the two data series. While it is a strictly positive relationship, the curvature depends on the values of life expectancy: for low values, the relation is strictly convex, while for higher values it is concave. In Azomahou et al. (2008b) the authors investigate the impact of AIDS on economic growth. The empirical investigation is based on a general equilibrium model in which two scenarios, low and high AIDS prevalence rates, are implemented. They find that via increasing mortality rates, and decreasing life expectancy and employment, there is a negative long-run impact of AIDS on the economy in Sub-Saharan Africa.

Health is also negatively affected by environmental pollution, see for example Pautrel (2008), or by low income, which negatively affects health through malnutrition; van Zon and Kiiver (2006) summarize the relevant empirical literature on this issue. The literature argues that inadequate nutrition not only negatively affects health and general mental development, but also that children with poor health spend less time at school and hence do not have the chance to obtain a good education. Low education leads to low-paid jobs or even unemployment, so that the children's children also grow up in poverty. This problem is called 'intergenerational poverty trap'. They further state that "even with the current speed of improvement of nutritional standards, about 1 billion children will be impaired in their mental development in 2020 due to the compound effect of malnutrition of parents and children" (van Zon and Kiiver, 2006, p.3). Health affects economic growth via different channels, e.g. poor health leading to lower accumulation of human capital and hence to lower economic growth or poor health leading to lower life expectancy and hence to lower growth.

These chains link the three dimensions of development, which are the focus of this work. Earlier empirical work on the link between education and economic growth can be found in Barro and Sala-i Martin (1995) and Benhabib and Spiegel (1994). Their main findings are that a high level of education and public spending on education positively influence economic growth. The positive influence can be explained by a high stock of human capital that increases the rate of innovation and technological diffusion, which in turn increase growth.

Ranis and Stewart (2005) not only investigate the impact of social (or human as the authors call it) development (HD) on economic growth (EG), but also the impact of EG on HD, in 69 developing countries. For social development they primarily focus on health and education. Hence, they explicitly include the three 
dimensions of development. They first set up a causal chain for each direction of the relation and then empirically establish the links between the different elements in the chain. They find that the strength of the links in both chains vary considerably. This means that both economic growth and social development can be achieved through different channels. They find that social development measured by the infant mortality shortfall reduction, is directly influenced not only by economic development, GDP per capita growth, but also by the social expenditure ratio (public health and education expenditures relative to total public expenditures), female education enrollment, and lower inequality and poverty. The conclusion we draw from this is that economic growth alone is not sufficient for social development. Social development can be achieved only when the poor are able to take part in the overall development of an economy. The importance of human development can be seen when looking at empirical evidence for the chain from social development to economic growth, measured by the GDP per capita growth rate. The coefficients of the literacy rate, literacy shortfall reduction, log life expectancy and life expectancy shortfall reduction are all highly significant, even when additionally introducing GDP per capita and gross domestic investment.

From their results, Ranis and Stewart (2005), categorize the countries into four groups: virtuous, vicious, HD-lopsided and EG-lopsided. A virtuous development is when good economic performance leads to good human development, which in turn positively enhances economic growth, enforcing an upward spiral of development. A vicious development on the other hand is the corresponding downward spiral. HD-lopsided are countries that experience a good social development, but the linkage to EG are too weak to enforce the upward spiral. EG-lopsided countries in turn are those experiencing economic growth, but stagnation in social development, which was the case for most African countries after colonial time. Ranis and Stewart (2005) put each country in one of the four categories for each decade in their analysis. From the moves over time of the countries between these categories, one can see that good economic performance alone is not enough to enforce the upward spiral, no EG-lopsided country made it directly into the virtuous category, just as hardly any country managed to get from HD-lopsided to virtuous. Unfortunately most countries in Africa and South Asia seem to be in the vicious cycle of low EG enforcing low HD. Most of the countries in the Middle-East and Latin America are in the HD-lopsided category, while most of the East-Asian countries were able to enter the virtuous development via HD-lopsidedness, showing the importance of education and health for development.

The literature most relevant to the question at hand is quite limited. Most authors in this field also contributed to McGillivray et al. (2008): David Fielding and Sebastian Torres (e.g. Fielding, 2002; Fielding and Torres, 2005; Fielding et al., 2008; Fielding and Torres, 2009), Mark McGillivray (McGillivray, 2008; Fielding et al., 2008), Howard White and Nina Blöndal (White, 2002; White and Blöndal, 2008), and Stephan Klasen and various coauthors (e.g. Klasen, 2008; Grosse et al., 2008). In this book about the Millennium Development Goals (MDGs), they apply different empirical techniques to analyze progress toward the MDGs based on different development indicators. To start with, McGillivray (2008) shortly describes the Millennium Development Goals and the progress that has been made since their announcement in 2000. White and Blöndal (2008) give an overview 
on existing methods to project the path toward the MDGs. The authors differentiate between "naïve" projections only based on time trends, outcome-income projections based on international forecasts of GDP and GDP growth, and more sophisticated multi-equation models.

The analysis in Fielding et al. (2008) belongs to the latter category. Their approach is similar to the approach in Fielding (2002) and Fielding and Torres (2005). They analyze the link between aid, material well-being, and some MDG related indicators including the under-5 mortality rate, educational attainment, access to piped water (as a proxy for access to improved water sources and sanitation), and fertility. The authors set up a structural model including one equation per MDG indicator and an additional equation for aid. All the indicators appear on both sides in this system of equations, once as a dependent variable, and also as an explanatory variable in the other equations (not necessarily in all). Additionally, a set of exogenous variables covering geographic factors and population structure is included. This system of equations is then estimated using the simultaneous equation method three-stage least squares (3SLS). They infer on the relationship between the indicators directly from the coefficients, that is how proportional changes in the explanatory variables translate into proportional changes in the dependent variables.

Fielding and Torres (2009) also use this approach of developing the partially reduced form system of equations from a system of structural equations, but when estimating the system they distinguish between different income quintiles to explicitly consider the effect of inequality. All of these papers reduce the number of endogenous variables to include some measure of wealth (GDP per capita, material well-being), education (literacy rate, primary school completion rate), health (life expectancy at birth, under-5 mortality rate), and one or two other measures of development, e.g. fertility, democracy, inequality, access to piped water or aid transfers, treating the remaining indicators as exogenous. This is possible because the endogenous indicators can be seen as development outcomes whereas the remaining indicators are development inputs. ${ }^{2}$

The econometric development literature summarized here finds significant relations between different development (mostly outcome) indicators. The interdependencies between these indicators will be put into a new context in the following analysis by explicitly applying complementarity analysis.

\subsection{Complementarity analysis}

Let a 'strategy' be representing a development indicator, a policy measure or a measure of the outcome of a policy. Then, an informal definition of complementarity between two strategies is:

Two strategies are complementary if following both strategies simultaneously has a higher payoff than following each strategy separately.

or as stated by Amir (2003), p.2:

\footnotetext{
${ }^{2}$ Recall that, based on Szirmai (2010), the development indicators introduced in Chapter 3 have been classified as development outcome indicators and development input indicators.
} 
"If in a maximization problem, the objective reflects a complementarity between an endogenous variable and an exogenous parameter, in the sense that having more of one increases the marginal return to having more of the other, then the optimal value of the former will be increasing in the latter. In the case of multiple endogenous variables, then all of them must also be complements so as to guarantee that their increases are mutually reinforcing."

This definition clearly corresponds to what is called the productivity approach (PROD) of complementarity analysis (Mohnen and Röller, 2003). Milgrom and Roberts (Milgrom and Roberts, 1990, 1995) derive their theory of complementarity from the mathematics of supermodularity. This theory gives a more formal definition of complementarity. Given strategies $s, s^{\prime} \in R^{n}$, a function $f: R^{n} \rightarrow R$ is supermodular if

$$
f\left(\min (s), \min \left(s^{\prime}\right)\right)+f\left(\max (s), \max \left(s^{\prime}\right)\right) \geq f(s)+f\left(s^{\prime}\right)
$$

which is equivalent to

$$
f\left(\max (s), \max \left(s^{\prime}\right)\right)-f\left(s^{\prime}\right) \geq f(s)-f\left(\min (s), \min \left(s^{\prime}\right)\right) .
$$

The LHS of the inequality shows the change in payoff of increasing $s$ to its maximum value given that $s^{\prime}$ is higher than its minimum value, while the RHS shows the payoff of increasing $s$ to a value higher than minimum, given that $s^{\prime}$ has its minimum value. If the above inequality holds, raising $s$ on the LHS has a higher value of function $f$ than raising it on the RHS. Amir (2003) calls this property 'increasing differences'. It implies that $s$ and $s^{\prime}$ are complementary, if the function $f\left(s, s^{\prime}\right)$ is supermodular in $s$ and $s^{\prime}$. This formal definition corresponds exactly to the informal definition given above.

There are only a few papers applying complementarity theory to macro-economic data, the most famous being those on capital-skill complementarity, e.g. Duffy et al. (2004) or Krusell et al. (1997), complementarity of agent activities, e.g. Cooper and Haltiwanger (1996), money-capital complementarity, e.g. Kar and Pentecost (2000), or the effects of private and public capital aggregate output and productivity as in Ramirez (2007). What is common to all of these papers is the use of an aggregate production function and the PROD complementarity methodology based on the supermodularity theory. To conduct a complementarity analysis using this theory, an objective function measuring the payoff of adopting strategy $s$ and/or strategy $s^{\prime}$ is needed.

In short, the PROD approach works as follows: first estimate an objective function and then test whether the cross elasticities are positive or negative. The actual procedure is more involving, starting with the choice of the appropriate functional form of the objective. It is necessary to use a flexible form that does not impose a priori restrictions on the elasticities of substitution that are too strong. Hence, it is not possible to use any of the linear, the Cobb-Douglas, the Leontief or the constant-elasticity-of-substitution (CES) production functions. In addition, it has to be ensured that there is no endogeneity problem in the data; choosing the appropriate estimation technique is therefore an important step in 
the analysis. The last step is to calculate the cross elasticities from the estimated parameters.

This method was pioneered by Griliches (1969), where he tested capital-skill complementarity using a nested CES function. The approach is followed up more recently in for example Duffy et al. (2004) on the same subject, or Kemfert (1998), testing complementarity between the three production factors capital, labor and energy. Duffy et al. (2004) test the hypothesis that physical capital is more complementary to skilled than to unskilled labor. For that they need to show that the elasticity of substitution of capital and unskilled labor is greater than the elasticity of substitution of capital and skilled labor. The nested CES function however requires separability of inputs. A functional form, that does not require the separability of inputs, is for example the translog specification, which has been widely applied in empirical studies, inter alia in studies on energy-capital complementarity as in Berndt and Wood (1979) or Griffin and Gregory (1976).

Lokshin et al. (2007) use a slightly different approach. Rather than comparing substitution elasticities, they define $s$ and $s^{\prime}$ to be substitutes (complements) in the function $f\left(s, s^{\prime}\right)$ if and only if (the interaction term) $\frac{\partial^{2} f}{\partial s \partial s^{\prime}} \leq 0(\geq 0)$ for all values of $\left(s_{1}, \ldots, s_{n}\right)$, with the inequality holding strictly for at least one value. This goes back to Topkis' Monotonicity Theorem, see Lemma 1 in Amir (2003). This Lemma states that if we have a problem in $\mathbb{R}^{2}$, then if $f\left(s, s^{\prime}\right)$ is twice differentiable, increasing differences, as defined in Equation (4.2), are equivalent to $\left.\partial f\left(s, s^{\prime}\right)\right) /\left(\partial s \partial s^{\prime}\right) \geq 0$. Now, assume

$$
\frac{\partial^{2} f}{\partial s \partial s^{\prime}}=\alpha_{s s^{\prime}} ;
$$

to conclude that there is complementarity between $s$ and $s^{\prime}$, it is therefore sufficient to show that the coefficient of the interaction term $\alpha_{s s^{\prime}}$ is positive (and significant).

As a single measure of development does not exist, the PROD approach as such is not directly applicable, although it does give the background for what is called here PROD without objective value. As shortly described by Mohnen and Röller (2003), who refer to Miravete and Pernías (1998), the approach of the latter is to "estimate the correlation in choice variables from the first order conditions". That is, they simultaneously estimate the system of structural equations that result from taking the first derivatives of the profit function (they aim at finding complementarities between different innovation strategies) and setting those equal to zero. This is possible because it is assumed that firms maximize their profits when choosing their output level and deciding about engagement in innovation practices. This means, rather than actually having an objective, i.e. dependent, variable with specific values as in the PROD approach, for the approach without objective value the objective variable only needs to be there theoretically, to set up such an objective function.

When applying this PROD without objective value approach it is sufficient to assume that some aggregated development measure indeed exists, without having actual data on it. To follow the argumentation in Miravete and Pernías (1998), it would be necessary to assume that the policies of a country aim at an optimal overall development of the country. There exist different superordinate development policy goals in for example the EU Sustainable Development Strategy European 
Council (2006): economic prosperity, social equity and cohesion, and environmental protection; or as defined by the Human Development Report Office: "a long and healthy life, knowledge and a decent standard of living" 3 . Even though these policy goals exist, the theoretical optimality assumption of development is, at least in Sub-Saharan African countries, not given in reality. Including a partial adjustment model into the first order conditions allows us to still follow this approach. The partial adjustment model controls for the fact, that actual development differs from optimal development.

\subsection{Modeling development complementarities}

The model developed in this section aims at finding complementarities between the three dimensions of development: standard-of-living, health, and education. The corresponding indicators were introduced in Chapter 3. While using GDP per capita as a measure of a country's development or of the living conditions in a country is criticized by e.g. Stiglitz et al. (2009), it well reflects the economic dimension of development. GDP can be seen as a measure of production, whereas household consumption expenditures per capita might better reflect people's disposable income. Additionally, in light of the 2010 IEA World Energy Outlook's chapter on energy poverty (IEA, 2010b), total primary energy consumption is used as a measure of standard-of-living.

Life expectancy at birth summarizes the health status of a population and additionally is an indicator for which data is readily available for many countries. Alternatively, we measure the health status with the reciprocal value of the under- 5 mortality rate, i.e. the share of children born within one year that survive at least until the age of five. This indicator is also one of the indicators with which the progress toward Millennium Development Goal (MDG) 4 "Reduce child mortality" is measured. The two education indicators used here are the literacy rate and the primary school completion rate, which relates to MDG 2 "Achieve universal primary education".

These indicators, GDP per capita $(G D P C)$, household consumption expenditures per head $(H C E H)$ or total primary energy consumption per capita (TPEC), life expectancy at birth $(L I F E)$ or under-5 survival rate $(U 5 S R)$, and the literacy rate $(L I T R)$ or primary school completion rate $(P S C R)$ are modeled as development outcomes and hence relate to the three endogenous variables $S_{1}, S_{2}$, and $S_{3}$ that together constitute the overall development $D$ of a country. As mentioned before, there does not exist an overall development measure $D$, so that the approach followed here is the PROD without objective value.

The model developed here combines the approach of Lokshin et al. (2007) and Miravete and Pernías (2006). That is, $S_{i}$ and $S_{j}$ are defined to be complements (substitutes) if $\partial^{2} D /\left(\partial S_{i} \partial S_{j}\right)>0\left(\partial^{2} D /\left(\partial S_{i} \partial S_{j}\right)<0\right)$. By using the approach of Miravete and Pernías (2006), it is possible to assume that a measure of a country's overall development exists, without actually having data on it. When taking the first order conditions, the objective variable drops out of the system that is to be estimated. It is, however, implicitly defined by the first order conditions.

\footnotetext{
${ }^{3}$ http://hdr.undp.org/en/statistics/indices/
} 
Let $D$ be the general (non-measurable) development measure and vector $\mathbf{S}$ contain the endogenous variables. The number of endogenous variables is three, which corresponds to the number of development dimensions considered. The development production function is set up using a translog specification as in Berndt and Wood (1979) with variables $S_{1}, S_{2}$, and $S_{3}$. Let $d$ denote $\ln D$ and $s_{i}$ denote $\ln S_{i}$.

$$
\begin{aligned}
d= & \alpha_{10} s_{1 t}+\alpha_{20} s_{2 t}+\alpha_{30} s_{3 t} \\
& +\frac{1}{2}\left[\alpha_{11}\left(s_{1 t}\right)^{2}+\alpha_{22}\left(s_{2 t}\right)^{2}+\alpha_{33}\left(s_{3 t}\right)^{2}\right] \\
& +\alpha_{12} s_{1 t} s_{2 t}+\alpha_{13} s_{1 t} s_{3 t}+\alpha_{23} s_{2 t} s_{3 t} .
\end{aligned}
$$

Strategies $s_{i}$ and $s_{j}$ are complements if the corresponding coefficient of the interaction term $s_{i} s_{j}$, that is $\alpha_{i j}$ is positive. The derived first order conditions are:

$$
\begin{aligned}
& \frac{\partial d_{t}}{\partial s_{1 t}}=\alpha_{10}+\alpha_{11} s_{1 t}+\alpha_{12} s_{2 t}+\alpha_{13} s_{3 t} \hat{=} 0 \\
& \frac{\partial d_{t}}{\partial s_{2 t}}=\alpha_{20}+\alpha_{12} s_{1 t}+\alpha_{22} s_{2 t}+\alpha_{23} s_{3 t} \hat{=} 0 \\
& \frac{\partial d_{t}}{\partial s_{3 t}}=\alpha_{30}+\alpha_{13} s_{1 t}+\alpha_{23} s_{2 t}+\alpha_{33} s_{3 t} \hat{=} 0
\end{aligned}
$$

Solving these for $s_{1 t}, s_{2 t}$, and $s_{3 t}$, the conditions for the optimal levels of development of $s_{i}$ at time $t, s_{i t}^{\star}$ follow:

$$
\begin{aligned}
& s_{1 t}^{\star}=-\frac{1}{\alpha_{11}}\left[\alpha_{10}+\alpha_{12} s_{2 t}^{\star}+\alpha_{13} s_{3 t}^{\star}\right]=a_{10}+a_{12} s_{2 t}^{\star}+a_{13} s_{3 t}^{\star} \\
& s_{2 t}^{\star}=-\frac{1}{\alpha_{22}}\left[\alpha_{20}+\alpha_{12} s_{1 t}^{\star}+\alpha_{23} s_{3 t}^{\star}\right]=a_{20}+a_{21} s_{1 t}^{\star}+a_{23} s_{3 t}^{\star} \\
& s_{3 t}^{\star}=-\frac{1}{\alpha_{33}}\left[\alpha_{30}+\alpha_{13} s_{1 t}^{\star}+\alpha_{23} s_{2 t}^{\star}\right]=a_{30}+a_{31} s_{1 t}^{\star}+a_{32} s_{2 t}^{\star}
\end{aligned}
$$

with coefficients $a_{i j}$ fulfilling $a_{12} a_{23} a_{31}=a_{13} a_{32} a_{21}$. This follows from the six conditions imposed on the six unknown $\alpha$ 's:
(a) $a_{12}=-\frac{\alpha_{12}}{\alpha_{11}}$
(b) $a_{13}=-\frac{\alpha_{13}}{\alpha_{11}}$
(c) $a_{21}=-\frac{\alpha_{12}}{\alpha_{22}}$
(d) $a_{23}=-\frac{\alpha_{23}}{\alpha_{22}}$
(e) $a_{31}=-\frac{\alpha_{13}}{\alpha_{33}}$
(f) $a_{32}=-\frac{\alpha_{23}}{\alpha_{33}}$

Solving (a) and (b) for $\alpha_{11}$ gives $\alpha_{12}=\alpha_{13} a_{12} / a_{13}$, solving (c) and (d) for $\alpha_{22}$ gives $\alpha_{12}=\alpha_{23} a_{21} / a_{23}$, so that $\alpha_{13} a_{12} / a_{13}=\alpha_{13} a_{21} / a_{23} \Leftrightarrow \alpha_{13}=\alpha_{23} a_{21} a_{13} /\left(a_{12} a_{23}\right)$. Solving (e) and (f) for $\alpha_{33}$, we have that $\alpha_{13}=\alpha_{23} a_{31} / a_{32}$, so that the coefficient restriction is $\alpha_{23} a_{21} a_{13} /\left(a_{12} a_{23}\right)=\alpha_{23} a_{31} / a_{32} \Leftrightarrow a_{12} a_{23} a_{31}=a_{13} a_{32} a_{21}{ }^{4}$. Additionally, coefficients $a_{i j}$ and $a_{j i}$ have to be of the same sign, that is they have to

\footnotetext{
${ }^{4}$ For four endogenous variables this single restriction becomes six different conditions (all possible combinations of multiplying three and four variables) that the coefficients need to fulfill.
} 
fulfill $a_{i j} a_{j i}>0$. Assuming that the objective function is indeed maximized, the corresponding Hessian matrix has to be negative definite, that is the entries on the diagonal, $\alpha_{i i}$, should be negative to ensure that the objective function is concave in $s_{i}$.

Using first order conditions assumes optimality in the strategies, implying that the level of development is optimal. As development in the Sub-Saharan African countries is by no means optimal, the optimal strategies here are approximated using a partial adjustment model (Greene, 2003) for each strategy $s_{i}$ :

$$
s_{i t}-s_{i t-1}=b_{i}\left(s_{i t}^{\star}-s_{i t-1}\right) \text {. }
$$

Here, $s_{i t}^{\star}$ is the desired optimal level of, in this case, development in either one of the three dimensions, whereas $s_{i t}$ is the actual observed level of development. The fraction $b_{i}, 0<b_{i}<1$, is the speed of adjustment of the actual level to the desired level. Solving this for the optimal level gives

$$
s_{i t}^{\star}=\frac{1}{b_{i}} s_{i t}+\left(1-\frac{1}{b_{i}}\right) s_{i t-1}=\frac{1}{b_{i}} \Delta s_{i t}+s_{i t-1} .
$$

Now replacing the optimal $s_{i t}^{\star}$ in system (4.6) by (4.9) gives

$$
\begin{aligned}
& \Delta s_{1 t}=a_{10} b_{1}+\frac{a_{12} b_{1}}{b_{2}} \Delta s_{2 t}+\frac{a_{13} b_{1}}{b_{3}} \Delta s_{3 t}-b_{1} s_{1 t-1}+a_{12} b_{1} s_{2 t-1}+a_{13} b_{1} s_{3 t-1} \\
& \Delta s_{2 t}=a_{20} b_{2}+\frac{a_{21} b_{2}}{b_{1}} \Delta s_{1 t}+\frac{a_{23} b_{2}}{b_{3}} \Delta s_{3 t}+a_{21} b_{2} s_{1 t-1}-b_{2} s_{2 t-1}+a_{23} b_{2} s_{3 t-1} \\
& \Delta s_{3 t}=a_{30} b_{3}+\frac{a_{31} b_{3}}{b_{1}} \Delta s_{1 t}+\frac{a_{32} b_{3}}{b_{2}} \Delta s_{2 t}+a_{31} b_{3} s_{1 t-1}+a_{32} b_{3} s_{2 t-1}-b_{3} s_{3 t-1}
\end{aligned}
$$

This system shows that development, i.e. the first difference, in each of the three dimensions theoretically depends on development in the other two dimensions and the previous level (at time $t$-1) of each of the three dimensions. Directly estimating this system is not possible because it is not identified. It is therefore necessary to add at least one ${ }^{5}$ exogenous variable to each equation that does not influence development in the other two dimensions, denoted $x_{i}$. These exogenous variables also act as control variables that at least partly take care of country heterogeneities. The choice of exogenous variables is explained in the results section.

\subsection{Results}

From the model derived in the previous section we get the following system of structural equations including exogenous variables $x_{i}$ :

$$
\begin{aligned}
& \Delta s_{1 t}=c_{10}+c_{12} \Delta s_{2 t}+c_{13} \Delta s_{3 t}+l_{11} s_{1 t-1}+l_{12} s_{2 t-1}+l_{13} s_{3 t-1}+k_{1} x_{1 t-1}+\varepsilon_{1} \\
& \Delta s_{2 t}=c_{20}+c_{21} \Delta s_{1 t}+c_{23} \Delta s_{3 t}+l_{21} s_{1 t-1}+l_{22} s_{2 t-1}+l_{23} s_{3 t-1}+k_{2} x_{2 t-1}+\varepsilon_{2} \\
& \Delta s_{3 t}=c_{30}+c_{31} \Delta s_{1 t}+c_{32} \Delta s_{2 t}+l_{31} s_{1 t-1}+l_{32} s_{2 t-1}+l_{33} s_{3 t-1}+k_{3} x_{3 t-1}+\varepsilon_{3}
\end{aligned}
$$

${ }^{5}$ This is the minimum number of exogenous variables to be added in order to satisfy the order condition for identifying equations as explained in Greene (2003), Ch. 15, p. 392. 
This system of structural form equations ${ }^{6}$ is estimated with two-stage least squares using data on the different development outcome indicators for a panel of five-year average data ${ }^{7}$ for the past three decades for about 40 Sub-Saharan African countries. These indicators represent three dimensions of development: standard-of-living (SoL), health (Hea) and education (Edu). The indicators chosen for each of the dimensions are GDP per capita $(G D P C)$, household consumption expenditure per capita $(H C E H)$ and total primary energy consumption per capita $(T P E C)$ for SoL, under-five survival rate $(U 5 S R)$ and life expectancy at birth $(L I F E)$ for health and primary school completion rate $(P S C R)$ and literacy rate $(L I T R)$ for education. It turned out that no significant relations were found for $L I F E$ and $L I T R$, so these results are not reported here ${ }^{8}$. The choice of exogenous variables, that also act as instruments together with the lagged endogenous variables, is explained on p. 56.

In time series econometrics or if there are more observations in time in panel data, testing the series for their order of integration is important. As in this data set there are at most six observations in time per variable per country, and only about four on average, testing the data for stationarity is not possible. Existing panel unit root tests as developed for example in Levin et al. (2002), which is referred to as a test for small samples by Breitung and Pesaran (2005), only give the necessary test statistics for 25 or more observations in time. As at least part of the individual country effects are taken care of by taking first differences, hence controlling for level effects, and by using exogenous control variables, estimating a pooled model is sufficient.

In short, the main result is that the primary school completion rate $(P S C R)$ and the under-5 survival rate $(U 5 S R)$ are complements. The relation between these two is always positive, and significant in almost all specifications. A decent education and good health therefore are mutually reinforcing.

Figure 4.1 summarizes these results, the dotted lines representing insignificant relations and the solid lines significant relations, with a ' + ' sign next to the line connecting two variables $s_{i}$ and $s_{j}$ indicating that $\alpha_{i j}$ is positive, that is $s_{i}$ and $s_{j}$ are complements, and a '-' sign indicating that $\alpha_{i j}$ is negative. A negative $\alpha_{i j}$ does not necessarily imply that $s_{i}$ and $s_{j}$ are substitutes. Rather, applying both $s_{i}$ and $s_{j}$ at the same time does not increase the return to either of these two. The total impact on development $d$ of applying both strategies can still be positive depending on the size of $\alpha_{i 0}$ and $\alpha_{j 0}$ and the actual level of $s_{i}$ and $s_{j}$.

A more detailed look at the results includes a description of the size, sign and significance of the coefficients at the different levels of the model: the structural form coefficients and those relating to the partial adjustment model and the first order conditions, i.e. the coefficients defining complementarity.

\footnotetext{
${ }^{6}$ Note that by estimating the $c_{i j}$ and $l_{i j}$ coefficients the original $a_{i j}$ 's are overidentified, because they can be calculated as $a_{i j}=-l_{i j} / l_{i i}$ or as $a_{i j}=c_{i j} l_{i i} / l_{j j}$.

${ }^{7}$ Recall, the average for time $t$ is taken from all available years in the period from $t-2$ to $t+2$, that is for example the average of all available years between 1978 and 1982 for the data point labeled 1980. This method has been applied in the literature before and proven to be useful, see for example Adler et al. (2009).

${ }^{8}$ This insignificance might be due to the fact that both life expectancy at birth and the literacy rate change rather slow compared to the changes in the other indicators, under- 5 survival rate or primary school completion rate. To find significant relations of these indicators, longer time series might be necessary.
} 

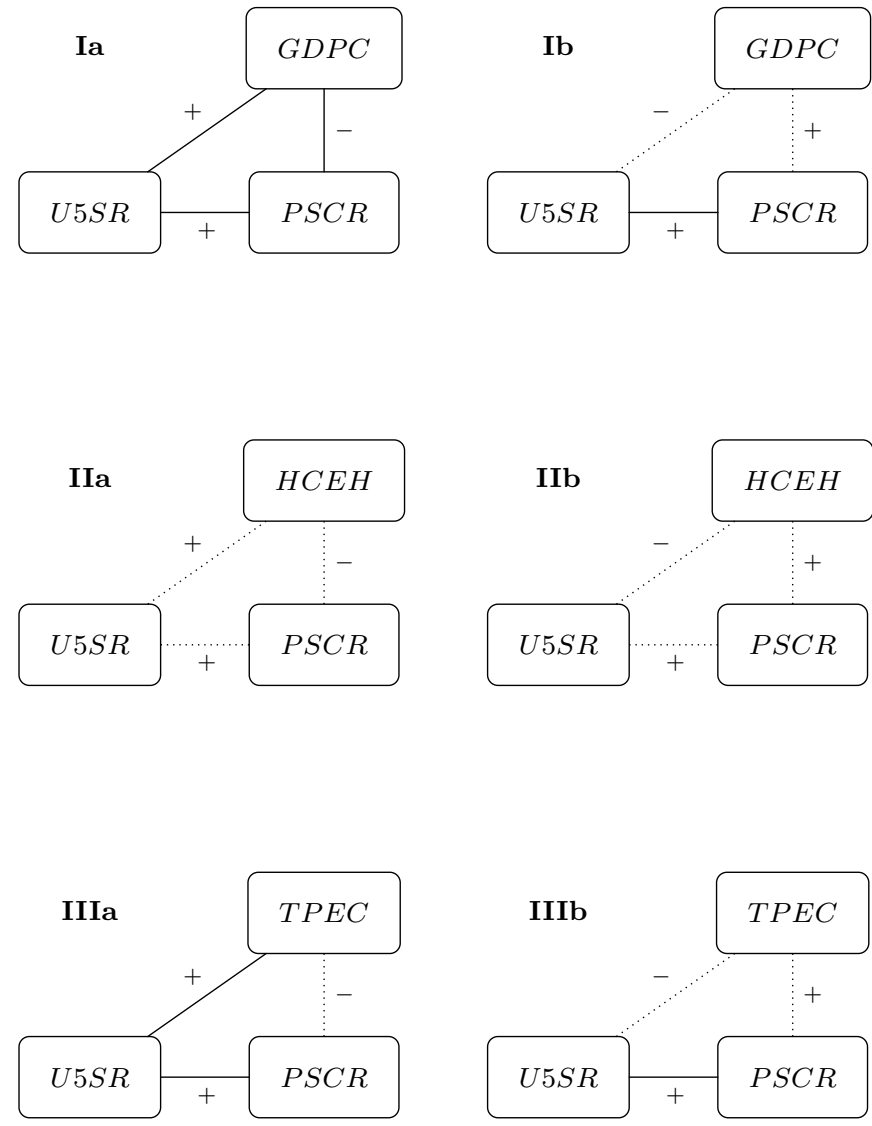

— significant coefficient

.. . insignificant coefficient

Figure 4.1: Complementarities

\subsubsection{Structural form equations}

For each of the three combinations of endogenous variables (Model I: $G D P C$, U5SR, PSCR; Model II: HCEH, U5SR, PSCR; Model III: TPEC, U5SR, $P S C R)$, two specifications are presented in Tables 4.1 through 4.3, differing in the choice of exogenous variables. Note that a subscript ' 1 ' always refers to the standard-of-living indicator, subscript ' 2 ' to the health indicator and ' 3 ' to the education indicator. These tables display the 2SLS estimation results for structural coefficients, $c_{i j}$ and $l_{i j}$, of equation system (4.11).

The coefficients in the standard-of-living (SoL) equations are not significant in any of the model specifications, i.e. the variables chosen here do not necessarily explain development of GDP, household consumption expenditures or total primary energy consumption per capita very well. This does not make the exercise irrele- 
Table 4.1: Estimation results Model I

\begin{tabular}{|c|c|c|c|c|c|c|}
\hline & \multicolumn{2}{|c|}{ Model Ia } & \multicolumn{3}{|c|}{ Model Ib } \\
\hline & & Coef. & SE t-val. & Coef. & SE & t-val. \\
\hline SoL & Equation & \multicolumn{2}{|c|}{$\boldsymbol{\Delta} \log (\mathbf{g d p c})_{\mathbf{t}}$} & \multicolumn{3}{|c|}{$\Delta \log (\mathbf{g d p c})_{\mathbf{t}}$} \\
\hline$c_{10}$ & Intercept & \multicolumn{2}{|c|}{$13.93824 .253 \quad 0.575$} & \multicolumn{3}{|c|}{$-25.83866 .387-0.389$} \\
\hline$c_{12}$ & $\Delta \log (u 5 s r)_{t}$ & \multicolumn{2}{|c|}{$-8.39523 .354-0.359$} & \multicolumn{2}{|c|}{30.74566 .223} & 0.464 \\
\hline$c_{13}$ & $\Delta \log (p s c r)_{t}$ & 1.009 & $1.001 \quad 1.007$ & -0.831 & 2.521 & -0.33 \\
\hline$l_{11}$ & $\log (g d p c)_{t-1}$ & 0.107 & $0.098 \quad 1.102$ & 0.043 & 0.071 & 0.607 \\
\hline$l_{12}$ & $\log (u 5 s r)_{t-1}$ & -2.343 & $3.776-0.621$ & 3.913 & 0.373 & 0.377 \\
\hline$l_{13}$ & $\log (p s c r)_{t-1}$ & 0.331 & $0.398 \quad 0.832$ & -0.353 & 0.962 & -0.367 \\
\hline \multirow[t]{2}{*}{$k_{1}$} & $\log (\text { eind })_{t-1}$ & \multirow[t]{2}{*}{0.02} & $0.182 \quad 0.111$ & \multirow[b]{2}{*}{0.049} & \multirow[b]{2}{*}{0.19} & \multirow[b]{2}{*}{0.26} \\
\hline & $\log (\operatorname{trad})_{t-1}$ & & & & & \\
\hline \multicolumn{2}{|c|}{ Hea Equation } & \multicolumn{2}{|c|}{$\boldsymbol{\Delta} \log (\mathbf{u} \mathbf{5 s r})_{\mathbf{t}}$} & \multicolumn{3}{|c|}{$\boldsymbol{\Delta} \log (\mathbf{u} \mathbf{5} \mathbf{s r})_{\mathbf{t}}$} \\
\hline$c_{20}$ & Intercept & 1.518 & 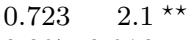 & 0.911 & 0.249 & $3.661^{\star \star \star}$ \\
\hline$c_{21}$ & $\Delta \log (g d p c)_{t}$ & -0.089 & $0.097-0.916$ & 0.017 & 0.036 & 0.466 \\
\hline$c_{23}$ & $\Delta \log (p s c r)_{t}$ & 0.095 & 0.0990 .958 & 0.027 & 0.027 & 0.981 \\
\hline & $\log (g d p c)_{t-1}$ & 0.01 & 0.0110 .963 & -0.001 & 0.003 & -0.259 \\
\hline$l_{22}$ & $\log (u 5 s r)_{t-1}$ & -0.251 & $0.128-1.967^{\star}$ & -0.14 & 0.041 & $-3.408^{\star \star \star}$ \\
\hline$l_{23}$ & $\log (p s c r)_{t-1}$ & 0.032 & $0.031 \quad 1.037$ & 0.011 & 0.009 & 1.305 \\
\hline$k_{2}$ & $\log (d p t i)_{t-1}$ & 0.001 & 0.0110 .108 & 0.001 & 0.006 & 0.187 \\
\hline
\end{tabular}

\begin{tabular}{|c|c|c|c|c|}
\hline Edu & Equation & $\boldsymbol{\Delta} \log (\mathbf{p}$ & $\mathbf{s c r})_{t}$ & $\boldsymbol{\Delta} \log (\mathbf{p s c r})_{\mathbf{t}}$ \\
\hline$c_{30}$ & Intercept & -14.519 & $7.29-1.992^{\star \star}$ & 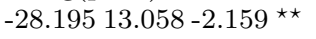 \\
\hline$c_{31}$ & $\Delta \log (g d p c)_{t}$ & 0.875 & 0.5271 .661 & $-0.531 \quad 1.304-0.407$ \\
\hline$c_{32}$ & $\Delta \log (u 5 s r)_{t}$ & 9.414 & $7.984 \quad 1.179$ & $30.0521 .0631 .427^{\prime}$ \\
\hline$l_{31}$ & $\log (g d p c)_{t-1}$ & -0.104 & $0.056-1.853^{\star}$ & $\begin{array}{lll}0.024 & 0.102 & 0.232\end{array}$ \\
\hline$l_{32}$ & $\log (u 5 s r)_{t-1}$ & 2.412 & $1.1232 .147^{\star \star}$ & $1.8882 .304^{\star \star}$ \\
\hline$l_{33}$ & $\log (p s c r)_{t-1}$ & -0.345 & $0.113-3.054^{\star \star \star}$ & $0.138-2.834^{\star \star \star}$ \\
\hline$k_{3}$ & $\log (\operatorname{sep} n)_{t-1}$ & 0.019 & $0.178 \quad 0.104$ & \\
\hline & $\log (\text { gser })_{t-1}$ & & & $0.165-0.196$ \\
\hline & No. Obs. & 291 & & 342 \\
\hline & DoF & 270 & & 321 \\
\hline & Log.Lik & 717 & & 656 \\
\hline & $\mathrm{AIC}$ & -1390 & & -1268 \\
\hline
\end{tabular}

vant as the aim is to identify the relation between the endogenous variables and not to perfectly explain development in the different dimensions of development. The reason for analyzing three different endogenous SoL indicators is to show that this insignificance does not depend on how living standards are measured. Instead, it seems that no significant complementarity relation between this dimension and the other two dimensions exist. Both Fielding et al. (2008) and Fielding and Torres (2009) measure living standards with a combined index of data from World Bank's Health, Nutrition and Poverty Data on inter alia access to electricity, piped water and a flush toilet, and possession of radio, TV, refrigerator or a car. The findings show a positive relation between this wealth measure and the primary school completion rate and a negative relation with the under-5 mortality rate. Both coefficients are, however, not always significant. The negative relation between the primary school completion rate and the under-5 mortality rate is always significant, confirming the significant positive relation we find between PSCR and 
Table 4.2: Estimation results Model II

\begin{tabular}{|c|c|c|c|c|c|c|}
\hline & \multicolumn{2}{|c|}{ Model IIa } & \multicolumn{3}{|c|}{ Model IIb } \\
\hline & & Coef. & SE t-val. & Coef. & SE & t-val. \\
\hline SoL & Equ & \multicolumn{2}{|c|}{$\boldsymbol{\Delta} \log (\text { hceh })_{\mathbf{t}}$} & \multicolumn{3}{|c|}{$\boldsymbol{\Delta} \log (\text { hceh })_{\mathbf{t}}$} \\
\hline$c_{10}$ & Intercept & \multicolumn{2}{|c|}{11.21721 .686} & \multicolumn{2}{|c|}{8.31915 .025} & \\
\hline$c_{12}$ & $\Delta \log$ & -22.983 & $30.057-0.765$ & \multicolumn{2}{|c|}{$-21.59724 .539$} & .88 \\
\hline$c_{13}$ & $\Delta \log (p s c r)_{t}$ & 0.988 & 1.320. & 1.004 & 1.099 & \\
\hline$l_{11}$ & $\log (\text { hceh })_{t-1}$ & 0.005 & $\begin{array}{ll}0.097 & 0.048\end{array}$ & -0.05 & 0.152 & -0.329 \\
\hline$l_{12}$ & $\log (u 5 s r)_{t-1}$ & -1.771 & $3.38-0$. & -1.319 & 2.376 & \\
\hline$l_{13}$ & $\log (p s c r)_{t-1}$ & 0.262 & 0.3250 .804 & 0.273 & 0.275 & 0.993 \\
\hline \multirow[t]{2}{*}{$k_{1}$} & $\log (r$ & \multirow[t]{2}{*}{0.001} & 0.2110 .005 & \multirow[b]{2}{*}{0.027} & & \multirow[b]{2}{*}{0.21} \\
\hline & & & & & 0.126 & \\
\hline \multicolumn{2}{|c|}{ Hea Equation } & \multicolumn{2}{|c|}{$\boldsymbol{\Delta} \log (\mathbf{u} 5 \mathbf{s r})_{\mathbf{t}}$} & \multicolumn{3}{|c|}{$\boldsymbol{\Delta} \log (\mathbf{u} \mathbf{5 s r})_{\mathbf{t}}$} \\
\hline$c_{20}$ & & 0.493 & $1.05 \quad 0.469$ & 0.415 & 0.397 & \\
\hline$c_{21}$ & $h c e h)_{t}$ & -0.043 & $0.192-0$. & -0.037 & 0.03 & -1.227 \\
\hline$c_{23}$ & $\Delta$ lo & 0.043 & 0.0710 .6 & 0.042 & 0.025 & 1.684 \\
\hline$l_{21}$ & $(e h)_{t-1}$ & 0 & $0.005 \quad 0.036$ & -0.001 & 0.003 & -0.283 \\
\hline$l_{22}$ & $\log (u$ & -0.078 & $0.151-0.5$ & -0.066 & $0.063-$ & -1.045 \\
\hline$l_{23}$ & $\log (p s c r)_{t-1}$ & 0.011 & $\begin{array}{ll}0.031 & 0.367\end{array}$ & 0.011 & 0.009 & 1.178 \\
\hline$k_{2}$ & $\log (d p t i)_{t-1}$ & 0 & 0.0210 .005 & 0.001 & 0.006 & 0.188 \\
\hline
\end{tabular}

\begin{tabular}{ll}
\multicolumn{2}{c}{ Edu Equation } \\
$c_{30}$ & Intercept \\
$c_{31}$ & $\Delta \log (\text { hceh })_{t}$ \\
$c_{32}$ & $\Delta \log (u 5 s r)_{t}$ \\
$l_{31}$ & $\log (\text { hceh })_{t-1}$ \\
$l_{32}$ & $\log (u 5 s r)_{t-1}$ \\
$l_{33}$ & $\log (\text { pscr })_{t-1}$ \\
$k_{3}$ & $\log (\text { sepn })_{t-1}$
\end{tabular}

$\boldsymbol{\Delta} \log (\mathbf{p s c r})_{\mathbf{t}}$

$-11.16535 .423-0.315$

$\begin{array}{llll}1.071 & 11.284 & 0.095\end{array}$

$23.463 \quad 39.14 \quad 0.599$

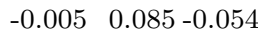

$\begin{array}{lll}1.766 & 4.79 & 0.369\end{array}$

$-0.261 \quad 0.676-0.386$

$-0.009 \quad 1.684-0.005$
$\Delta \log (\mathbf{p s c r})_{\mathbf{t}}$

-9.119 7.606-1.199

$0.707 \quad 1.053 \quad 0.672$

20.79310 .4781 .984 *

$\begin{array}{lll}0.016 & 0.077 & 0.213\end{array}$

$\begin{array}{lll}1.437 & 1.181 & 1.217\end{array}$

$-0.2920 .166-1.756$ *

$\begin{array}{lll}0.05 & 0.254 & 0.196\end{array}$

\begin{tabular}{lrr} 
No. Obs. & 234 & 231 \\
DoF & 213 & 210 \\
Log.Lik & 861 & 551 \\
AIC & -1679 & -1058 \\
\hline Signif. codes: ${ }^{\star \star \star}$ & $0.01,{ }^{\star \star} 0.05,{ }^{\star} 0.10, "$ " $0.20,{ }^{\prime}, 1.00$
\end{tabular}

$U 5 S R$.

Both development in health, measured by the number of children that survive at least until the age of five, and education, measured by the primary school completion rate, are significantly influenced by their own lagged variables as well as those of the other dimensions in models I and III. The coefficients of the respective own lags $\left(l_{22}\right.$ and $\left.l_{33}\right)$ are always negative. On the one hand this results in positive partial adjustment coefficients $b_{2}$ and $b_{3}$, while on the other hand it also indicates that for lower previous levels of health and education the increase, i.e. the first difference, in the respective variable is higher (when looking at this effect alone, without considering the influence of the other independent variables). Health is positively influenced by the lagged education indicator. The coefficient of the lagged SoL indicator is significant at $10 \%$ and $20 \%$ in models Ia and IIIa, respectively. The coefficient is negative, which results in a negative value of $a_{31}$ as displayed in Table 4.4. The corresponding coefficients in models Ib and IIIb are 
Table 4.3: Estimation results Model III

\begin{tabular}{|c|c|c|c|c|c|}
\hline & \multicolumn{2}{|c|}{ Model IIIa } & \multicolumn{2}{|c|}{ Model IIIb } \\
\hline & & Coef. & SE t-val. & Coef. & SE t-val. \\
\hline SoL & Equation & $\boldsymbol{\Delta} \log (\mathbf{t}$ & pec $)_{t}$ & $\boldsymbol{\Delta} \log \left(\mathbf{t}_{\mathbf{r}}\right.$ & $\mathrm{pec})_{t}$ \\
\hline$c_{10}$ & Intercept & -14.234 & $53.519-0.266$ & -16.691 & $29.248-0.571$ \\
\hline$c_{12}$ & $\Delta \log (u 5 s r)_{t}$ & 7.693 & $49.365 \quad 0.156$ & 21.473 & 32.6350 .658 \\
\hline$c_{13}$ & $\Delta \log (p s c r)_{t}$ & -0.114 & $2.477-0.046$ & -0.48 & $1.447-0.332$ \\
\hline$l_{11}$ & $\log (t p e c)_{t-1}$ & -0.025 & $0.16-0.158$ & 0.069 & $0.0511 .356^{\prime}$ \\
\hline$l_{12}$ & $\log (u 5 s r)_{t-1}$ & 2.19 & $8.366 \quad 0.262$ & 2.541 & $\begin{array}{ll}4.581 & 0.555\end{array}$ \\
\hline$l_{13}$ & $\log (p s c r)_{t-1}$ & -0.086 & $0.872-0.099$ & -0.244 & $0.558-0.437$ \\
\hline$k_{1}$ & $\log (\text { eman })_{t-1}$ & -0.092 & $0.075-1.228$ & -0.069 & $0.083-0.837$ \\
\hline
\end{tabular}

$\begin{array}{ll}\text { Hea Equation } \\ c_{20} & \text { Intercept } \\ c_{21} & \Delta \log (\text { tpec })_{t} \\ c_{23} & \Delta \log (\text { pscr })_{t} \\ l_{21} & \log (\text { tpec })_{t-1} \\ l_{22} & \log (u 5 s r)_{t-1} \\ l_{23} & \log (\text { pscr })_{t-1} \\ k_{2} & \log (\text { dpti })_{t-1}\end{array}$

Edu Equation

$c_{31} \Delta \log (\text { tpec })_{t}$

$c_{32} \Delta \log (u 5 s r)_{t}$

$l_{31} \log (\text { tpec })_{t-1}$

$l_{32} \log (u 5 s r)_{t-1}$

$l_{33} \log (\text { pscr })_{t-1}$

$k_{3} \log (\text { sepn })_{t-1}$ $\log (\text { gser })_{t-1}$

$\boldsymbol{\Delta} \log (\mathbf{u} 5 \mathbf{s r})_{\mathbf{t}}$

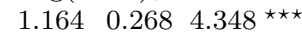

$\begin{array}{llll}0.01 & 0.036 & 0.281\end{array}$

$\begin{array}{llll}0.037 & 0.037 & 0.977\end{array}$

$\begin{array}{llll}0.003 & 0.002 & 1.685 \text { * }\end{array}$

$\begin{array}{lll}-0.181 & 0.039 & -4.572^{\star \star \star}\end{array}$

$\begin{array}{lll}0.014 & 0.011 & 1.213\end{array}$

$\begin{array}{llll}0.002 & 0.006 & 0.405\end{array}$
$\boldsymbol{\Delta} \log (\mathbf{u} \mathbf{5 s r})_{\mathbf{t}}$

$\begin{array}{lll}0.832 & 0.249 & 3.348^{\star \star \star}\end{array}$

$\begin{array}{llll}0.022 & 0.027 & 0.821\end{array}$

$\begin{array}{lll}0.02 & 0.036 & 0.552\end{array}$

$-0.002 \quad 0.003-0.623$

$-0.1270 .042-3.043^{\star \star \star}$

$\begin{array}{lll}0.01 & 0.011 & 0.855\end{array}$

$\begin{array}{lll}0.003 & 0.006 & 0.475\end{array}$

\begin{tabular}{|c|c|c|}
\hline No. Obs. & 291 & 324 \\
\hline DoF & 270 & 303 \\
\hline Log.Lik & 406 & 507 \\
\hline $\mathrm{AIC}$ & -768 & -969 \\
\hline
\end{tabular}

positive but not significantly different from zero, indicating that progress toward the optimal level of living standards is not clearly visible.

The coefficient of the lagged primary school enrollment rate in the health equations is always positive, but not necessarily significant. The coefficient of the health indicator in the education equation is positive and significant for models I and III, defining the significant complementarity relation between health and education via coefficient $a_{32}=-l_{32} / l_{33}$. This significant relation is also confirmed for $a_{32}=c_{32} l_{33} / l_{22}{ }^{9}$, as all of these coefficients are significant in models Ib, IIIa and IIIb. Models IIa and IIb have the smallest number of significant coefficients, but both $c_{23}$ and $c_{32}$ are positive and significant at $10 \%$, again confirming the complementarity relation found between the health and education indicators.

Possible exogenous variables for education and health dimensions have been

\footnotetext{
${ }^{9}$ Recall that the $a_{i j}$ 's are overidentified and can therefore be calculated either as $a_{i j}=-l_{i j} / l_{i i}$ or as $a_{i j}=c_{i j} l_{i i} / l_{j j}$.
} 
selected on the basis of the short correlation analysis in Chapter 3. Therefore, specifications were estimated, that include the immunization rate of two-year olds against either measles (IMMU) or diphtheria (DPTI) as the exogenous variable in the health equation and the primary (SEPN) or total (GSER) school enrollment rates in the education equation. For the standard-of-living equation different indicators relating to the economic structure such as the share of trade (TRAD), industry (EIND) or manufacturing (EMAN) in GDP, or actual value added in manufacturing (MANH) or industry (INDH) per capita, or to the population structure, such as the share of population living in rural areas (RPTP), were used. The exogenous variables enter the model in lagged logarithms.

Including either one of the immunization rate of two-year olds against measles (IMMU) or diphtheria (DPTI) as the exogenous control variable in the health equation gives similar results, with those of DPTI being slightly more significant. The coefficient of DPTI is always positive, but very close to zero. That means that immunizing infants against diphtheria has a small but positive impact on their survival rate until the age of five. In models I and III the coefficient of the lagged primary school enrollment rate is positive, while that of the total school enrollment rate is negative.

\subsubsection{Complementarity and partial adjustment coefficients}

The estimation results of the structural model define the outcome of the overall analysis, that is the coefficients identifying complementarity, $a_{i j}$, and corresponding $\alpha_{i j}$. Table 4.4 displays the $a_{i j}$ coefficients from the set of first order conditions (4.6) and the $b_{i}$ coefficients resulting from the use of the partial adjustment model. Coefficients $a_{i j}$ and $b_{i}$ are calculated from the estimated structural form coefficients $c_{i j}$ and $l_{i j}$, compare systems (4.10) and (4.11). $b_{i}$ is exactly defined as $b_{i}=-l_{i i}$ for all $i . a_{i j}$ however can be either calculated from the coefficient of lagged variable $j$ in equation $i$ as $a_{i j}=-l_{i j} / b_{i}=-l_{i j} / l_{i i}$, reported in the first columns of each model in Table 4.4, or from the coefficient of the first difference of variable $j$ in equation $i$ as $a_{i j}=c_{i j} l_{j j} / l_{i i}$, reported in the fourth column. Columns 2 and 3 and 5 and 6 contain the corresponding approximated standard errors ${ }^{10}$ and t-statistics.

In Table 4.4 two specifications, that differ in the choice of exogenous variables, are displayed for each of model I, II and III. These results well represent the overall findings from different specifications with regard to the exogenous control variables: There is no significant complementarity relation between the standardof-living indicators and both education and health indicators. This can be seen

\footnotetext{
${ }^{10}$ The standard errors are approximated using Taylor series expansion: for $a_{i j}=-l_{i j} / l_{i i}$ $S E\left(a_{i j}\right)=\left(\left(\frac{\partial a_{i j}}{\partial l_{i j}}\right)^{2} S E\left(l_{i j}\right)^{2}+\left(\frac{\partial a_{i j}}{\partial l_{i i}}\right)^{2} S E\left(l_{i i}\right)^{2}+2 \frac{\partial a_{i j}}{\partial l_{i j}} \frac{\partial a_{i j}}{\partial l_{i i}} \operatorname{Cov}\left(l_{i j}, l_{i i}\right)\right)^{1 / 2}$$$
=\left(\left(\frac{1}{-l_{i i}}\right)^{2} S E\left(l_{i j}\right)^{2}+\left(\frac{l_{i j}}{l_{i i}^{2}}\right)^{2} S E\left(l_{i i}\right)^{2}+2 \frac{1}{-l_{i i}} \frac{l_{i j}}{l_{i i}^{2}} \operatorname{Cov}\left(l_{i j}, l_{i i}\right)\right)^{1 / 2} \text { and for } a_{i j}=c_{i j} * l_{j j} / l_{i i}
$$$$
S E\left(a_{i j}\right)=\left(\left(\frac{\partial a_{i j}}{\partial c_{i j}}\right)^{2} S E\left(c_{i j}\right)^{2}+\left(\frac{\partial a_{i j}}{\partial l_{j j}}\right)^{2} S E\left(l_{j j}\right)^{2}+\left(\frac{\partial a_{i j}}{\partial l_{i i}}\right)^{2} S E\left(l_{i i}\right)^{2}+2 \frac{\partial a_{i j}}{\partial c_{i j}} \frac{\partial a_{i j}}{\partial l_{i i}} \operatorname{Cov}\left(l_{i j}, l_{i i}\right)\right.
$$$$
\left.+2 \frac{\partial a_{i j}}{\partial c_{i j}} \frac{\partial a_{i j}}{\partial l_{j j}} \operatorname{Cov}\left(c_{i j}, l_{j j}\right)+2 \frac{\partial a_{i j}}{\partial l_{j j}} \frac{\partial a_{i j}}{\partial l_{i i}} \operatorname{Cov}\left(l_{j j}, l_{i i}\right)\right)^{1 / 2}
$$$$
=\left(\left(\frac{l_{j j}}{l_{i i}}\right)^{2} S E\left(c_{i j}\right)^{2}+\left(\frac{c_{i j}}{l_{i i}}\right)^{2} S E\left(l_{j j}\right)^{2}+\left(\frac{c_{i j} l_{j j}}{l_{i i}^{2}}\right)^{2} S E\left(l_{i i}\right)^{2}+2 \frac{l_{j j}}{l_{i i}} \frac{c_{i j} l_{j j}}{l_{i i}^{2}} \operatorname{Cov}\left(c_{i j}, l_{i i}\right)\right.
$$$$
\left.+2 \frac{l_{j j}}{l_{i i}} \frac{c_{i j}}{l_{i i}} \operatorname{Cov}\left(c_{i j}, l_{j j}\right)+2 \frac{c_{i j}}{l_{i i}} \frac{c_{i j} l_{j j}}{l_{i i}^{2}} \operatorname{Cov}\left(l_{j j}, l_{i i}\right)\right)^{1 / 2} \text { with } \operatorname{Cov}\left(l_{i j}, l_{i i}\right), \operatorname{Cov}\left(c_{i j}, l_{i i}\right), \operatorname{Cov}\left(c_{i j}, l_{j j}\right) \text { and }
$$$$
\operatorname{Cov}\left(l_{j j}, l_{i i}\right) \text { given by the coefficient covariance matrix of the 2SLS estimation. }
$$ 
Table 4.4: Complementarity and partial adjustment coefficients

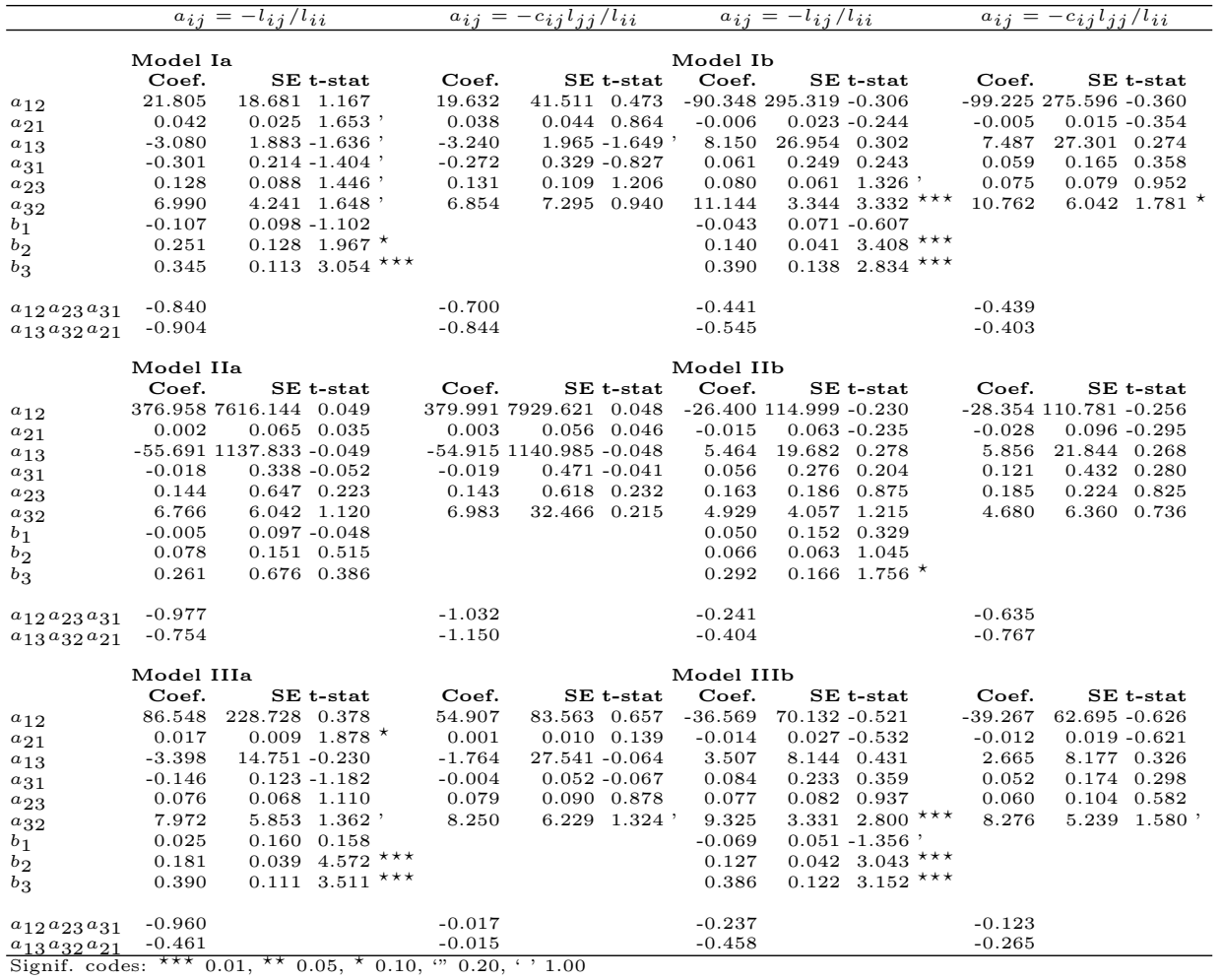

from the insignificance of the respective coefficients ( $a_{12}$ and $a_{21}$, and $a_{13}$ and $a_{31}$ ), and the contradicting signs of the coefficients when comparing specifications a and $\mathrm{b}$ for each of model I, II, and III. Coefficient $a_{12}$ however, if significant at the $12 \%$ level as in Model Ia and IIIa, is positive, which indicates that there could be a complementary relation between standard-of-living and health.

Coefficient $a_{32}$ (and partly also coefficient $a_{23}$ ) is the most significant of the complementarity coefficients in all model specifications. Further, $a_{32}$ and $a_{23}$ are positive in all specifications tested (as a robustness check), not only those displayed here. These two coefficients determine sign and significance of $\alpha_{23}$, which is the coefficient of the interaction term of the health and education indicator in the development objective. $\alpha_{23}$ is therefore significantly different from zero and positive, which indicates that there is a complementary relation between health and education.

The very last row of the table checks the restriction on the $a_{i j}$ coefficients that is obtained from the six conditions in system (4.7). Using this system, it is possible to calculate $\alpha_{12}, \alpha_{13}$ and $\alpha_{23}$. Given that we normalize either one of $\alpha_{11}, \alpha_{22}$ or $\alpha_{33}$ to -1 , we have that $\alpha_{12}, \alpha_{13}$ and $\alpha_{23}$ have the same sign as the corresponding $a_{i j}$ and $a_{j i}$. To conclude whether or not $s_{i}$ and $s_{j}$ are complements it is therefore sufficient to check whether the sign of $a_{i j}$ and $a_{j i}$ is the same. In addition, since the $\alpha_{i j}$ 's are overidentified from the first order conditions, it should 
hold that $a_{12} a_{23} a_{31}=a_{13} a_{32} a_{21}$, as derived in the previous section. In practice the coefficient products are not the same but sufficiently close together in order to conclude that the restrictions on the model coefficients are indeed fulfilled.

The $b_{i}$ coefficients enter the overall development model through the partial adjustment model, Equation (4.9). These coefficients relate to the speed of adjustment of the current level of development to the optimal level of development and should therefore theoretically take values between zero and one ${ }^{11}$. However, the adjustment coefficient of the standard-of-living indicator $b_{1}$ is, although not significant, negative. This is due to the fact that these indicators decreased during most part of the late 1980s and the 1990s in many African countries, only attaining their 1980's level again after 2000, as described in Chapter 3. The remaining $b_{i}$ 's are significant and between 0.02 and 0.4 showing that there is some progress toward the 'optimal' level of development, but that it is very slow. According to these results, the primary school completion rate has a higher rate of adjustment, represented by coefficients $b_{3}$, than the under- 5 survival rate with adjustment rates $b_{2}$. This is also confirmed by the data analysis in Chapter 3 .

\subsection{Conclusion}

This chapter takes an approach from productivity analysis of finding complementarities between innovation strategies and adapts it to finding complementarities between three dimensions of development, standard-of-living, education and health. Analysis at the firm level can use the assumption of profit optimizing strategies, which is not immediately transferable to the problem at hand. The model was therefore extended to also include a partial adjustment approach that describes adjustments in the deviation from the optimal development path. The difference to the development models of David Fielding and others $(2002 ; 2005$; $2008 ; 2009)$ is the derivation of the structural model, the interpretation of the coefficients (as indications of complementarity), the inclusion of lagged development indicators and the explicit consideration of non-optimal development.

The more dimensions are included in such a model the more important are testable restrictions. The restrictions on the coefficients of the model are twofold, relating to both the multiplicity and the signs of the complementarity coefficients in the first order conditions and to the partial adjustment coefficients. The former are verified by the empirical analysis, while for the latter a negative partial adjustment coefficient was obtained. This can be explained by the nature of the underlying data that reflects the period of stagnating or negative growth in the Nineties. The low partial adjustment coefficients show that development in Sub-Saharan Africa is indeed far from optimal. Development in many African countries is hampered by political difficulties. The measures relating to good governance, however, were not significant in this purely quantitative empirical investigation.

With regard to the issue of complementarity, the main result is that good health and education outcomes (measured by the number of children surviving to the age of five, an indicator relating to MDG 4, and the primary school comple-

\footnotetext{
${ }^{11}$ In practice, both overshooting (values greater than one) and divergence (values lower than zero) are possible.
} 
tion rate, which represents MDG 2, respectively) are mutually reinforcing. A clear relation of these variables with living standards, measured with three different indicators, is however not apparent, thus confirming the statement of Bourguignon et al. $(2008 a)$. Development policies that aim at increasing both health and education outcomes at the same time will have a higher effect on a country's overall development than policies aiming at either one individually.

The empirical results in Chapter 5 show that there is indeed a positive effect of development policies that enhance both education and health outcomes. The policy measures analyzed in Chapter 5 are government spending on health and education and general government spending. The main result is that overall development - measured with the Human Development Index - can be significantly improved if resources are allocated to both education and health sector.

The methodology developed in this chapter has only been applied to a very limited data set. Future research could include an estimation of the model using a more extensive data set. A more extensive data set may include more observations in time per country, a lower level of regional aggregation or more and different indicators. If more observations per country are available it is, for example, possible to account for country heterogeneities by using a fixed effect model rather than pooled estimation. In addition, with more observations in time it is also possible to use more advanced time series methods, e.g. to find the correct lag lengths. An example for a more extensive data set are the EUROSTAT Sustainable Development Indicators, that were shortly described in Section 2.2. Furthermore, a comparison of empirical results across different world regions can provide valuable insights on disparities in the development progress. 



\section{Chapter 5}

\section{Public spending for development*}

The previous chapters show that both level and progress of development in SubSaharan Africa are low and that education as well as health are important driving forces for a country's overall development. Using the notation of Ranis and Stewart (2005), most countries are either in a vicious development circle or a virtuous development circle, where good human development fosters economic growth and vice versa. Most African countries turn out to be in the vicious development circle, where low human development hampers economic growth and economic stagnation hampers human development. Over the past 50 to 60 years a large variety of development projects carried out by organizations reaching from large international organizations such as the World Bank, the United Nations Development Program or other UN organizations, governmental development agencies, for example DFID (UK), USAID (US), GIZ (Germany) or BTC (Belgium), church organizations or other national NGOs (non-governmental organizations) such as 'Brot für die Welt' in Germany, to small private organizations, that engage in single communities. However, the largest part of aid is in the form of official development aid (ODA) by national governments in the industrialized countries. In the context of the MDGs the UN target ${ }^{1}$ of providing $0.7 \%$ of donor countries' gross national income (GNI) for ODA in 2015 was also ratified by the European Council (2005). Despite all these programs and billions of Euros that have been spent on development in Africa, hardly any progress has been made. A recent overview on the effects of development aid can be found in the special issue of the Review of Development Economics from 2009 (Mavrotas, 2009).

During the last decade an increasing group of people, including African economists such as James Shikwati (2006) or Dambisa Moyo (2009), criticize monetary development aid and propose its complete removal. They argue that recipients only become dependent and most of the aid disappears in corrupt elites anyhow (Grill, 2009). Rajan and Subramanian (2005) even find that aid has a negative impact on growth. In addition, if aid is directly channeled to specific programs or projects,

${ }^{*}$ This chapter is based on van Zon and Wiebe (2010).

${ }^{1}$ http://www.unmillenniumproject.org/press/07.htm 
local policy makers do not control where the aid flows go. In light of this discussion we will explore a way in which African policy makers would be able to influence development, that is through a better channeling of their public expenditures. Policy makers can decide about the distribution of public expenditures among the different budget items such as education, health, infrastructure, military, etc.. An indicator readily available for measuring a country's development is the Human Development Index (HDI). As shown by Morse (2003), the HDI ranking is indeed picked up in newspapers and policy makers do use it to assess the development progress of their countries. His examples are from all over the world including industrialized countries such as Canada, Ireland or Korea, emerging economies such as India, and developing countries such as Nepal or Burma. Neumayer (2001) further states that "from the beginning, publication of the HDI has aroused a lot of attention among policy makers and the wider public alike" (p. 101/102).

Now, assuming that policy makers aim at maximizing development progress of their country based on the HDI and that the sole policy measure they can take is an efficient distribution of the government budget over the different budget items, the allocation of the budget becomes a constrained optimization problem that resembles the problem known from optimal portfolio theory (OPT). In short, the problem in financial OPT is to allocate a given budget efficiently over several assets as to maximize the expected return minus the variance of the expected return multiplied by a parameter of risk aversion. Here, we assume that the government's portfolio consists of education, health, and general welfare and that it has to efficiently allocate the budget to the individual items. Including a parameter of risk aversion is important in this context as policy makers are generally risk averse, that is they prefer policy measures with a rather certain outcome (low variance of the impact) over policy measures with highly varying outcomes (high variance).

The next section introduces the research on government expenditures in developing countries, followed by a section on optimum portfolio theory. Section 5.3 combines portfolio theory, public spending and the HDI into one model of efficient development portfolio design. Results are presented in Section 5.4. The chapter is concluded by summarizing possible policy implications of the results.

\subsection{Public spending in developing countries}

There are three main strands of literature that analyze public expenditure in developing countries. First, there is the more descriptive literature about how much the government spends in total, as a percentage of GDP, or, more differentiated, on which sector; how public spending develops over time and across countries. These descriptions are, for the most part, followed by some kind of analysis, e.g. the analysis of the impacts of public spending on growth as in Fan and Rao (2003). Second, more popular, there is the analysis of public spending efficiency, i.e. how effective are for example health or education expenditures in determining health and education outcomes in different countries and at different times (e.g. Herrera and Pang, 2005; Herrera, 2007; Gupta et al., 1997; Jayasuriya and Wodon, 2008). Murillo-Zamorano (2004) surveys different efficiency frontier techniques in this context. The third strand of literature stems from growth theory, where the effect of public spending on long-run economic growth is analyzed, e.g. Aschauer 
(1989); Barro (1990); Devarajan et al. (1996) or Fan and Rao (2003), but not all of these distinguish between different spending categories such as education or health. Further, this literature measures the effects of government expenditure solely on economic growth, which is an indicator considered too narrow to measure the overall development of a country. Gomanee et al. (2005) assess the effect of aid on development - measured by the HDI and the infant mortality rate - through public expenditures. They distinguish between pro-public expenditures and those that do not enhance a society's well-being. They find that both public expenditures on the different items as well as aid have significant effects on the development outcomes. They however do not distinguish between the individual spending categories in their aid estimations, rather they combine the different expenditures categories into one index, so their main finding is that aid does not affect development through public expenditures.

These different approaches are useful for the subsequent analysis: First, a descriptive analysis summarizes the development of public spending. Second, the different approaches to the determination of efficiency of public spending are useful to determine the effect of additional education and health expenditures on education and health outcomes. And third, even though the literature only takes into account the effect of public spending and the effect of the composition of public spending on growth, we can learn about different direct and indirect channels through which public spending affects growth: partly through education and health of the labor force.

The literature on public spending efficiency distinguishes between parametric (deterministic and stochastic) and non-parametric methods. The most commonly used methods for estimating the production possibility frontiers or efficiency frontiers of public spending are Free Disposable Hull (FDH) and Data Envelopment Analysis (DEA $)^{2}$, both non-parametric methods. Their deterministic nature does not allow them to capture random variation in the data (Greene, 2003). The two stochastic methods frequently used in this field are the econometric panel approaches of an error component model and a fixed effects model (Jayasuriya and Wodon, 2008) ${ }^{3}$. The drawback of these parametric methods is their nature of presuming a specific functional form.

Herrera (2007) suggests that for "policymaking purposes, working with the best-practice cases may be more informative and useful than working with average behavior" (p.19), especially when using production function approaches to determine the efficiency frontier. Both FDH and DEA determine efficiency frontiers for the underlying sample. These frontiers consist of stepwise linear or convex functions between 'best-practice' cases, i.e. those cases with highest outcome for a given input or, vice versa, lowest input for a given output. Efficiency in DEA or FDH is always relative efficiency. The agents on the frontier are efficient, while inefficiency increases with and is measured as distance to the frontier.

Herrera and Pang (2005) distinguish between different inputs (different types of government expenditures, teachers per student, adult literacy, and private spend-

\footnotetext{
${ }^{2}$ For a detailed description of these methods see for example Herrera and Pang (2005) or Jayasuriya and Wodon (2008).

${ }^{3}$ For a detailed discussion of stochastic frontier methods in this context the reader is referred to Greene (2003) and Murillo-Zamorano (2004).
} 
ing on health), and different outcomes: health and education indicators such as life expectancy at birth, immunization against measles and DPT, disability adjusted life expectancy, school enrollment and completion rates, average years of schooling and youth literacy. They use FDH and DEA to determine the efficiency frontiers for both public spending on education and public spending on health, and present results for single-input-single-output as well as multiple-inputmultiple-output cases. However, they do not put the education and health inputs and outputs together into one model. This leads to a disregard of the interaction effects between education and health, which are important for a country's overall development, as pointed out by Fielding et al. (2008). They find that efficiency of public spending varies greatly across countries and they use a TOBIT model to explain that variation with the help of different control variables, such as the total size of government expenditures, a budget composition indicator, GDP per capita, urbanization, prevalence of AIDS, income inequality, share of public sector in provision of services, external aid, and different institutional variables.

Gupta et al. (1997) also apply FDH to analyze public spending efficiency. They claim that DEA is too restrictive as it imposes convexity and hence a pre-specified functional form on the efficiency frontier. They use data regarding public expenditure on health and education in 37 African countries between 1984 and 1995 . Their main finding is that African countries are "relatively inefficient in the provision of education and health services" (p.5), despite some productivity increase over time. Others applying FDH or DEA are for example Afonso and St.Aubyn (2004) or Afonso et al. (2005). The latter calculate public sector performance (PSP) and public sector efficiency (PSE) for a public spending aggregate for 23 OECD countries and apply FDH analysis to determine the production possibility frontier. Afonso and St.Aubyn (2004) also look at OECD countries, but differentiate between public spending on health and public spending on education and their respective outcomes.

Aschauer (1989) asks the question "Is public expenditure productive?". Using a neo-classical approach with a generalized Cobb-Douglas production function and data on the U.S. economy between 1949 and 1985 he finds that non-military public spending is relatively more important in determining total factor productivity. Barro (1990) extends an endogenous growth model with constant returns to also include taxes and government spending to find out about the effect of total government spending on economic growth. As this is too aggregated, Devarajan et al. (1996) develop a model where they distinguish between productive and unproductive public spending. To find out about whether a specific type of government expenditure is productive or unproductive they test "whether the share allocated to different components of government expenditure is associated with higher growth" (p. 321). To this end they use contemporary public expenditure shares as independent variables and 5-year forward moving averages of economic growth as the dependent variable in a country fixed effects regression. Control variables are continent dummies, share of government expenditure in GDP, the black market foreign exchange rate and a shock variable including the world's real interest rate, and export and import price indices. Public spending categories are declared productive or unproductive depending on the sign of the coefficients of public spending category shares in the estimation equation. This interpretation is 
possible because the focus is on public spending composition (the shares of the different categories, i.e. an increase in one share is only possible with a simultaneous decrease in at least one of the other shares) and not on the level of the different categories (allocative efficiency).

Fan and Rao (2003) measure the impacts of public spending on different sectors (agriculture, forestry, fishing and hunting, education, health, transport and communication, social security, defense, others) on economic growth. Though they differentiate the inputs (spending on the different sectors, and GDP per capita and urbanization as control variables), they only consider one output: economic growth. Using a production function approach they calculate the elasticity of output with respect to the different public spending categories and find that the different spending categories have different impacts on economic growth. They conclude this outcome suggests a potential for improvements: a decrease in spending on defense, and an increase in spending on agriculture, which is the most important economic sector in developing countries.

Jayasuriya and Wodon (2008) use the stochastic frontier method of an error component approach to measure the efficiency of public spending. Outcome indicators are life expectancy at birth and net primary school enrollment rate. Independent variables are GDP per capita, adult literacy rate, and public spending on either health or education. They model the error term in the production frontier equation with two components $\mu_{i}-u_{i}$ : first a random noise $\mu_{i}$, which captures shocks and measurement errors, and then a non-negative term $u_{i}$ reflecting the deviation from the best-practice outcome. The measure of efficiency then is the expected value of the outcome indicator given the input indicators, some dummy variables and the actual $u_{i}$, which was determined by maximum likelihood estimation of the production frontier function, divided by this expected value for $u_{i}=0$ - This stochastic formulation differs from the deterministic formulation by the specification of the error term (Murillo-Zamorano, 2004). In deterministic models the error term consists of only one component, which itself is directly interpreted as the shortfall of output from the frontier, i.e. a measure of inefficiency.

The Efficient Development Portfolio (EDP)-approach fits in with the second ('efficiency') strand of literature, but it does not stop with the measurement of inefficiencies. It also provides a direct indication on how a reallocation of the public spending budget may improve the effectiveness of total spending in improving the Human Development Index. The notion of the efficiency of the public spending portfolio itself however differs slightly from the efficiency measures above. It is defined not just in terms of the maximization of the returns/HDI for a given level of resources available (the 'traditional' efficiency concept), but also for a given level of the variance in the expected returns/HDI (the 'extended' efficiency concept from optimum portfolio theory): an EDP requires both 'traditional' and 'extended' efficiency of the allocation of resources.

\subsection{Optimum Portfolio Theory}

Optimum portfolio theory stems from financial economics and was first described by Markovitz (1952). It provides a theoretic framework to solve the problem of distributing a given budget over different financial assets, each of them with its 


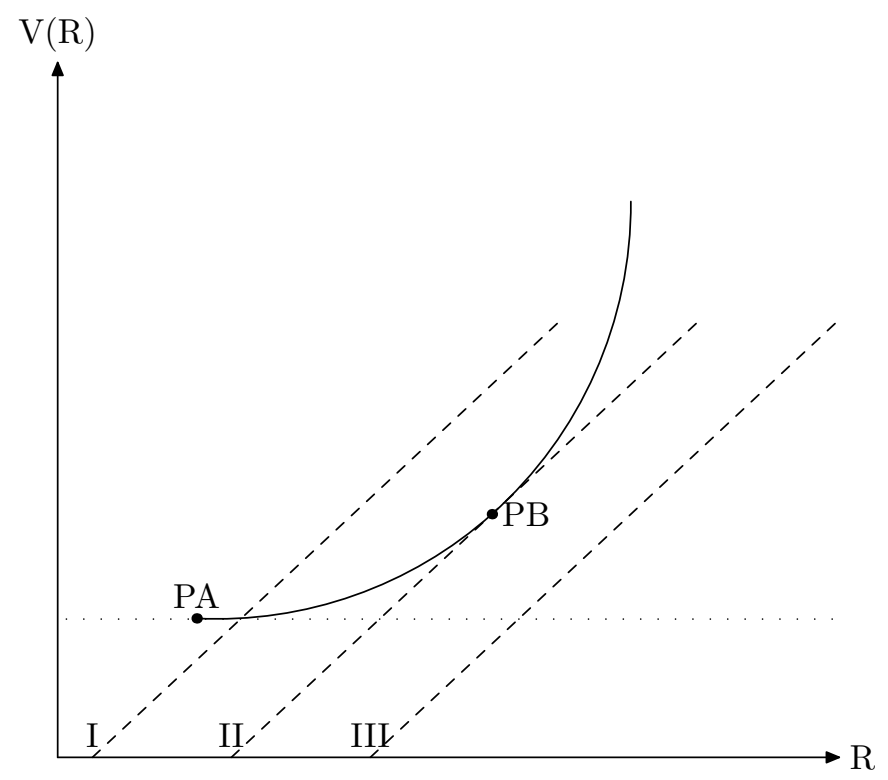

Figure 5.1: The optimum portfolio selection problem

own expected rate of return and a given covariance matrix between the expected returns of these assets. The general problem is to minimize the variance $V$ for a given expected portfolio return, $R$, or to maximize the expected return given a certain level of variance of the expected return return. The combinations of the minimal variances for different levels of expected returns or vice versa constitute the efficient portfolio frontier, which generally is a convex function in the $R-V$ plane as displayed in Figure 5.1.

Let $N$ be the number of financial assets in which a risk-averse person can invest, and let $r$ be the $N \times 1$ vector of expected rates of return associated with these assets, while $S$ is the corresponding $N \times N$ co-variance matrix of these rates of return. $B$ is the size of the financial budget to be distributed over the assets. Furthermore, let $y$ be the $N \times 1$ vector of budget shares of the individual assets. In that case, we have for the expected portfolio return $R$ that:

$$
R=r^{\prime} y
$$

where $r^{\prime}$ is the transpose of $r$. The corresponding variance $V$ of the expected portfolio return $R$ is then given by:

$$
V=y^{\prime} S y
$$

The adding-up constraint for the budget shares implies:

$$
i^{\prime} y=1
$$

with $i^{\prime}$ being a summation row-vector containing only 1's.

An efficient portfolio is defined as a vector $y \geq 0$, such that for a given level of $R, V$ is minimized, or, for a given level of $V, R$ is maximized, conditional on the 
previous three equations. Since Lagrange formulations of both problems give rise to equivalent systems of first order conditions, both formulations will generate the same portfolio, implicitly given by the following set of equations:

$$
\begin{aligned}
y & =y\left(r^{\prime}, S, R\right) \\
V & =V\left(r^{\prime}, S, R\right)
\end{aligned}
$$

where both equations represent the solution to the problem of defining an efficient portfolio, given the exogenous numbers $r^{\prime}$ and $S$. The relation $V=V\left(r^{\prime}, S, R\right)$ describes a convex curve in the $R$ - $V$-plane (for given $r^{\prime}$ and $S$ ) as shown in Figure 5.1. This convex curve is a graphical representation of the set of all efficient portfolios, and will further be called the efficient portfolio frontier (EPF). An optimum portfolio is an efficient portfolio that optimizes some valuation function in which both $V$ and $R$ are arguments. Usually the contribution of $R$ to the objective function is positively valued, while that of $V$ is negatively valued (because of risk-aversion). The simplest possible objective function would be linear in both arguments, and could be formulated as follows:

$$
\Theta=R-\alpha V
$$

In this equation, $\alpha$ is a positive constant, and it reflects the impact of risk-aversion (through $V$ ) on the valuation of a portfolio. Note that Equation (5.6), for a given value of $\alpha$, describes the combinations of $R$ and $V$ that would generate the same value of the objective function, i.e. Equation (5.6) becomes an iso-evaluationline given by $V=(\Theta-R) / \alpha$. An optimum portfolio would maximize Equation (5.6) with respect to $R$ conditional on Equation $(5.5)^{4}$. By setting $\partial \Theta / \partial R=0$ after substituting Equation (5.5) into Equation (5.6), we find that the optimum portfolio is implicitly given by:

$$
\frac{\partial \Theta}{\partial R}=1-\alpha \frac{\partial V}{\partial R} \hat{=} 0 \Rightarrow \frac{\partial V}{\partial R}=\frac{1}{\alpha}
$$

According to this equation the optimum value of $R$ (and hence the optimum portfolio) is defined by the requirement that the slope of the convex curve $V=V\left(r^{\prime}, S, R\right)$ in the $R$ - $V$-plane for the optimum value of $R$ is equal to $1 / \alpha$, which is also equal to the slope of the iso-valuation lines. Hence, this prescription is consistent with the notion that the optimum portfolio is defined by the point of tangency between the curve and the iso-valuation line that is furthest removed from the origin (and represents the highest objective function value therefore), i.e. point $P B$ in Figure 5.1 .

Optimum portfolio theory has been widely applied and extended (Merton, 1969; Samuelson, 1969), also in non-financial directions (e.g. Helfat, 1988; Seitz and Ellison, 1995; Awerbruch and Berger, 2003; van Zon and Fuss, 2008; Fuss, 2008).

\footnotetext{
${ }^{4}$ Note that Equation (5.5) implicitly describes the set of efficient portfolios as a relation between $V$ and $R$. The determination of this set in a development portfolio design context is described in more detail in Section 5.3.2.
} 


\subsection{Portfolio theory, public spending and the HDI}

In this section we will first introduce the data that is used to carry out the model calculations before developing the corresponding model. This is necessary for the reader to understand why the model is set up as it is. This is due to the additive nature of the (old) Human Development Index and the resulting modeling possibilities.

\subsubsection{Data}

For our analysis we need data on the HDI-components, and on public expenditures by HDI-component. Additionally, some exogenous control variables are used that capture the general context of the development process. Table 5.1 gives an overview on the variable names and data sources, as well as some descriptive statistics. Table 5.2 displays the country coverage.

In this chapter, different from the previous chapters, the three sub-indices of the 'old' Human Development Index are directly used. 'Old' refers to the fact, that in 2010, for the 20th anniversary of the HDI, the HDRO introduced a new calculation method (UNDP, 2010) and new sub-indices for the HDI as explained in Chapter 2. Recall that the 'old' HDI is an arithmetic average ${ }^{5}$ of a health index lex, calculated from life expectancy at birth $(L I F E)$, an education index $e d u$, calculated from the literacy rate $L I T R$ and the gross school enrollment rate $G S E R$. The standard of living index $g d p$ is based on GDP per capita $G D P C$.

$$
\begin{aligned}
H D I & =\frac{1}{3} l e x+\frac{1}{3} e d u+\frac{1}{3} g d p \\
l e x & =\frac{85-L I F E}{85-25} \\
e d u & =\frac{2}{3} L I T R+\frac{1}{3} G S E R \\
g d p & =\frac{\ln (G D P C)-\ln (100)}{\ln (40000)-\ln (100)}
\end{aligned}
$$

The data used here has been published in the 2009 Human Development Report of the UNDP (UNDP, 2009).

The HDI shows some significant advances over these years, but, unfortunately, also a worsening of the index for some countries. The range of HDI values in 1995 was between $25 \%$ and $75 \%$, which increased to values between $31 \%$ and $84 \%$ in 2005, while its mean only increased by little more than 2 percentage points from $46.4 \%$ to $48.7 \%$. The highest HDI in SSA can be found in the Seychelles (only available for 2005) and Mauritius, and the lowest in Niger. Most countries have an HDI-score between 0.3 and 0.5 .

Data source for government expenditures are the WHO (2009) and WDI (2009) databases. WHO (2009) provides data for per capita government expenditure on

\footnotetext{
${ }^{5}$ Using weights other than $1 / 3$ does not really change the ranking of countries in accordance with their HDI-score, although, of course, it does change the value of the index (Klugman et al., 2008).
} 
Table 5.1: Data sources and descriptive statistics

\begin{tabular}{|c|c|c|c|c|c|c|c|}
\hline \multicolumn{2}{|c|}{ Variable } & Source & \multicolumn{2}{|c|}{ Obs Mean Std } & \multirow{2}{*}{$\begin{aligned} \text { Dev. } \\
0.13\end{aligned}$} & \multirow{2}{*}{$\begin{array}{r}\text { Min } \\
0.25\end{array}$} & \multirow{2}{*}{$\begin{array}{r}\operatorname{Max} \\
0.80\end{array}$} \\
\hline hdi & Human Development Index & HDRO & 60 & 0.48 & & & \\
\hline lex & Life expectancy index & HDRO & 60 & 0.42 & 0.13 & 0.19 & 0.79 \\
\hline edu & Education index & HDRO & 60 & 0.54 & 0.19 & 0.14 & 0.86 \\
\hline gdp & GDP index & HDRO & 60 & 0.48 & 0.15 & 0.30 & 0.79 \\
\hline get & Total gov. expenditures & calculated & \multicolumn{2}{|c|}{60658.22} & \multicolumn{3}{|c|}{892.0371 .033264 .92} \\
\hline geh & Health expenditures & WHO & 60 & 63.03 & 94.42 & 3.00 & 465.00 \\
\hline ged & Education expenditures & calculated & & 21.36 & 179.73 & 8.36 & 666.89 \\
\hline geg & General expenditures & calculated & & 173.83 & 631.53 & 55.00 & 2335.20 \\
\hline \multicolumn{8}{|c|}{ Control variables } \\
\hline gbcd & British colony dummy & & 60 & 0.18 & 0.39 & 0.00 & 1.00 \\
\hline popd & Population density & WDI & 60 & 94.42 & 138.29 & 2.01 & 612.13 \\
\hline arbr & Urbanization rate & WDI & 60 & 32.98 & 14.51 & 7.22 & 60.20 \\
\hline empr & Employment rate & WDI & 60 & 65.03 & $13.51:$ & 38.64 & 86.46 \\
\hline eind & Industry as $\%$ of value added & WDI & 60 & 26.83 & 14.38 & 9.96 & 82.00 \\
\hline er & alue added & WDI & 60 & 45.45 & 11.47 & 6.51 & 65.76 \\
\hline $\mathrm{ad}$ & Trade as $\%$ of value added & WDI & 60 & 75.52 & 38.32 & 24.32 & 200.76 \\
\hline hivr & HIV prevalence rate & MDG & 60 & 5.71 & 6.60 & 0.05 & 24.88 \\
\hline tbpr & TB prevalence rate & MDG & & 397.60 & 160.67 & 38.88 & 682.72 \\
\hline atss & $\begin{array}{l}\text { Access to improved sanitation } \\
\text { facilities }\end{array}$ & & 60 & 34.75 & 20.76 & 5.00 & 94.00 \\
\hline
\end{tabular}

health in international PPP $\$$ (variable geh) and for general government expenditure on health as percentage of total government expenditure (for now called percenth $)^{6}$. Using data from these two sources, we calculated total government expenditure in international PPP $\$$ as get $=$ geh/percenth. WDI (2009) provides data on public spending on education as a percentage of government expenditure (percentedu $)^{7}$. Per capita government expenditure on education then is ged $=$ get $\times$ percentedu. Remaining government expenditures were simply calculated as the residual: $g e g=$ get - geh - ged.

Public spending per capita varies greatly between the SSA countries in our sample. Total government expenditures per capita (get) in 1995 are between 70

\footnotetext{
${ }^{6}$ WHO Report 2005 definitions p.94: Total health expenditure as percentage of Gross Domestic Product (GDP) Percentage of total general government expenditure that is spent on health. Total health expenditure is the sum of general government expenditure on health and private expenditure on health in a given year (in international dollars). GDP is the value of goods and services provided in a country by residents and non-residents without regard to their allocation among domestic and foreign claims. This corresponds to the total sum of expenditure (consumption and investment) of the private and government agents of the economy during the reference year. General government expenditure includes consolidated direct outlays and indirect outlays, including capital of all levels of government. Social security institutions, autonomous bodies, and other extra-budgetary funds. International dollars are derived by dividing local currency units by an estimate of their Purchasing Power Parity (PPP) compared to US dollar, i.e. a measure that minimizes the consequences of differences in price levels existing between countries.

${ }^{7}$ World Bank http://data.worldbank.org/indicator/SE.XPD.TOTL.GB.ZS Public spending on education, total (\% of government expenditure) Public expenditure on education consists of current and capital public expenditure on education includes government spending on educational institutions (both public and private), education administration as well as subsidies for private entities (students/households and other privates entities). Source: United Nations Educational, Scientific, and Cultural Organization (UNESCO) Institute for Statistics. Catalog Sources World Development Indicators.
} 
Table 5.2: Country coverage

\begin{tabular}{lllllllcc}
\hline & 1995 & 2000 & 2005 & & & 1995 & 2000 & 2005 \\
BEN Benin & $\mathrm{x}$ & $\mathrm{x}$ & $\mathrm{x}$ & MDG & Madagascar & $\mathrm{x}$ & $\mathrm{x}$ & $\mathrm{x}$ \\
BWA Botswana & $\mathrm{x}$ & & $\mathrm{x}$ & MWI Malawi & $\mathrm{x}$ & $\mathrm{x}$ & \\
BFA Burkina Faso & $\mathrm{x}$ & & $\mathrm{x}$ & MLI Mali & & $\mathrm{x}$ & $\mathrm{x}$ \\
BDI Burundi & $\mathrm{x}$ & $\mathrm{x}$ & $\mathrm{x}$ & MRT & Mauritania & $\mathrm{x}$ & $\mathrm{x}$ & $\mathrm{x}$ \\
CMR Cameroon & & $\mathrm{x}$ & $\mathrm{x}$ & MUS Mauritius & $\mathrm{x}$ & $\mathrm{x}$ & $\mathrm{x}$ \\
TCD Chad & & & $\mathrm{x}$ & NAM Namibia & $\mathrm{x}$ & $\mathrm{x}$ & \\
COM Comoros & & $\mathrm{x}$ & & NER Niger & $\mathrm{x}$ & & $\mathrm{x}$ \\
COG Congo, Republic of & & $\mathrm{x}$ & $\mathrm{x}$ & RWA & Rwanda & & & $\mathrm{x}$ \\
CIV Côte d'Ivoire & $\mathrm{x}$ & $\mathrm{x}$ & & SEN & Senegal & $\mathrm{x}$ & & $\mathrm{x}$ \\
GNQ Equatorial Guinea & $\mathrm{x}$ & $\mathrm{x}$ & & ZAF & South Africa & $\mathrm{x}$ & $\mathrm{x}$ & $\mathrm{x}$ \\
ETH Ethiopia & $\mathrm{x}$ & $\mathrm{x}$ & $\mathrm{x}$ & SWZ Swaziland & $\mathrm{x}$ & & \\
GMB Gambia, The & $\mathrm{x}$ & $\mathrm{x}$ & & TGO Togo & $\mathrm{x}$ & $\mathrm{x}$ & $\mathrm{x}$ \\
GHA Ghana & $\mathrm{x}$ & & & UGA Uganda & $\mathrm{x}$ & & $\mathrm{x}$ \\
GNB Guinea-Bisseau & & $\mathrm{x}$ & & ZMB Zambia & $\mathrm{x}$ & $\mathrm{x}$ & \\
LSO Lesotho & & $\mathrm{x}$ & $\mathrm{x}$ & & & & & \\
\hline
\end{tabular}

USD and 3200 USD. While the minimum steadily increases to more than 100 USD in 2005, the maximum decreases to 2900 USD in 2000 before increasing again to about 3200 USD per person in 2005. Even though South Africa has the highest total spending (get), it lags far behind Botswana in spending on education (ged) and health $(g e h)$. At the top end of public expenditures per capita are Mauritius and Namibia. Ethiopia and Niger have the lowest government expenditures per capita. While Ethiopia spends very little on all categories, Niger is doing comparably well on education and health spending. Burundi spends the least on health (about 4USD per capita per year in all years). For some of the least developed countries, such as Sierra Leone or the Democratic Republic of the Congo, data is not even available.

The exogenous variables can be grouped into different indicator categories: structural indicators, development indicators and additional dummies (former British $g b c d$ or French frcd colony dummy). Structural indicators are population density popd, urbanization rate urbr, employment rate empr, the share of agriculture eagr, industry eind, services eser, and trade trad in value added, and the crop production index crop. Development indicators mostly relate to health issues: immunization against measles immu, malaria cases malc, HIV hivr and tuberculosis $t b p r$ prevalence rates, and access to improved water sources atsw and to sanitation facilities atss. We also included aid per capita aidc, but this turned out to be insignificant in all regression equations, as did several of the other variables, given that we included the three government expenditure categories. The Freedom House indices for political rights FHPR and civil liberty FHCL and a combination of these two FREE also turned out to be non-significant in the regressions, even though they do explain some of the deviation of the actual HDI from the efficient portfolio frontier as will be explained in Section 5.4.3. Descriptive statistics for those variables that were finally used in the estimation are presented in Table 5.1. All of these variables are commonly used as control variables when measuring development achievements of different countries, see, for example, the literature summarized in Chapter 4. 


\subsubsection{Efficient development portfolio design}

The formal model from optimum portfolio theory (OPT) provides the theoretical framework for the efficient development portfolio (EDP) model developed and applied in this chapter. The similarities to OPT are obvious. In this case the portfolio that is to be optimized is composed of the three components of the Human Development Index (HDI). Policy makers can choose to spend their given budget on education, health or general government spending (which is defined as the total spending minus education and health expenditures). As policy makers generally are risk averse, a parameter of risk aversion $\alpha>0$ is included in the model. The development goal is the maximization of the expected HDI, denoted by $\hat{D}$, minus its variance multiplied by $\alpha:^{8}$

$$
\Theta=\hat{D}-\alpha \hat{V}(D)
$$

Note that this linear form is the simplest possible form of an objective function that positively values the development outcome and negatively values the variance of the outcome. The HDI is the arithmetic average of three components or development targets health, education and GDP per capita. Let the $T \times 1$ vector $t$ denote the vector of the corresponding development indices, in this case $T=3$. We then have that

$$
\hat{D}=w^{\prime} \hat{t}
$$

where $w$ is the vector of weights, which in this case are the same and equal to $1 / 3$. This corresponds to Equation (5.1). The difference to OPT is that $w$ is given, whereas $y$ is the vector of budget items that is subject of the optimization. The budget shares do not have a single direct influence on the overall development outcome, rather the different development outcomes also depend on the amount spent on the other dimensions and on $X$ external factors such as the economic structure or demographic factors, collected in vector $x$. The EDP model therefore contains an additional constraint linking government expenditures $y$ (in logarithms) to development outcomes:

$$
\hat{t}=\hat{J} y+\hat{K} x
$$

$J$ is the $T \times Y$ matrix of coefficients describing the unit-contributions of the expenditure categories to the HDI components, while $K$ is the $T \times X$ matrix of coefficients linking the the exogenous variables to the HDI components. As the indices in $t$ are restricted to be in the interval between zero and one, and the transformation includes, at least in the case of GDP per capita, logarithms, for the estimation of Equation (5.14) the logarithms of the right hand side are taken as well, that is $y$ and $x$ are the logs of the respective variables. The budget constraint is therefore non-linear in the expenditure variables $y_{i}$ :

$$
B=\sum_{i=1}^{T} \exp \left(y_{i}\right) .
$$

${ }^{8}$ Variable $\hat{z}$ denotes the estimated/expected value of $z$, i.e. $\hat{z}=E[z]$. 
The final constraint that is missing is the variance, which is derived in Appendix A.1:

$$
V=\frac{1}{T^{2}} \sum_{i=1}^{T} \sum_{j=1}^{T}\left(y^{\prime} \Omega_{i j}^{y y} y+y^{\prime} \Omega_{i j}^{y x} x+x^{\prime} \Omega_{i j}^{x y} y+x^{\prime} \Omega_{i j}^{x x} x\right) .
$$

The resulting maximization problem that we need to solve is

$$
\begin{aligned}
\max _{y} \Theta & =\hat{D}-\alpha \hat{V} \\
\text { s.t. } \hat{D} & =w^{\prime} \hat{t} \\
\hat{V} & =\hat{V}(y) \\
\hat{t} & =\hat{J} y+\hat{K} x \\
B & =\sum_{i=1}^{T} \exp \left(y_{i}\right)
\end{aligned}
$$

The only difference to the OPT problem is the presence of Equation (5.14) as an additional constraint. However, Equation (5.14) can be removed through direct substitution of (5.14) into (5.13). This step redefines $D$ (comparable in nature to the portfolio return $R$ in the original OPT framework) in terms of the products of a number of matrices $(J$ and $K)$, the vector of policy variables $(y)$ and the vector of exogenous variables $(x)$, rather than just being the inner-product of the asset returns vector $r^{\prime}$ and the policy vector $y$ as in the original OPT problem. This makes the calculations more cumbersome, but the biggest problem, numerically speaking, is the non-linearity of the budget-constraint. The latter implies that the FOC's that implicitly describe the optimal solution to (5.17) become nonlinear themselves. However, using Wolfram's Mathematica, we have been able to calculate $y$ numerically (and directly) as the solution to a set of simultaneous nonlinear equations. The derivation of this set of non-linear equations is described in detail in Appendix A.1.

Solving the model requires several steps: we first need to estimate equation (5.14), then get the corresponding variance-covariance matrix, calculate the expected HDI $\hat{D}$ and its variance and solve the non-linear optimization problems for a range of $\alpha$ 's.

\subsection{Results}

\subsubsection{Estimation results}

Recall Equation (5.14) $t=J y+K x$. The vector $t$ consists of $T=3$ development outcome variables $l e x, e d u$, and $g d p$, that is the three HDI components, while vector $y$ consists of $Y=3$ policy strategies, that is government expenditures on health (geh), education (ged), and remaining (more general) government expenditures $(\mathrm{geg})$. We are interested in estimating the impact of the policy measures $y$ on the development outcomes $t$. Equation (5.14) is the reduced form of the 
structural model below with $J=(I-V)^{-1} L$ and $K=(I-V)^{-1} H$ :

$$
\begin{aligned}
t & =L y+H x+V t \\
(I-V) t & =L y+H x \\
t & =(I-V)^{-1} L y+(I-V)^{-1} H x .
\end{aligned}
$$

For this moment we abstract from the possibility that GDP per capita has an influence on investments, i.e. on government spending in all categories, through taxes. If this loop was taken into account, we would need an additional system of equations: $y=W t+U x$, with government expenditures depending on target variables $t$, exogenous variables $x$ and possibly also on other variables ${ }^{9}$, resulting in a six-equation system $(t=J y+K x$ and $y=W t+U x)$ that is to be estimated by three-stage least squares (3SLS) or the generalized methods of moments (GMM).

Equation (5.14) describes the most general specification of our linear public expenditure system. Each equation could in principle have been estimated separately, but in our case we cannot exclude the possibility that the errors associated with the equations are correlated, because we have restricted some of the parameter values in $J$ and $K$ to zero ${ }^{10}$. In that case, it is no longer possible to use equation-by-equation OLS, and $\mathrm{SUR}^{11}$ is an appropriate technique. We employ the SUR technique using Aitken's generalized least squares ${ }^{12}$, which also provides the co-variances between the parameter estimates of all the model-parameters, also those across equations, which are needed to obtain the portfolio-variance as used in Equation (A.6) in Section A.1. Using SUR ensures that we explicitly take into account the interdependencies between the equations. The system of equations is estimated for a pooled dataset of the countries displayed in Table 5.2 on p. 70 .

Table 5.3 on p. 90 displays the estimation results for five different specifications of Equation (5.14). We chose to estimate different specifications to be able to conduct a sensitivity analysis (see Section 5.4.5) in order to assess the validity of the model given the low number of observations and resulting low number of degrees of freedom. Specifications I through IV differ with respect to the specific coefficients of the three expenditure categories that are constrained to zero in the separate equations. While in specifications I and II both the coefficient of lnged (expenditure on education) and the coefficient of lngeg (remaining expenditures) are constrained to zero for the lex-equation (life expectancy index), only the coefficient of lngeg is constrained to zero in specifications III and IV. When including lngeg in the estimation, none of the coefficients corresponding to the expenditure categories were significant. This effect already becomes apparent in specifications

\footnotetext{
${ }^{9}$ Agénor et al. (2004) develop an extensive structural model for developing economies taking into account the links between aid, government expenditures, public debt and growth. They also distinguish between three categories of government expenditures: spending on health, education, and infrastructure. They model the fraction of government expenditure in GDP as a function of the tax-to-GDP ratio, the fraction of non-food aid flows in GDP, and the foreign debt to GDP ratio.

${ }^{10}$ We restricted some of the coefficients to zero because they were insignificant.

${ }^{11}$ SUR stands for the technique of 'seemingly unrelated regression' which was developed by Zellner (1962). The SUR technique allows for the possibility that different equations that are using the same data and that are supposedly independent of each other, may still have errors that are correlated across the equations (Greene, 2003).

12 as implemented in Stata7
} 
III and IV, where neither of the coefficients of lngeh or lnged were significant at $10 \%$ (confidence level).

Specifications II and III do not restrict the coefficient of lngeg in the edu (education index) equation to zero. While the coefficient of lngeh is significant at $1 \%$ in all other specifications, it is only significant at $10 \%$ in specifications II and III. The coefficient of lnged is significant at $10 \%$ in specification IV only, when it is also included in the lex equation. Still, its value is between 0.03 and 0.04 in all specifications except for those not restricting lngeg. Also, Aikaike and SchwarzBayesian Information Criteria (AIC and BIC) are highest for specifications II and III, so these two seem to be the least appropriate of the five specifications. AIC and BIC are third highest for specification IV, where neither coefficient of lngeh and lnged are significant in the lex equation.

Specification $\mathrm{V}$ differs from specification $\mathrm{I}$ in the control variables. It additionally includes lnempr in lex. Including the employment rate, which is not significant in lex, slightly improves the fit of the regression (measured by R-squared) and lowers the (root) mean squared error (RMSE). The value of this coefficient is similar to those in specifications I and IV, but neither AIC nor BIC indicate that specification IV outperforms specification I, which therefore seems to be the most appropriate. There is no indication of either heteroscedasticity or autocorrelation, so that specification $I$ is valid and efficient. Using the other specifications for a sensitivity analysis we found that the different specifications do not change the final outcomes to a great extent. Nonetheless, we have to keep in mind that the results depend entirely on the correct specification of the model. Possible sources of misspecification here are the restriction of some coefficients in the $J$-matrix to zero, the disregard of effects of lagged dependent variables that usually are important for development outcomes, and the disregard of country heterogeneities by using pooled data for the estimation. This may result in Type I errors, by rejecting the possibly true null hypotheses that, first, all budget items have an influence on all policy outcomes in form of the HDI indicators, that, second, the current level of development in the individual aspects depends on the previous level of development, and that, third, individual country heterogeneities have an influence on the development outcome. These three issues will be tackled in future research. From now on we will concentrate on the results from specification I, to show the applicability of the EDP method to designing development policies.

As the signs of the coefficients of all types of government expenditures in Table 4 are positive, an increase in government spending improves the value of the individual HDI components. Still, it should be noted that not all expenditure categories are equally important for all the HDI components. Only government expenditure on health seems to have an impact on the life expectancy index. These expenditures are also important for the other two indices (edu and $g d p)$. Education expenditures have a lower impact (about 0.038) on the education index than health expenditures (about 0.072). Remaining government expenditures are not significant for lex or edu, but are important for the GDP index (the coefficient is positive and significant at $1 \%$ ).

The index for life expectancy at birth is higher if urbanization rate (lnurbr), population density (lnpopd), employment rate (lnempr), share of services in total value added (lneser), and trade as percentage of total value added (lntrad) are 
higher, and if tuberculosis and HIV prevalence rate are lower. Former British colonies $(g b c d)$ seem to have a lower life expectancy at birth but better education than those countries that were not British colonies. The share of industry in total value added (lneind), the employment rate (lnempr), and the percentage of population with access to safe sanitation (lnatss) have a positive impact on the education index. The GDP index $(g d p)$ is positively influenced by the degree of urbanization (lnurbr) and higher population density (lnpopd). Again, being a former British colony has a negative, though not very significant, impact.

\subsubsection{Portfolio application results}

Given the estimates for matrices $\hat{J}$ and $\hat{K}$, including the cross-equation variances of the parameter estimates, the variance of the HDI $V(D)$ can be calculated as described in Section A.1. Given the HDI variance, the efficient development portfolio (EDP) optimization problem (Equation (A.7) can be solved for every country and every year for which a full dataset is available as displayed in Table 5.2 in Appendix A.

To avoid numerical problems, we have multiplied the $K$ and $J$ matrices by a factor $10^{3}$, and the elements of the covariance matrix $\Omega$ by $10^{6}$ (since $\operatorname{Var}(1000 x)=$ $\left.1000^{2} \operatorname{Var}(x)\right)$ in order to retain a sufficient degree of numerical precision while tracing the EPFs for a wide range of $\alpha$ 's. This has the effect of multiplying the expected HDI and its standard-deviation (being the square root of the variance) by a factor $10^{3}$ as well.

The EPF for a given budget for some country in some year, can be (graphically) traced by calculating a sequence of optimum development portfolios for a range of values of the risk-aversion parameter $\alpha$. In our case, the range for all values of $\alpha$ is given by $\alpha=1.5^{c}$ for all integer values of $c$ from -19 to 9 , implying that $\alpha$ increases by 50 percent for each unit increase in $c$. We found no significant numerical trouble in calculating the OPF's for this wide range of values, but for even slightly wider ranges we did. For $\alpha=1.5^{-20}$ LSO 2005 starts giving numerical trouble. Such trouble also arises for $\alpha=1.5^{10}$. However, the remaining range for $\alpha$ is wide enough to be empirically relevant, as the slope of the EPFs gets close enough to zero and infinity.

We also varied the budget over a given range as given by $B=50 \times 2^{c}$ for all integer values of $c$ in the range $0-6$ (light gray to dark gray in Figure 5.2). The budget range coincides with the observed range of variation for the actual budgets over the countries and years under consideration. The actual Ethiopian 1995 per capita budget is only slightly higher than the budget low-bound, while Mauritius in 2005 is close to the budget high-bound.

In addition to this, we traced the EPF for the actually observed per capita budget (black curve). In the graphs, the variance $(V)$ of an efficient development portfolio is plotted against its corresponding HDI-value $(D)$. The resulting EPF has a convex shape, as we would expect, given the resemblance of our EDP-composition-problem with an 'ordinary' OPT-problem. Here this shape is ensured by the positive definite variance-covariance matrix. The results shown below include the actual HDI given by UNDP (represented by the vertical line), and the predicted HDI from our model (obtained by substituting Equation (5.14) 
into (5.13)) and its corresponding variance for the actual budget (denoted by the position of the 'star'). Therefore, if the actual budget would be spent efficiently, the 'star' would need to be on the black EPF, save for the occurrence of random shocks in the contribution to the various targets of our model variables. Each star corresponds to a specific probability distribution; the higher the variance, the thicker the tails of the corresponding distribution and hence, the more likely to draw an HDI value that is further away from the optimum value.

The sequence of EPFs one obtains by varying the budget over the budget-range of 50-3200 dollars per capita can essentially be classified using two different 'shapeclasses'. First, there are EPF sequences that have (near) constant variance for low budgets, but then increasing variance for higher budgets (and correspondingly higher levels of HDI) for the highest value of $\alpha$ (i.e. the low-end of the EPF). Examples for this 'increasing' shape-class are Burkina Faso and Ethiopia in 1995, see top plots in Figure 5.2 ${ }^{13}$. But sometimes it is the case that for the lowest budgets, the low-ends of the low budget-EPFs exceed those of higher budget EPFs. This suggests that in some cases, an expansion of the budget may give rise to a 'development double dividend' for risk-averse development policy makers: they could simultaneously improve their HDI score and reduce the riskiness of that score by increasing spending. In fact, in the example provided in the third row in Figure 5.2, we see that in the years around 1995, the policy-makers in Botswana have apparently been able to identify the size of the budget for which the double dividend becomes a trade-off between risk and return again, since an increase in the budget above the actual budget would tend to raise HDI but at the expense of a higher associated risk. The shape explained here is called ' $\mathrm{u}$-shape' in the remainder of the chapter. ${ }^{14}$ An explanation for increasing variance for low budgets might be a possibly low diversification of spending. A large budget can be spend on different projects in different regions, so that the overall effect of the policy measure is an average of some failures and some success stories, while a small budget can only be spend on one or a few projects or a small number of regions. If, on the one hand, that project fails or the selected region experiences other difficulties development outcomes may be limited. On the other hand, the project might be a great success and development is accelerating. The possible span of the overall development outcome is larger for little diversification, resulting in a higher risk and higher variance.

Note, from the examples above, that Burkina Faso (top left plot in Figure 5.2) has been 'unlucky', while Botswana in 1995 (left plot in third row of ) has a 'lucky' draw ${ }^{15}$ as the actual HDI of the latter countries exceeds the predicted HDI, and that of the former country falls below the predicted value. This also applies to Botswana in 2005, where, despite a doubling of the total government budget from just below 1600 USD to 3200, the actual HDI decreased. For Botswana the

\footnotetext{
${ }^{13}$ One should keep in mind that the observations for year $t$ are actually the five-year averages of the years $t-2$ to $t+2$.

${ }^{14}$ Strictly speaking, it is possible that there is only one u-shaped class, of which the monotonically increasing shape class is a special case (i.e. numerically covering only the right-arm of the U-shape). For the moment this question is left for future research.

${ }^{15}$ We will come back to the 'lucky' versus 'unlucky' draw in more detail in the next section that deals with the measurement of the impact of policy inefficiencies and pure chance on HDI scores.
} 

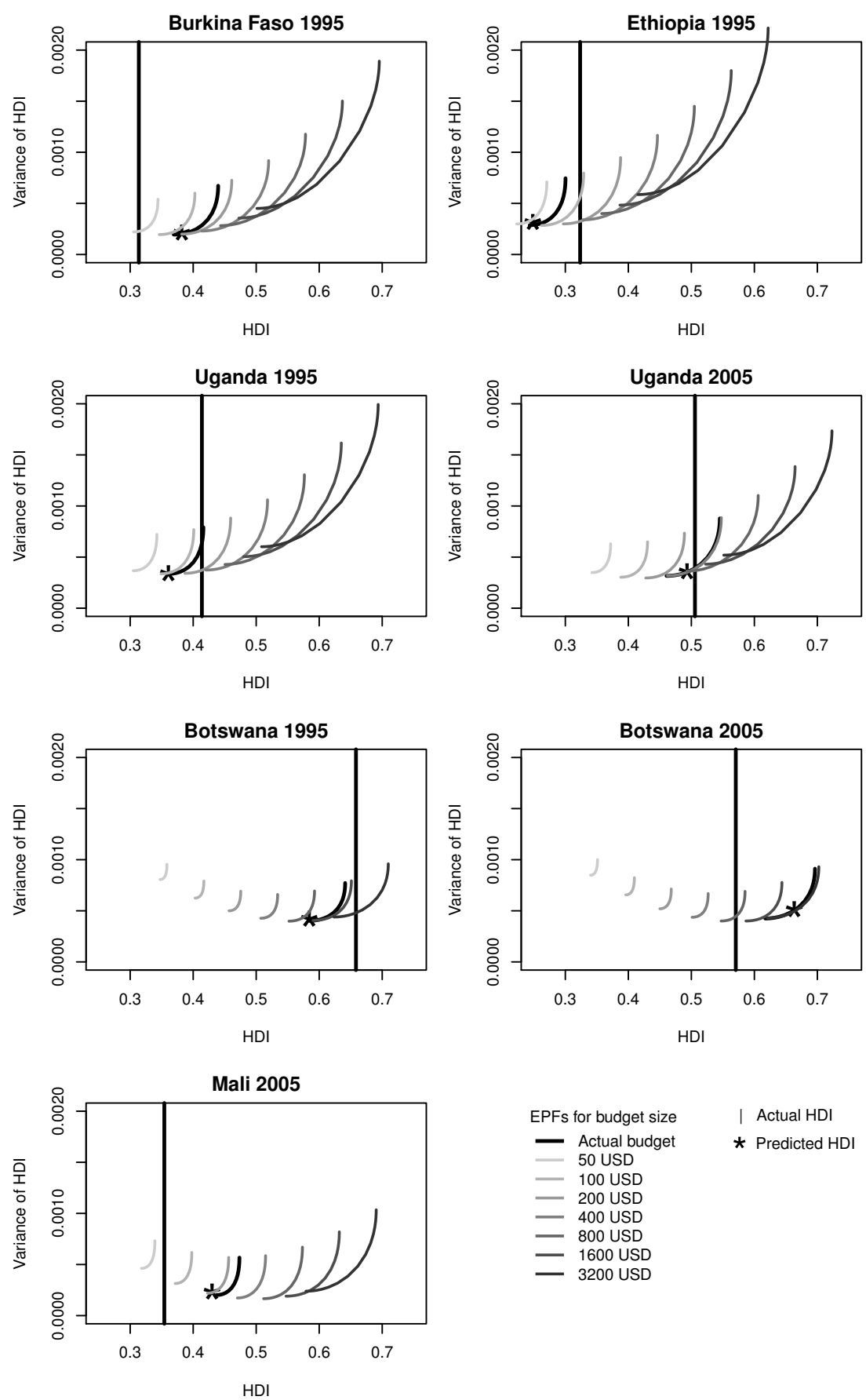

Figure 5.2: Efficient portfolio frontiers 
decrease in the HDI is mainly due to a lower life expectancy because of a relatively high HIV rate. Uganda on the other hand almost quadrupled its total government budget between 1995 and 2005 and the HDI increased as predicted by the model. In addition, the variance of the predicted HDI remained stable as indicated by the vertical position of the $\star$ in the two plots in the second row of Figure 5.2.

Five countries belong to the first group ('increasing'): BDI, BFA, ETH, MDG, and UGA; and 24 countries to the second group ('U-shaped'): BEN, BWA, COG, CIV, CMR, COM, GHA, GMB, GNB, GNQ, LSO, MLI, MRT, MUS, MWI, NAM, NER, RWA, SEN, TCD, TGO, SWZ, ZAF, and ZMB. ${ }^{16}$ Of these countries, Mali in 2005 could definitely have benefited from the double-dividend situation it is in by increasing the total budget, since the black EPF shown in the bottom left plot in Figure 5.2 is entirely to the left of the minimum in the U-shaped EPF-sequence.

\subsubsection{Performance measurement}

The EPFs that we have traced for all countries, all years and all budgets are all nicely convex, as expected. However, the observed HDI does not necessarily intersect with the black EPF (i.e. the EPF achievable with the observed budget), nor is it necessarily the case that the 'star', i.e. the combination of predicted HDI and variance for the actual budget, lies on the black EPF. The deviation of the actual HDI from its expected value (as given by HDI-coordinate of the 'star') may either be due to the fact that by using pooled estimation we assume that the coefficients are the same across countries or simply be due to statistical flukes. ${ }^{17}$ However, the difference between the HDI-coordinate of the 'star' and that of the point on the EPF with the same V-coordinate must be due to inefficiencies in the allocation of the public development budget. This non-stochastic part of the extended efficiency losses associated with such inefficiency can be removed by changing the budget allocation such that the 'star' will be on the (black) EPF. In this section we will measure the minimum amount by which extended efficiency could be improved for a given budget, by efficiently spending that budget.

In Figure 5.3, point C (the 'star') depicts the Variance-HDI-coordinates $(V-D$ coordinates) that correspond with the expected values associated with the actual budget allocation, while the vertical line through point $\mathrm{K}$ corresponds with the actual realization of the expected HDI. The EPF is the convex curve through points $\mathrm{E}$ and $\mathrm{G}$. Point $\mathrm{E}$ is some point on the EPF that would be chosen by a person with an $\alpha$ equal to the co-tangent of the angle $\varphi$. This is because the line tangent to the convex $\mathrm{EPF}$ in point $\mathrm{E}$ is an iso-valuation line, implicitly given by $\Theta^{E}=D^{E}-\alpha^{E} V^{E}$, implying that $V^{E}=D^{E} / \alpha^{E}-\Theta^{E} / \alpha^{E}$ (the superscript $E$ here refers to point $\mathrm{E}$ on the EPF). Note that this iso-valuation line represents the highest value of the objective function that a person with $\alpha=\alpha^{E}$ can achieve.

\footnotetext{
${ }^{16}$ See Table 5.2 on p. 70 in the Appendix for the actual country names.

${ }^{17}$ Strictly speaking, the error could also be due to a misspecification of the model - as discussed before, which could make the country under observation differ from the 'representative' country covered by our estimated model. Obviously, we make the implicit assumption that our linear model is completely and correctly specified. Also using estimation specifications 2 to 5 for this analysis we find that the resulting relative positions of the black EPF, the predicted HDI (the 'star'), and the actual HDI (black vertical line) do not change. The only exceptions to this are BDI1995, GNQ1995, and ZMB 1995, where the predicted HDI is very close to the actual HDI in all cases.
} 


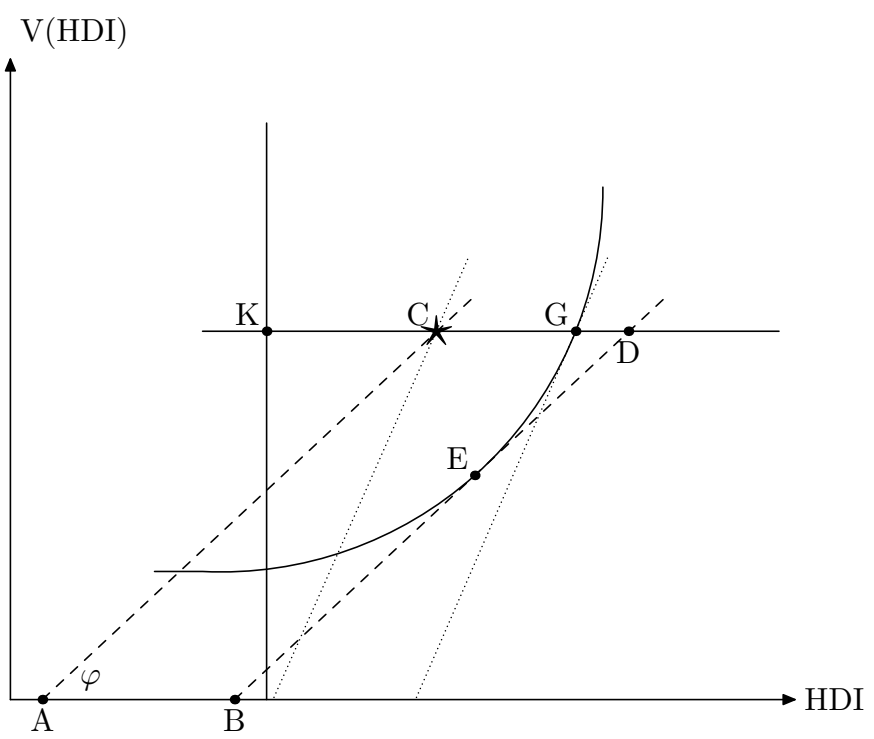

Figure 5.3: Extended efficiency measurement

Point E would represent the optimum portfolio for that person. That person would value point $\mathrm{C}$ using the same $\alpha^{E}$, and obtain an objective function value given by the HDI-coordinate of point A on the horizontal axis (note that on the horizontal axis, the $\mathrm{V}$-coordinate is zero, so the objective function value associated with some point on the horizontal axis must be equal to the HDI-coordinate). But since $\mathrm{C}$ and $\mathrm{A}$ are on the same iso-valuation line, the objective function value in $\mathrm{C}$ is also equal to the HDI coordinate of point A. This also holds for points B and D.

In order to measure the potential size of extended efficiency improvements due to more efficient spending, we would like to know the minimum improvement that people could count on by moving from a point like $\mathrm{C}$, which has been arbitrarily chosen in Figure 5.3, to some point on the EPF, say a point like E, i.e. we are looking for (a person with) a degree of risk-aversion $\alpha^{E}$ that implicitly defines point $\mathrm{E}$ such that the extended efficiency gain from the move from $\mathrm{C}$ to $\mathrm{E}$ would be minimal. Hence, having any other degree of risk aversion results in an even larger gain. The extended efficiency gain from a move from $\mathrm{C}$ to $\mathrm{E}$ is given by:

$$
\begin{aligned}
\Delta \Theta & =\Theta^{E}-\Theta^{C} \\
& =\left(D^{E}-\alpha^{E} V^{E}\right)-\left(D^{C}-\alpha^{E} V^{C}\right) \\
& =D^{E}-D^{C}-\alpha^{E}\left(V^{E}-V^{C}\right)
\end{aligned}
$$

It should be noted that a movement along the EPF can be interpreted as a change in $V$ that comes from a change in HDI $(D)$ that in turn is caused by a change in $\alpha^{E}$. But then, minimization of $\Delta \Theta$ (as given by Equation 5.19) with respect to $\alpha^{E}$, implies:

$$
\frac{\partial \Delta \Theta}{\partial \alpha^{E}}=\frac{\partial D^{E}}{\partial \alpha^{E}}-\left(V^{E}-V^{C}\right)-\alpha^{E} \frac{\partial V^{E}}{\partial D^{E}} \frac{\partial D^{E}}{\partial \alpha^{E}}=0
$$




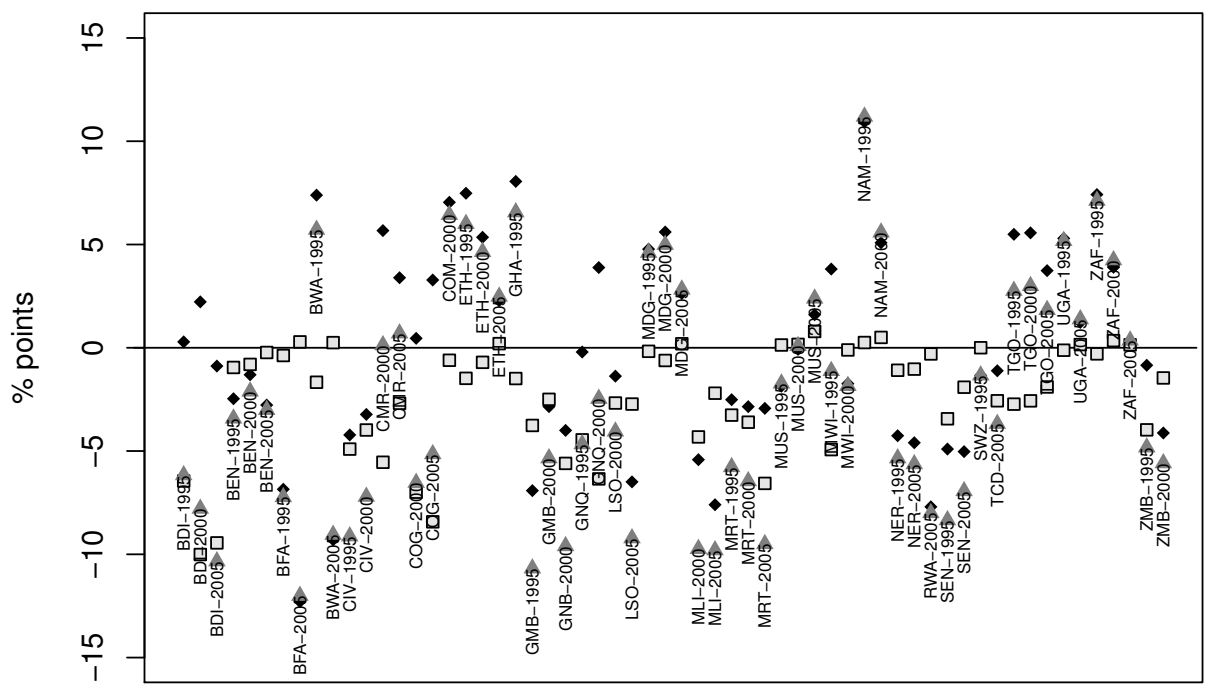

- HDIK-HDIC = Stochastic component HDI surplus/deficit, releative to expected HDI

口 $\mathrm{HDIC-HDIG}=$ Inefficiency component HDIsurplus/deficit

- HDIK-HDIG = Total HDI surplus/deficit measured relative to efficient HDI

Figure 5.4: Extended efficiency surpluses and deficits

Note that $\partial V^{E} / \partial D^{E}$ is the slope of the EPF in point E, and so we must have that $\partial V^{E} / \partial D^{E}=1 / \alpha^{E}$. But then (5.20) implies that $V^{E}=V^{C}$, that is the point on the EPF that represents the smallest improvement of the objective function relative to point $\mathrm{C}$ must have the same $\mathrm{V}$-coordinate as point $\mathrm{C}$. Hence, the point we are looking for must be point $\mathrm{G}^{18}$, and the extended efficiency gain involved in moving from $\mathrm{C}$ to $\mathrm{G}$ is given by the length of the line-segment in between those two points and is measured in HDI-units. Note, however, that the corresponding extended efficiency levels (in equivalent HDI-terms) are given by the HDI coordinates of the points of intersection of the parallel dotted (not dashed) lines through $\mathrm{C}$ and $\mathrm{G}$ with the horizontal axis. Since the dotted lines in Figure 5.3 are parallel, the HDIdifference between points $\mathrm{C}$ and $\mathrm{G}$ is exactly equal to the HDI difference between points $\mathrm{A}$ and $\mathrm{B}$. The latter difference, however, represents the extended efficiency difference between points $\mathrm{A}$ and $\mathrm{B}$ (since the variance component is zero in points $\mathrm{A}$ and $\mathrm{B}$ ), and so the HDI-difference between points $\mathrm{C}$ and $\mathrm{G}$ is also equal to the extended efficiency difference between these points, we can therefore interchange extended efficiency and HDI-differences, as we have done in Figure 5.4.

Unfortunately, the extended efficiency function that we use does not have a 'natural' point zero, like absolute zero on the Kelvin temperature scale, for ex-

\footnotetext{
${ }^{18}$ It should be noted that the second derivative $\partial^{2} \Delta \Theta / \partial^{2} \alpha^{E}=-\partial V^{E} / \partial D^{E} \partial D^{E} / \partial \alpha^{E}>0$ since a higher degree of risk-aversion would lower both $D$ and $V$, i.e. $\partial D^{E} / \partial \alpha^{E}<0$. The extended efficiency gain is therefore indeed minimized when moving from $\mathrm{C}$ to $\mathrm{G}$, since the second derivative is positive.
} 
ample. People with high degrees of risk-aversion may be faced with negative values of the objective function and be perfectly happy with that. In that case relative changes in the objective function value make little sense, even though absolute changes still do. We will therefore provide information in terms of absolute changes.

The extended efficiency contributions of both the transitory and the structural components are shown in Figure 5.4 for all country/year combinations for which a full data-set is available. The calculations are based on Figure 5.3, where point $G$ is the point of reference, and the total extended efficiency surplus consists of two components: $\Theta^{K}-\Theta^{G}=\left(\Theta^{K}-\Theta^{C}\right)+\left(\Theta^{C}-\Theta^{G}\right)$. The first bracketed term represents the extended efficiency surplus over the expected value of extended efficiency, given the way in which the budget was spent in actual fact (if positive, it was a 'lucky' draw). The second bracketed term represents the extended efficiency surplus of the way in which the actual budget was spent over the extended efficiency associated with an efficient spending of the same budget. Obviously, one would expect the latter surplus to be negative, or at most equal to zero if the actual budget allocation would have been efficient. This is what we can actually observe in Figure $5.4^{19}$, where the extended efficiency changes mentioned above have been expressed in equivalent HDI changes (see parallel dotted lines in Figure 5.3). Note that the total inefficiency measure $\Theta^{K}-\Theta^{G}$ does not directly but only indirectly depend on the observed HDI (C) through the impact of all observed HDI-values on the estimated coefficients and, therefore, on the expected, i.e. estimated, HDI (represented by the vertical line through point $\mathrm{K}$.

\subsubsection{Allocation inefficiencies}

Total inefficiencies, marked with a gray triangle, as well as both components (allocation, marked with squares, and 'good/bad luck' market with black diamonds) are presented in Figure 5.4. The first country to look at is Burundi (BDI on the very left of the graph), for which allocation inefficiencies seem to be relatively important. The contribution of 'good/bad luck' $\left(\Theta_{K}-\Theta_{C}\right)$ has been of limited size, so that the negative extended efficiency effects for Burundi are mainly structural in nature. However, these extended efficiency deficits could be fixed, by adopting more efficient spending programs. In contrast, Ethiopia (ETH at about one third of the graph from the left) has consistently been lucky, although the contribution of luck has fallen and that of efficient resource allocation has risen over time. Other countries that have seriously suffered from bad luck ${ }^{20}$ are BWA-2005, BFA1995, BFA-2005, GMB-1995, LSO-2005, MLI-2000/2005, RWA-2005, SEN-2005 whereas such countries as BWA-1995, CMR-2000/2005, GHA-1995, MDG-2000,

\footnotetext{
${ }^{19}$ There are some minor positive deviations, however, that are due to the fact that we obtain the value of $\alpha^{G}$ numerically using Mathematica's Interpolation function that represents the black $\mathrm{EPF}$ as an interpolation of the outcomes of the efficient combinations of $V$ and $D$ that we have calculated for the range of $\alpha$ 's discussed above. We then invert this interpolated function to obtain the $\alpha$ corresponding to a certain value of variance $V$. This variance $V$ is the value that we can calculate using equation (A.6) for the observed budget allocation. The resulting value of $\alpha$ is then used to evaluate the implied objective function value for that interpolated value of $V$, as we also have obtained HDI along the EPF as an interpolated function of $\alpha$.

${ }^{20}$ Defined here as a transitory loss that is more than 5 percentage points larger than the inefficiency loss.
} 
NAM-1995/2000, ZAF-1995, but also TOG-1995/2000 and UGA-1995 have been lucky using the same measure. Overall, the contribution of pure chance or 'fate', i.e. having a lucky or unlucky draw, is generally of considerable importance. ${ }^{21}$

The bonus of experiencing inefficiencies instead of being confronted with fate is that the former can be tackled, whereas, in principle, fate cannot. We have correlated the various extended efficiency deviations from Figure 5.4 (but now scaled by the budget in order to take differences in budget-sizes and their impact on HDI scores into account) with some governance indicators, the hypothesis being that both fate and bad allocation decisions might have something to do with the lack of quality of governance. To this end, we calculated the correlations (K-tau and Spearman because of their small sample properties) between extended efficiency deviations and different governance indicators. The latter are the Freedomhouse political rights (FHPR) and civil liberty (FHCL) index and a combination of these two, called FREE 22

The correlations between these governance indicators and the partial and total deviations are shown in Table 5.4 on p. 90. It becomes immediately clear that a relatively high extended efficiency surplus due to efficient spending is positively correlated with good governance, indicated by the highly significant correlations in the second row of Table 5.4. These correlations of the surplus and governance are negative for FHPR and FHCL (where high values indicate bad governance), and positive for FREE (where low values indicate bad governance). The correlations of total extended efficiency surplus with the governance indicators, displayed in the first row, are of the same sign, but no longer significant. This underlines both the practical importance and the unpredictability of the contribution of fate to the total extended efficiency surplus. Even though the extended efficiency contribution of inefficiencies in government spending is relatively limited, these inefficiencies are strongly correlated with governance indicators, suggesting that extended efficiency would be improved as the quality of governance increases.

In order to establish the practical importance of reducing inefficiencies in government spending, the most important information from Figure 5.4, i.e. the potential (minimum) improvement in extended efficiency due to a move from point $\mathrm{C}$ to point $\mathrm{G}$ in Figure 5.3 and denoted by the squares in Figure 5.4, has been presented again in Figure 5.5. Figure 5.5 represents the extended efficiency change in percentage points of HDI associated with a move from point $\mathrm{C}$ to point $\mathrm{G}$. The largest change is about 10 percentage points for Burundi in 2000 and 2005, but also countries like Congo (Brazzaville) in 2005 (COG-2005) and Mauritius in 2005 (MUS-2005) would benefit greatly from more efficient government spending. This potential 10 percentage point increase in HDI in Burundi represents a proportional increase of 30 percent relative to the expected HDI, which is slightly above 0.3 , but that is extremely low to start with. For some other countries too, more efficient government spending can bring about relative changes in those countries' HDI

\footnotetext{
${ }^{21}$ This could probably be reduced when using a structural econometric model instead of estimating the reduced form equations 5.14 or when using panel estimation techniques that consider country heterogeneities instead of pooling the data for the estimation as has been done here.

${ }^{22}$ FREE. Both FHPR and FHCL are measured on a scale from 1 to 7 , with 1 representing the highest degree of freedom and 7 the lowest. FREE on the other hand is equal to 1 , if the average of FHPR and FHCL is lower than 3.5 (i.e. a country is relatively free), equal to 0.5 for an average between 3.0 and 5.5, and 0 for an average higher than 5.5.
} 


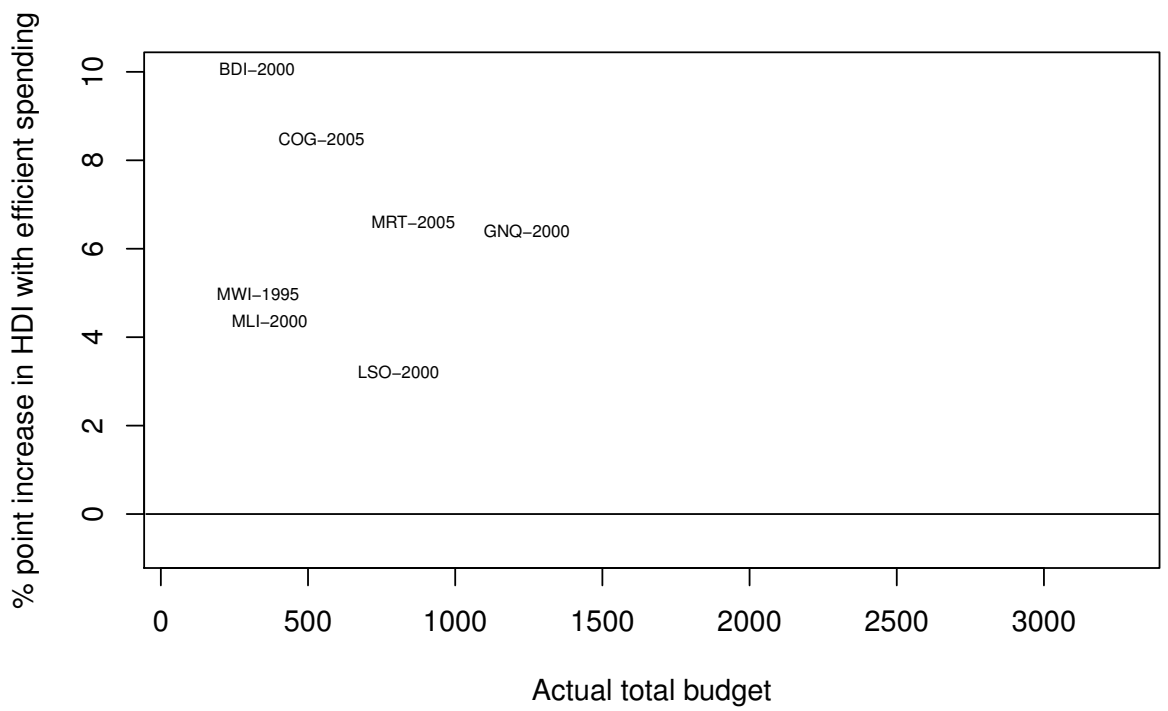

Figure 5.5: Improvement in HDI with efficient spending

of more than 10 percent. Examples are Malawi (MWI-1995), Mali (MLI-2000), Equatorial Guinea (GNQ-2000) or Lesotho (LSO 2000). Note that Figure 5.5 displays percentage point increases and not percentage increases. For most countries, however, the potential increase in HDI is limited to less than 4 percentage points, and hence to less than 10 percent, of the expected HDI. However, an increase of even a few percentage points in the HDI of a country may be of considerable practical importance for the people involved, as it could make the difference between just being alive or being alive and able to make a living.

This plot further indicates that there are large discrepancies between the countries. Firstly, the total per capita budgets vary greatly with a skewed frequency distribution toward low budgets (of 500 USD per capita or less). Secondly, there is a wide disparity between countries in terms of their efficiency gains possible, and these percentage point HDI gains do not seem to be correlated with the size of the budget, if the budget is small. For large budgets on the other hand, both a very small potential gain coming from efficiency improvements and little or no dispersion in these potential gains are apparent. This seems to point to the possibility that a bigger government budget allows for better decision making on the one hand (i.e. being close to or even on the EPF), and for a better implementation of these decisions on the other.

A final general result pertains to what would happen to extended efficiency/HDI if the per capita budget would change, in a situation of efficient spending. Since we calculated the shadow-prices of a budget-increase associated with each country/year combination, we are able to check whether increasingly larger per capita 


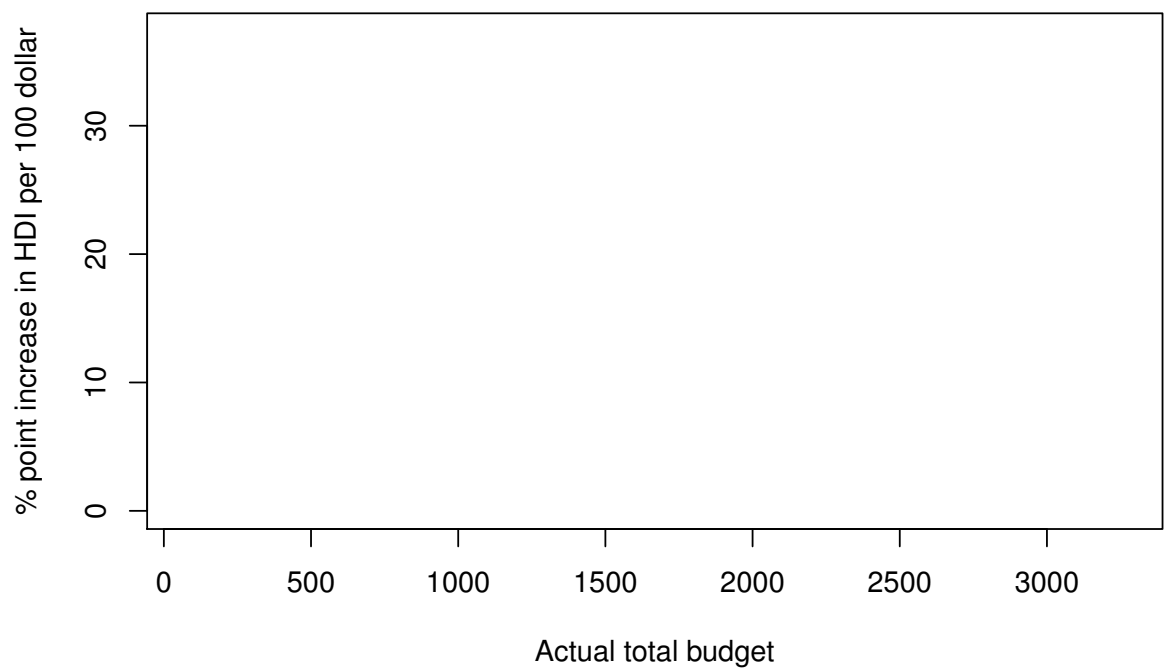

Figure 5.6: Shadow price

budgets would be likely to suffer from decreasing returns. To this end, we have reformulated the shadow-price originally stated in terms of units of extended efficiency per dollar as additional equivalent percentage points of HDI per 100 dollar of per capita spending. The results are presented in Figure 5.6. We see that the measured shadow-prices behave as expected. For low budgets, shadow-prices are high, and for high budgets, shadow prices are low. We see that, save for two exceptional countries (MWI-2000 and NER-1995), the bulk of the countries have little to spend (500 dollars per capita or less) and are facing a shadow price of in between 2 and 10 percentage points per 100 dollar extra budget. The truly small spenders could double their budget from 100 to 200 dollars and have at least a 5 percentage point increase in their HDI. For big spenders the extra HDI is close to zero. For the small spenders, this increase in HDI seems to be roughly comparable in size to the improvement in HDI that can be achieved by an efficient reallocation of their government budgets, as shown in Figure 5.5.

The question is what the removal of inefficiencies requires, in terms of the reallocation of the government budget. To answer this question, we have calculated the percentage point differences between the budget distributions in points $\mathrm{G}$ and point $\mathrm{K}$ in Figure 5.3, for each country/year combination for which we have a complete data set. In order to be able to assess the practical significance of the changes in the budget allocation thus calculated, we also present the actual budget allocation in Figure 5.7, to give an impression of the size of the numbers involved and the variation in these numbers over countries and over time. Figure 5.8 contains the differences between the efficient budget distribution and the actual budget dis- 


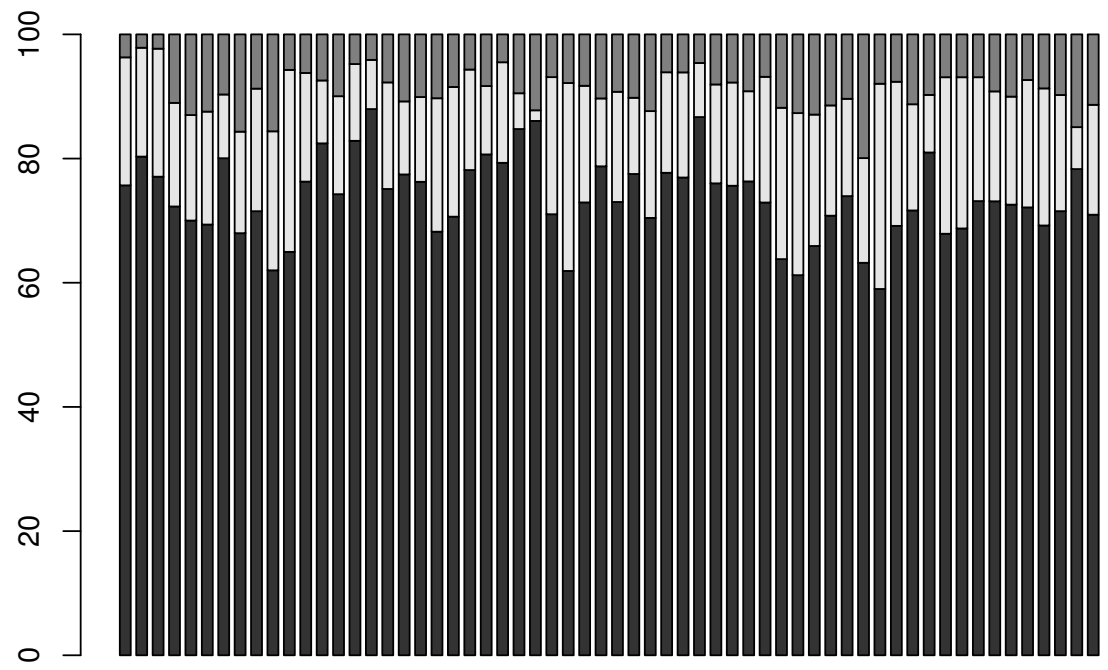

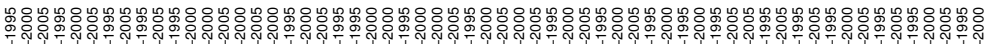

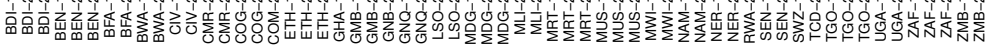

- Budget share general $\square$ Budget share health $\square$ Budget share education

Figure 5.7: Actual budget shares

tribution over the three categories. Hence, Figure 5.8 shows the percentage point change in the budget allocation that would need to be implemented in order to make the development portfolio efficient and to realize the percentage point HDI gains shown in Figure 5.5.

Figure 5.7 shows that the share of general government spending (dark gray) is relatively high, and relatively stable at around 70-80 percent of the total budget, with just a few exceptions in which the share exceeds 80 percent (like BFA-1995, BDI-2000, CMR-2000, TCD-2005, COG-2000/2005, GNQ-1995/2000 and MRT2005) and some in which the share is below 70 percent (BEN-2005, BWA-2005, BFA-2005, CIV-995, ETH-2005, LSO-2005, MWI-2000, NAM-1995/2000, RWA2005 and SEN-1995/2005). This leaves relatively little to distribute over health and education expenditures. The share of education expenditures (light gray) takes roughly 20 percent of the budget, while health expenditures (medium gray) take the remainder, i.e. roughly 5-10 percent. It should be noted that the countries that are below average general government spenders do spend more on education in particular. In general it can be concluded that variation in education and health expenditure shares between countries is stronger than variation in general government expenditure shares.

In the majority of cases, extended efficiency could be improved by increasing the budget spending shares of education and health as indicated in Figure 5.8. In cases where the budget reallocation is of considerable size, most of the drop in general government expenditures goes to health expenditures and less to education, thus effectively making the distribution of the budget more even among the 


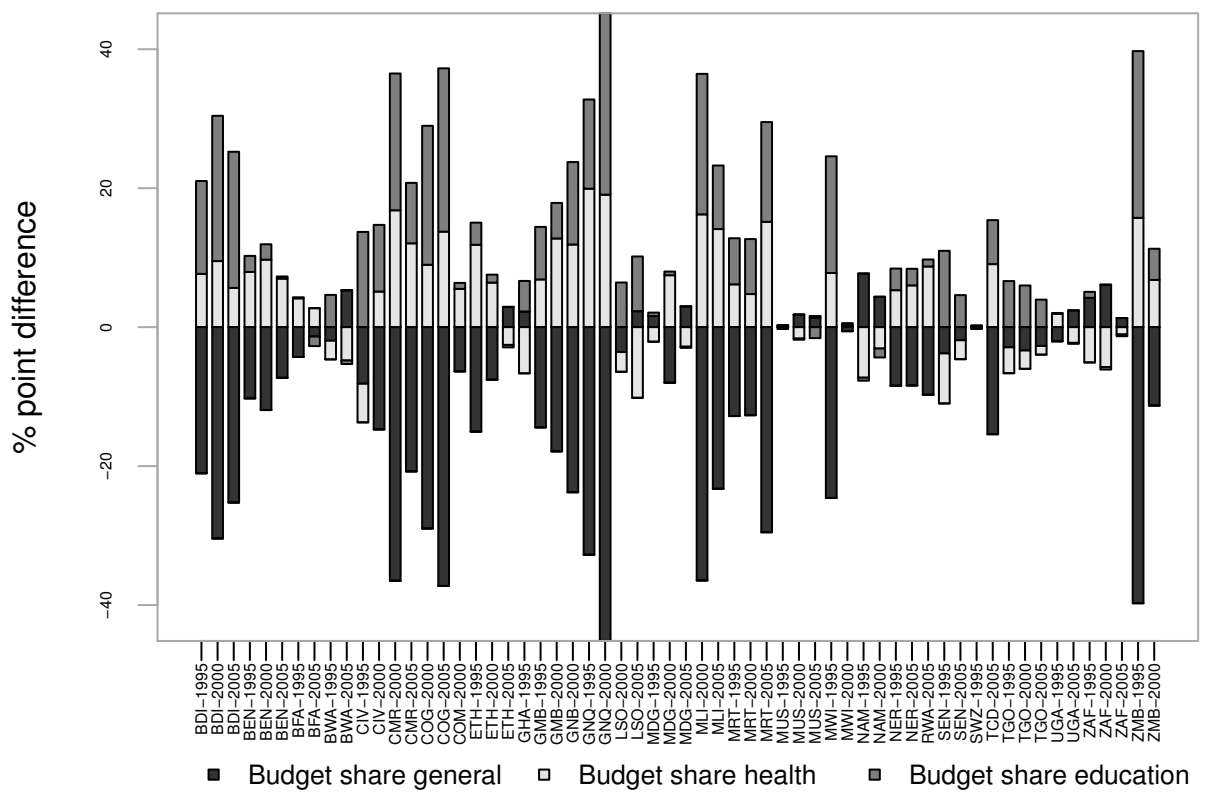

Figure 5.8: Difference between efficient and actual budget distribution

three categories. There are very few countries where general government budget expansions are wanted, and if so, the increase in the share of general government expenditures amounts to just a few percentage points. These countries are the ones that were spending their budgets relatively efficiently (see also Figure 5.4). However, there are a number of countries for which large reductions (20\% or more) in the share of general government expenditures are required, or, equivalently, equally large increases in the joint share of expenditures on health and education are/would have been required. These countries are BDI1995-2005, COG2000-2005, GNB1995-2000, MWI1995, MRT2005, NGA1995, ZMB1995.

\subsubsection{Sensitivity analysis}

Portfolio analysis is generally only applicable to data sets with a large number of observations as it is necessary to have good estimates of the expected return/variance combinations. The data set used here is, however, rather small, so that conducting a sensitivity analysis with regard to changing (co-)variances of the expected development outcome is necessary. We therefore estimated different specifications of Equation 5.14 that links the development targets $t$, i.e. the HDI components, to the policy actions $y$, i.e. the amount spent on the different budget items.

When plotting the EPF's for the different specifications in Table 5.3, we found that the general shape and position of these EPF's in Variance-HDI-space did not change much (not shown here). More variation could be observed in the 


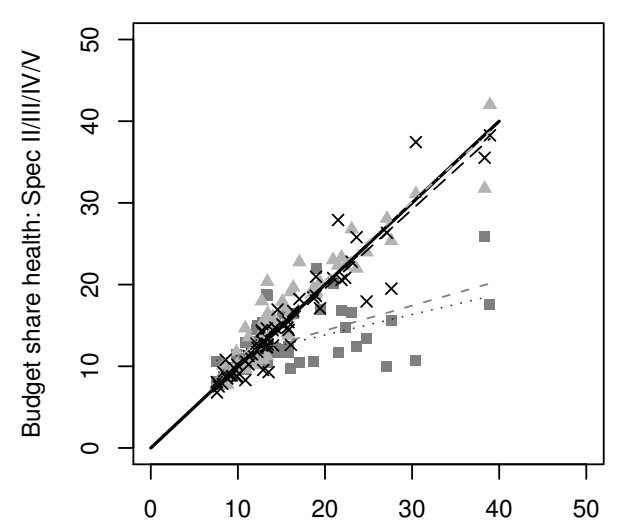

Budget share health: Specification I

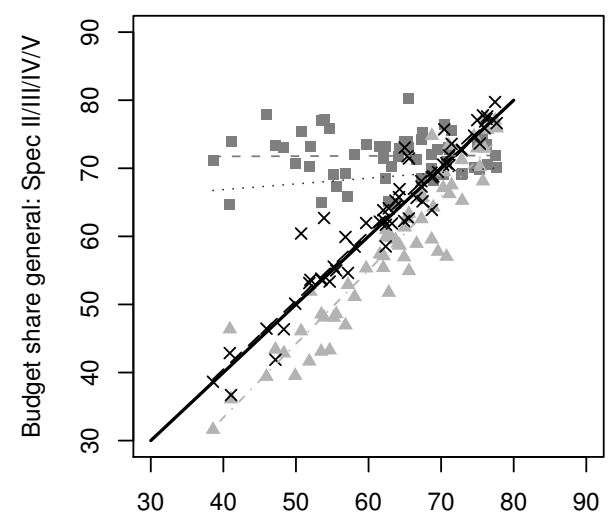

Budget share general: Specification I

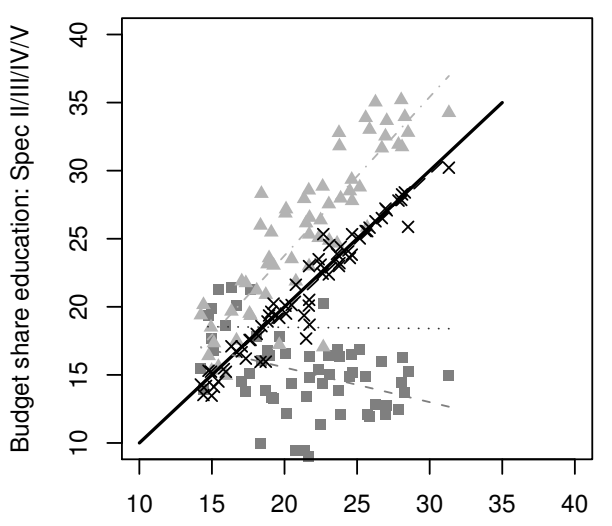

Budget share education: Specification I

Figure 5.9: Sensitivity results

underlying expenditure shares, even though specifications V and I are remarkably similar, indicating that the employment rate impact (the only 'real difference' between specifications I and V), including the contribution of its co-variance does not do much. Figure 5.9 plots the optimal expenditure shares associated with specifications II to IV (in Table 5.3) for each country/year combination against each corresponding country/year combination in specification I. The thick black line in each Figure represents a reference line as it is associated with specification I against specification I, hence the unit-slope. The results of specification I and IV are relatively similar. Still, specification IV involves a structural three percentage point change in the share of education expenditures at the expense of general expenditures. This is because education now also has an impact on health, so there is a double-dividend to education expenditures in specification IV as compared to specification I.

There is however a substantial difference between specifications II and III on 
the one hand and specification I on the other. The cause of the difference is the relatively large positive coefficient of $l n g e g$ in the edu equation in combination with that coefficient being insignificant, i.e. showing a relatively large (co-)variance. Both aspects are important, because on the one hand the double dividend of general expenditures now raises the share of the latter, while on the other hand the increased contribution of $l n g e g$ to portfolio variance introduces a motive to move out of these expenditures, even more so if these expenditures are relatively high initially, raising the other expenditure shares in the process. This has the effect of reducing the slopes of the fitted lines for specifications II and III relative to specification I. Still, according to the econometric model, lngeg is not significant in edu, which suggests that keeping it the model may result in a Type II error of accepting a false null hypothesis. And even though the adjusted R-squared suggest a better fit of either specifications II or III, the Akaike and BayesianSchwartz Information Criteria are higher for these two specifications compared to the other three specifications, suggesting that specifications I, IV, and V are to be preferred over specifications II and III on purely statistical grounds.

\subsection{Policy implications}

This chapter outlines a method that enables the assessment of the efficiency by which development is promoted in Sub-Saharan African (SSA) countries through local government spending. We describe the effect of a change in budget spending on development through its associated impact on the Human Development Index (HDI). A sensitivity analysis concerning the widely criticized linear aggregation scheme with equal weights for the three indexes is left for future research. The purpose of this exercise is to show the application possibilities of the method in this field.

First, we estimate a simple cross SSA country simultaneous system of equations that links government expenditures on the three HDI components to the scores on the three HDI components in a setting that allows for exogenous differences between countries that determines the general setting in which the underlying development processes are taking place, and that define in part the effectiveness of government spending in raising the HDI components. By estimating this system of equations, we obtain measures of the risk associated with the use of the three spending instruments. We make the assumption that policy-makers are risk-averse, implying that they would prefer a policy outcome of spending a given budget on the three HDI components, which has a particular expected value of the HDI outcome and a corresponding variance of that outcome, above a policy with the same expected HDI but a higher variance of that outcome. Policy makers do of course not know the variance, but they might have developed an intuition on which combination of policy measures is less likely to bring about unpredictable outcomes. This setting resembles the one known from Optimum Portfolio Theory (OPT), but it extends the OPT setting by allowing for multiple constraints on the use of (policy) instruments. Here, the simultaneous estimation model forms an additional set of constraints next to the government budget adding-up constraint and the one that links the value of the HDI to its components.

In this setting, an efficient development portfolio is a distribution of the gov- 
ernment budget that minimizes the variance of the HDI for a given expected value of the HDI. We find that the efficient portfolio frontiers are convex upward sloping functions in the variance-HDI-plane. Using this setting, we are able to define a point on the EPF of each SSA country that marks the minimum increase in extended efficiency (a measure that includes both the expected HDI and its variance) that could be realized by an efficient spending of the government budget. The actual performance of each SSA country can be split into a transitory component brought upon these countries by good or bad luck, and a structural component that is linked to good/bad budget allocation decision making. Furthermore, the good/bad luck component is of considerable importance. However, to some extent it may be the case that what we have called 'luck', is actually a 'measure of our ignorance'. The potential reduction of that ignorance is left for future research.

The structural extended efficiency loss component is correlated with a number of governance indicators pointing to the 'rule of thumb' that good governance is associated with efficient budget spending and bad governance with inefficient spending. The changes in the composition of the budget for countries that are spending inefficiently are considerable, i.e. expenditures on health and education should be increased by 20 percentage points or more, whereas in most cases expenditures on health and education are in the order of 20 percent to start with. Hence, efficient reallocation requires a doubling of the health and education budget, and a more equal distribution of the overall budget over the three expenditure categories. For some countries, general government expenditures would need to be raised, but only by a small amount, while the other categories need to be adjusted accordingly. This is the case only for countries that are already spending relatively efficiently. A very interesting aspect to analyze in future research is to find out which weights of the individual HDI items minimize the inefficiencies. This relates to the idea of the sensitivity analysis of the $\gamma_{i}$ 's in Table 6.3 in Section 6.2.2, which aims at identifying the 'real' valuation weights that most probably deviate from the artificial weights of $1 / 3,1 / 3,1 / 3$.

The sensitivity analysis we performed led to the conclusion that the shape and position of the EPF as well as the predicted HDI are robust to different estimation specifications, while the necessary budget changes to get to the EPF show more variability. Using specifications with insignificant parameter contributions by some expenditure category does introduce a bias against using that category through its relatively high (co-) variance in combination with risk-aversion. We conclude that estimating the model correctly is essential for applying the method and interpreting the results. This leads to future research that will include a more advanced specification of the econometric model, including lagged variables to consider intertemporal effects, using panel estimation techniques that take into account country heterogeneities, and estimating a structural rather than a reduced form model.

These results together with the outcome of the complementarity analysis in Chapter 4 emphasize the importance of development policies that aim at increasing both health and education outcomes in Sub-Saharan African countries. 
Table 5.3: EDP estimation results

\begin{tabular}{|c|c|c|c|c|c|}
\hline Specification & I & II & III & IV & $\mathrm{V}$ \\
\hline \multicolumn{6}{|c|}{ Health (lex) equation } \\
\hline lngeh & $0.0205 *$ & $0.0204 *$ & 0.0005 & 0.0005 & $0.0287 * *$ \\
\hline lnged & & & 0.0289 & 0.0290 & \\
\hline \multicolumn{6}{|l|}{ lngeg } \\
\hline lnurbr & $0.0578 * *$ & $0.0583 * *$ & $0.0620 * *$ & $0.0616 * *$ & $0.0616^{* *}$ \\
\hline $\operatorname{lnpopd}$ & $0.0163 *$ & $0.0165 *$ & 0.0132 & 0.0130 & 0.0111 \\
\hline lnempr & & & & & 0.0832 \\
\hline lneser & $0.1002 * * *$ & $0.0999 * * *$ & 0.0588 & 0.0592 & $0.1086^{* * *}$ \\
\hline lntrad & 0.0418 & 0.0418 & 0.0249 & 0.0249 & $0.0425 *$ \\
\hline lntbpr & $-0.0420 * *$ & $-0.0419 * *$ & $-0.0491 * *$ & $-0.0492 * *$ & $-0.0432 * *$ \\
\hline lnhivr & $-0.0266 * * *$ & $-0.0266 * * *$ & $-0.0293 * * *$ & $-0.0293 * * *$ & $-0.0253 * * *$ \\
\hline gbcd & -0.0418 & -0.0418 & -0.0312 & -0.0313 & $-0.0460 *$ \\
\hline const & -0.1840 & -0.1849 & 0.0336 & 0.0346 & -0.5782 \\
\hline RMSE & 0.0751 & 0.0751 & 0.0733 & 0.0734 & 0.0747 \\
\hline R-squared & 0.6549 & 0.6549 & 0.6708 & 0.6707 & 0.6585 \\
\hline \multicolumn{6}{|c|}{ Education (edu) equation } \\
\hline lngeh & $0.0722 * * *$ & $0.0555 *$ & $0.0543 *$ & $0.0698 * * *$ & $0.0734 * * *$ \\
\hline lnged & 0.0379 & 0.0253 & 0.0273 & $0.0401 *$ & 0.0381 \\
\hline lngeg & & 0.0415 & 0.0401 & & \\
\hline lneind & $0.1375 * * *$ & $0.1202 * * *$ & $0.1211 * * *$ & $0.1380 * * *$ & $0.1384 * * *$ \\
\hline lnempr & $0.2985 * * *$ & $0.3046 * * *$ & $0.3018 * * *$ & $0.2958 * * *$ & $0.3080 * * *$ \\
\hline lnatss & $0.0685 * * *$ & $0.0616 * *$ & $0.0620 * *$ & $0.0685 * * *$ & $0.0676 * * *$ \\
\hline gbcd & 0.0307 & 0.0387 & 0.0386 & 0.0310 & 0.0307 \\
\hline \multicolumn{6}{|l|}{ free } \\
\hline const & $-1.7606 * * *$ & $-1.8329 * * *$ & $-1.8212 * * *$ & $-1.7523 * * *$ & $-1.8051 * * *$ \\
\hline RMSE & 0.1068 & 0.1061 & 0.1061 & 0.1068 & 0.1068 \\
\hline R-squared & 0.6857 & 0.6900 & 0.6900 & 0.6858 & 0.6858 \\
\hline \multicolumn{6}{|c|}{ Standard-of-living ( $g d p)$ equation } \\
\hline lngeh & $0.0431 * * *$ & $0.0439 * * *$ & $0.0413 * * *$ & $0.0405 * * *$ & $0.0444 * * *$ \\
\hline \multicolumn{6}{|l|}{ lnged } \\
\hline lngeg & $0.0797 * * *$ & $0.0786 * * *$ & $0.0819 * * *$ & $0.0830 * * *$ & $0.0780 * * *$ \\
\hline lnurbr & $0.0328 * *$ & $0.0329 * *$ & $0.0323 * *$ & $0.0322 * *$ & $0.0332 * *$ \\
\hline $\operatorname{lnpopd}$ & $0.0099 * *$ & $0.0099 * *$ & $0.0098 * *$ & $0.0098 * *$ & $0.0100 * *$ \\
\hline gbcd & -0.0180 & -0.0181 & -0.0176 & -0.0174 & -0.0182 \\
\hline const & $-0.2513 * * *$ & $-0.2486 * * *$ & $-0.2557 * * *$ & $-0.2583 * * *$ & $-0.2477 * * *$ \\
\hline RMSE & 0.0483 & 0.0483 & 0.0482 & 0.0482 & 0.0483 \\
\hline $\mathrm{R}$-squared & 0.8923 & 0.8922 & 0.8924 & 0.8925 & 0.8922 \\
\hline Obs. & 60 & 60 & 60 & 60 & 60 \\
\hline DoF & 32 & 31 & 30 & 31 & 31 \\
\hline $\mathrm{AIC}$ & -394.8532 & -393.4306 & -392.8158 & -394.2604 & -393.9627 \\
\hline $\mathrm{BIC}$ & -348.7776 & -345.2607 & -342.5516 & -346.0905 & -345.7928 \\
\hline
\end{tabular}

Significance levels: *** 1\%, ** 5\%, *10\%

Table 5.4: Governance correlations

\begin{tabular}{|c|c|c|c|c|c|c|}
\hline & \multicolumn{3}{|c|}{ K-tau } & \multicolumn{3}{|c|}{ Spearman } \\
\hline & FHPR & FHCL & FREE & FHPR & FHCL & FREE \\
\hline $\mathrm{OBJ}(\mathrm{K})-\mathrm{OBJ}(\mathrm{G})$ & -0.072 & -0.050 & 0.024 & -0.109 & -0.079 & 0.054 \\
\hline $\mathrm{OBJ}(\mathrm{C})-\mathrm{OBJ}(\mathrm{G})$ & $-0.317 * * *$ & $-0.371 * * *$ & 0.306 & $-0.482 * * *$ & $-0.555 * * *$ & 0.483 \\
\hline $\mathrm{OBJ}(\mathrm{K})-\mathrm{OBJ}(\mathrm{C})$ & 0.074 & 0.123 & -0.117 & 0.136 & 0.204 & -0.182 \\
\hline \multicolumn{7}{|c|}{ Note. Significance levels: *** $1 \%, * * 5 \%, * 10 \%$} \\
\hline OBJ(K)-OBJ(G) & \multirow{2}{*}{\multicolumn{6}{|c|}{$\begin{array}{l}=\text { total extended surplus }(+/-) \text {, measured relative to efficient point } G \\
=\text { extended efficiency surplus }(+/-) \text { due to efficient/inefficient budget } \\
\text { allocation }\end{array}$}} \\
\hline $\mathrm{OBJ}(\mathrm{C})-\mathrm{OBJ}(\mathrm{G})$ & & & & & & \\
\hline $\mathrm{OBJ}(\mathrm{K})-\mathrm{OBJ}(\mathrm{C})$ & \multicolumn{6}{|c|}{$\begin{aligned}= & \text { extended efficiency surplus }(+/-) \text { due to good/bad luck, measured } \\
& \text { relative to point } G\end{aligned}$} \\
\hline
\end{tabular}




\section{Chapter 6}

\section{A growth model for development}

As mentioned in Chapter 2, sustainable development is a long-run concept; changes in investment and technology that support sustainable development are long-run processes. A standard way of analyzing a country's long-run development is the use of endogenous growth models. Their general conceptual framework seems to be particularly suited for studying sustainability issues. Most of the currently existing endogenous growth models for sustainable development were developed within and for industrial countries that are well endowed with physical capital, knowledge and technology. Most developing countries, especially in Africa, however, have low capital endowments, low rates of capital accumulation and low technological capabilities.

In 1988 Lucas showed that the neoclassical growth models of Solow (1956) or Denison (1961) are not models of economic development. They can well be used to model GDP growth rates for the US economy, but fail to explain possible differences between countries' income growth. This is due to the fact that the growth rate, which only depends on technological change and the labor share, is insensitive to changes in the remaining model parameters (Lucas, 1988, p. 15), which capture most of the country differences.

Still, nowadays only few endogenous growth approaches explaining the development of countries, especially for developing countries, exist. One approach is the unified growth theory developed by Oded Galor. This theory combines an endogenous growth model with elements from evolutionary economics, thus explicitly modeling the transition possibilities from one phase of development into the next phase. Several extensions of the basic model exist, covering various aspects of development, such as inequality, fertility or the gender gap, see for example Galor and Weil (1996); Galor and Moav (2000, 2004). More recently developed theoretical growth models for developing countries are the Cass-Koopmanns model as for example in Lecocq and Shalizi (2007) and the models by Pierre-Richard Agénor and Nihil Bayraktar (Agénor et al., 2004, 2005) for analyzing progress toward the Millennium Development Goals (MDGs).

When using theoretical growth models to analyze growth dynamics in devel- 

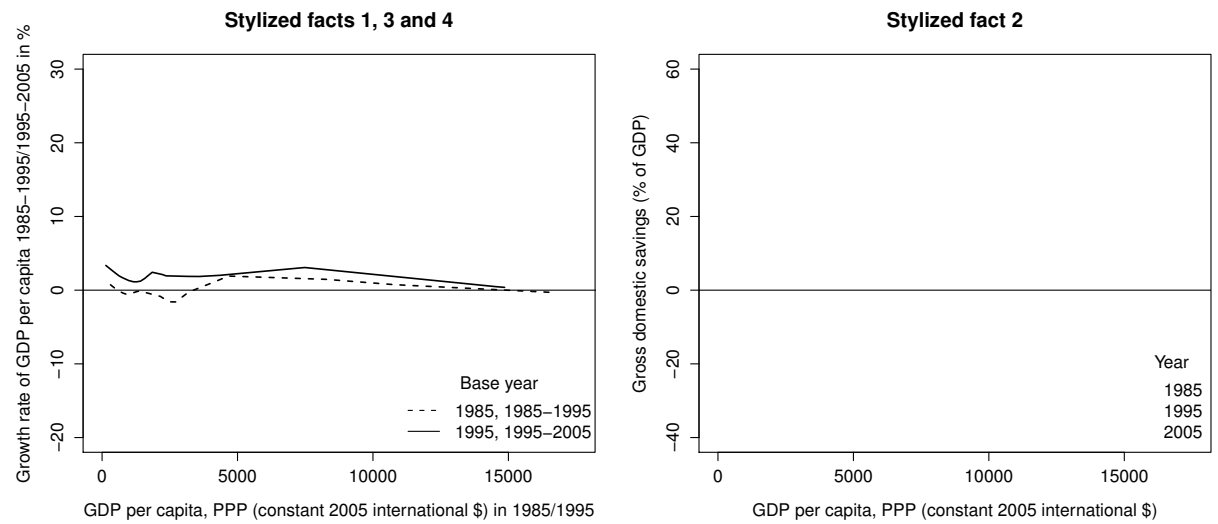

Source: based on Data of WDI (2011)

Figure 6.1: Stylized facts of economic growth in developing countries: Sub-Saharan Africa

oping countries, however, it is most important to explicitly consider that these countries are far from being in a long-run equilibrium state. According to Steger (2000, p. 12) one possibility "to explain persistent underdevelopment, defined narrowly, within the framework of growth theory consists of interpreting real world growth dynamics as representing transition processes to dynamic equilibria". In other words, when using theoretical growth models, it is not the long-run equilibrium which represents development, but rather the transition of the economy from any state toward the equilibrium ${ }^{1}$. Steger (2000) identified four stylized facts of economic growth in developing countries, that are replicated in the transition process toward the steady state in his models on subsistence consumption, productive consumption and endogenizing control variables in transitional dynamics The stylized facts are (Steger, 2000, p. 4):

1. A considerable diversity in the growth rates of per capita income;

2. a positive correlation between the saving rate and the level of per capita income; and

3. a positive correlation between the growth rate and the level of per capita income, i.e. $\beta$-divergence.

4. More generally, many authors report $\beta$-divergence for the lower range of per capita income and $\beta$-convergence for the upper range of per capita income, i.e. a hump-shaped pattern of growth.

\footnotetext{
${ }^{1}$ A short note on notation: the terms 'long-run equilibrium', 'dynamic equilibrium', 'balanced growth path' and 'steady state' are used almost interchangeably in the literature. Steger (2000, p. 12/13) explains the differences between these terms in detail, but in short, these refer to a state of the economy "in which the various quantities grow at constant (perhaps zero) rates" (Barro and Sala-i Martin, 2004, p.33).
} 
Figure 6.1 shows data of Sub-Saharan African countries corresponding to these stylized facts. The diversity of growth rates (stylized fact 1 ) becomes immediately apparent when looking at the vertical spread of the dots in the left graph. This graph plots the ten-year average growth rates of Sub-Saharan African countries for the periods 1985 to 1995 and 1995 to 2005 on the vertical axis, and the corresponding GDP per capita in the base years (1985 and 1995) on the horizontal axis. Stylized fact $3, \beta$-divergence, cannot be confirmed from this plot, however $\beta$ convergence (stylized fact 4 ) for the upper range of per capita incomes can well be the case as indicated by the two lines (solid and dotted), that decrease for higher values of per capita income. These two lines are simple linear regression lines for the two periods, with the 10-year average growth rate being the dependent and GDP per capita being the independent variable. The graph on the right plots the savings rate in 1985, 1995 and 2005 against the corresponding per capita GDP. Stylized fact 2 predicts a positive correlation between these two indicators, which can also be observed here.

GDP, GDP growth or the per capita versions of both are not the only important issues for developing countries. Also, as stated above, they have rather low physical capital endowments (though this starts to change, especially because of foreign direct investments from Asian emerging economies in African countries). However, they have large young populations, that are expected to grow in the future. This means that they have huge potential amounts of human capital. For this potential human capital to become productive human capital, the population needs to be well educated and healthy, both of which are major development concerns addressed by many development programs for Africa, captured, for instance, in the MDGs or in the Human Development Reports (HDR) by the United Nations Development Programme (UNDP).

A growth model for developing countries should therefore put special emphasis on these non-monetary issues of development. Van Zon and Muysken (2001), for example, explicitly model both the education and the health sector based on the Lucas-Uzawa model of human capital accumulation. In this chapter we take the van Zon and Muysken (2001) model and extend it to explicitly consider education next to health and consumption in the utility function.

In Chapters 3, 4 and 5 development progress and interactions between the different aspects of development have been analyzed empirically. Several of these relations can also be found in theoretical growth models. The next section gives a short overview of existing growth models for sustainable development including both environmental-economic models (EEMs) and socio-economic models (SEMs) and summarizes relations between different aspects of the three different dimensions of development, that have been covered in these theoretical models. Then theoretical growth models that explicitly consider the context of developing countries are introduced. In section 6.2 a development growth model is developed. The main feature of this model is that utility does not only depend consumption but also on health and education. Both the long-run equilibrium and the transition toward the long-run equilibrium of the model are analyzed. Section 6.3 concludes and introduces some ideas for future research. 


\subsection{Growth theory and sustainable development}

\subsubsection{Theoretical relations between sustainable development issues}

Some endogenous growth models, that focus on pollution, resource, energy and health, show a trade-off between environmental or social factors and economic growth. Whether or not these trade-offs affect the population's welfare depends on the utility function. If people positively value environmental quality, health or a longer life, they are willing to accept lower consumption and output. In the long run, if environmental quality deteriorates too much, the ecology would face a break down that would not only harm economic growth but all aspects of life. Even though better health and longer life might harm economic growth in the short run, they might favor it in the long run. Additionally, high inequality is found to lead to lower health and education and hence to lower economic growth in the long run.

What is missing in most theoretical growth models is the feedback from economic growth to the other factors. Van den Bergh and Nijkamp (1994) explicitly consider the two-way interactions between the economy and the environment. Bretschger (2006) models energy use as a function of income (and energy prices) and income is in turn affected by energy use via investments. The model by Pautrel (2008) is one of the few considering both environmental and social factors and their feedbacks. The integrated treatment of these issues and the identification of interdependencies within and between these dimensions is important for sustainable development, not only for European countries $^{2}$, but also for developing countries, especially in Sub-Saharan Africa (SADC, 2008).

A theoretical model for sustainable development should include interactions between each pair of the three pillars of sustainable development. In this context, the human (social) development pillar can be partitioned into education and health, whereas the environmental pillar can be partitioned into pollution and resources. Education and health contribute to the formation of human capital and pollution and resource use determine the availability of natural capital. In addition to physical capital, both human and natural capital formation are important contributing factors to economic growth. The interactions between these different aspects of sustainable development, that are modeled in growth models and reviewed in this section, are displayed in Figure 6.2.

Summarizing existing sustainable development models, the objective function is to maximize utility which positively depends on consumption and/or health and negatively on pollution, subject to the households' budget constraint depending on consumption, education and health, the natural resource constraint depending on resource use and pollution and the production function depending on physical capital, education, health and resources. Trade-offs can be introduced into the model via the budget constraint and public investments.

\footnotetext{
${ }^{2}$ The European Commission has recognized the importance of these issues. There is a variety of FP6 and FP7 projects on sustainable development. These projects, however, do neither use growth theory nor pure econometric models for the assessment of interdependencies. See for example www.decoin.eu, www.ecmodels.eu, www.indi-link.net, www.matisse-project.net.
} 


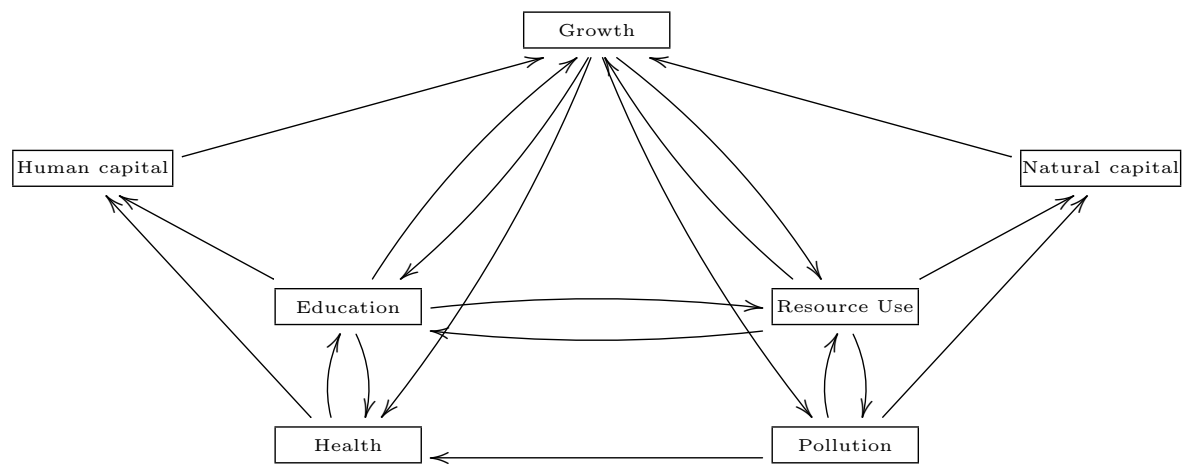

Figure 6.2: Theoretically modeled relations

Economic growth models commonly assume the existence of a steady state, i.e. production, physical capital and consumption growth converge to a constant rate along the balanced growth path. As shown in Figure 6.2, growth is influenced by human and natural capital, education and resource use directly and in turn influences education, health, resource use and pollution. To explain the channels of influence and causation between these key factors we need additional variables reflecting the sectoral structure of the economy: for example the labor force, differentiated according to labor in output production, education, R\&D and health sector; investment in the capital stock, education, health, R\&D (especially environmentally friendly technologies and resource productivity) and infrastructure in general, as pointed out by Agénor et al. (2004) and Agénor et al. (2005); the capital stock itself, abatement activities, resource productivity and availability and quality of food (nutrition).

Several relations between the factors mentioned above are well defined. Socioeconomic models predict positive relations between labor in education and health, the level of health and education, human capital formation and growth in the long-run. In the short-run there might be trade-offs due to the labor and capital constraints: as more workers and capital are employed in the education and health sector, less labor and/or capital is available for output production. If this labor and/or capital shortage is not compensated for by technological change (laboraugmenting/capital-augmenting), production slows down. In the long run, once investment (labor and capital) in health and education pay off, production can reach a higher growth path than it would have attained without the respective investments.

In environmental-economic models, resource availability positively influences production possibilities and resource use positively influences output production and hence growth, while it negatively influences natural capital (a high flow, i.e. high resource use, reduces the stock, i.e. natural capital), as does pollution. Abatement activities reduce pollution and hence have a positive influence on natural capital, but they are costly, reduce the potential capital stock and might therefore 
have a negative impact on other areas where investment is also needed. This is due to the capital constraint: the resources available can either be used for abatement activities or for education or health, but the necessary capital inflow into the health sector in turn might be lower if there is lower pollution. This could be tested empirically using complementarity/substitutability analysis as is done in Chapter 4, for example.

Pautrel (2008) is the only ${ }^{3}$ endogenous growth model that explicitly considers a relation between the environmental and social pillar of sustainable development. He employs a probability-of-dying function that depends on the level of pollution at the time a cohort is born. The mortality rate at any point in time increases as pollution increases, hence life expectancy decreases and the overall available labor force is decreased compared to the case of lower pollution. There are, however, many more possibly important relations between the social and environmental pillar that have not been modeled yet. What is for example the effect of a high level of education on pollution? Is this a direct effect, i.e. are societies with a high level of education more aware of the pollution problem or do they simply care more? Or is it an indirect effect: a high level of education leading to innovation of environmentally friendly technologies and abatement activities? Do highly educated societies use resources more efficiently? Or simply more sustainable? How does the environmental quality affect food availability and quality? Are there direct effects of pollution on health, not only via the probability-of-dying-function? Unfortunately, answering these question is beyond the scope of this work, as the focus here is to assess possible relations between standard-of-living, education and health, as argued in Chapter 2.

When modeling an economy it is important to distinguish between stock and flow variables. The society's wealth, which is a stock variable, is directly and positively influenced by its production/income, and investment in both private and public capital stock. It is influenced indirectly by almost all variables through production/income, which is the flow variable corresponding to wealth. A large capital stock is generally assumed to influence income positively, as is investment, which increases the capital stock (e.g. Bertinelli et al., 2006), labor in output production (as a ratio of total labor force), the flow of resources (Aghion and Howitt, 2005; Hofkes, 1996), research and development and the resulting high technological standard, the education, health and nutrition level (van Zon and Kiiver, 2006). Ambiguous effects on production are caused by investment in education, health and nutrition, since these investments are crowding out investments in the capital stock and reduce the number of workers in output production (van Zon and Kiiver, 2006; Agénor et al., 2004, 2005). In the long run, though, a healthier and better educated workforce will be able to generate higher growth and hence more income.

Private and public capital stocks are positively influenced by investment, which is the corresponding flow variable. In addition, a higher wealth itself has a positive influence on the capital stock, whereas expensive abatement activities decrease it (Hofkes, 1996). While influences on investment in the private capital stock are not modeled, investment in health and education have a negative influence on investment in public capital stock (Agénor et al., 2005), which is seen as infrastructure such as roads, streetlights, public transportation, electricity lines etc., showing

\footnotetext{
${ }^{3}$ To the knowledge of the author.
} 
some trade-off between the different fields a government can and should invest. Furthermore, increasing labor in education and health leaves less labor for output production.

Education (Aghion and Howitt, 2005; van Zon and Kiiver, 2006), health and nutrition levels (van Zon and Muysken, 2001; van Zon and Kiiver, 2006) positively depend on income. In addition to this, the education level is positively influenced by investment in the public capital stock (Agénor et al., 2004, 2005), investment (Agénor et al., 2004, 2005) and labor (van Zon and Muysken, 2001) in education and health and nutrition level. Healthier and well nourished children can attain schools and studying is possible. Investment in infrastructure increases the number of children that can actually get to school through better roads and a better public transportation system. Health is positively influenced by investment in the public capital stock and the nutrition level. Additionally, investment in health and nutrition as well as labor in the health sector positively influence the level of health. Employment in the health sector has a direct influence on health, since more skilled health personal can provide better and more medical assistance. This direct influence might not be observable in the EU or other developed countries, but it clearly makes a difference in least developed countries (LDCs). The nutrition level is solely influenced by income and quantity and quality of food. There is some trade-off between investment and labor in health and education (van Zon and Muysken, 2001). This is due to the government's budget constraint. If an economy spends more on education, it has less money left to spend on health or infrastructure. While there is a trade-off between investment in the capital stock and all other investment goods in the short-run, investment in education, R\&D, health and infrastructure might provide synergies in the long-run. Investment in health, for example, might not only raise the level of health itself, but also the level of education, since healthy children are more likely to attend school.

Natural capital in theoretical growth models is understood as an indicator for environmental quality (Aghion and Howitt, 2005; Bertinelli et al., 2006; Hofkes, 1996). Environmental quality decreases with resource extraction and pollution and increases with abatement activities, resource productivity and natural regeneration capabilities (Hofkes, 1996). Hence, the pollution level increases with the flow of pollution and decreases according to regeneration capabilities. The flow of pollution decreases with regeneration capabilities, e.g. trees absorbing $\mathrm{CO}_{2}$, and also with abatement activities. The resource stock decreases with resource extraction, i.e. the flow of resources into the economy, and increases with regeneration capabilities (only for renewable resources).

\subsubsection{Developing countries and transitional dynamics}

The above overview shows that various interdependencies between different aspects of development have been modeled. The growth models described above were all developed within and for industrialized countries that are well endowed with physical capital, knowledge and technology. Most developing countries have lower endowments, lower rates of capital accumulation and lower technological capabilities. Theorem 3 of Bertinelli et al. (2006), for example, states that countries with a very low initial stock of machines, either have to jump to the optimal 
scrapping path of machinery, or they will not be able to reach it. This jump might be impossible for a country if it cannot afford costly new machinery. A sustainable development path might only be reached with a time delay because old, environmentally unfriendly machinery is continued to be used. This is a very pessimistic view, stating that poorer countries might not be able to develop in an environmentally sustainable way at all.

Still, there are other theoretical growth models that generate similar findings. Van Zon and Kiiver (2006) model the relation between ability distributions of the current and the next generation and the relation between per capita income of the current and the ability distribution of the next generation and find that there are two possible equilibria, one with a large share of workers in low-ability goods production, where inequality persists, and one where it is possible to move from the low-income-low-education group to the high-income-high-education group, leaving fewer workers in low-ability goods production.

Aghion and Howitt (2005), too, explicitly deal with the effects of inequality on growth. The channel through which inequality affects growth in their model is investment. For inequality to negatively influence growth, it is necessary to assume decreasing marginal returns on investment. A more equal redistribution of income, and hence a redistribution of investment, education and medical possibilities, substitutes the lower marginal returns of the rich by the higher marginal returns of the poor and hence fosters economic growth in the economy. These effects point in the same direction as those modeled in Galor and Moav (2004). With their unified growth theory approach they are able to capture the effect of inequality on growth at different stages of development. They can show, for example, that the positive impact of inequality on growth changes in the process of development from physical capital accumulation to human capital accumulation. Physical capital is scarce in early stages of development, which creates a high marginal product of capital and hence a strong incentive for investments in physical capital. There is no incentive to invest in human capital and development is solely enhanced through physical capital accumulation. In this period, the 'poor' completely consume their wage, too. They are not able to save, i.e. not able to accumulate capital, and hence do not transfer any wealth to their children. These in turn are also poor and have to consume their complete wage. A poverty trap can arise. The 'rich', however, have additional capital income and can consume and save at the same time. Their accumulated capital is transferred to the next generation. These transfers increase over time, as do the physical capital stock of the economy and wages. This results in increasing returns to human capital (labor) and decreasing return to physical capital. As soon as the rate of return to human capital is sufficiently large, the next stage of development is entered, in which the wage rate increases further and investment in human capital becomes increasingly feasible, not only for the rich but also for the poor, since credit constraints are no longer binding. According to classical theory, the distribution of physical capital does not matter, given the assumption of non-diminishing returns to physical capital. Galor and Moav (2004) assume that there are diminishing returns to human capital. The actual effect of inequality on growth then depends on the relative returns to human and physical capital.

A literature search in journals for development economics and at the databases 
of the UN, the World Bank, the OECD and others did not give many results for growth models that can be directly applied to developing countries. Lecocq and Shalizi (2007) use a Cass-Koopmans growth model for analyzing the impacts of climate change on economic growth in developing countries, while Agénor et al. (2005) developed a macroeconomic model, explicitly considering foreign aid and the link to several MDGs. In addition, the book on Transitional dynamics and economic growth in developing countries by Thomas Steger (2000) provides valuable insights for modeling development in endogenous growth models.

The basic model in Lecocq and Shalizi (2007) is a one sector model using a Cobb-Douglas production function with factor inputs capital and labor. Effects of climate change are introduced into the model by a variable $E$ representing environmental quality in the utility function. Their main finding is that implications of climate change on welfare and growth depend on the sign of the substitution possibilities between consumption and environment in the utility function. If this is positive, i.e. if consumption and environmental quality are complements, and the environmental quality decreases, the steady state savings rate, capital-labor ratio and consumption-labor ratio decrease as well and so does economic growth. If, on the other hand, consumption and environmental quality are substitutes, savings rate and capital-labor ratio increase opening the way to higher growth possibilities.

This model is rather simple, but it helps to clarify limitations of growth models. The possibly strongest drawback of these models is shown by empirical studies which suggest that not even half of the growth in developing countries can be accounted for by factor accumulation. Growth in total factor productivity (TFP) (which can be calculated as a residual from economic growth and capital and labor accumulation) therefore contributes just as much to economic growth as factor accumulation. Lecocq and Shalizi (2007) confirm earlier insights, that differences in output levels and output growth rates cannot be accounted for by differences in input levels and input growth rates alone. They put forward four factors that play an important role in TFP growth and are not accounted for in most growth models: policy and institutional factors, structural factors, geographic factors and different kinds of shocks.

Some endogenous growth models exist that distinguish between different sectors, and hence taking some structural factors into account. Nonetheless, Lecocq and Shalizi (2007) raise a valid point when criticizing the applicability of growth models especially in developing countries.

Van Zon and Muysken (2001) argue that for some parameter specifications their model might be a valid representation of developing countries. Especially high or low values of certain parameters, for example, represent a very low productivity in the health sector, which is certainly the case for some developing countries. In these cases, the graphical solution only displays very few values of $v$, the fraction of the labor force employed in the health sector, for which positive growth can be achieved. To help these countries to change their situation, accelerate growth and increase life expectancy, aid could be directly aimed at changing the relevant parameters.

Agénor et al. (2005) claim that the micro-approach to monitoring the Millennium Development Goals (MDGs) which has mainly been used so far is not 
sufficient to assess "several key aggregate linkages between foreign aid, mediumterm expenditure frameworks, growth, and the MDGs" (p.5). These linkages can only be accounted for in a macroeconomic framework, which enables the occurrence of positive externalities between, for example, public investment in health and educational attainment.

The main feature of the model is the assumption that public capital is not always effectively used. The capital stock does not only depend on last year's capital stock and total investment, but total investment is additionally multiplied by an efficiency parameter $\alpha \in(0,1)$. An $\alpha<1$ corresponds to less than full efficiency of public investments, which is the case not only in developing countries, but also in most developed countries. The authors point out the importance of concurrent investment in health and in infrastructure, not only in education but also in transportation networks, safer roads, access to safe water and sanitation. Good transportation networks and safe roads increase educational attainment, while access to safe water and sanitation improves health and therewith the ability to learn. Furthermore, a good health improves the quality of labor, while a good infrastructure fosters the productivity of private factors used in to generate output. The findings in Chapter 5 are in line with the observations made by Agénor et al. (2005).

Agénor et al.'s model can directly provide values for poverty (measured as the poverty headcount ratio at national poverty line in $\%$ of population) and literacy rates. While the literacy rate is simply the ratio of educated labor to total population (both of which are variables in the model), the calculation of poverty is more complicated. They use two different methods, first, linking poverty to consumption using partial growth elasticities. In countries for which no estimates of the elasticities are available, Agénor et al. (2005) consider 'neutral' (-1), 'low' $(-0.5)$ and 'high' $(-1.5)$ values, which cover the range of growth elasticities in SSA countries. Second, they link the model to a household survey and initially base the calculations of the poverty rate on actual consumption spending, then generate the growth rate of consumption per capita and the consumer price index in the model following the simulation of a shock. The consumer price index is then used to update the poverty line.

The remaining four MDG indicators considered are linked to the model through cross-country regressions. Malnutrition prevalence negatively depends on public health expenditure and real private consumption per capita and positively on poverty. Infant mortality is negatively related with public health expenditure and GDP per capita, and positively with poverty, while life expectancy is positively related with public health expenditure and GDP per capita and negatively with poverty. The share of the population with access to safe water depends positively on population density, GDP per capita and public infrastructure expenditure per capita.

Agénor et al. (2005) use their model to look at the effects of aid on the process of achieving the MDGs. The linkages in the model are therefore mainly based on public expenditures (on health, education, infrastructure). They do not directly look at the effects of and on growth. They find that aid simply substitutes the government's effort to collect taxes. There are different approaches to modeling the effects of aid on an economy (compare references in Agénor et al., 2004). 
While some of the authors point to the importance of good institutions for the effectiveness of aid, others find that "aid appears to spur growth unconditionally" (Agénor et al., 2004, p. 5).

The three models in Steger (2000) consider subsistence consumption, productive consumption and transitional dynamics with endogenous control variables. While the first two are theoretical growth models, endogenizing the control variables is an empirical task. Both theoretical models are kept very small, but are able to replicate some of the stylized facts, which become apparent during the transition toward the long-run equilibrium. Subsistence consumption enters the model in the utility function, implying Stone-Geary preferences. The other model differentiates between final consumption and consumption that either enhances the human capital stock or labor productivity. Both models have transition periods of more than 200 years, starting off with growth rates very close to zero. The great variability of growth rates in developing countries (stylized fact 1) is explained by the countries being at very different stages of the transition period. The increase in the growth rates increases during the first part of the transition path (stylized fact 3: $\beta$-divergence). Only when getting closer to the long-run equilibrium does it decrease again (stylized fact 4 : hump-shape). The positive relation between the savings rate and the level of per capita income is also replicated in all models.

Iacopetta (2010) follows Funke and Strulik (2000) by arguing that there are three stages of development that are characterized by physical capital accumulation as modeled in the Cass-Koopmans model, human capital accumulation as modeled in the Lucas-Uzawa model, and human capital formation and technological innovation as can be modeled by extending the Lucas-Uzawa model with product varieties as is done in Grossmann and Helpman (1991). The next section introduces a growth model for development based on the Lucas-Uzawa model. Both the long-run equilibrium as well as the transitional dynamics are analyzed.

\subsection{The Lucas model, education and health}

The van Zon and Muysken (2001) version of the Lucas model includes both consumption and health in the utility function. The new Human Development Index (HDI) as introduced in UNDP (2010) is a geometric average of three components: standard-of-living, health and education. Here, we will reformulate the utility function in terms of the HDI and therefore extend it to also include education. The section starts with a short presentation of the original Lucas model from 1988 as well as the addition of a health sector by van Zon and Muysken (2001).

By introducing education as schooling time into the model, which influences the level of human capital, Lucas (1988) allows for permanent differences in income across countries, but not for differences in growth rates. The optimization problem in the Lucas model is to maximize intertemporal utility $W$ subject to the physical and human capital accumulation constraints, $\dot{K}$ and $\dot{h}$. The control variables in this problem are consumption $c$ and the fraction of the population participating in the education sector $z$. Further variables are the size of the population $L$, capital stock $K$, a technology parameter $A$, the discount rate $\rho$, a productivity parameter in the human capital sector $\delta$, human capital endowment per person $h$, and $(1-z)$ the fraction of the population employed in final output production $Y$ : 


$$
\begin{aligned}
W & =\max _{c, z} \int_{0}^{\infty} e^{-\rho t} u(c(t)) L(t) d t \\
\dot{K} & =A[[1-z(t)] h(t) L(t)]^{\alpha} K(t)^{1-\alpha}-c(t) L(t) \\
\dot{h} & =\delta z(t) h(t) .
\end{aligned}
$$

Van Zon and Muysken (2001) extend the basic Lucas model by introducing a health sector. Health aspects enter the model by van Zon and Muysken (2001) in three different ways (p.175): "First, a fall in the average health level of the population may be expected to cause a fall of the amount of effective labor services that the population can supply. Second, the generation of health takes scarce resources that have alternative uses (like the production of output or human capital), while third, a good health may be expected to influence utility directly." To model this, they first define life expectancy $T=\mu g$, with $\mu$ being a constant and $g$ being the average health level of the population. They further assume that people are only working until the age of $R<T$, and that at each point $t$ in time a cohort of $n$ persons is born with health level $g(t)$ and education level $h(t)$, that leave the population by sudden death at the age of $T$.

The representation of the health sector is based on the Romer model from 1990 with the number of specializations in medicine, $\Omega$, depending on the level of human capital $h$ and a scaling factor $\pi, \Omega=\pi h$, and the supply of labor is measured in efficiency units, $h g n R$, where $g$ is the level of health, $n$ is the number of persons born in one year and $R$ is the number of years the persons spend working. One crucial assumption of the model are decreasing returns to the provision of health services, reflected by $0<\beta \leq 1$. The essential result of the analysis of the health sector itself is that "a higher share of employment in the health sector will result in a higher equilibrium health level, $g^{*}$, while human capital formation as such increases the speed of adjustment toward that equilibrium level". The health production model implies that the increase in health of one generation to the next is given by a function that brings all features of health production together:

$$
\frac{d g}{d t}=\Psi\left(\frac{R}{\mu}\right)^{\beta} \pi^{(1-\beta)} v^{\beta} h
$$

where $v$ is the share of labor employed in the health sector, $\pi$ is a scaling parameter of the effect of the level of education $h$ and $\Psi$ is a productivity parameter. By taking into account that with increasing medical knowledge and technology the perception of the health level is decreasing, van Zon and Muysken (2001) also include a term for the loss of labor time due to this effect in the health generation function (the second term in the square brackets):

$$
\frac{d g}{d t}=\left[\Psi\left(\frac{R}{\mu}\right)^{\beta} \pi^{(1-\beta)} v^{\beta}-\zeta \pi g\right] h .
$$

The model essentially becomes the following maximization problem, where the 
health status $g$ is directly considered in the utility function:

$$
\begin{aligned}
W & =\max _{c, z, v} \int_{0}^{\infty} e^{-\rho t} \frac{L}{1-\theta}\left[g^{\gamma}\left(\frac{C}{L}\right)^{(1-\gamma)}\right]^{1-\theta} d t \\
Y & =A[(1-z-v) h g n R]^{\alpha} K^{1-\alpha} \\
\dot{K} & =Y-C \\
\dot{h} & =\delta z g h \\
\dot{g} & =\left[\Psi\left(\frac{R}{\mu}\right)^{\beta} \pi^{(1-\beta)} v^{\beta}-\zeta \pi g\right] h .
\end{aligned}
$$

Utility, represented through a CIES function with $\gamma$ being the relative contribution of health to intertemporal utility and $1 / \theta$ being the intertemporal elasticity of substitution, positively depends on the state of health $g$ and consumption $c$. Output $Y$ is represented by a Cobb-Douglas production function, where the term in the squared brackets is the fraction of the effective labor force available for final output production, a fraction $z$ is used in human capital production and a fraction $v$ in the health sector. The first term on the RHS of the $\dot{g}$ function represents the increase in the level of health from one cohort to the next due to increased human capital and health service accumulation. The second term represents the negative effect of technical change on health, e.g. stress or a lower perceived level of health due to more cure possibilities.

The model is not analytically solvable. The authors therefore present a graphical solution from which trade-offs between health and human capital accumulation as well as between health and consumption can be seen. The first trade-off is due to the labor force constraint. If more health services are needed, less labor is available for human capital and final output production. This lowers final output production directly and indirectly and hence also economic growth through a lower rate of human capital accumulation. Since health, too, (and not just consumption) increases utility, a higher level of health can offset the utility loss of lower consumption possibilities.

\subsubsection{Modeling the HDI}

The 'new' Human Development Index, which was introduced in Chapter 2, is a geometric average of a standard-of-living, an education and a health indicator. This geometric average nicely resembles a utility function that can be used in an endogenous growth model.

Standard-of-living in the HDI is represented by Gross National Income (GNI) per capita. But as Stiglitz et al. (2009) emphasize, this is a measure of production rather than of the amount of money people are actually able to spend (disposable income) and so afford a certain standard of living, which is better reflected by consumption per capita. Therefore, the standard-of-living dimension of the HDI is here represented by consumption per capita $c=C / L$ in the utility function, where $L=n T$ is the size of the population, with $n$ being the number of persons per cohort and $T$ being life expectancy. To reflect the population increase due to increasing fertility and decreasing infant mortality rates, $n$ is allowed to change 
over time. $T=\mu g$ depends on the general health level $g$ of the population and a constant scaling parameter $\mu$. The health index of the HDI is represented by life expectancy at birth.

Total human capital in the model is represented by $P=h L$, with $h$ being the average level of human capital per capita. The average level of human capital directly enters the utility function. In addition, also the share of people employed in the education sector $z$ is included in the utility function ${ }^{4}$. Including both of these measures reflects the composite education indicator in the HDI, which is a geometric average (with equal weights) of the expected years of schooling (a quality parameter, here represented by $h$ ) and the average years of schooling (a quantity parameter, here represented by $z$ ). This does not mean that either one of $h$ or $z$ should be interpreted as expected or average years of schooling. Rather, the inclusion of both variables aims at explicitly considering education quality and education quantity in the model, which both are important development aspects.

The HDI weighs each of the components - standard of living $(S o L)$, health (Health), and education $(E d u)$ - by one third ${ }^{5}$ :

$$
\begin{aligned}
H D I & =(\text { SoL })^{1 / 3}(\text { Health })^{1 / 3}(\text { Edu })^{1 / 3} \\
& =c^{1 / 3} T^{1 / 3}\left(z^{1 / 2} h^{1 / 2}\right)^{1 / 3} \\
& =c^{1 / 3}(\mu g)^{1 / 3}\left(z^{1 / 2} h^{1 / 2}\right)^{1 / 3}
\end{aligned}
$$

where $\mu$ (which is a scaling parameter) and $z$, the share of the working population in human capital production, are constant in the steady state. It should be noted, however, that, these weights of one third are decided upon by politicians and researchers who developed the HDI. Hence, these weights do not necessarily reflect utility preferences of the population, so that for the resulting constant intertemporal elasticity of substitution (CIES) utility function we use more general preference parameters $\gamma_{i}^{6}$ for the central planner solution:

$$
\max _{c, z, v} U=\int_{0}^{\infty} e^{-\rho t} \frac{L}{1-\theta}\left[c^{\gamma_{c}}(\mu g)^{\gamma_{g}} h^{\gamma_{h}} z^{\gamma_{z}}\right]^{1-\theta} d t .
$$

Output $Y$ is produced using physical capital and healthy human capital ${ }^{7}$, which is employed until retirement age $R^{8}$ :

$$
Y=A[(1-z-v) h g n R]^{\alpha} K^{1-\alpha},
$$

with $A$ being a technology parameter and $v$ the share of the working population in the health sector. Naturally, $v+z<<1 . r=(1-\alpha) Y / K$ is the return to capital

\footnotetext{
${ }^{4}$ This share $z$ does not only include teachers, but also everyone else who is involved in human capital production ranging from primary and high school students to doctoral candidates and researchers in the $\mathrm{R} \& \mathrm{D}$ sector. Note that in the following text the description of this is often abbreviated to 'labor share in education' or the like.

${ }^{5}$ Equation (2) in the Statistical Annex of UNDP (2010).

${ }^{6}$ with $\gamma_{h}=\epsilon_{h} \gamma_{h z}, \gamma_{z}=\epsilon_{z} \gamma_{h z}, \epsilon_{h}+\epsilon_{z}=1$ and $\gamma_{c}+\gamma_{g}+\gamma_{h z}=1$

${ }^{7}$ Healthy human capital is the number of people working $n R$ multiplied by their health level $g$ and their human capital level $h$.

${ }^{8} \mathrm{~A}$ constant value of the retirement age $R$, which therefore is independent of the health level, is one of the assumptions of van Zon and Muysken (2001). In the context of developing countries having an active labor force smaller than total population can be explained by the high share of labor in the informal sector.
} 
and $q=c L / Y$ is the propensity to consume. Physical capital accumulation is given by

$$
\dot{K}=\frac{d K}{d t}=Y-C=Y-L c .
$$

Note, that we disregard the depreciation of physical capital for now. Human capital production is similarly modeled as in Lucas (1988) and in van Zon and Muysken (2001), but starts from the total amount of human capital in the population $P$. Total human capital is accumulated at rate $\dot{P}$ which depends on $z$, the share of the population working in the education/research sector, the total amount of human capital in the society $P$, the health level of the population $g$ and a constant $\delta$ :

$$
\dot{P}=\delta z g P
$$

so that the growth rate of the level of human capital per capita $h=P / L$ is

$$
\begin{aligned}
\hat{h} & =\left(\frac{\hat{P}}{L}\right)=\hat{P}-\hat{L}=\hat{P}-\hat{g}-\hat{n} \\
\Rightarrow \dot{h} & =h \frac{\dot{P}}{P}-h \frac{\dot{g}}{g}-h \frac{\dot{n}}{n} \\
& =\delta z g h-h \frac{\dot{g}}{g}-h \frac{\dot{n}}{n},
\end{aligned}
$$

where we have used $L=n T=n \mu g$. This modeling takes into account the possibly diminishing impact of a growing population on per capita production. The health production function used here is similar to van Zon and Muysken (2001), but does not depend on the level of human capital. It is possible to disregard the effect of the level of human capital in the health sector because of Baumol's Disease (Baumol, 1993) in this sector. ${ }^{9}$ The main essence of this Baumol'S theory is that labor productivity increases in this sector are very limited, if present at all. If the doctors get a better education they cannot necessarily treat more patients, they can only treat them better. The overall effect of a higher level of human capital in the health sector is therefore limited. A higher number of health personnel as represented by share $v$, however, can have a huge effect, because doctors and nurses can take better care of their patients if they have fewer patients. The possibility of disregarding $h$ in the health sector is also confirmed by the estimations in Chapter 4, where the coefficients of the lagged level of the education variable are not significant at $10 \%{ }^{10}$. The health level increases at rate:

$$
\begin{aligned}
\dot{g}=\frac{d g}{d t} & =\Psi\left(\frac{R}{\mu}\right)^{\beta} \sigma^{(1-\beta)} v^{\beta}-\zeta \sigma g \\
& =\zeta \sigma\left(\phi v^{\beta}-g\right),
\end{aligned}
$$

with $\phi=\frac{\Psi}{\zeta}\left(\frac{R}{\mu \sigma}\right)^{\beta}$. The current-value Hamiltonian following the maximization of intertemporal utility $U$, with control variables $c, v$ and $z$ and state variables $g, h$

\footnotetext{
${ }^{9}$ Additionally, including $h$ in $\dot{g}$ results in undesirable out-of-steady state behavior, which would give problems for the transitional dynamics presented later in this chapter.

${ }^{10}$ See Table 4.4. The change in the level of education, however, has a positive impact on the change in the health status and vice versa.
} 
and $K$, is given by

$$
\begin{aligned}
H= & u+\lambda_{K} \dot{K}+\lambda_{h} \dot{h}+\lambda_{g} \dot{g} \\
= & \frac{L}{1-\theta}\left[c^{\gamma_{c}}(\mu g)^{\gamma_{g}} h^{\gamma_{h}} z^{\gamma_{z}}\right]^{1-\theta}+\lambda_{K}\left[A[(1-z-v) h g n R]^{\alpha} K^{1-\alpha}-L c\right] \\
& +\lambda_{h}\left[\delta z g h-\frac{\zeta \sigma h\left(\phi v^{\beta}-g\right)}{g}-h \frac{\dot{n}}{n}\right]+\lambda_{g}\left[\zeta \sigma\left(\phi v^{\beta}-g\right)\right] .
\end{aligned}
$$

For each of the co-state variables, the corresponding growth equations can be calculated either from the first order conditions of the control variables (Equations (B.4) - (B.6) on p. 134 in Appendix B.1), by solving these for the respective costate variable $\lambda_{K}, \lambda_{h}$ and $\lambda_{g}$, and then taking the derivative with respect to time, and from the first order conditions with respect to the state variables, that is from Equations (B.10) - (B.12). Using these results in combination with Equations (B.8) and (B.9), the co-state variables and their growth rates, which are displayed in Appendix B.2, can be eliminated from the system.

The final system of growth equations for all growth rates in variables $g, v, z$, $r, q, \hat{h}, \hat{q}, \hat{L}, \hat{n}, \hat{A}$ and the model parameters is

$$
\begin{aligned}
\hat{K} & =\frac{r(1-q)}{1-\alpha} \\
\hat{g} & =\zeta \sigma \frac{v^{\beta} \phi-g}{g} \\
\hat{h} & =g z \delta-\hat{g}-\hat{n} \\
\hat{c} & =\frac{1}{1-\gamma_{c}(1-\theta)}\left[(1-\theta)\left(\hat{g} \gamma_{g}+\hat{h} \gamma_{h}+\hat{z} \gamma_{z}\right)+r-\rho\right] \\
\hat{z} & =f(g, v, z, q, \hat{g}, \hat{h}, \hat{Y}, \hat{q}) \\
\hat{v} & =f(g, v, z, q, \hat{g}, \hat{h}, \hat{Y}, \hat{q}, \hat{c}, \hat{n}) \\
\hat{Y} & =\hat{A}+\hat{K}+\frac{-\alpha}{(1-z-v)}[v \hat{v}+z \hat{z}-g z \delta(1-z-v)] \\
\hat{r} & =\hat{Y}-\hat{K} \\
\hat{q} & =\hat{c}+\hat{L}-\hat{Y} \\
\hat{L} & =\hat{g}+\hat{n} .
\end{aligned}
$$

The growth equations of $z$ and $v$ are long expressions, that are displayed in Appendix B.3.

\subsubsection{Long-run balanced growth path}

The long-run balanced growth path is defined here as the state of the system where the labor shares of physical capital production and in the education and health sectors are constant, i.e. $(1-z-v), z$ and $v$ are constant. Furthermore, consumption $c$, physical and human capital, $K$ and $h$ respectively, grow at constant proportional rates. Following the reasoning of van Zon and Muysken (2001), we 
assume that the health level is constant along the long-run balanced growth path, so that $\hat{g}=\dot{g} / g=0$, and hence $g^{\star}=\phi v^{\beta}$, implying that

$$
\hat{h}=\dot{h} / h=\delta z g^{\star}=\delta z \phi v^{\beta} .
$$

Life expectancy $T$ as well as total population $L$ are constant under the additional assumption that $\hat{n}=0$, implying that is there is no exogenous fertility increase. Both the return to capital $r$ and the savings rate $s=1-q$ are assumed to be constant in the long-run state of the economy. However, development in SubSaharan Africa seems to be far removed from such a long-run balanced growth path. Therefore, the long-run balanced growth analysis shown here only serves as a basis for the analysis of the system's transitional dynamics in Section 6.2.3.

The system of growth equations that is solved for the growth rates of $c, h, K$, $Y$, and the variables $r$ and $g$ consists of expressions $(6.11),(6.14),(6.15),(6.17)$, (6.18) and (6.19). This gives

$$
\begin{aligned}
\kappa & =\frac{\dot{c}}{c}=\frac{\dot{h}}{h}=\frac{\dot{K}}{K}=\frac{\dot{Y}}{Y}=\frac{\rho(q-1)}{E} \\
r & =\frac{\rho(\alpha-1)}{E} \\
g^{\star} & =\frac{1}{\delta z} \frac{(q-\alpha) \beta\left(z \alpha \gamma_{c}+q(-1+v+z) \gamma_{z}\right) \zeta \sigma \rho}{v(q-\alpha) \alpha \gamma_{c} \rho+\left[(v+v \beta+\beta) \gamma_{c} \alpha+\beta q(1-z-v)\left(\gamma_{z}-\gamma_{g}\right)\right] \zeta \sigma E}(6.24) \\
\text { with } E & =\alpha-(1-\theta)\left(\gamma_{c}+\gamma_{h}\right)+q\left((1-\theta)\left(\gamma_{c}+\gamma_{h}\right)-1\right) .
\end{aligned}
$$

Here, consumption per capita, average human capital, physical capital and final output production all grow at the same rate, $\kappa$. The final system of equations (growthsys) to solve for $z, v, \kappa$ and $q=1-s$ are equations (6.13), (6.16), (6.22) and (6.24). The parameters in this system are the rate of time preference $\rho$, the intertemporal elasticity of substitution $1 / \theta$, the relative contributions of the HDI components to intertemporal utility $\gamma_{i}$, productivity parameter $\delta$ of the education sector, a parameter $0<\beta \leq 1$ reflecting decreasing returns in health generation, and a set of positive constants $\phi, \zeta$ and $\sigma$ that influence productivity in the health sector. The system of equations (6.13), (6.16), (6.22) and (6.24) is solved numerically $^{11}$ for different combinations of parameter values. To test the robustness of the system, the parameters are changed one-by-one for a sensitivity analysis. The parameter value ranges are displayed in columns 'minimum value' and 'maximum value' of Table 6.1. The initial set of parameter values is displayed in column 4 of the table. The initial values are taken from the literature, see for example the overview in Table 3.2 in Steger (2000). The transversality conditions as displayed in Appendix B.4 hold for this initial set of parameter values.

The relative contribution of consumption, education and health to intertemporal utility is most likely not equal. Most endogenous growth model assume that only consumption is part of the utility function, however - as also argued in van Zon and Muysken (2001) - health, too, has a significant influence on perceived wellbeing as well. Education does contribute to general utility, although for African and other developing countries education is relatively less important, considering

\footnotetext{
${ }^{11}$ Using Mathematica's FindRoot routine.
} 
that survival first of all depends one's health status and on the consumption of food and fresh water and basic living supplies such as clothing and housing. In this context Steger (2000) introduces a subsistence consumption utility function, assuming that there exists a minimum level of consumption below which nobody can survive. This specification could also be included in the present model, but since all components enter the utility function in a multiplicative way, while the health level is explicitly considered, consumption without health is not possible. The relative contributions of consumption, education and health have been set to $\gamma_{c}=0.6, \gamma_{z}+\gamma_{h}=0.05+0.05=0.1$ and $\gamma_{g}=0.3$ respectively. Table 6.3 displays results for other values of the relative contributions that will be described in more detail later.

Figures 6.3 to 6.5 display results for the balanced growth rate $\kappa$ (in all graphs on the vertical axis), the share of human capital in the education sector $z$ and in the health sector $v$ (in the graphs to the left), the share of human capital in the production sector $(1-z-v)$ and the long-run savings rate $s=1-q$ in the graphs in the middle, and the long-run health level $g^{\star}$ and rate of return to capital $r$ on the right. Low values of the changing parameter are displayed in dark (red) and higher values in lighter color (yellow) and vice versa for changes in $\delta$ and $\sigma$. The black dots indicate the solution corresponding to the initial choice of parameter values. Note that for some graphs the distance between two consecutive dots are changing. This reflects a non-linear dependence of the variables on the corresponding parameter. In addition, sometimes a non-linear relation between the variables displayed in one graph becomes apparent. This is for example shown in the graphs of $\kappa, g^{\star}$ and $r$ of a changing $\rho$ or $\theta$ in Figure 6.3 (on the right).

The solution of the long run equilibrium based on the initial choice of parameter values results in a labor distribution across final production, education and health of $60 \%, 30 \%$ and $10 \%$, respectively. The corresponding growth rate of physical and human capital, consumption and production, $\kappa$, is 0.02 , the savings rate $10 \%$ (note that the axis label for $10 \%$ is 0.1 ), the rate of return to capital $8.5 \%$ and the general health level 0.69. This is a very abstract number, but it could be interpreted as the share of the population being healthy. However, $g^{\star}$ changes proportionally with parameter $\phi$, so that the choice of $\phi$ directly influences the value of $g^{\star}$, which is not bounded above by one. Recall that life expectency is $T=\mu g$. Now for $\mu=100$, life expectency in the long run equilibrium would be 69 years, which is approximately the global average life expectancy in 2010, see Figure 3.1 on p. 26. Hence, $g$ should rather be interpreted as the level of health, which - multiplied by the constant scaling parameter $\mu$ - determines life expectancy.

Both $\rho$ and $\theta$ have a direct impact on the intertemporal utility, $\alpha$ on final output production, $\delta$ on human capital production and through the latter channel also on final output and intertemporal utility. $\beta, \phi, \zeta$ and $\sigma$ enter the system through the health sector and will therefore also have an influence on human and physical capital accumulation as well as intertemporal utility.

\section{Changing $\rho$}

According to Grossmann et al. (2010), a typical value for the rate of time preference $\rho$ is 0.02 . Steger (2000) reports values between 0.02 and 0.1 for $\rho$. The initial value 
$\kappa$

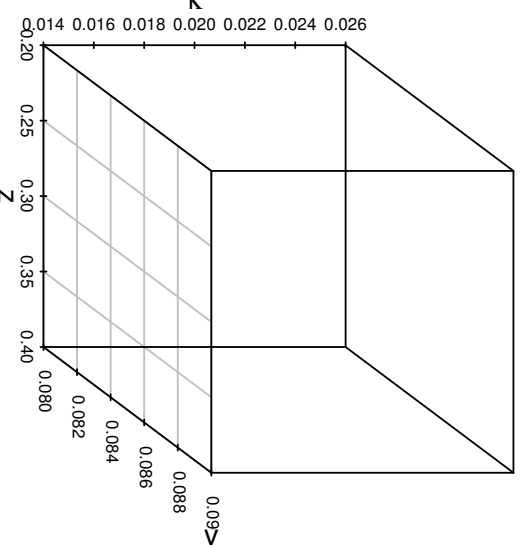

$\kappa$

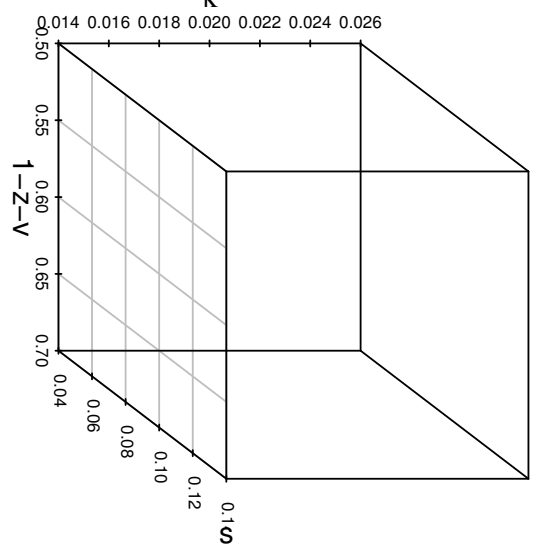

$\kappa$

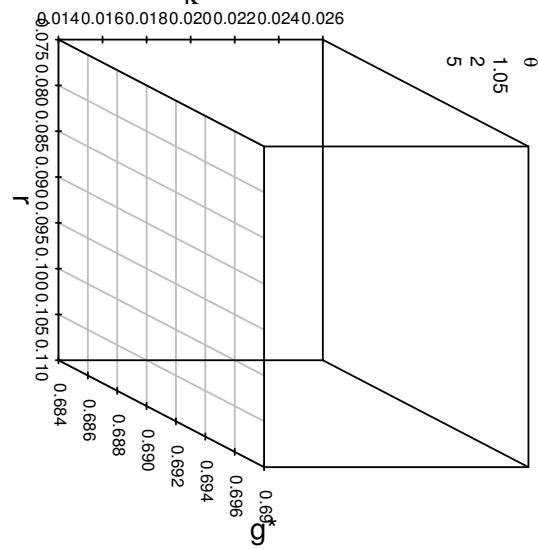

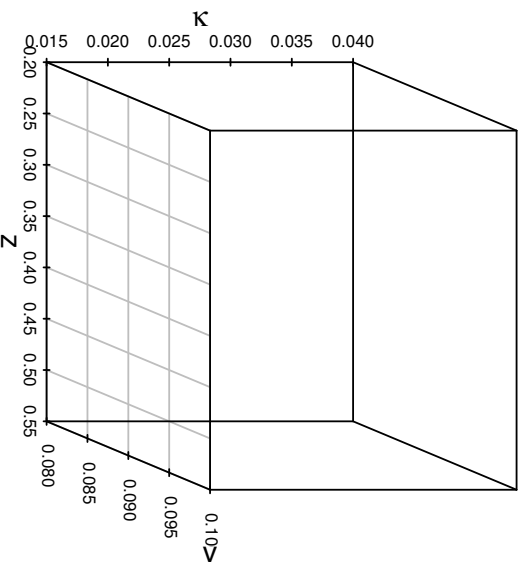

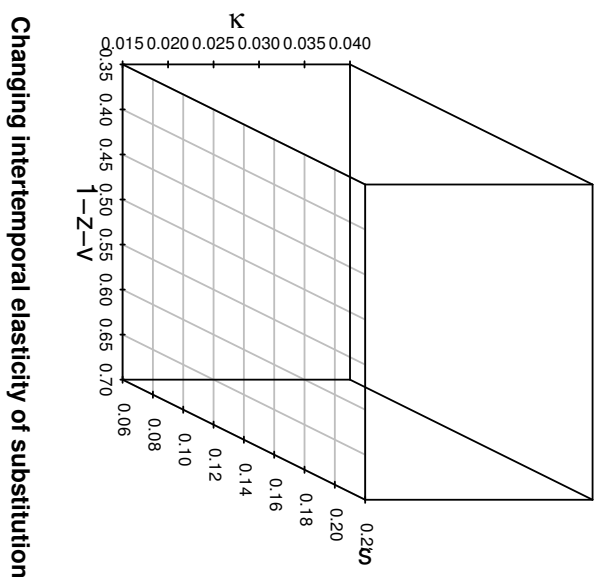

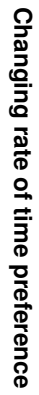

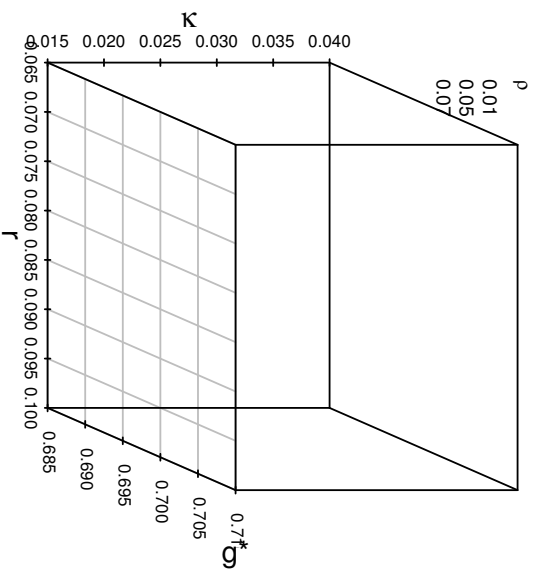

Figure 6.3: Changing $\rho$ and $\theta$ 
$\kappa$
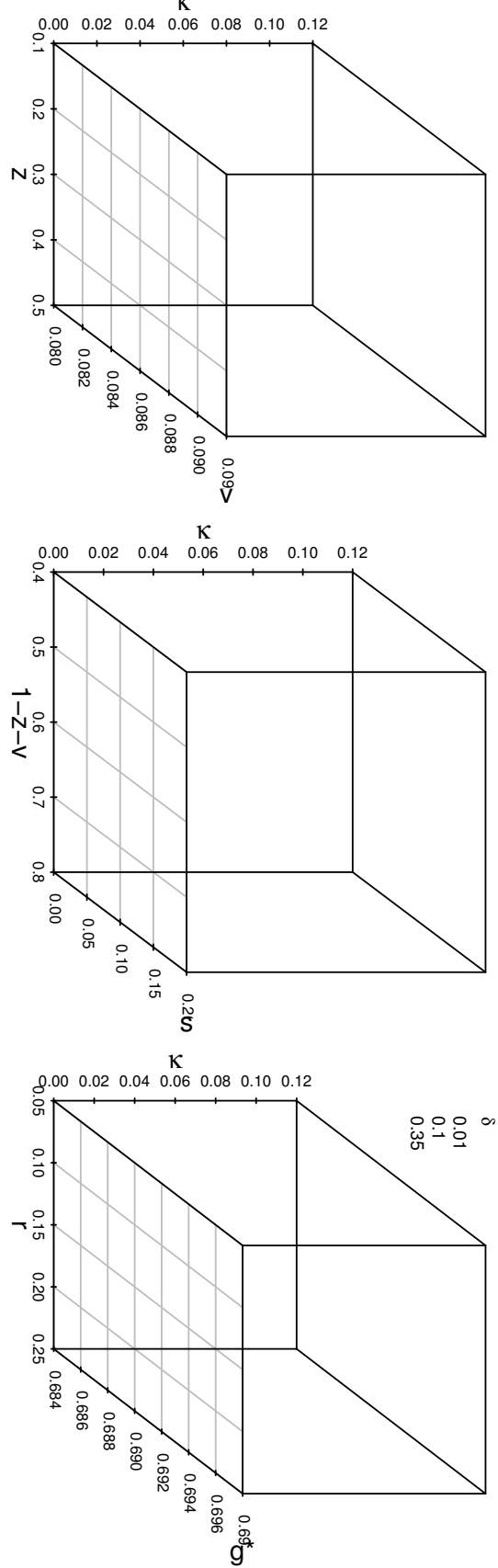
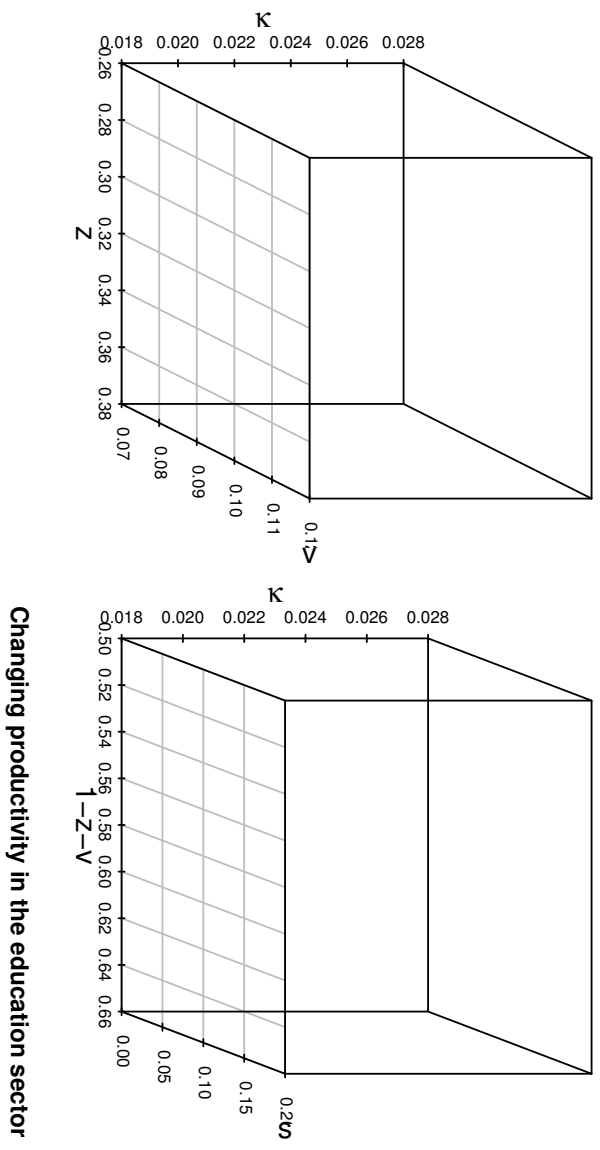

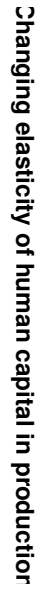

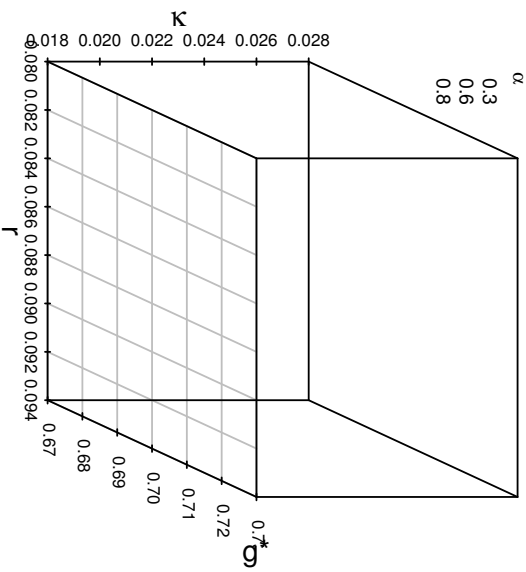

Figure 6.4: Changing $\alpha$ and $\delta$ or $\phi$ 

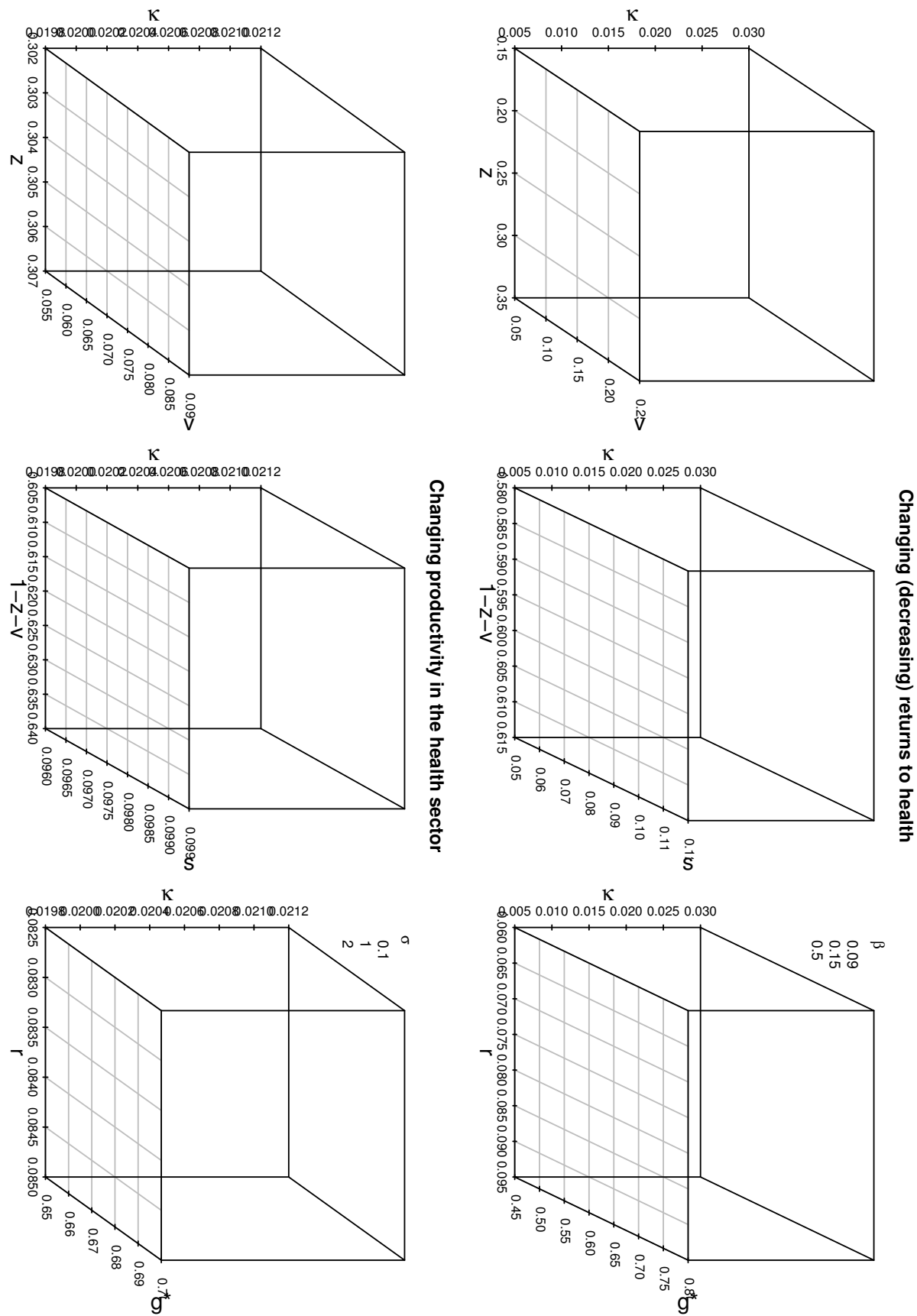

Figure 6.5: Changing $\beta$ and $\sigma$ or $\zeta$ 
Table 6.1: Set of parameter values

\begin{tabular}{crrrr}
\hline $\begin{array}{c}\text { Para- } \\
\text { meter }\end{array}$ & $\begin{array}{r}\text { Minimum } \\
\text { value }\end{array}$ & $\begin{array}{r}\text { Initial } \\
\text { value }\end{array}$ & $\begin{array}{r}\text { Maximum } \\
\text { value }\end{array}$ & $\begin{array}{r}\text { Step } \\
\text { size }\end{array}$ \\
\hline$\rho$ & 0.01 & 0.05 & 0.07 & 0.001 \\
$\theta$ & 1.05 & 2.00 & 5.00 & 0.050 \\
$\alpha$ & 0.30 & 0.60 & 0.80 & 0.010 \\
$\delta$ & 0.01 & 0.10 & 0.35 & 0.010 \\
$\beta$ & 0.09 & 0.15 & 0.50 & 0.010 \\
$\phi$ & & 1.00 & & \\
$\sigma$ & 0.10 & 1.00 & 2.00 & 0.100 \\
$\zeta$ & & 1.00 & & \\
\hline
\end{tabular}

chosen here is 0.05 and for the sensitivity analysis $\rho$ increases from 0.01 to 0.07 in steps of 0.001 . This increase in $\rho$, that is a rise in the preference for present utility over future utility, results in a decreasing long-run savings rate $s$ (by $14 \mathrm{pp}^{12}$ ) as consumption today is valued more than consumption in the future, and a decreasing long-run growth rate $\kappa$ (by $-2 \mathrm{pp}$ ). The share of human capital in the education sector $z$ is cut in half from more than $50 \%$ to $25 \%$, while the share in the production sector increases from $39 \%$ to $67 \%$. The share of human capital in the health sector, $v$, only changes from $10 \%$ to $8 \% . g^{\star}$ is slightly reduced, while $r$ increases by $3 p p$.

\section{Changing $\theta$}

Guvenen (2006) reviews the discussion on the intertemporal elasticity of substitution, $1 / \theta$. Some economists, such as Hall (1988), believe that it is close to zero. Others, however, claim that it is closer to one, with a $\theta=2$ being high according to Lucas (1990). Ortigueira and Santos (1996) choose $\theta=1.5$. Here, the initial value is $\theta=2$, resulting in an intertemporal elasticity of substitution of 0.5. For the sensitivity analysis $\theta$ is increased from 1.05 to 5.0, resulting in a range of 0.95 to 0.2 of the intertemporal elasticity of substitution (IES). This decrease in the IES results in a significantly decreasing share of human capital in human capital production $z$, and a corresponding substantial increase in the share of human capital $(1-z-v)$ in final output production $Y$. An increasing value of $\theta$ furthermore implies a decreasing value of the balanced growth rate $\kappa$, the long-run savings rate $s$ and the steady state health level $g^{\star}$, as shown in the lower three graphs in Figure 6.3 .

In economies/societies where the future is valued higher (as reflected by low values of $\rho$ and $\theta$ ), less labor is employed in final output production and more in the education sector. The propensity to consume is lower, i.e. the savings rate higher and the growth rate is higher as well, compared to economies/societies with a preference for present utility over future utility.

\footnotetext{
${ }^{12} \mathrm{pp}=$ percentage points
} 


\section{Changing $\alpha$}

The relative contribution of healthy human capital to production $Y$ (measured by the partial output elasticity of healthy human capital) is $\alpha$, while the relative contribution of physical capital $K$ is $(1-\alpha)$. In the top plots in Figure $6.4, \alpha$ increases from 0.3 to 0.8 in steps of 0.01 . This range covers the plausible parameter range rather well, as the usual value of $\alpha$ is assumed to be about 0.6 , see for example Ortigueira and Santos (1996) or Steger (2000). Increasing $\alpha$ from 0.3 to 0.8 implies decreasing shares of human capital in both the education and the health sector. A high value of $\alpha$, reflected by the light dots at the lower right end of the curves in the top plots of Figure 6.4, implies that labor is relatively more important than capital in final output production. Lower values of $\alpha$ (moving up the curves from the light dots in the lower corners to the darker dots at the top) imply that labor becomes relatively less important, e.g. when moving from an agricultural based economy to a more capital based economy, the share of human capital (that is the share of labor) employed in the final output sector is lower, while the shares employed in education and health and the long-run health level increase. As the contribution of capital (1- $\alpha)$ grows, the savings rate is higher as well, as is $r$, the rate of return to capital.

\section{Changing $\delta$ or $\phi$}

$\delta$ and $\phi$ are productivity parameters in the education and health sector, respectively. As $\delta$ and $\phi$ only enter growthsys as a product $\delta \phi$, the reaction of the system to changes in either one of these parameters is exactly the same. For this analysis we have normalized $\phi$ to 1 . The reactions induced by changes in $\delta$, as explained below, are also valid for proportional changes in $\phi$. The only difference is the direct proportional impact of $\phi$ on the health level $g^{\star}$.

The higher $\delta$, the higher the productivity in the education sector and the faster the increase in the level of human capital and hence the growth rate. With increasing $\delta$ a higher share $(z)$ of the working population is employed in the education sector, at the expense of the share $(1-z-v)$ of people employed in the production sector. For low values of $\delta$, that is low productivity in the education sector reflected by the light (white-yellow) dots in the lower left/right in the plots in the bottom of Figure 6.4, the share of labor in final output production is high, the savings rate $s$ and the rate of return to capital $r$ are low as is the growth rate $\kappa$. As the productivity in the education sector increases, the share of labor in the other two sectors decreases, resulting in a higher long-run health level. The rate of return to capital and the savings rate increase as well.

\section{Changing $\beta$}

Decreasing returns in the health sector are reflected by $0<\beta<1$. As $\beta$ increases, $v^{\beta}$ decreases (for a constant $v$ ). The share of labor in the health sector $v$ increases from 0.05 to 0.23 as $\beta$ increases from 0.09 to 0.5 . Still, as $\phi$ remains constant, the increase in $v$ does not offset the increasingly decreasing returns in the health sector, so that $g^{\star}=\phi v^{\beta}$ decreases as shown in Figure 6.5. The share of labor in the other two sectors however decreases sharply, as do the savings rate and the 
rate of return to capital. What is not considered here is that $\phi$ also depends on $\beta$. The effect of a changing $\beta$ can therefore be amplified or reduced by its effect on $\phi$.

\section{Changing $\sigma$ or $\zeta$}

$\sigma$ and $\zeta$ influence the variety of products, i.e. a variety of treatment methods or, more genera, the extent of medical knowledge, and the general productivity in the health sector. Just as $\delta \phi, \sigma \zeta$ only enter growthsys as a product, hence inducing the same reactions by the system. In Figure $6.5 \zeta$ is constant at a value equal to 1 , while $\sigma$ increases from 0.1 to 2. The results also apply to $\sigma=1$ and a changing $\zeta$. For low values of $\sigma$, the effect of increasing it by 0.1 is large, as reflected by the large gaps between two consecutive dots in Figure 6.5. For higher values of $\sigma$, the effect becomes much smaller. An increase in $\sigma$ has a positive effect on $\kappa, v, r$ and $g$. The savings rate, and the share of labor in the education and final output sectors on the other hand slightly decrease.

\section{Relative valuation of consumption, education and health}

As for all equilibrium solutions in endogenous growth models, the results displayed here are based on assumptions that are - if at all - only applicable to long-run balanced growth paths. The parameter values chosen for the empirical analysis are based on those found in the literature or they are simply normalized to one as in the case of $\phi, \sigma$ or $\zeta$. As in van Zon and Muysken (2001), a positive correlation between the savings rate $s$ and the balanced growth rate $\kappa$ is apparent, confirming the necessary increase in the savings rate to keep the capital-output ratio at a constant level in order to sustain higher growth. This model does not confirm the negative correlation that van Zon and Muysken (2001) found between the share of human capital in education $z$ and in health $v$ as displayed in Table 1 on p. 180 of van Zon and Muysken (2001). This can be explained by the main difference of the model presented here to the van Zon and Muysken model, which is the inclusion of education in the utility function. This inclusion reflects a higher valuation of both the quality of human capital $h$ and the quantity of human capital $z$, which makes $z$ relatively more important in the model. We have a negative correlation between labor in the health sector $v$ and labor in the final output production sector $(1-z-v)$. When changing the relative preferences of the different components in the utility function, i.e. the $\gamma^{\prime}$ 's as displayed in Table 6.3, changes in $\gamma_{z}$ have a higher impact on the overall system than changes (of the same order) in the other variables, as will be explained in the next paragraphs. The share of labor in the education sector is positively correlated with the growth rate and the savings rate, underlining the importance of a good education for sustainable long-run growth. The share of labor in the health sector is positively correlated with the long-run growth rate as long as the decreasing returns in the health sector are maintained.

Table 6.3 displays equilibrium results of this model for different specifications of the relative contribution of consumption, education and health in the utility function. The upper part of the table shows how the model outcomes change when increasing the relative contribution of education and health from values close to zero to values that are slightly higher than their initial values. The relative valuation of education and health remains the same. At first the relative contribution 
Table 6.2: Responses to parameter changes

\begin{tabular}{cccccccc}
\hline & $\kappa$ & $z$ & $v$ & $1-z-v$ & $s$ & $r$ & $g^{\star}$ \\
\hline$\rho$ & - & - & - & + & - & + & - \\
$\theta$ & - & - & - & + & - & + & - \\
$\alpha$ & - & - & - & + & - & - & - \\
$\delta$ or $\phi$ & + & + & + & - & + & + & + \\
$\beta$ & - & - & + & - & - & - & - \\
$\sigma$ or $\zeta$ & + & - & + & - & + & + & + \\
\hline
\end{tabular}

of consumption to intertemporal utility is almost one, hence resembling a common assumption of endogenous growth models. The corresponding growth rate is very low, as are the shares of labor in both education and health sector. More than $90 \%$ of the population is working in final output production and the propensity to consume $q$ is very high, resulting in a savings rate $s$ of only $2.9 \%$. The return to capital is relatively low, as is the health level $g^{\star}$. As education and health contribute more to intertemporal utility, the corresponding labor shares, the growth rate $\kappa$, the savings rate, the rate of return to capital and the health level increase significantly. Labour in final output production decreases with the relatively lower contribution of consumption to utility.

In the second part of the table the relative contribution of consumption to utility also decreases from values close to one to one third, while the relative contributions of education $\left(\gamma_{z}+\gamma_{h}\right)$ and health $\left(\gamma_{g}\right)$ are equal and increase from values close to zero to one third. For $\gamma_{h}=\gamma_{z}=0.005$ and $\gamma_{g}=0.01$ the growth rate $\kappa$ is less than $0.3 \%$ and savings rate $s$ and health level $g^{\star}$ are very low as well, with values of $2 \%$ and 0.49 , respectively. $6 \%$ of the population are busy with human capital production $(z)$ and less than one percent is employed in the health sector $(v)$. As the relative contribution of education and health to utility rise, so do the corresponding labor shares. When $\gamma_{h}+\gamma_{z}=\gamma_{g}=\gamma_{c}=1 / 3$ (the last row in the second part of Table 6.3) the growth rate amounts to almost $4 \%$, and the savings rate, the rate of return to capital and the value of the health level are substantially increased as well. The share of labor in education and health have increased by a factor 10 or more, while the share of labor in final output production dropped from $93 \%$ to $35 \%$. It should be noted, that an equal valuation of education, health and consumption, as suggested by the weighting scheme of the HDI, implies a labor share of more than $50 \%$ in the education sector, while the share of labor in the health sector remains unchanged (at about 8 to $9 \%$ ) compared to the initial relative contributions $\gamma_{c}=0.6, \gamma_{h}=\gamma_{z}=0.05$ and $\gamma_{g}=0.3$. A relatively higher contribution of education and a relatively lower contribution of consumption to utility result in a distribution of labor across sectors that cannot be observed in the real world ${ }^{13}$. However, if the valuation of $1 / 3,1 / 3,1 / 3$ as suggested by the

\footnotetext{
${ }^{13}$ For example, the sum of labor in the German education (2.3 million) + R\&D sector (0.2 million excluding researchers employed in private industrial enterprises or businesses) + the part of the population (above the age of 10) that is currently educated (11 million) is about $29 \%$ of the total population that is working or in education (36 million +11 million). The number of persons employed in the German health sector is 4.5 million and, thus, about $9.6 \%$ of the total population that is working or in education. Employment data for 2010 published in the
} 
Table 6.3: Relative valuation of consumption, education and health

\begin{tabular}{rrrrrrrrrrrrrr}
\multicolumn{2}{c}{ Increasing } & \multicolumn{10}{c}{$\gamma_{h}, \gamma_{z}$ and $\gamma_{g}$ to their equilibrium levels } \\
$\gamma_{c}$ & $\gamma_{h}$ & $\gamma_{z}$ & $\gamma_{g}$ & $\kappa$ & $z$ & $v$ & $1-z-v$ & $s=(1-q)$ & $r$ & $g^{\star}$ \\
0.960 & 0.005 & 0.005 & 0.030 & 0.0043 & 0.0794 & 0.0156 & 0.9049 & 0.0292 & 0.0584 & 0.5360 \\
0.920 & 0.010 & 0.010 & 0.060 & 0.0072 & 0.1244 & 0.0260 & 0.8496 & 0.0451 & 0.0639 & 0.5784 \\
0.840 & 0.020 & 0.020 & 0.120 & 0.0112 & 0.1806 & 0.0419 & 0.7775 & 0.0633 & 0.0709 & 0.6214 \\
0.680 & 0.040 & 0.040 & 0.240 & 0.0178 & 0.2644 & 0.0709 & 0.6647 & 0.0882 & 0.0806 & 0.6723 \\
0.600 & 0.050 & 0.050 & 0.300 & 0.0210 & 0.3030 & 0.0859 & 0.6111 & 0.0991 & 0.0846 & 0.6919 \\
0.450 & 0.100 & 0.100 & 0.350 & 0.0306 & 0.4369 & 0.0935 & 0.4696 & 0.1257 & 0.0975 & 0.7008
\end{tabular}

Increasing $\gamma_{h}, \gamma_{z}$ and $\gamma_{g}$ : equal importance of education and health

$\begin{array}{rrrrrrrrrrr}\gamma_{c} & \gamma_{h} & \gamma_{z} & \gamma_{g} & \kappa & z & v & 1-z-v & s=(1-q) & r & g^{\star} \\ 0.980 & 0.005 & 0.005 & 0.010 & 0.0029 & 0.0593 & 0.0084 & 0.9322 & 0.0208 & 0.0558 & 0.4887 \\ 0.960 & 0.010 & 0.010 & 0.020 & 0.0056 & 0.1048 & 0.0149 & 0.8803 & 0.0366 & 0.0610 & 0.5320 \\ 0.920 & 0.020 & 0.020 & 0.040 & 0.0089 & 0.1576 & 0.0223 & 0.8200 & 0.0530 & 0.0673 & 0.5654 \\ 0.840 & 0.040 & 0.040 & 0.080 & 0.0137 & 0.2295 & 0.0324 & 0.7381 & 0.0724 & 0.0758 & 0.5979 \\ 0.680 & 0.080 & 0.080 & 0.160 & 0.0217 & 0.3420 & 0.0481 & 0.6099 & 0.0984 & 0.0882 & 0.6343 \\ 0.333 & 0.167 & 0.167 & 0.333 & 0.0395 & 0.5766 & 0.0809 & 0.3425 & 0.1447 & 0.1093 & 0.6857\end{array}$

\begin{tabular}{|c|c|c|c|c|c|c|c|c|c|c|}
\hline$\gamma_{c}$ & & $\gamma_{z}$ & $\gamma_{g}$ & $\kappa$ & $z$ & $v$ & $1-z-v$ & $s=(1-q)$ & $r$ & $g^{\star}$ \\
\hline .333 & 0.328 & 0.005 & 0.333 & 0.0333 & 0.4972 & 0.0696 & 0.4332 & 0.1265 & 0.1054 & 0.6705 \\
\hline .333 & 0.323 & 0.010 & 0.333 & 0.0336 & & 01 & & & & 6712 \\
\hline 0.333 & 0.313 & 0.020 & 0.333 & 0.0342 & 0.5083 & 0.0711 & & & & 6727 \\
\hline 0.333 & 0.293 & 0.040 & 0.333 & 0.0352 & 0.52 & 0.0729 & & & & 6752 \\
\hline 0.333 & 0.253 & 0.080 & 333 & 0.0369 & & 0.0760 & & & & 6794 \\
\hline & 0 . & & & & & & & & & \\
\hline & & & & & & & & & & 901 \\
\hline 0.333 & 0.040 & 0.293 & 333 & 0.0421 & 0.6082 & 0.0856 & 0.3062 & & 0.1 & 0.6916 \\
\hline 0.333 & 0.020 & 0.313 & 333 & 0.0424 & 0.6119 & 0.0862 & 0.3020 & 1579 & 0.1073 & 0.6923 \\
\hline 0.333 & 0.010 & 0.323 & 0.333 & 0.0425 & 0.6136 & 0.0865 & 0.2999 & & 0.1071 & 0.6927 \\
\hline 0.333 & 0.005 & 0.328 & 0.333 & 0.0426 & 0.6144 & 0.0866 & 0.2990 & 0.1592 & 0.1070 & 0.6928 \\
\hline
\end{tabular}

HDI was indeed correct, that is education and health were equally important as consumption, the current distribution of labor is far from optimal. In fact, more resources should be allocated to human capital production and health. This result is confirmed by the empirical findings in Chapter 4 and 5 .

The lower part of Table 6.3 assumes an equal valuation of consumption, education and health as has just been discussed. To identify which of the two education variables, the quality-related level of human capital $h$ or the quantity-related share of the working population busy with human capital production $z$, brings about the changes in the labor distribution, $\gamma_{h}$ drops from $(1 / 3-0.005)$ to 0.005 , while $\gamma_{z}$ increases from 0.005 to $(1 / 3-0.005)$. The effects on all model outcomes, but the share of labor in final output production, are positive. This means that a higher valuation of education quantity ${ }^{14}$ relative to education quality increases the number of people occupied with human capital production and health generation, and

System of National Accounts, DESTATIS (2011) and data on education for 2008 is published in BMBF (2010). The corresponding shares in African developing countries are very likely to be significantly lower than that.

${ }^{14}$ Recall that this does not only include teachers, but also everyone else who is devoted to human capital production ranging from primary and high school students to doctoral candidates and researchers in the $\mathrm{R} \& \mathrm{D}$ sector. 
implies a higher growth, savings and return to capital rates as well as a higher value of the health level. This result corresponds to Millennium Development Goal 2 Target 2 A: Ensure that, by 2015, all children everywhere, boys and girls alike, will be able to complete a full course of primary schooling.

\subsubsection{Transitional dynamics}

Steger (2000) emphasizes the importance of interpreting the development of a country as its transition toward the steady state. Jonathan Temple (2003, p. 509) regarding the same issue (also cited in Trimborn et al. (2006)): "Ultimately, all that a long-run equilibrium of a model denotes is its final resting point, perhaps very distant in the future. We know very little about this destination, and should be paying more attention to the journey."

The analysis of transitional dynamics in this extended version of the Lucas model is based on an algorithm provided by Trimborn et al. (2008) and implemented in Mathematica by Manuel Bichsel (2011). For the calculations the system of ten growth equations (6.11) to (6.20) is reduced to a system in six variables, which are the state variables $K, h$ and $g$ and the control variables $c, z$ and $v$. This dynamic system is then first transformed into its reduced form and then into its equivalent scale adjusted form, which describes the evolution over time of the growth rates relative to their long-run growth values.

The values for an equilibrium balanced growth path solution, from now on called BGP solution, were chosen given the results for the long run equilibrium analysis of the previous section, that is the initial parameter values displayed in Table 6.1. The values chosen for the remaining model variables are normalized to one, with the exception of the growth rate of technology $\hat{A}$ and the exogenous population increase $\hat{n}$, which are set to zero. Note that from growthsys (as defined on p. 107) we obtain $\kappa^{\star}, z^{\star}, v^{\star}$ and $q^{\star}$. From Equations (6.23) and (6.24) we have values for $r^{\star}$ and $g^{\star}$. Physical capital $K$ is normalized to 1 . Initial values for $h$ and $c$ can then be calculated by combining equations for the rate of return to capital $r=(1-\alpha) Y / K$ and the propensity to consume $q=c L / Y$.

This BGP solution has two stable (negative) eigenvalues and one equal to zero, or at least very close to zero, as is common for scale adjusted systems (Steger, 2011): $\quad \lambda_{K}=1.0465, \quad \lambda_{h}=-1.01712, \quad \lambda_{g}=0.175334, \lambda_{c}=-0.0920515, \lambda_{z}=0.0596788$, $\lambda_{v}=3.02041 * 10^{-8}$.

To visualize the transition path, the initial values of the state variables have been set equal to fractions of their BGP solution. These fractions are $0.01,0.1$ and 0.5 for capital $K$, and $0.3,0.5$ and 0.7 for human capital $h$ and health level $g$. As it is very unlikely that only one of the variables is out of its long run equilibrium, a more thorough analysis is conducted for a joint shock on $K, h$ and $g$ and the corresponding transition paths are displayed in Figures 6.6 through 6.7. The analysis of the individual shocks can be found in Appendix B.5, which serves the purpose of identifying the individual effects. For all shocks it proved to be the case that those variables that have definite long run equilibrium values, such as $g, z, v, s$ and $r$ always converge to their respective values. For the remaining variables we have observed that their growth rates converge to the corresponding long run balanced growth rate $\kappa$. In addition, the transition paths of the present 

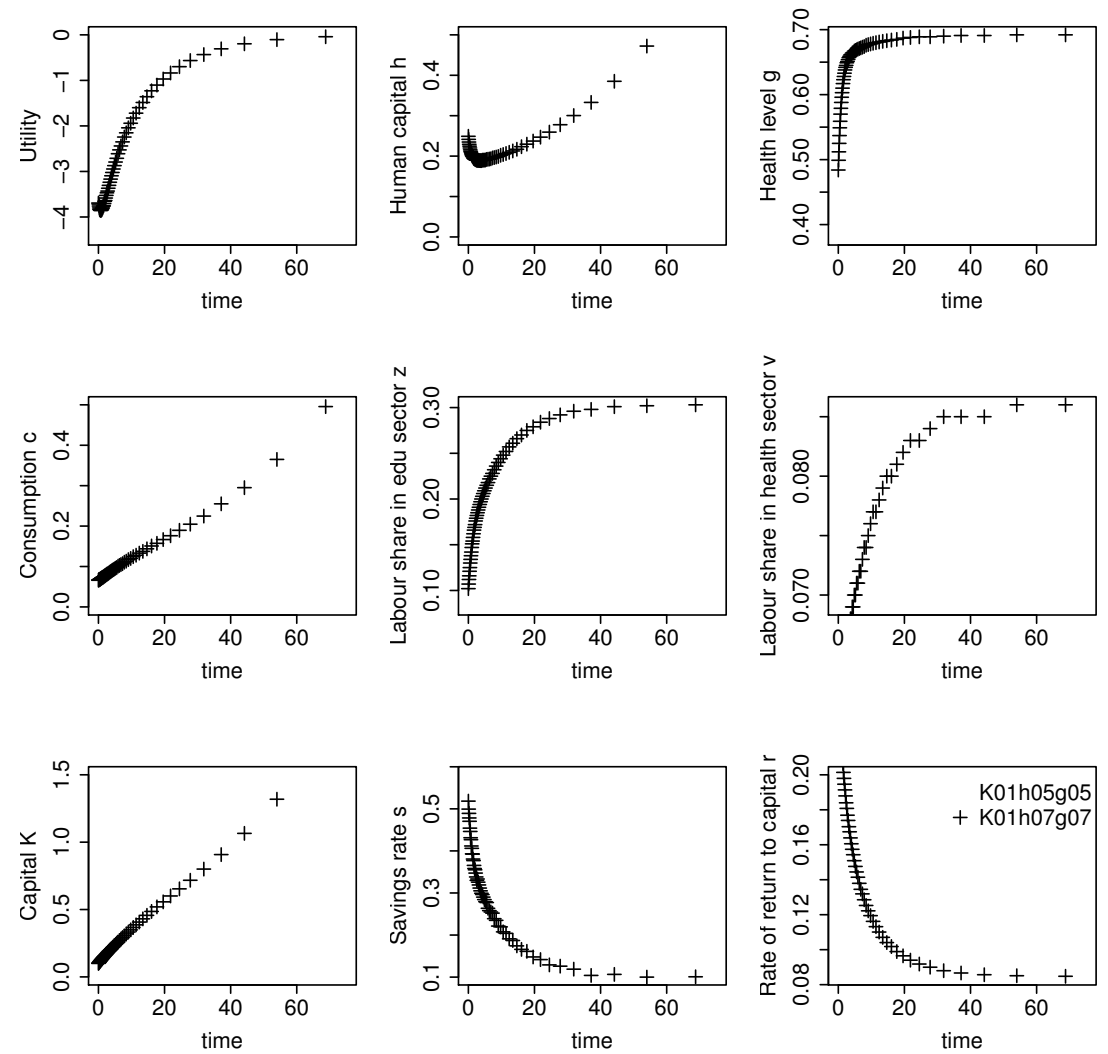

Figure 6.6: Shocking K, h and g

value of instantaneous utility $u=e^{-\rho t} L /(1-\theta)\left[c^{\gamma_{c}} h^{\gamma_{h}} z^{\gamma_{z}} g^{\gamma_{g}}\right]^{1-\theta}$ are displayed.

In case of developing countries, all physical and human capital as well as the health status of the population are far below something that could be a long run equilibrium. The discussion in Steger (2000) clearly shows that his stylized facts of economic growth in developing countries could be modeled as being part of the transition process toward the long-run equilibrium.

Figures 6.6 and 6.7 show the transition paths of an economy, which has very low initial levels of physical capital, human capital and health, toward the future balanced growth equilibrium. For the African developing countries the current state of the European countries could be seen as this future resting point of the economy. The 'shocks' chosen for this exercise are a value of capital $K$ of 0.1 of the BGP solution value (which was normalized to one), a human capital endowment of 0.5 or 0.7 , which is about the ratio of the share of literate people in African countries to literate people in Europe ${ }^{15}$. Life expectancy in Europe is about 80

\footnotetext{
${ }^{15}$ The median share of literate people in Sub-Saharan Africa over the past three decades, as shown in row LITR in Table 3.2 on p. 25 is $58 \%$. Literacy in Europe is almost $100 \%$, so that choosing $0.5=50 \% / 100 \%$ and $0.7=70 \% / 100 \%$ seems to be an appropriate approximation of the
} 
years, compare Figure 3.1 on p. 26, while that in Sub-Saharan Africa only is about 50 years, resulting in a ratio of 0.6 . Hence, for the initial health level the two fractions we have chosen values $g_{0}=0.5 g^{\star}$ and $g_{0}=0.7 g^{\star}$. Results are displayed for two cases: case 0.5 , with fractions of the BGP solution values 0.1 for $K$ and 0.5 for both $h$ and $g$, and case 0.7 , with 0.1 for $K$ and 0.7 for both $h$ and $g$. Figure 6.6 plots the transition paths for both cases 0.5 (K01h05g05, circles) and 0.7 (K01h07g07, plus-signs).

Using the algorithm of Trimborn et al. (2008) it is possible to rescale the transition path to reflect actual time. Figure 6.6 displays the first 75 years of the transition phase on the horizontal axis, as most of the adjustment takes place during this period. The health level (top right plot) strongly increases from the start, resulting in an initial decrease in the level of human capital (top center plot). The reason is the very low health level, which directly influences the rate of human capital accumulation. For values of $g$ that reduce the overall input in the education sector $\delta z g$ to values relatively lower than the rate of health increase, the level of human capital (that is the quality indicator of education) decreases even further. Only for a sufficient level of average health $g$ combined with a higher share of the population involved in human capital accumulation $z$, an actual increase in average human capital $h$ is possible, compare Equation 6.13.

Both labor shares in education and health increase toward their steady state values, somewhat slower for the smaller shock, that is higher initial values $(0.7)$ for $h$ and $g$, marked by the plus-signs in Figure 6.6. The share of the population involved in human capital accumulation increases strongly. Recall that this result relates to MDG 2, which targets a $100 \%$ primary school enrollment rate, indicating the need for more education. Both the savings rate and the rate of return to capital are very high initally and then decrease toward their steady state values, again at a slower rate for the 0.7 case.

For low levels of capital, investment returns are usually high as the capital stock increases. For countries with high capital stocks, the return to capital is lower reflecting decreasing marginal returns to capital. High capital returns tend to induce high savings rates, which is also the case here. Still, when following Steger's line of argumentation (Steger, 2000), saving is not possible for consumption levels below subsistence consumption. However, in this model the effect of the capital shock dominates the effect of education and health shocks, which induce negative saving rates.

Consumption $c$ and capital $K$, displayed in the center and bottom plots of the left column, grow from the start. While capital accumulation is initially very high and then slows down after about the first five years, consumption only increases slowly at first. Instantaneous utility is derived from consumption, education quality $h$ and quantity $z$ and the health level. The initial decline in human capital per capita has a significant influence on instantaneous utility as can be seen from the top left plot in Figure 6.6. However, as soon as human capital accumulation increases again, utility follows. In contrast to the result of the sensitivity analysis in Table 6.3 in the previous section regarding the relative valuation of consumption, both education indicators and health (where $h$ only had a limited impact on the long run growth rate), $h$ does have a significant impact on utility, as can be seen

possible range. 
here.

The two plots at the top of Figure 6.7 display the transition paths toward the long-run constant consumption-output-ratio $q$ and the long run constant capitaloutput ratio $(1-\alpha) / r$. The different shades of gray indicate the time, the first years in light gray, then getting darker. For both cases 0.5 and 0.7 output is relatively higher than both consumption and capital. The long run growth trajectories, i.e. the straight lines, are reached from below, indicating that most effort is put into building up the capital stock. However, the immediate increase in health is even stronger, which reduces both human capital and physical capital endowments per capita as the population growth is too high ${ }^{16}$.

This effect is displayed in the graph in the middle of Figure 6.7, which shows the movements of human capital (circles and plus signs) and per capita physical capital (dots and stars) relative to the average health level. Per capita endowments of both types of capital first decline as the health level increases, but then start increasing toward the long-run growth trajectory (which in this case is horizontal as we assumed a constant long-run health level). For human capital the turning point is very close to the long run health level indicating the importance of a good health for education and hence productive human capital.

The lower two graphs in Figure 6.7 display the evolution of the labor shares over the first 50 years. At that point in time the deviation from the long run equilibrium values is less than $1 \%$ for both initial values 0.5 and 0.7 of health and education. The labor shares are only $8.2 \%$ and $10.2 \%$, respectively, for education at the start, and $7 \%$ and $6.1 \%$, respectively for education. In the 0.5 case, the labor share in health is actually higher in the beginning than in the 0.7 case. This is because labor is immediatly allocated to the health sector in order to increase health if the initial health level is insufficient. This stresses the importance of a sufficiently high health level of the population for achieving growth in the other sectors.

Analyzing the entire transition path provides valuable insights into the dynamics of the modeled economy. Whether, and if so, how these dynamics change with the underlying parameters is an interesting question, which is left for future research.

\subsection{Model implications and future research}

Endogenous growth models are a standard way of analyzing a country's long term development. This chapter has introduced a growth model that is in line with current discussions on the measurement of the welfare of nations. Both Stiglitz et al. (2009) and OECD (2011) emphasize the importance of considering non-monetary development issues such as education and health in addition to the standard economic measures such as GDP or its growth rate. The growth model developed here extends the model of van Zon and Muysken (2001), which is based on the Lucas-Uzawa model of human capital accumulation, by including both health and education next to consumption in the utility function. This explicit consideration results in a relatively high share of the population in the education sector as can

\footnotetext{
${ }^{16}$ Recall that total population directly depends on the health status: $L=n \mu g$.
} 


\section{Long run propensity to consume}

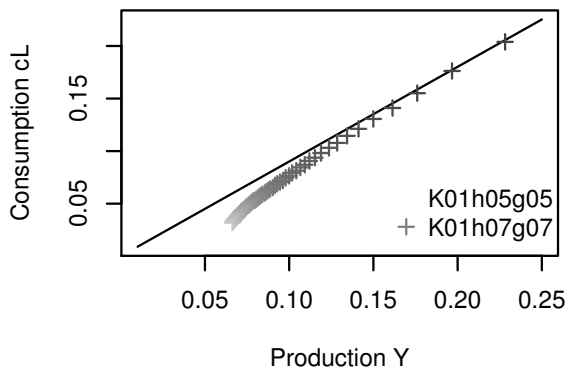

\section{Long run return to capital}

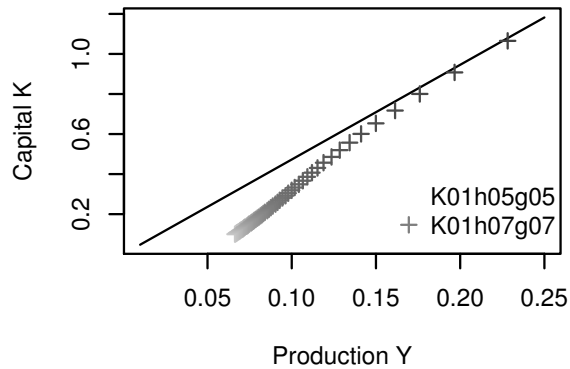

Transition to steady state health level

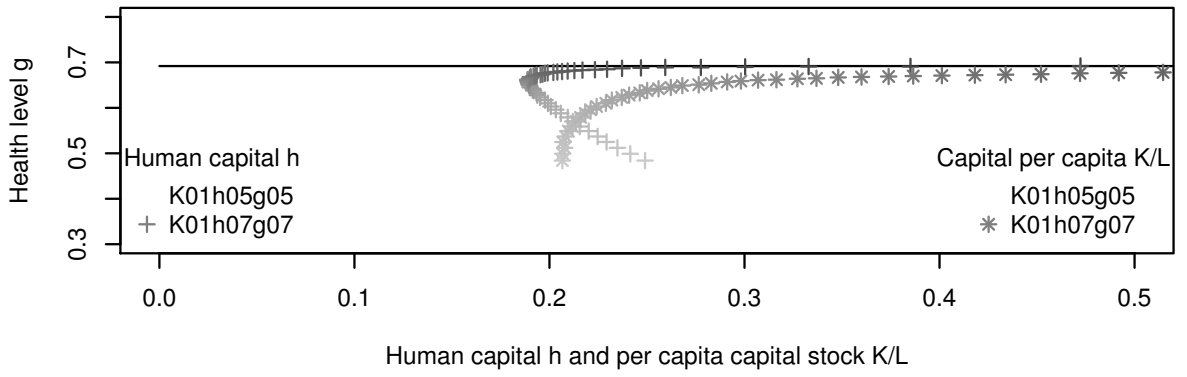

Labour shares: K01h05g05

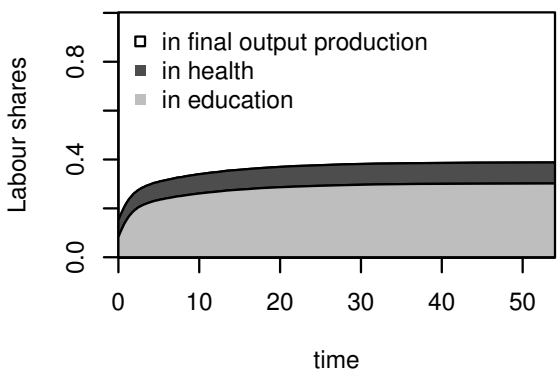

Labour shares: K01h07g07

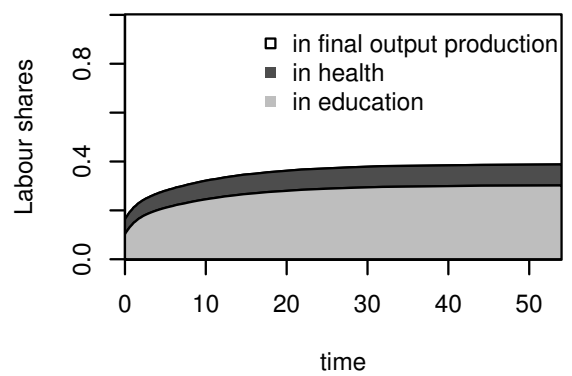

Figure 6.7: Shocking K, h and g: Transition paths 
be seen from the sensitivity analysis of the long run balanced growth situation with regard to various parameter combinations. During the transition process the importance of health and education is clearly visible. Without an adequate health level there is a constraint on the availability of productive labor. Only when the population is sufficiently healthy, human and physical capital endowments per person can increase. This shows that even though health and both education and economic growth are complementary in the long run, they are substitutes in the short run. This result also shows the importance of further empirical investigation, such as the analyses in Chapter 4 and 5, using longer time series to identify short run and long run complementary development processes and development policies.

The actual transition paths of the economy depend on the parameter constellation, which implies the actual production technologies, health provision and education systems, and the initial conditions. The analysis of the transitional dynamics in this chapter shows the working principles of this model, but leaves the investigation of development trajectories corresponding to other parameter combinations for future research. The immediate reactions of the system are very strong, that is the predicted immediate convergence process is very fast. This may, however, result from the underlying optimality assumption in this optimum growth model. Still, this shows that the model is not yet able to replicate all stylized facts of economic growth in developing countries that were introduced in the introduction to this chapter. There is no positive relation between the growth rate and the level of per capita income, i.e. there is no $\beta$-divergence for low levels of per capita income (stylized fact 3). As the economy approaches the long run balanced growth path (BGP), growth rates slow down, so that stylized fact 4, $\beta$-convergence for higher income levels, is modeled here. Stylized facts 1 and 2, a considerable diversity of growth rates and a positive correlation between savings rate and per capita income cannot directly be observed from the two transition paths analyzed here.

Future research should include an analysis of the model dynamics for different parameter specifications, as has been done for the steady state. A further idea is to also introduce the concept of subsistence consumption into the model as suggested by Steger (2000). In addition, relating to the area of future research introduced in Chapter 7, the model could be extended to include the provision of energy as well. 


\section{Chapter 7}

\section{Concluding remarks}

Sustainable development is multi-dimensional in multiple dimensions: time, location and aspects of life. This work has developed and applied different quantitative economic methods to comprehensively analyze the interdependencies between different aspects of development: living standards/income, education and health. The short answer to the main research question is

There is a positive mutual reinforcement between education and health outcomes. Furthermore, decent education and good health are necessary conditions for economic development and, hence, for overall human development.

This answer is not only the interpretation of the results of a single chapter, but summarizes the overall finding of this thesis.

\subsection{Summary of the main findings}

The descriptive analysis of development in Sub-Saharan Africa in Chapter 3 showed that despite the good progress that has been made over the past decade, the level of development is still very low in many African countries. Most Sub-Saharan African countries will not achieve all of the Millennium Development Goals that have been set by the United Nations General Assembly in 2000. However, this should not lead to the conclusion that there was no progress at all or that the MDGs are unfair to Africa, rather, as stressed in Chapter 2, without setting such goals no clear development targets are identified and thus no clear development policy measures can be implemented. By setting these goals the UN provided development targets that all countries should and do strive for.

Chapter 4 builds on the data introduced in Chapter 3. Using econometric complementarity analysis a mutually reinforcing relation between health and educational aspects has been identified. The underlying econometric complementarity model had to be extended to also include a partial adjustment model to account for the apparent deviation from the optimal development path. The indicators used are the under-5 mortality rate (representing health outcomes) and the primary school completion rate (representing educational outcomes). The relation of 
these two indicators to the economic dimension of development, measured using GDP per capita, household consumption expenditures per capita and total primary energy consumption per capita, remained unclear. Still, the results clearly show that development policies that aim at fostering both education and health outcomes will have a higher effect on a country's overall development than policies aiming to improve either education or health individually.

This result directly leads to the question which policy options there are to boost educational achievements and improve health, especially for local policy makers. As the political situation in the individual African countries is very different, the aim here was not to suggest detailed policy measures. Instead Chapter $\mathbf{5}$ takes a macro-economic approach to detect policy options by identifying the optimal allocation of the government budget to maximize overall development measured by the Human Development Index. The efficient development portfolio approach developed here builds on Markowitz' optimal portfolio theory. The approach consists of three steps: estimating the effect of public spending on the development outcomes GDP per capita, education and health to get the variance-covariance matrix of the parameter estimates, calculate the expected overall development outcome and solve the optimization problem taking into account the uncertainties associated with the effect of public spending on these outcomes for different degrees of risk aversion. The results show that in most African countries the government budget is not allocated efficiently. These inefficiencies mostly arise from too little spending on health and education, resulting in a necessary reallocation of public spending of up to $20 \%$ of the government budget toward these two spending categories. Additionally, an increase in total government spending, especially at low levels, has a significant positive impact on development measured with the HDI.

Chapter 6 complements the analysis of interdependencies between the different development aspects by investigating the long-run development trajectories of economies in an endogenous growth model setting. The results of the previous chapters clearly stressed the importance of considering both health and education when assessing the welfare of a country's population. The growth model developed in Chapter 6 incorporates these findings by including health, education and consumption in the utility function. The sensitivity analysis of the long-run solution shows that the relative valuation of health and education in the utility function has a significant impact on the relative importance of the different sectors in the economy. The dynamic transition path of an economy that starts off with low physical and human capital endowments and a low health status, illustrates the necessity of a good health for the accumulation of both types of capital. The dynamics in the theoretical model still need to be analyzed for different constellations of the parameter settings that account for country differences.

This thesis showed to working principles of the different quantitative models that have been developed in the previous chapters. These models can be used to assess sustainable development not only in Africa, but also in other regions. The empirical application of the methodologies to other regions will most likely be easier as more data exists and the quality of data is better. 


\subsection{Suggestions for future research}

The analysis of the interdependencies between different aspects of sustainable development has - for the most part - left aside the environmental dimension, that is resource extraction, pollution and climate change. An area that closely links living standards and economic production with environmental issues is energy. Total primary energy consumption was used as an indicator for living standards in the empirical analysis of Chapters 3 and 4. Energy consumption in most African countries is very low, as are green house gas emissions. One exception is the emerging economy South Africa with its strong economic growth and associated high increase in energy demand. Electricity production in South Africa is mostly coal based, so that the per capita carbon emissions produced in South Africa are comparable to those in the industrialized countries.

The current global discussion relating to energy is centered around two main issues: first, the discussion on a fair burden sharing of the reduction of greenhouse gas emissions and, second, on the widespread energy poverty in developing countries. During the climate conference in Durban in December 2011, the African representatives emphasized the importance of a global climate agreement as their countries are the ones that are most strongly (and negatively) affected by a changing climate: droughts, as in Ethiopia in 2011, increase the vulnerability of the very poor even further because of the resulting food shortages and agricultural based earning possibilities, leading to a resettlement of the population. Storms and floods may completely destroy the already weak infrastructure, cutting off transportation routes and leaving households without clean water and/or electricity. Energy is necessary for cooking, for using refrigerators, for providing light at night to read and write and study, for fast(er) transportation to schools and hospitals, for using a computer and participating in the global information society. Millions of people still lack access to modern electricity ${ }^{1}$. The only possibility to provide the global population with energy is to use decentralized renewable energy sources. 2012 is the year of 'Sustainable energy for all'. Ban Ki-moon, Secretary-General of the United Nations, also emphasizes the importance of this subject ${ }^{2}$ :

"Some argue that in times of economic uncertainty, sustainability is a luxury we cannot afford. I say that we cannot afford to wait. Science and economics reach the same conclusion: advancing economic growth, lifting people out of poverty and protecting our planet are all part of the same agenda: the sustainable development agenda. What connects them is energy. Sustainable energy for all is an idea whose time has come. Turning ideas into action depends on us all."

There is still lots of research to do be done to find out about the quantitative links between the social and economic issues discussed in this work with the emerging issues sustainable energy, environmental protection and climate compatible development, i.e. mitigation and adaptation.

\footnotetext{
${ }^{1}$ http://www.sustainableenergyforall.org/about

${ }^{2}$ January 17, 2012: Powering sustainable energy for all http://www.beta.undp.org/content/ undp/en/home/ourperspective/ourperspectivearticles/2012/01/17/powering-sustainable-energy -for-all-ban-ki-moon.html.
} 
Including these environmental issues in the empirical and theoretical models developed and presented in this thesis gives rise to methodological challenges. As mentioned in Chapter 4, including one more dimension into the complementarity model results in six restrictions instead of a single restriction on the complementarity coefficients. Similarly, the calculation of the efficient development portfolio variance in Chapter 5 and the optimization problem in the theoretical growth model in Chapter 6 become disproportionately more complicated. There exist basically two options to tackle this challenge: either extend the existing models to include more than three dimensions and cope with the mathematical problems that might arise from the higher-dimensionality, or restrict the number of development aspects that are simultaneously analyzed to three and select only those aspects that are of interest for the analysis. One possibility to include more than three individual development aspects in the latter option is to define three broad aspects of development, e.g. economic, social and environmental development, that represent the more detailed aspects, i.e. production and consumption (economic), health and education (social), and energy use, resource use and pollution (environmental). 


\section{Appendix A}

\section{Mathematical appendix to Chapter 5}

\section{A.1 Derivation of the EDP FOC's}

In this appendix to Chapter 5 the first order conditions (FOC's) of the maximization problem, including the expression for the development portfolio variance, are derived. Firstly, errors in $D$ can only be caused by errors in $t$. Hence, from Equation (5.13) we have that

$$
\varepsilon^{D}=w^{\prime} \varepsilon^{t}=i^{\prime} \varepsilon^{t} / T,
$$

with $i$ being a vector of ones. Moreover, assuming that we know both $y$ and $x$ with absolute certainty ${ }^{1}$, it follows from Equation (5.14) that:

$$
\begin{aligned}
\varepsilon^{t} & =t-\hat{t}=(J y+K x)-(\hat{J} y+\hat{K} x) \\
& =(J-\hat{J}) y+(K-\hat{K}) x=\varepsilon^{J} y+\varepsilon^{K} x .
\end{aligned}
$$

Note that this equation assumes that there are no measurement errors in $x$ or implementation errors in $y$ nor any other (forecast) errors. Using Equation (A.1), the variance in the HDI is given by:

$$
\begin{aligned}
V(D) & =E\left[\varepsilon^{D}\left(\varepsilon^{D}\right) \prime\right]=E\left[i^{\prime} \varepsilon^{t} \varepsilon^{t} / i / T^{2}\right] \\
& \left.=i^{\prime} E\left[\varepsilon^{t} \varepsilon^{t}\right]\right] i / T^{2}=\sum_{i=1}^{T} \sum_{j=1}^{T} E\left[\varepsilon_{i}^{t} \varepsilon_{j}^{t}\right] / T^{2},
\end{aligned}
$$

In Equation (A.3) $\varepsilon_{j}^{t}$ is the j-th element in the error-vector $\varepsilon^{t}$, i.e. it represents the error (the deviation from expectation) in target variable $j$. From Equation (A.2)

\footnotetext{
${ }^{1}$ The assumption that we know $y$ with certainty is always valid as policy makers set the amount of government spending. However, it is possible that $x$ cannot be known with complete certainty due to measurement errors or something similar in which case we would also have to include the variation in $x$ in the calculation of $\varepsilon^{t}$. Even though it is relatively straight forward to include this source of variance (by means of a linearization of the term $K x$ in Equation (A.2) around its expected value), we have not done this here for reasons of simplicity.
} 


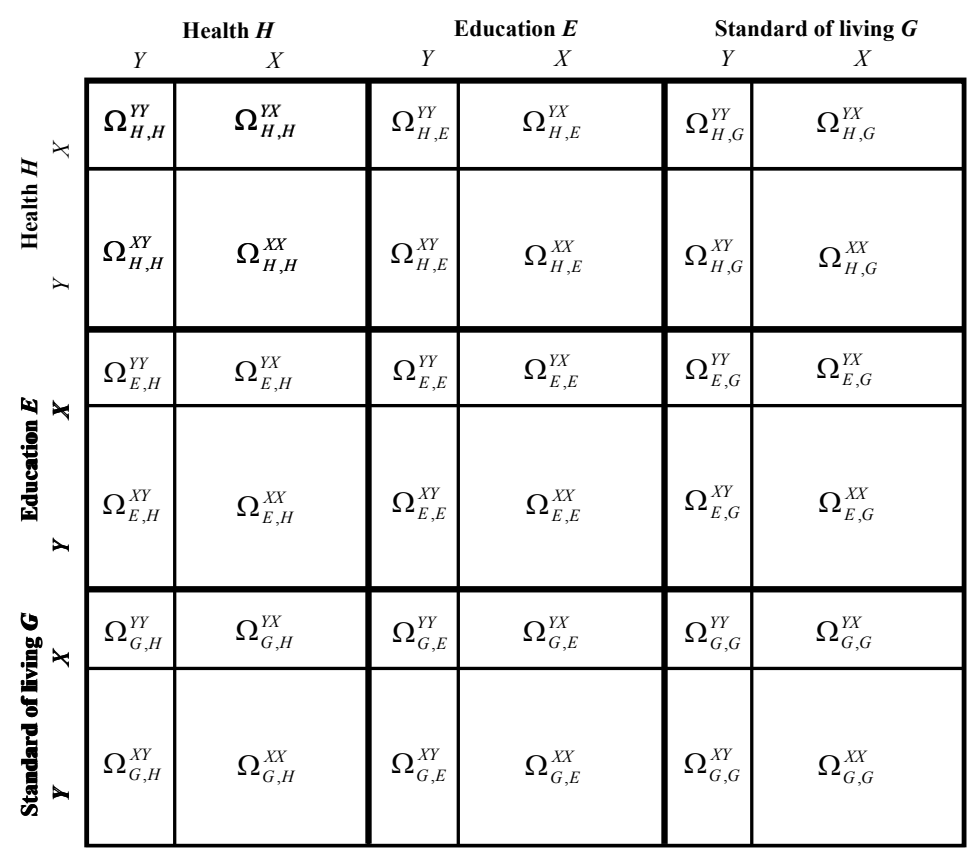

Figure A.1: Variance-covariance matrix partitions

it follows that

$$
\varepsilon_{j}^{t}=\sum_{k=1}^{Y} \varepsilon_{j k}^{J} y_{k}+\sum_{l=1}^{X} \varepsilon_{j l}^{K} x_{l} .
$$

Then substituting Equation (A.4) into Equation (A.3), we get:

$$
\begin{aligned}
E\left[\varepsilon_{i}^{t} \varepsilon_{j}^{t}\right]= & \sum_{k=1}^{Y} y_{k} \sum_{m=1}^{Y} E\left[\varepsilon_{i k}^{J} \varepsilon_{j m}^{J}\right] y_{m}+\sum_{k=1}^{Y} y_{k} \sum_{m=1}^{X} E\left[\varepsilon_{i k}^{J} \varepsilon_{j m}^{K}\right] x_{m} \\
& +\sum_{k=1}^{X} x_{k} \sum_{m=1}^{Y} E\left[\varepsilon_{i k}^{K} \varepsilon_{j m}^{J}\right] y_{m}+\sum_{k=1}^{K} x_{k} \sum_{m=1}^{X} E\left[\varepsilon_{i k}^{K} \varepsilon_{j m}^{K}\right] x_{m} .
\end{aligned}
$$

The expectation terms in Equation (A.5) refer to specific elements from the variancecovariance matrix of the parameter estimates of our linear system. This matrix is symmetric and consists of $T^{2}$ submatrices (associated with each combinations of the targets) further called $\Omega_{i j} \forall i, j=1, \ldots, T$ with dimensions $(Y+X) \times(Y+X)$. Each submatrix is in turn partitioned into four submatrices of dimensions $(Y \times Y)$, $(Y \times X),(X \times Y)$ and $(X \times X)$, further called $\Omega_{i j}^{Y Y}, \Omega_{i j}^{Y X}, \Omega_{i j}^{X Y}$ and $\Omega_{i j}^{X X}$, as displayed in in Figure A.1. 
$\Omega_{i j}^{Y Y}$ is the covariance matrix between the expenditure parameter estimates (as captured by matrix $J$ in Equation (5.14)) for target variables $i$ and $j$, while $\Omega_{i j}^{Y X}$ is the covariance matrix of the expenditure parameter estimates in the equation for target variable $i$ and the parameter estimates of the exogenous variable (as captured by matrix $K$ ) in the equation for target variable $j . \Omega_{i j}^{X Y}$ and $\Omega_{i j}^{X X}$ are similarly defined. Using this notation it follows from Equations (A.3) and (A.5) that the variance in $D$, further called $V$, can be written as in Equation (5.16):

$$
\begin{aligned}
V & =\frac{1}{T^{2}} \sum_{i=1}^{T} \sum_{j=1}^{T}\left(y^{\prime} \Omega_{i j}^{y y} y+y^{\prime} \Omega_{i j}^{y x} x+x^{\prime} \Omega_{i j}^{x y} y+x^{\prime} \Omega_{i j}^{x x} x\right) \\
& =y^{\prime} \bar{\Omega}^{Y Y} y+y^{\prime} \bar{\Omega}^{Y X} x+x^{\prime} \bar{\Omega}^{X Y} y+x^{\prime} \bar{\Omega}^{X X} x
\end{aligned}
$$

where $\bar{\Omega}^{Z}$ represents the arithmetical average over all $\bar{\Omega}_{i j}^{Z} \forall Z=Y Y, Y X, X Y, X X$. Note that the term $1 / T^{2}$ vanishes in the RHS since $\bar{\Omega}^{Z} \equiv \sum_{i} \sum_{j} \Omega_{i j}^{Z} / T^{2}$. Replacing $t$ in Equation (5.13) by (5.14), and inserting (5.14) into the objective function, the Lagrangian of maximization problem (5.17) is given by:

$$
\begin{aligned}
\Theta & =\hat{D}-\alpha V+\lambda\left(B-i^{\prime} \exp (y)\right) \\
& =i^{\prime}(\hat{J} y+\hat{K} x) / T-\alpha V+\lambda\left(B-i^{\prime} \exp (y)\right)
\end{aligned}
$$

where $\lambda$ is the Lagrange multiplier of the budget constraint, and $\exp (y)$ represents the column vector $\left(\exp \left(y_{1}\right), \ldots, \exp \left(y_{Y}\right)\right)$ \%. Maximizing (A.7) by a suitable choice of $y$ results in the following first order conditions:

$$
\begin{aligned}
\frac{\partial \Theta}{\partial y} & =\frac{\hat{J} \prime i}{T}-\alpha \frac{\partial V}{\partial y}-\lambda \exp (y) \\
& =\frac{\hat{J} \prime i}{T}-\alpha\left(\left(\bar{\Omega}^{Y Y}+\bar{\Omega}^{Y Y} \prime\right) y+\left(\bar{\Omega}^{Y X}+\bar{\Omega}^{X Y} \prime\right) x\right)-\lambda \exp (y) \\
& \hat{=} 0
\end{aligned}
$$

Note that Equation (A.8) and the per capita budget constraint define $(Y+1)=$ $(T+1)$ non-linear simultaneous equations in the $(Y+1)$ unknowns $y$ and $\lambda$, the solution of which is obtained using Mathematica's FindRoot routine. The solution depends on all elements of matrix $\hat{J}$, the covariances in $\bar{\Omega}^{Y Y}, \bar{\Omega}^{X Y}$ and $\bar{\Omega}^{Y X}$, and on $\alpha$. By varying $\alpha$ over a predefined range, we can calculate the corresponding solutions of the simultaneous system and therewith trace the efficient development frontier, since the optimum development portfolio for each $\alpha$ must be efficient as well. Note, moreover, that $\lambda$ is the shadow price of the per capita budget, i.e. it measures by how much the objective function would rise for a one unit increase in the per capita budget.

\section{A.2 The estimated variance-covariance matrix}

Next to the parameter coefficients of the SUR estimation, their cross-equation variance-covariance matrix plays a crucial role in our model, as shown in Section A.1. The overall structure of this covariance matrix is provided in Figure A.1, 
which shows how the particular $\bar{\Omega}$-partitions taken together make up the covariance matrix. The numerical values in the covariance matrix are provided in Table A.1. Note that in our formal notation, the number of exogenous and endogenous variables included as independent variables in each equation is the same. However, in Table A.1 those columns and rows from the $\bar{\Omega}$-partitions containing only zero's are left out. These zero-values arise, as the statistically insignificant impact parameters have been set equal to zero, and so are the implied values for the elements in the covariance matrix of such independent variables therefore (if they are not there, they cannot co-vary). An example is the independent variable lnhivr (the HIV-prevalence rate in logarithms) that contributes to the health target variable but not to the other targets. Consequently, the lnhivr rows are missing for the other targets, and so are the corresponding columns, because of the overall symmetry of the covariance matrix. 
Table A.1: Variance-covariance matrix

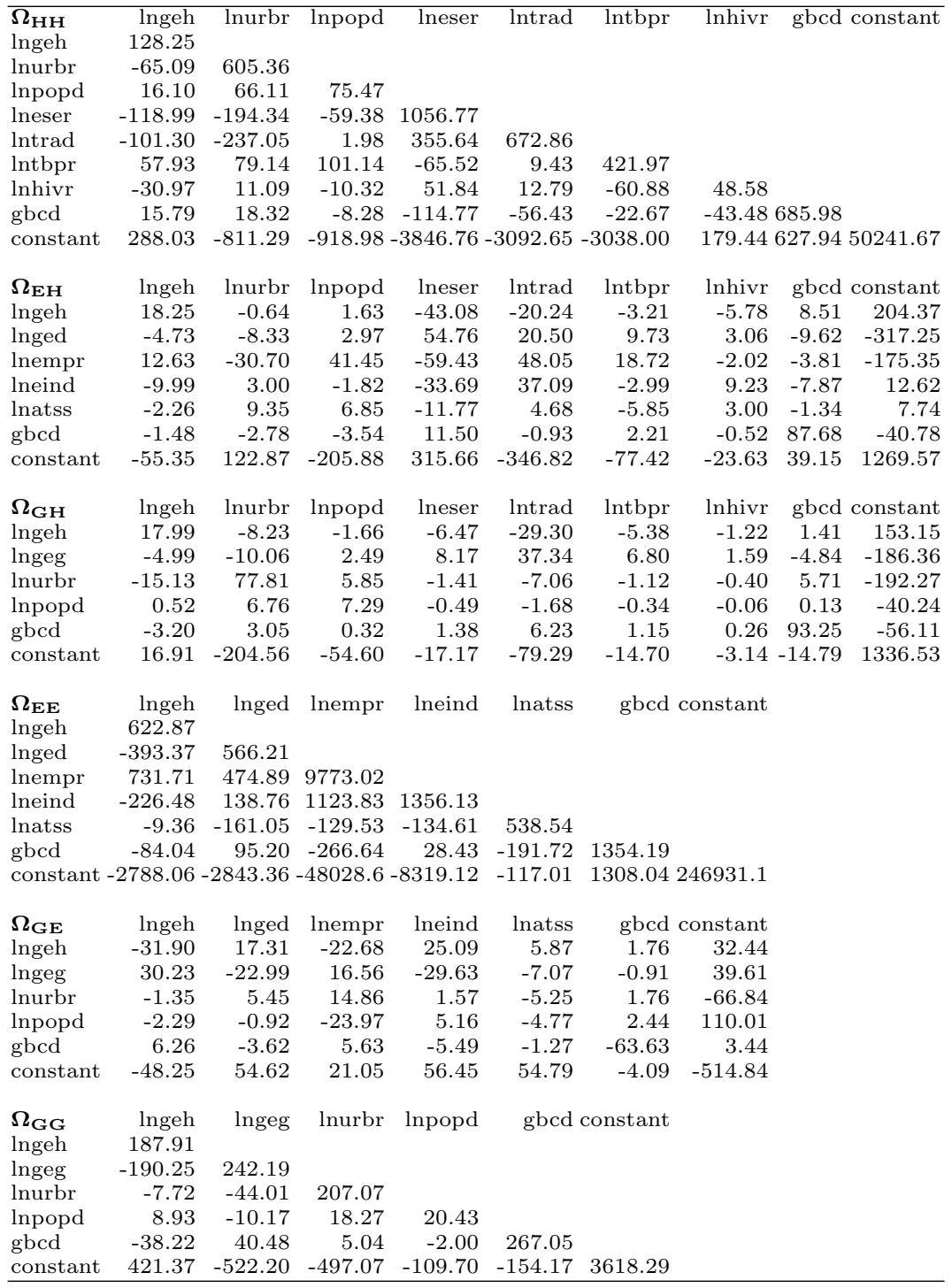




\section{Appendix B}

\section{Mathematical appendix to Chapter 6}

\section{B.1 First order conditions}

The first order conditions (F.O.C.s) are calculated from the present value Hamiltonian, Equation (6.10), and can be subdivided into three groups: F.O.C.s with respect to the control variables $c, z$ and $v$ :

$$
\frac{\partial H}{\partial c}=0, \frac{\partial H}{\partial z}=0, \frac{\partial H}{\partial v}=0
$$

w.r.t. the state variables $K, h$ and $g$

$$
\dot{\lambda}_{K}=-\frac{\partial H}{\partial K}+\rho \lambda_{K}, \dot{\lambda}_{h}=-\frac{\partial H}{\partial h}+\rho \lambda_{h}, \dot{\lambda}_{g}=-\frac{\partial H}{\partial g}+\rho \lambda_{g},
$$

and with respect to the co-state variables $\lambda_{K}, \lambda_{h}$ and $\lambda_{g}$. The latter are already defined by the rate of physical and human capital accumulation $\dot{K}, \dot{h}$, and $\dot{g}$. Thus, we get the growth rates of capital accumulations

$$
\begin{aligned}
\frac{\dot{K}}{K} & =\frac{Y-L c}{K}=\frac{r}{1-\alpha}(1-q)=\frac{r}{1-\alpha} s \\
\frac{\dot{h}}{h} & =\delta z g-\frac{\zeta \sigma\left(\phi v^{\beta}-g\right)}{g}-\frac{\dot{n}}{n} \\
\frac{\dot{g}}{g} & =\frac{\zeta \sigma\left(\phi v^{\beta}-g\right)}{g}
\end{aligned}
$$


The F.O.C.s with respect to the control variables are given by

$$
\begin{aligned}
\frac{\partial H}{\partial c}= & L \gamma_{c} \frac{1}{c}\left[c^{\gamma_{c}}(\mu g)^{\gamma_{g}} h^{\gamma_{h}} z^{\gamma_{z}}\right]^{1-\theta}-\lambda_{K} L \hat{=} 0 \\
\frac{\partial H}{\partial z}= & L \gamma_{z} \frac{1}{z}\left[c^{\gamma_{c}}(\mu g)^{\gamma_{g}} h^{\gamma_{h}} z^{\gamma_{z}}\right]^{1-\theta} \\
& +\lambda_{K} A[(1-z-v) h g n R]^{\alpha} K^{1-\alpha} \frac{-\alpha}{(1-z-v)}+\lambda_{h} \delta g h \hat{=} 0 \\
\frac{\partial H}{\partial v}= & \lambda_{K} A[(1-z-v) h g n R]^{\alpha} K^{1-\alpha} \frac{-\alpha}{(1-z-v)} \\
& +\lambda_{h} h \frac{1}{g} \zeta \sigma \phi \beta v^{\beta-1}+\lambda_{g} \zeta \sigma \phi \beta v^{\beta-1} \hat{=} 0 .
\end{aligned}
$$

Equation (B.4) implies that

$$
\left[c^{\gamma_{c}}(\mu g)^{\gamma_{g}} h^{\gamma_{h}} z^{\gamma_{z}}\right]^{1-\theta}=\lambda_{K} \frac{c}{\gamma_{c}} .
$$

Using this together with the rates of capital accumulation and the propensity to consume, the F.O.C.s with respect to $z$ and $v$ reduce to

$$
\lambda_{h}=-\frac{1}{g h \delta} \lambda_{K} Y\left[\frac{-\alpha}{(1-z-v)}+\frac{q \gamma_{z}}{\gamma_{c} z} \gamma_{z}\right]
$$

and also

$$
\lambda_{g}=\lambda_{K} \frac{\alpha v^{1-\beta} Y}{(1-v-z) \beta \zeta \sigma \phi}+\lambda_{h} \frac{h}{g}
$$

The F.O.C.s with respect to the state variables $K, h$ and $g$ are

$$
\begin{aligned}
\dot{\lambda}_{K}= & -\frac{\partial H}{\partial K}+\rho \lambda_{K} \\
= & -\lambda_{K}(1-\alpha) A[(1-z-v) h g n R]^{\alpha} K^{-\alpha}+\rho \lambda_{K} \\
= & -\lambda_{K}(1-\alpha) \frac{Y}{K}+\lambda_{K} \rho=\lambda_{K}(-r+\rho) \\
\dot{\lambda}_{h}= & -\frac{\partial H}{\partial h}+\rho \lambda_{h} \\
= & -L \gamma_{h} \frac{1}{h}\left[c^{\gamma_{c}}(\mu g)^{\gamma_{g}} h^{\gamma_{h}} z^{\gamma_{z}}\right]^{1-\theta} \\
& -\lambda_{K} \alpha h^{\alpha-1} A[(1-z-v) g n R]^{\alpha} K^{1-\alpha} \\
& -\lambda_{h}\left[\delta z g-\frac{\zeta \sigma\left(\phi v^{\beta}-g\right)}{g}-\frac{\dot{n}}{n}\right]+\rho \lambda_{h} \\
= & -\lambda_{K} \frac{Y}{h}\left[\frac{q}{\gamma_{c}} \gamma_{h}-\alpha\right]+\lambda_{h}\left[\rho-\frac{h}{h}\right] \\
\dot{\lambda}_{g} & -\frac{\partial H}{\partial g}+\rho \lambda_{g} \\
= & -L \gamma_{g} \frac{1}{g}\left[c^{\gamma_{c}}(\mu g)^{\gamma_{g}} h^{\gamma_{h}} z^{\gamma_{z}}\right]^{1-\theta} \\
& -\lambda_{K} \alpha g^{\alpha-1} A[(1-z-v) h n R]^{\alpha} K^{1-\alpha} \\
& -\lambda_{h} h\left[\delta z-\frac{\zeta \sigma\left(\phi v^{\beta}\right)}{-g^{2}}\right]+\lambda_{g} \frac{\zeta \sigma\left(\phi v^{\beta}\right)}{-g^{2}} \rho \lambda_{h}
\end{aligned}
$$




\section{B.2 Differential equations of co-state variables}

To differential equations for the co-state variables are obtained by solving Equations (B.4) to (B.6) for $\lambda_{K}, \lambda_{h}$ and $\lambda_{g}$, respectively, then differentiating with respect to time and dividing both sides by the corresponding co-state variable

$$
\begin{aligned}
\frac{\dot{\lambda}_{K}}{\lambda_{K}}= & {\left[\gamma_{c}(1-\theta)-1\right] \frac{\dot{c}}{c}+(1-\theta)\left[\beta \gamma_{g} \frac{\dot{v}}{v}+\gamma_{h} \frac{\dot{h}}{h}+\gamma_{z} \frac{\dot{z}}{z}\right] } \\
\frac{\dot{\lambda}_{h}}{\lambda_{h}}= & \frac{\dot{\lambda}_{K}}{\lambda_{K}}+\frac{\dot{Y}}{Y}-\frac{\dot{h}}{h}-\frac{\dot{g}}{g}+\frac{\dot{q}}{q}-\frac{\dot{z}}{z}+\frac{z(1-v) \frac{\dot{z}}{z}-v \frac{\dot{v}}{v}-\frac{\dot{q}}{q}(1-v-z) \alpha \gamma_{c}}{(1-z-v)\left(z \alpha \gamma_{c}-q(1-v-z) \gamma_{z}\right)} \\
\frac{\dot{\lambda}_{g}}{\lambda_{g}}= & \frac{g^{2} v z \alpha\left[\left(\frac{\dot{\lambda}_{K}}{\lambda_{K}}+\frac{\dot{Y}}{Y}\right)(1-z-v)+z \frac{\dot{z}}{z}+v \frac{\dot{v}}{v}(1-z-(1-z-v) \beta)\right] \gamma_{c} \delta}{(1-z-v)\left[g^{2} v z \alpha \gamma_{c} \delta+v^{\beta} \beta\left(z \alpha \gamma_{c}-q(1-z-v) \gamma_{z}\right) \zeta \sigma \phi\right]} \\
& +\frac{v^{\beta} \beta z\left[\left(\frac{\dot{\lambda} K}{\lambda_{K}}+\frac{\dot{Y}}{Y}+2 \frac{\dot{g}}{g}\right)(1-z-v)+v \frac{\dot{v}}{v}+z \frac{\dot{z}}{z}\right] \zeta \sigma \phi}{(1-z-v)\left[g^{2} v z \alpha \gamma_{c} \delta+v^{\beta} \beta\left(z \alpha \gamma_{c}-q(1-z-v) \gamma_{z}\right) \zeta \sigma \phi\right]} \\
& +\frac{-v^{\beta} \beta q\left[\frac{\dot{q}}{q}-2 \frac{\dot{g}}{g}+\frac{\dot{Y}}{Y}-\frac{\dot{z}}{z}+\frac{\dot{\lambda}_{K}}{\lambda_{K}}\right](1-z-v)^{2} \gamma_{z} \zeta \sigma \phi}{(1-z-v)\left[g^{2} v z \alpha \gamma_{c} \delta+v^{\beta} \beta\left(z \alpha \gamma_{c}-q(1-z-v) \gamma_{z}\right) \zeta \sigma \phi\right]}
\end{aligned}
$$

\section{B.3 Growth equations for $z$ and $v$}

The proportional growth rates of $z$, i.e. $\hat{z}=G z$, and $v$, i.e. $\hat{v}=G v$, are displayed here for the sake of completeness. The expressions are non-linear and it is not immediately obvious how to interpret the different terms and their contribution. For the growth rate of the share of the population active in education $z$, i.e. $G z$, we obtain the following expression:

$G z=\left(\left(-g^{2}\right) K^{\alpha} z(-1+v+z) \delta\left(\alpha^{2}(v+z(-1+\beta)) \gamma_{c}\left(1+\gamma_{c}(-1+\theta)\right)+\alpha\left(\gamma_{c}(-1+\right.\right.\right.$ $\left.z+\beta-v \beta-z \beta+q v \gamma_{h}(-1+\theta)\right)+q v \gamma_{h}\left(1+\gamma_{z}(-1+\theta)\right)-(1-z+(-1+v+z) \beta) \gamma_{c}^{2}(-1+$ $\left.\theta))-q(1-z+(-1+v+z) \beta) \gamma_{h}\left(1+\gamma_{c}(-1+\theta)+\gamma_{z}(-1+\theta)\right)\right)-A q g^{(1+\alpha)} h^{\alpha} n^{\alpha} R^{\alpha}(1-$ $v-z)^{(1+\alpha)}(-1+\alpha) \gamma_{c}\left((-z)(-1+\beta)\left(\alpha\left(1+\gamma_{c}(-1+\theta)\right)+\gamma_{z}(-1+\theta)\right)+(-1+v(\alpha-\right.$ $\left.\beta)+\beta) \gamma_{z}(-1+\theta)\right)-g K^{\alpha}\left(G A z(-1+v+z) \alpha(-1+\beta) \gamma_{c}\left(1+\gamma_{c}(-1+\theta)\right)+z \alpha((-1+\right.$ $z)(-1+\beta)+v(1-2 \alpha+\beta)) \gamma_{c} \zeta\left(1+\gamma_{c}(-1+\theta)\right) \sigma-q(-1+v+z)(-1+z+v \alpha-$ $\left.(-1+v+z) \beta) \gamma_{z}\left((-G n)\left(-1+\gamma_{c}+\gamma_{h}\right)+G n\left(\gamma_{c}+\gamma_{h}\right) \theta-\rho+\left(\gamma_{g}-\gamma_{h}\right) \zeta(-1+\theta) \sigma\right)\right)-$ $K^{\alpha} v^{\beta} \zeta\left(q(-1+v)(-1+v(\alpha-\beta)+\beta)\left(\gamma_{g}-\gamma_{h}\right) \gamma_{z}(-1+\theta)+z\left(v \alpha^{2} \gamma_{c}\left(1+\gamma_{c}(-1+\theta)\right)-\right.\right.$ $\alpha\left(\gamma_{c}\left(1+(-1+v) \beta\left(1+q\left(\gamma_{g}-\gamma_{h}-\gamma_{z}\right)(-1+\theta)\right)\right)+q\left((-1+v) \beta\left(\gamma_{g}-\gamma_{h}-\gamma_{z}\right)-v\left(\gamma_{g}-\right.\right.\right.$ $\left.\left.\left.\gamma_{h}\right) \gamma_{z}(-1+\theta)\right)+(1+(-1+v) \beta) \gamma_{c}^{2}(-1+\theta)\right)+q\left((-2+v)\left(\gamma_{g}-\gamma_{h}\right) \gamma_{z}(-1+\theta)+(-1+\right.$ v) $\left.\left.\beta\left(-\gamma_{h}-\gamma_{z}-\left(-2 \gamma_{h} \gamma_{z}+\gamma_{c}\left(\gamma_{h}+\gamma_{z}\right)\right)(-1+\theta)+\gamma_{g}\left(1+2 \gamma_{z}+\gamma_{c}(-1+\theta)-2 \gamma_{z} \theta\right)\right)\right)\right)+$ $z^{2}\left(\alpha^{2} \beta \gamma_{c}\left(1+\gamma_{c}(-1+\theta)\right)-\alpha\left((-1+2 \beta) \gamma_{c}+q \beta\left(\gamma_{g}-\gamma_{h}-\gamma_{z}\right)\right)\left(1+\gamma_{c}(-1+\theta)\right)+\right.$ $q\left(\left(\gamma_{g}-\gamma_{h}\right) \gamma_{z}(-1+\theta)+\beta\left(-\gamma_{h}-\gamma_{z}-\left(\left(-\gamma_{h}\right) \gamma_{z}+\gamma_{c}\left(\gamma_{h}+\gamma_{z}\right)\right)(-1+\theta)+\gamma_{g}\left(1+\gamma_{z}+\right.\right.\right.$ $\left.\left.\left.\left.\left.\left.\gamma_{c}(-1+\theta)-\gamma_{z} \theta\right)\right)\right)\right)\right) \sigma \phi\right) / K^{\alpha} /\left(g\left(q(-1+v)(-1+v(\alpha-\beta)+\beta) \gamma_{z}\left(1+\gamma_{c}(-1+\theta)+\right.\right.\right.$ $\left.\gamma_{z}(-1+\theta)\right)+q z(-2+v+v \alpha+2 \beta-2 v \beta) \gamma_{z}\left(1+\gamma_{c}(-1+\theta)+\gamma_{z}(-1+\theta)\right)+z^{2}(-1+$ $\left.\left.\beta)\left(\alpha^{2} \gamma_{c}\left(1+\gamma_{c}(-1+\theta)\right)+\alpha \gamma_{c}\left(-1+\gamma_{c}-\gamma_{c} \theta\right)+q \gamma_{z}\left(-1+\gamma_{c}+\gamma_{z}-\left(\gamma_{c}+\gamma_{z}\right) \theta\right)\right)\right)\right)$.

Similarly, for the growth rate of the share of labor in the health sector $v$, i.e. $G v$, we find:

$G v=\left(K^{\alpha} z^{2}(-1+\alpha) \alpha^{2} \gamma_{c}^{2}\left(1+\gamma_{c}(-1+\theta)\right)\left(g v(g(-1+v+z) \delta-2 \zeta \sigma)+v^{\beta}(v+\right.\right.$ $z \beta) \zeta \sigma \phi)-q^{2}(-1+v+z)^{2} \gamma_{z}\left(1+\gamma_{c}(-1+\theta)+\gamma_{z}(-1+\theta)\right)\left(A g^{(1+\alpha)} h^{\alpha} n^{\alpha} R^{\alpha} v(1-\right.$ 
$\left.v-z)^{\alpha}(-1+\alpha) \alpha \gamma_{c}-K^{\alpha} v^{\beta}(-1+v+z) \beta\left(\gamma_{g}-\gamma_{h}-\gamma_{z}\right) \zeta \sigma \phi\right)-q(-1+v+$ $z) \alpha \gamma_{c}\left(g^{2} K^{\alpha} v z\left((-z)(-1+\alpha) \gamma_{h}+(-1+v+z) \alpha \gamma_{z}\right) \delta\left(1+\gamma_{c}(-1+\theta)+\gamma_{z}(-1+\right.\right.$ $\theta))+A g^{(1+\alpha)} h^{\alpha} n^{\alpha} R^{\alpha} v(1-v-z)^{\alpha} z(-1+\alpha)^{2} \gamma_{c} \gamma_{z}(-1+\theta)+g K^{\alpha} v \gamma_{z}(G A(-1+$ $v+z)\left(1+\gamma_{c}(-1+\theta)+\gamma_{z}(-1+\theta)\right)+z(-1+\alpha)\left((-G n)\left(-1+\gamma_{c}+\gamma_{h}\right)+G n\left(\gamma_{c}+\right.\right.$ $\left.\left.\gamma_{h}\right) \theta-\rho\right)-(-1+v) \zeta \sigma-\zeta\left((-z)\left(-1+\gamma_{c}+\gamma_{g}-\alpha \gamma_{g}+(-1+\alpha) \gamma_{h}+\gamma_{z}\right)+(-1+\right.$ $\left.\left.v)\left(\gamma_{c}+\gamma_{z}\right)(-1+\theta)+z\left(\gamma_{c}+\gamma_{g}-\alpha \gamma_{g}+(-1+\alpha) \gamma_{h}+\gamma_{z}\right) \theta\right) \sigma\right)+K^{\alpha} v^{\beta} z \zeta\left(\gamma_{z}((-1+\right.$ v) $\left.\beta\left(1+\gamma_{c}(-1+\theta)+\gamma_{z}(-1+\theta)\right)-v(-1+\alpha)\left(\gamma_{g}-\gamma_{h}\right)(-1+\theta)\right)+z \beta\left(\gamma_{h}+2 \gamma_{z}+\right.$ $(-1+\alpha) \gamma_{g}\left(1+\gamma_{c}(-1+\theta)\right)-\alpha\left(\gamma_{h}+\gamma_{z}\right)\left(1+\gamma_{c}(-1+\theta)\right)+\left(\gamma_{z}^{2}+\gamma_{c}\left(\gamma_{h}+2 \gamma_{z}\right)\right)(-1+$ $\theta)) \sigma \phi)) / K^{\alpha} /\left(g v \alpha \gamma_{c}\left(q(-1+v)(-1+v(\alpha-\beta)+\beta) \gamma_{z}\left(1+\gamma_{c}(-1+\theta)+\gamma_{z}(-1+\theta)\right)+\right.\right.$ $q z(-2+v+v \alpha+2 \beta-2 v \beta) \gamma_{z}\left(1+\gamma_{c}(-1+\theta)+\gamma_{z}(-1+\theta)\right)+z^{2}(-1+\beta)\left(\alpha^{2} \gamma_{c}(1+\right.$ $\left.\left.\left.\left.\gamma_{c}(-1+\theta)\right)+\alpha \gamma_{c}\left(-1+\gamma_{c}-\gamma_{c} \theta\right)+q \gamma_{z}\left(-1+\gamma_{c}+\gamma_{z}-\left(\gamma_{c}+\gamma_{z}\right) \theta\right)\right)\right)\right)$.

\section{B.4 Transversality conditions in the long run equi- librium}

The transversality conditions, the sum of the state variables' growth rates and their respective co-state variable's growth rate has to be negative, which implies that the following inequalities should hold:

$$
\begin{aligned}
\hat{K}+\hat{\lambda}_{K}-\rho= & \frac{(1-q)\left(\gamma_{c}+\gamma_{h}\right)(1-\theta) \rho}{\alpha-(1-q)\left(\gamma_{c}+\gamma_{h}\right)(1-\theta)-q}-\rho<0 \\
\hat{h}+\hat{\lambda}_{h}-\rho= & \frac{q r\left(z \alpha \gamma_{c}^{2}\left(z\left(1+\gamma_{c}(\theta-1)\right)+\gamma_{z}(\theta-1)\right)+(v-1) \gamma_{z}(\theta-1)\right)\left(\rho+v^{\beta} z \alpha \delta \phi\right)}{q(1-z-v) \gamma_{z}-z \alpha \gamma_{c}} \\
& \frac{q z(1-v-z) \alpha \gamma_{c} \gamma_{z}(\theta-1)\left(\rho+v^{\beta} z \alpha \delta \phi\right)\left(\gamma_{c} \rho-v^{\beta} z \gamma_{h} \delta \phi\right)}{q(1-z-v) \gamma_{z}-z \alpha \gamma_{c}}-\rho<0 \\
\hat{g}+\hat{\lambda}_{g}-\rho= & F\left[(1-v-z) \beta \gamma_{z} \zeta(\theta-1) \sigma\left(\gamma_{c} \rho-v^{\beta} z \gamma_{h} \delta \phi\right)\right] \\
& +F\left[r \gamma_{c}\left((v-1) \beta \gamma_{z} \zeta \sigma(\theta-1)\right)\right] \\
& +F\left[r \gamma_{c}\left(z\left(\beta \gamma_{z} \zeta \sigma(\theta-1)+\alpha\left(1+\gamma_{c}(\theta-1)\right)\left(\beta \zeta \sigma+v^{1+\beta} \delta \phi\right)\right)\right)\right]-\rho<0
\end{aligned}
$$

with

$$
F=\frac{-q z \alpha \gamma_{c}(\beta \zeta \sigma+v 1+\beta \delta \phi)(\rho+v \beta z \alpha \delta \phi)}{\beta\left[z \alpha \gamma_{c}-q(1-z-v) \gamma_{z}\right] \zeta \sigma+v^{1+\beta} z \alpha \gamma_{c} \delta \phi}
$$

\section{B.5 Transition paths of individual shocks}

Individual 'shocks' to the different variables as described below, can be understood as a shock to an economy, which is on its long run balanced growth path but then - through a natural or man made disaster - the capital stock, be it physical or human, is destroyed or the health of the population is significantly affected due to some unexpected event. The analysis of the individual shocks here serves the purpose of identifying the individual effects of each of the shocks. Figures B.1 through B.3 display the first 50 (Figure B.1) or 75 (Figures B.2 and B.3) years of the transition paths of the system toward the long run equilibria after shocking just one of the variables. 

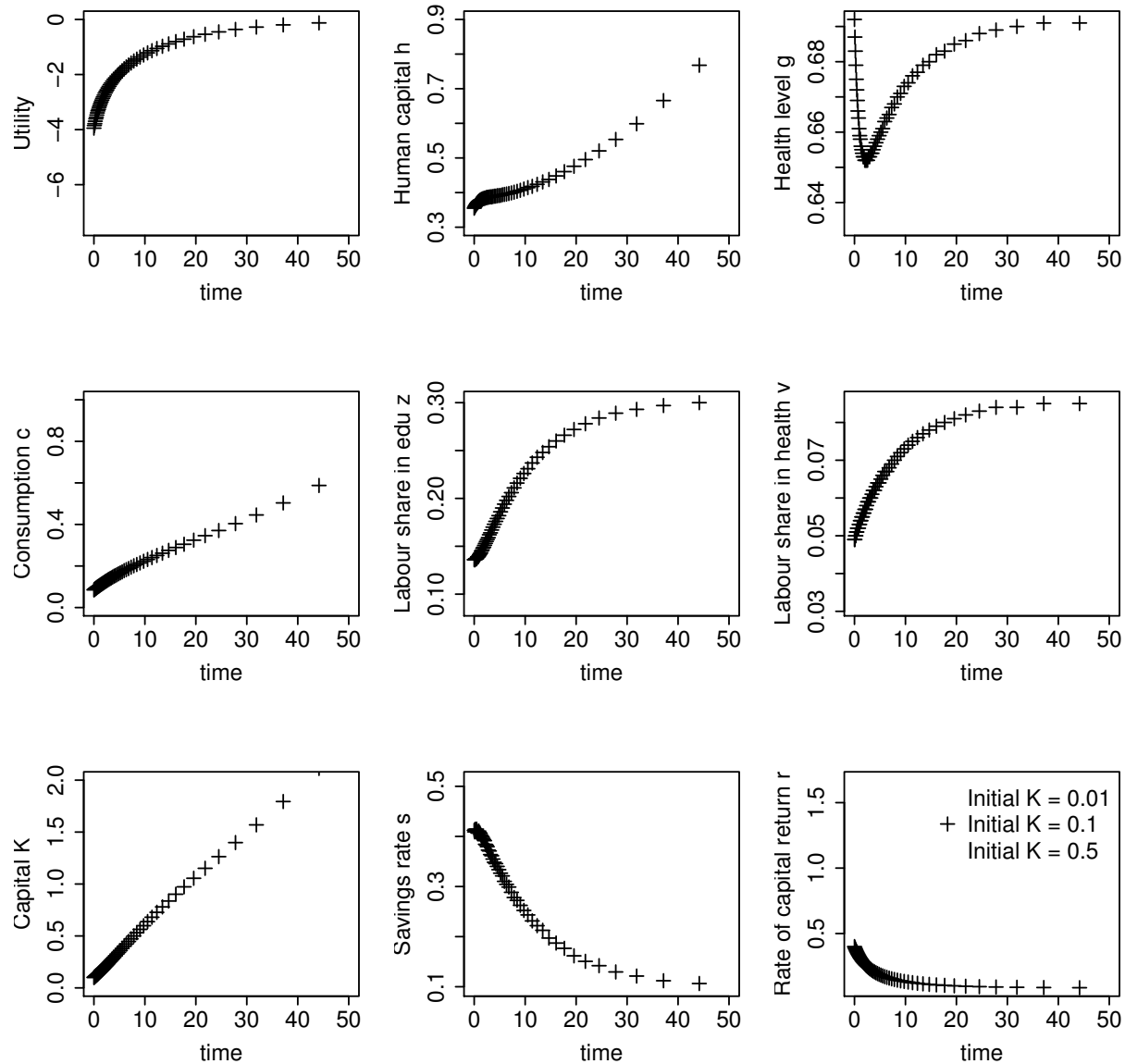

Figure B.1: Shocking capital K

Figure B.1 displays the transition paths of utility, its components, labor shares $z$ and $v$, capital $K$, savings rate $s$ and rate of return to capital $r$ for shocks to $K$ of 0.01 (displayed as circles in the graphs), 0.1 (displayed as plus-signs) and 0.5 (displayed as dots) of its BGP solution. The reactions of the individual variables is very different. The level of human capital first increases strongly, but then slows downs as $g$ increases. This is due to the fact that the growth rate of $h$ depends negatively on the growth rate of $g$, see Equation $6.13^{1}$. The change in $h$ is larger for lower initial values of $K$. As only $K$ is shocked at this point, $g$ starts off at its long run equilibrium level of about 0.69 . The low physical capital endowment, however, results in a reallocation of labor toward the production sector, so that the health level cannot be maintained and health deteriorates in the first years following the shock. As more labor is allocated to the health sector, the health level starts rising

\footnotetext{
${ }^{1} \mathrm{~A}$ more thorough explanation of this effect is given for the joint shock in Section 6.2.3.
} 

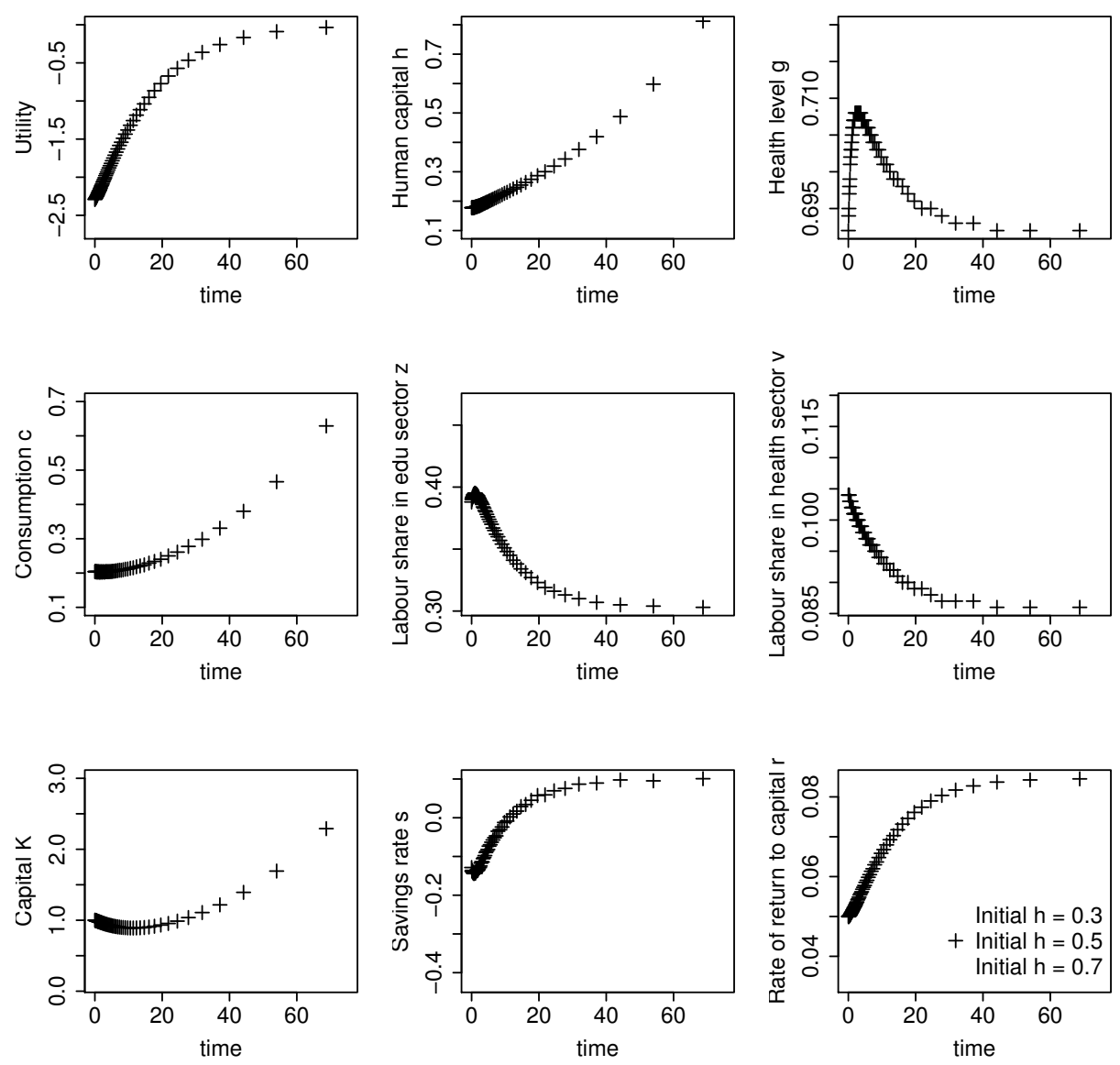

Figure B.2: Shocking human capital h

again. The labor share allocated to education is also lower compared to the long run equilibrium and only slowly starts increasing toward its equilibrium value.

The lower the initial capital endowment, the lower per capita consumption. However, consumption rises with capital as can be seen from the left graphs in the second and third row of Figure B.1. For low capital endowments, the savings rate is very high, and only slowly starts to decrease. The decrease becomes larger before it slows down to converge to the steady state value of about $10 \%$ after 50 years. The rate of return to capital, however, starts out even higher, but decreases immediatly and strongly to converge to its steady state value in a very short period of time (lower right plot in Figure B.1).

Instantaneous utility increases stronger for lower levels of initial capital endowment, but the the increase slows down and after about 30 years utility is almost identical for the three different initial values of capital. For shocks to $h$ and $g$, utility behaves very differently: Following a shock to $h$, the immediate increase 

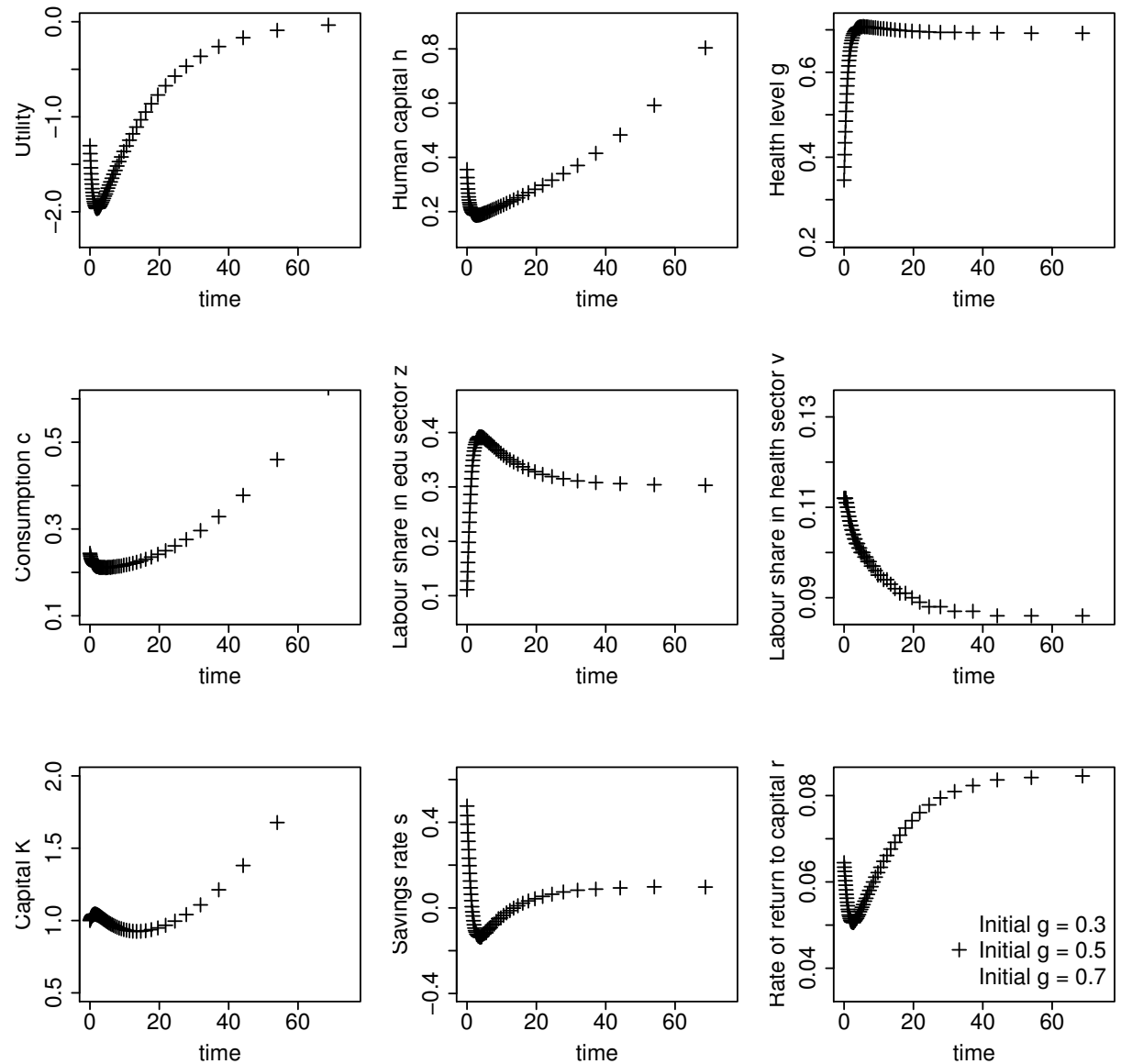

Figure B.3: Shocking health level g

in utility is slow, then increasing and then slows down again, following a S-curve. For a shock to $g$, utility immediately decreases and only starts to increase again after a few years. The utility decrease is caused by the decrease in $h$, which in turn is due to the relatively low inputs into the human capital sector compared to the increase in the health level as explained in Section 6.2.3.

The transition paths of shocks to the human capital level and the health level, as displayed in Figures B.2 and B.3, are similar to each other (with the exception of $h$ and therefore also utility as just described), but very different to that of a capital shock. In addition, the convergence is slower than in the case of a shock to $K$ so that for shocks to $g$ and $h$, the first 75 years of the transition periods are displayed. One interesting feature is the overshooting (in case of a shock to $g$ ) and initial reverse reaction (in case of a shock to $h$ ) of human capital, health level, share of labor in the education sector, savings rate and rate of return on capital. In case of a lower than initial level of human capital, $h$ itself, the savings 
rate and the rate of return on capital slightly drop at first before increasing to a higher level $(s$ and $r$ ) or infinitely for $h$ which asymptotically grows at rate $\kappa$, while $g$ and $z$ slightly increase at first and then asymptotically approach the same $(g)$ or a lower level $(z)$ over time. For a shock to $g$, the initial reactions are in the same direction, but they are stronger. The subsequent decrease/increase, however, is slower so that the variables asymptotically converge to their equilibrium levels from the other side than from where they started.

In both cases negative saving rates and very low returns to capital are present in the short run. Negative saving rates are not uncommon in the Sub-Saharan African countries, as shown in Figure 6.1, because people own less than what they need to survive. Steger (2000) also recognized this phenomenon and therefore introduced the concept of subsistence consumption.

The share of labor in health $v$ corresponding to the two shocks is higher than the equilibrium level. As time passes it approaches the equilibrium level from above. This shows that education and health are essential for the economy to start growing after a shock to either one of these two. For both shocks $c$ drops slightly during the first years after the shock, but then increases again. By contrast, $K$ first increases for one or two years after the health shock, then drops, but increases in the long run. For the human capital shock, $\mathrm{K}$ immediately starts to decrease but eventually increases as well. In the short run, capital and consumption are substitutes to $h$ and $g$, but in the long run they all become complements. 


\section{Bibliography}

Abdallah, S., S. Thompson, J. Michaelson, N. Marks and N. Steuer (2009). The Happy Planet Index 2.0: Why good lives don't have to cost the Earth. nef: London, downloadable from http://www.happyplanetindex.org/ learn/download-report.html.

Adler, N., E. Yazhemsky and R. Tarverdyan (2009). A framework to measure the relative socio-economic performance of developing countries. Socio-Economic Planning Sciences 44(2), 73-88.

Afonso, A. and M. St.Aubyn (2004). Nonparametric approaches to education and health expenditure efficiency in OECD countries. Technical University of Lisbon, Portugal.

Afonso, A., L. Schuknecht and V. Tanzi (2005). Public sector efficiency: An international comparison. Public Choice 123, 321-347.

Agénor, P.R., N. Bayraktar and K. El Aynaoui (2004). Roads out of poverty? Assessing the links between aid, public investment, growth and poverty reduction. Background study for the World Bank's 2004 Economic Memorandum for Ethiopia. World Bank.

Agénor, P.R., N. Bayraktar, E.P. Moreira and K. El Aynaoui (2005). Achieving the Millennium Development Goals in sub-saharan africa: A macroeconomic monitoring framework. Policy Resesarch Working Paper 3750. World Bank.

Aghion, P. and P. Howitt (2005). Endogenous Growth Theory. The MIT Press, Cambridge.

Amir, R. (2003). Supermodularity and complementarity in ecnomics: an elementary survey. CORE Discussion Papers 2003104. Université catholique de Louvain, Center for Operations Research and Econometrics (CORE).
Arrow, K.J., H.B. Chenery, B.S. Minhas and R.M. Solow (1961). Capital labour substitution and economic efficiency. Review of Economics and Statistics 43, 225-250.

Aschauer, D.A. (1989). Is public expenditure productive?. Journal of Monetary Economics 23, 177.

Awerbruch, S. and M. Berger (2003). Applying portfoilio theory to EU electricity planning and policy-making. International Energy Agency Working Paper EET/2003/03.

Azomahou, T.T., R. Boucekkine and B. Diene $(2008 a)$. A closer look at the relationship between life expectancy and economic growth. UNU-MERIT Working Paper Series 027. United Nations University, Maastricht Economic and social Research and training centre on Innovation and Technology.

Azomahou, T.T., R. Boucekkine and B. Diene $(2008 b)$. The economic impact of AIDS in Sub-Saharan Africa. UNU-MERIT Working Paper Series 038. United Nations University, Maastricht Economic and social Research and training centre on Innovation and Technology.

Barro, R.J. (1990). Government spending in a simple model of endogenous growth. The Journal of Political Economy 98(5), S103S125.

Barro, R.J. and X. Sala-i Martin (1995). Economic growth. The MIT Press, Cambridge.

Barro, R.J. and X. Sala-i Martin (2004). Economic Growth. 2 ed.. MIT Press, Cambridge.

Baumol, W.J. (1993). Health care, education and the cost disease: A looming crisis for public choice. Public Choice 77(1), 17-28.

Benhabib, J. and M.M. Spiegel (1994). The role of human capital in economic development: Evidence from aggregate cross-country and regional U.S. data. Journal of Monetary Economics 34, 143-173.

Bérenger, V. and A. Verdier-Chouchane (2007). Multidimensional measures of well-being: standard of living and quality of life across countries. World Development 35(7), 12591276 .

Berndt, E.R. and D.O. Wood (1979). Engineering and econometric interpretations of energy-capital complementarity. The American Economic Review 69(3), 342-354. 
Bertinelli, L., E. Strobl and B. Zou (2006). Sustainable economic development and the environment: Theory and evidence. CORE Discussion Papers 2006057. Université catholique de Louvain, Center for Operations Research and Econometrics (CORE).

Besley, T. and R. Burgess (2003). Halving gobal poverty. Journal of Economic Perspectives 17(3), 3-22.

Bichsel, M. (2011). Mathematica implementation of the Relaxation algorithm. ETH Zürich. Downloadable from http://www.uni-siegen.de/fb5/vwli/ forschung/relaxation/relaxation_mat/mathe matica_applications/relaxationdescription. txt?lang=de.

Bloom, D., D. Canning and J. Sevilla (2004). The effect of health on economic growth: A production function approach. World Development 32, 1-13.

BMBF, KK \& (2010). Bildung in Deutschland 2010. Kultusminister Konferenz \& Bundesministerium für Bildung und Forschung.

Bourguignon, F., A. Bénassy-Quéré, S. Dercon, A. Estache, J.W. Gunning, R. Kanbur, S. Klasen, S. Maxwell, J.-P. Platteau and S. Spadaro (2008a). Millennium Development Goals at midpoint: Where do we stand and where do we need to go?. DG Development and Relations with African, Caribbean and Pacific States. European Commission, September 2008.

Bourguignon, F., A. Bénassy-Quéré, S. Dercon, A. Estache, J.W. Gunning, R. Kanbur, S. Klasen, S. Maxwell, J.-P. Platteau and S. Spadaro (2008b). Millennium Development Goals at midpoint: Where do we stand and where do we need to go?. DG Development and Relations with African, Caribbean and Pacific States. European Commission, October 2008.

Breitung, J. and M.H. Pesaran (2005). Unit roots and cointegration in panels. Cambridge Working Papers in Economics 0535. Faculty of Economics, University of Cambridge.

Bretschger, L. (2006). Energy prices, growth, and the channels in between: Theory and evidence. Economics Working Paper Series ETH Zürich.

Brundtland, G.H., Ed. (1987). Our common future. Oxford University Press. Oxford.
BrundtlandCommission (1987). Our common future, chapter 2: Towards sustainable development. from A/42/427, Our common future: Report of the World Commission on Environment and Development, retrieved from the World Wide Web June 21st, 2008: http://www.un-documents.net/ocf-02.htm.

Camp, S.L. and J.J. Speidel (1987). The international Human Suffering Index. Washington, DC: Population Crises Committee.

Cass, D. (1965). Optimum growth in an aggregative model of capital accumulation. The Review of Economic Studies 32(3), 233-240.

Cass, D. (1966). Optimum growth in an aggregative model of capital accumulation: A turnpike theorem. Econometrica 34(4), 833-850.

Cheung, P. (2012). Facing the challenge of measuring the unmeasurable. DESA News 16(2), Featured Article.

Clemens, M.A. and T.J. Moss (2005). What's wrong with the Millennium Development Goals?. Policy Brief September 2005. Center for Global Development.

Clemens, M.A., C.J. Kenny and T.J. Moss (2007). The trouble with the MDGs: Confronting expectations of aid and development success. World Development 35(5), 735-751.

Constantini, V. and S. Monni (2005). Sustainable human development for European countries. Journal of Human Development 6(3), 329-351.

Cooper, R. and J. Haltiwanger (1996). Evidence on macroeconomic complementarities. Review of Economics and Statistics 77, 7893.

Dalal-Clayton, B. (2003). The MDGs and sustainable development: The need for a strategic approach. Chap. 5, pp. 73-92. In: D. Satterthwaite The Millennium Development Goals and local processes. IIED publication downloadable at www.iied.org.

Daly, H.E. (1990). Toward some operational principles of sustainable development. Ecological Economics 2, 1-6.

Daly, H.E. (1991). Towards an environmental macroeconomics. Land Economics 67(2), 255-259. 
Daly, H.E. (1996). Beyond Growth: The Economics of Sustainable Development. Beacon Press, Boston.

Dasgupta, P. and M. Weale (1992). On measuring the quality of life. World Development 20(1), 119-131. from Berenger2007.

Denison, E. (1961). The sources of economic growth in the United States.

DESTATIS (2011). Volkswirtschaftliche Gesamtrechnung, Fachserie 18, Statistisches Bundesamt Deutschland.

Devarajan, S., M.J. Miller and E. Swanson (2002). Goals for development: History, prospects, and costs. Policy Research Working Paper 2819. World Bank.

Devarajan, S., V. Swaroop and H. Zou (1996). The composition of public expenditure and economic growth. Journal of Monetary Economics 37, 313-344.

Duffy, J., C. Papageorgiou and F. PerezSebastian (2004). Capital-skill complementarity? Evidence from a panel of countries. Review of Economics and Statistics 86(1), 327-344.

Easterly, W. (2009). How the Millennium Development Goals are unfair to Africa. World Development 37(1), 26-35.

EIA (2011). International Energy Statistics, U.S. Energy Information Administration.

European Council (2000). Presidency conclusions. http://www.consilium.europa.eu/ uedocs/cms_data/docs/pressdata/en/ec/ 00100-r1.en0.htm. European Comission.

European Council (2005). External Relations Council - Council conclusions: Accelerating progress towards achieving the Millenium Development Goals, http://www.unmillenniumproject.org/ documents/euexternalrelations24may.pdf.

European Council (2006). Review of the EU Sustainable Development Strategy (EU SDS) - Renewed Strategy. Brussels.

EUROSTAT (2007). Measuring progress towards a more sustainable Europe: 2007 monitoring report of the EU sustainable development strategy. Eurostat Statistical Books, European Commission, Luxembourg.
EUROSTAT (2009). Sustainable development in the European Union - 2009 monitoring report on the EU sustainable development strategy. Eurostat Statistical Books, European Commission, Luxembourg.

Fan, S. and N. Rao (2003). Public spending in developing countries: trends, determination, and impact. EPTD Discussion Paper No. 99.

Farzin, Y.H. (2004). Is an exhaustible resource economy sustainable?. Review of Development Economics 8(1), 33-46.

Farzin, Y.H. (2006). Conditions for sustainable optimal economic development. Review of Development Economics 10(3), 518-534.

Fernandez, R. and R. Rogerson (1997). The determinants of public education expenditures: Evidence from the states, 1950-1990. NBER working paper 5995. National Bureau of Economic Research.

Fielding, D. (2002). Health and wealth: A structural model of social and economic development. Review of Development Economics 6(3), 393-414.

Fielding, D. and S. Torres (2005). A simultaneous model for economic development and income inequality. Journal of Economic Inequality 4, 279-301.

Fielding, D. and S. Torres (2009). Health, wealth, fertility, education, and inequality. Review of Development Economics 13(1), 39-55.

Fielding, D., M. McGillivray and S. Torres (2008). Achieving health, wealth and wisdom: Links between aid and theMillennium Development Goals. Chap. 3, pp. 55-89. In: McGillivray et al. (2008).

Frank, U., D. Heise, H. Kattenstroth and H. Schauer (2008). Designing and utilising business indicator systems within enterprise models-outline of a method. In: MobIS (Peter Loos, Markus Nüttgens, Klaus Turowski and Dirk Werth, Eds.). Vol. 141 of LNI. GI. pp. 89-105.

Freedom House (2011). Country ratings and status by region, FIW 1973-2011: Fiwallscoreratingsbyregion1973-2011.xls. Freedom House, downloadable from http://www.freedomhouse.org/template.cfm ?page $=439$. 
Funke, M. and H. Strulik (2000). On endogenous growth with physical capital, human capital, and product variety. European Economic Review 44, 491-515.

Fuss, S. (2008). Sustainable energy development under uncertainty. PhD thesis. Maastricht University School of Business and Economics, United Nations University Maastricht Economic and Social Research and Training Centre on Innovation and Technology (UNU-MERIT).

Galor, O. and D.N. Weil (1996). The gender gap, fertility and growth. American Economic Review 86, $374-387$.

Galor, O. and O. Moav (2000). Ability based technological transition, wage inequality, and economic growth. The Quarterly Journal of Economics 115(2), 469 - 498.

Galor, O. and O. Moav (2004). From physical to human capital accumulation: Inequality and the process of development. Review of Economic Studies 71, 1001 - 1026.

GAO, United States Government Accountability Office (2004). Informing our nation: Improving how to understand and assess theUSA's position and progress. Report to the Chairman, Subcommittee on Science, Technology, and Space, Committee on Commerce, Science, and Transportation, U.S. Senate.

Gomanee, K., O. Morrissey, P. Mosley and A. Verschoor (2005). Aid, government expenditure, and aggregate welfare. World Development 33(3), 355-370.

Greene, W.H. (2003). Econometric Analysis International Edition. Pearson Education, Inc., Upper Saddle River.

Griffin, J.M. and P.R. Gregory (1976). An intercountry translog model of energy substitution responses. The American Economic Review 66, 845-857.

Griliches, Z. (1969). Capital-skill complementarity. The Review of Economics and Statistics 4, 465-468.

Grill, B. (2009). Hilfe? Nein danke!. Die ZEIT, 10 Sept. 2009, Nr. 38.

Grosse, M., K. Harttgen and S. Klasen (2008). Measuring pro-poor progress towards the non-income Millennium Development Goals. Chap. 5, pp. 123-149. In: McGillivray et al. (2008).
Grossmann, G.M. and E. Helpman (1991). Innovation and growth in the global economy. MIT Press, Cambridge, MA.

Grossmann, V., T. Steger and T. Trimborn (2010). Quantifying optimal growth policy. CESifo Working Paper Series 3092. CESifo Group Munich.

Grüning, M. (2002). Messung und Steuerung von Unternehmungsleistung. Deutscher Universitäts-Verlag.

Gupta, S., K. Honjo and M. Verhoeven (1997). The efficiency of government expenditure: experiences from africa. IMF Working Paper WP/97/153. International Monetary Fund.

Guvenen, F. (2006). Reconciling conflicting evidence on the elasticity of intertemporal substitution: A macroeconomic perspective. Journal of Monetary Economics 53, 14511472 .

Hall, R.E. (1988). Intertemporal substitution in consumption. Journal of Political Economy 96, 339-357.

Harrod, R.F. (1939). An essay in dynamic theory. The Economic Journal 49(193), 14-33.

Helfat, C. (1988). Investment choices in industry. MIT Press, Cambridge, MA.

Herrera, S. (2007). Public expenditure and growth. Policy Research Working Paper 4372. World Bank.

Herrera, S. and G. Pang (2005). Efficiency of public spending in developing countries: an efficiency frontier approach. Policy Research Working Paper 3645. World Bank.

Herrero, C., R. Martínez and R. Villar (2010). Improving the measure of human development. Human Development Reports Research Paper 2010/12. United Nation Development Programme.

Hofkes, M.W. (1996). Modelling sustainable development: An economy-ecology integratedmodel. Economic Modelling 13, 333-353.

Iacopetta, M. (2010). Phases of economic development and the transitional dynamics of aninnovation-education growth model. European Economic Review 54, 317-330.

IEA (2009). World Energy Outlook 2009. International Energy Agency.

IEA (2010a). $\mathrm{CO}_{2}$ emissions. International Energy Agency. 
IEA (2010b). World Energy Outlook 2010. International Energy Agency.

IMF (2007). World Economic Outlook 2007: Globalization and inequality. World Economic and Financial Surveys. International Monetary Fund.

Jayasuriya, R. and Q. Wodon (2008). Measuring and explaining country efficiency in improving health andeducation indicators. Munich Personal RePEc Archive Paper No. 11183. MPRA.

JPOI (2002). Plan of Implementation of the World Summit on Sustainable Development, United Nations, Johannesburg, ZA, downloadable from http://www.un.org/esa/sustdev/documents/ wssd_poi_pd/english/wssd_planimpl.pdf.

Kaldor, N. (1961). Capital accumulation and economic growth. pp. 177-222. In: F.A. Lutz and D.C. Hagur (eds.) The theory of capital. St. Martin's Press, New York.

Kar, M. and E.J. Pentecost (2000). A system test of McKinnon's complementarity with an application to Turkey. Economic Research Paper No: 00/26. Loughborough University, Department of Economics.

Kemfert, C. (1998). Estimated substitution elasticities of a nested CES production function approach for Germany. Energy Economics 20, 249-264.

Keuning, S. and M. Verbruggen (2003a). European structural indicators, a way forward. Economic Systems Research 15(2), 185196.

Keuning, S. and M. Verbruggen (2003b). European structural indicators, a way forward. Economic Systems Research 15(2), 185-196.

Klasen, S. (2008). Economic growth and poverty reduction: Measurement issues using income and non-income indicators. World Development 36(3), 420-445.

Klugman, J., C. Ugaz, A. Kennedy, L. Carvajal, A. Gaye, P. Seck, C. Aiello and others from HDRO (2008). Human Development Indices - A statistical update 2008. Technical report. Published for the United Nations Development Programme.

Krusell, P., L.E. Ohanian, J.V.R. Rull and G.L. Violante (1997). Capital-skill complementarity and inequality: A macroeconomic analysis. RDS Report No 236. Federal Reserve Bank of Minneapolis.
Lange, G.M. and M. Wright (2004). Sustainable development in mineral economies: The example of Botswana. Environment and Development Economics 9, 485 - 505.

Lecocq, F. and Z. Shalizi (2007). How might climate change affect economic growth in developing countries?A review of the growth literature with a climate lense. Policy research working paper 4315. World Bank.

Levin, A., C.-F. Lin and C.-S.J. Chu (2002). Unit root tests in panel data: Asymptotic and finite-sample properties. Journal of Econometrics 108, 1-24.

Litchfield, J.A. (1999). Inequality: Methods and tools. Downloadable from World Bank's Web Site on Inequality, Poverty, and Socio-economicPerformance from http://siteresources.worldbank.org/INTPGI /Resources/Inequality/litchfie.pdf. World Bank.

Lokshin, B., M. Carree and R. Belderbos (2007). Testing for complementarity and substitutability in case of multiple practices. Msi 0708.

Lucas, R.E. (1988). On the mechanics of economic development. Journal of Monetary Economics 22, 3-42.

Lucas, R.E. (1990). Supply side economics: An analytical review. Oxford Economic Papers 42, 293-316.

Mairesse, J. and P. Mohnen (2010). Using Innovation Surveys for Econometric Analysis. Chap. 26, pp. 1129-1155. In B.H. Hall and N. Rosenberg Handbook of the Economics of Innovation, Volume 2. Elsevier B.V.

Markovitz, H.M. (1952). Portfolio selection. Journal of Finance 7(1), 77-91.

Mavrotas, G. (2009). Introduction: Development aid - Theory, policies, and performance. Review of Development Economics 13(3), 373-381.

McGillivray, M. (2005). Measuring noneconomic well-being achievements. Review of income and wealth 51(2), 337-364.

McGillivray, M. (2008). The Millennium DevelopmentGoals: Overview, progress and prospects. Chap. 1, pp. 1-14. In: McGillivray et al. (2008). 
McGillivray, M., P.B. Anand, S. Bholatra, N. Blöndal, I. Dutta, D. Fielding, M. Gross, K. Harttgen, S. Klasen, S. Torres, H. White and B. Zamora (2008). Achieving the Millennium Development Goals. Palgrave MacMillan in association with UNU-WIDER.

MDG (2010). MDG Metadata, available at http://unstats.un.org/unsd/mdg/metadata. aspx, United Nations Statistics Devision, Department of Economicand Social Affairs.

Meredith, M. (2005). The state of Africa. The Free Press, Simon and Schuster UK Ltd, London.

Merton, R. (1969). Lifetime portfolio selection under uncertainty: The continuoustime case. Review of Economics and Statistics 51(3), 247-257.

Milgrom, P. and J. Roberts (1990). The economics of modern manufacturing: Technology, strategy, and organization. American Economic Review 80, 511-528.

Milgrom, P. and J. Roberts (1995). Complementarities and fit: Strategy, structure and organizational change in manufacturing. Journal of Accounting and Economics 19, 179-208.

Miravete, E.J. and J.C. Pernías (1998). Innovation complementarity and the scale of production. Rr\#98-42. NY University, Department of Economics.

Miravete, E.J. and J.C. Pernías (2006). Innovation complementarity and the scale of production. The Journal of Industrial Economics 54, 1-29.

Mohnen, P. and L.-H. Röller (2003). Complementarities in innovation policy. Cirano working papers 2003s-60.

Morris, M.D. (1978). A physical quality of life index. Urban Ecology 3(3), 225 - 240. Special Issue The Quality of Life.

Morse, S. (2003). For better or for worse, till the Human Development Index do us part?. Ecological Economics 45, 281-296.

Moyo, D. (2009). Dead aid: Why aid is not working and how there is a better way for Africa. London: Allen Lane.

Murillo-Zamorano, L. (2004). Economic efficiency and frontier techniques. Journal of Economic Surveys 18, 1.
Nelson, R.R. and S.G. Winter (1982). An Evolutionary Theory of Economic Change. Cambridge, Mass: Harvard University Press.

Neumayer, E. (2010). Human development and sustainability. Human development reports research paper 2010/05.

Neumayer, Eric (2001). The Human Development Index and sustainability - a constructive proposal. Ecological Economics 39, 101-114.

Noll, H.H. (2004). Social indicators and indicator systems: Tools for social monitoringand reporting. Presentation at the OECD World Forum "Statistics, Knowledge, and Policy", Palermo, 10-13 November 2004.

Noorbakhsh, F. (1998). A Modified Human Development Index. World Development 26(3), 517-528.

OECD (2007). The OECD glossary of statistical terms.

OECD (2011). How's Life?: Measuring well-being. http://dx.doi.org/10.1787/ 9789264121164-en, OECD Publishing, Paris.

OECD and European Commission JRC (2008). Handbook on constructing composite indicators. OECD Publishing, Paris.

Ortigueira, S. and M.S. Santos (1996). On convergence in endogenous growth models. Discussion paper 110. Federal Reserve Bank of Minneapolis Institute for Empirical Macroeconomics.

Pautrel, X. (2008). Reconsidering the impact of the environment on long-run growth when pollution influences health and agents have a finite-lifetime. Environmental \& Resource Economics 40, 37 - 52 .

Pritchett, L. and L. Summers (1993). Wealthier is healthier. Country economics department working paper 1150. World Bank.

Rahman, T., R.C. Mittelhammer and P. Wandschneider (2005). Measuring the quality of life across countries: A sensitivity analysis of well-being indices.

Rajan, R. and A. Subramanian (2005). What undermines aid's impact on growth?. Imf working paper 05/126. International Monetary Fund. 
Ramirez, M.D. (2007). A panel unit root and panel cointegration test of the complementarity hypothesis in the Mexican case: 1960 - 2001. Atlantic Economic Journal 35, 343356.

Ramsey, F.P. (1928). A mathematical theory of saving. The Economic Journal 38(152), 543-559.

Ranis, G. and F. Stewart (2005). Dynamic links between the economy and human development. Desa working paper no. 8/2005. United Nations Department of Economic and Social Affairs.

Romer, P.M. (1989). Capital accumulation in the theory of long-run growth. pp. 51-127. In: R.J. Barro (ed.) Modern business cycle theory. Basil Blackwell, Oxford.

Romer, P.M. (1990). Endogenous technological change. Journal of Political Economy 98(2), S71-S102.

SADC (2008). The impact of climate change on the poverty situation in the region. Draft Background Document of the SADC International Conference on Poverty and Development: "Regional Economic Integration: A Strategy for Poverty Eradication towards Sustainable Development". http://www.sadc.int/conference/content/ english/CC\%20Backgrounds/An\%20Assesss ment $\% 20$ of\%20Poverty\%20Alleviation $\% 20$ Strategy\%20in\%20SADC(2).pdf.

Sagar, A.D. and A. Najam (1998). The Human Development Index: A critical review. Ecological Economics 25, 249-264.

Saltelli, A., M. Nardo, M. amd Saisana and S. Tarantola (2004). Composite indicators the controversy and the way forward. Presented at the OECD World Forum on key indicators.

Samuelson, P. (1969). Lifetime portfolio selection by dynamic stochastic programming. Review of Economics and Statistics 51(3), 239-246.

Seitz, N. and M. Ellison (1995). Capital Budgeting and long-term financing decisions. Dryden Press.

SERI and WI (2011). http://www.material flows.net/ the online portal for material flow data. Technical report. Sustainable Europe Research Institute (SERI), Vienna, Austria, and Wuppertal Institute for Climate, Environment and Energy, Wuppertal, Germany.
Shikwati, J. (2006). Fehlentwicklungshilfe. Mit eigenständigen Lösungen kann Afrika eine neue Rolle spielen. Internationale Politik.

Solow, R.M. (1956). A contribution to the theory of economic growth. Quarterly Journal of Economics 70, 65-94.

Steger, T. (2000). Transitional dynamics and economic growth in developing countries. Springer.

Steger, T. (2011). Uzawa-Lucas model (complete). Chap. 3.5. In: Quantiative Dynamic Macroeconomics, Lecture Notes, Thomas Steger, University of Leipzig, Winter Term 2010/11.

Stern, N. (2007). Stern Review on The Economics of Climate Change. Cambridge University Press.

Stiglitz, J.E., A. Sen and J.-P. Fitoussi (2009). Report by the Commission on the Measurement of Economic Performance and Social Progress. http://www.stiglitz-sen-fitoussi.fr.

Sundberg, M., F. Bourguignon and A. Gelb (2007). Global Monitoring Report 200\%. The World Bank.

Szirmai, A. (2010). Growth andstagnation: Theories and experiences.. Chap. 3. In A. Szirmai The Dynamics of Socio-Economic Development. Cambridge University Press.

Temple, J. (2003). The long-run implications of growth theories. Journal of Economic Surveys $\mathbf{1 7}(\mathbf{3}), 497-510$.

Teulings, C. and T. van Rens (2003). Education, growth and income inequality. $C E P R$ discussion paper 3863.

The Economist (2011). Africa rising. December 3,2011 .

Trimborn, T., K.-J. Koch and T.M. Steger (2006). Multi-dimensional transitional dynamics: A simple numerical procedure. $C E$ Sifo Working Paper No. 1745.

Trimborn, Timo, Karl-Josef Koch and Thomas M. Steger (2008). Multidimensional transitional dynamics: A simple numerical procedure. Macroeconomic Dynamics 12(03), 301-319.

UN (2000). 55/2. United Nations Millennium Declaration. 
UN (2001). Road map towards the implementation of the United Nations Millennium Declaration.

UN (2002). Implementation of the United Nations Millennium Declaration.

UN, United Nations (2007). The Millennium Development Goals Report 2007. New York.

UN, United Nations (2008a). Information retrieved from the world wide web in june 2008: http://www.un.org/esa/susdev/.

UN, United Nations (2008b). The Millennium Development Goals Report 2008. New York.

UNDP (1990). Human Development Report. New York: Oxford University Press.

UNDP (2009). Human Development Report: Statistics, hdi_trends_components_2009_rev.xls, available at http://hdr.undp.org/en/statistics/, United Nations Development Programme, Human Development Reports Office.

UNDP (2010). Human Development Report 2010 - The Real Wealth of Nations: Pathways to Human Development. Palgrave.

UNDP (2011). Human Development Report 2011 - Sustainability and Equity: A Better Future for All. New York: Oxford University Press.

UNECA (2008). Sustainable development report on Africa, United Nations Economic Commission for Africa, Addis Ababa, Ethiopia.

Uzawa, H. (1962). Production functions with constant elasticities of substitution. Review of Economic Studies 29(4), 291-299.

van den Bergh, J.C.J.M. and P. Nijkamp (1994). Dynamic macro modelling and materials balance: economic-environmental integration for sustainable development. Economic Modelling 11(3), 283-307. van Zon, A. and H. Kiiver (2006). On the persistence of inequality in the distribution of personalabilities and income. Working paper series 2006-13. UNU-MERIT.

van Zon, A. and J. Muysken (2001). Health and endogenous growth. Journal of Health Economics 20, 169-185.

van Zon, A. and K.S. Wiebe (2010). Efficient development portfolio design for subsaharan africa. Working paper series 2010050. UNU-MERIT.

van Zon, A. and S. Fuss (2008). Risk, embodied technical change and irreversible investments in UK electricity production: An optimum technology portfolio approach. Chap. 14, pp. 275-303. In M. Bazilan and F. Roques Analytical methods for energy diversity and security. Elsevier Publishers.

Vandemoortele, J. (2007). The MDGs: 'M' for misunderstood?

Volk, A. and J. Lippelt (2011). Kurz zum Klima:Müllberge - eine Bedrohung nicht nur für unser Klima. ifo Schnelldienst 64(19), 27-29.

WDI (2009). World Development Indicators Online, World Bank Group.

WDI (2011). World Development Indicators Online, World Bank Group.

White, H. (2002). Combining quantitative and qualitative approaches in poverty analysis. World Development 30(3), 511-522.

White, H. and N. Blöndal (2008). Projecting progress towards the Millennium DevelopmentGoals. Chap. 2, pp. 20-54. In: McGillivray et al. (2008).

WHO (2009). Data and statistics: National Health Accounts.

Zellner, A. (1962). An efficient method of estimating seemingly unrelated regressions and tests for aggregation bias. Journal of the American Statistical Association 57, 348 368. 


\section{Samenvatting}

Het feit dat Afrikaanse landen relatief slecht presteren op zowel het gebied van de economische en sociale ontwikkeling als dat van de bescherming van het milieu, suggereert het bestaan van een zekere onderlinge afhankelijkheid tussen deze gebieden. De centrale onderzoeksvraag gesteld in deze studie is dan ook: Op welke wijze hangen verschillende aspecten van duurzame ontwikkeling met elkaar samen?

Om deze vraag te beantwoorden wordt in Hoofdstuk 2 de onderbouwing gegeven voor de kwantitatieve analyse in de overige hoofdstukken, door samen te vatten op welke wijze duurzame ontwikkeling wordt gemeten, zowel theoretisch als in de praktijk. Tevens wordt in Hoofdstuk 2 ingegaan op de vraag wanneer ontwikkeling als duurzaam kan worden beschouwd. Duurzame ontwikkeling heeft een multi-dimensionaal karakter gedifferentieerd naar tijd, plaats en levensomstandigheden. In dit proefschrift worden verschillende kwantitatieve economische methoden ontwikkeld en toegepast om met behulp daarvan de onderlinge samenhang tussen de verschillende aspecten van duurzame ontwikkeling grondig te kunnen analyseren. Hierbij blijken verschillen tussen landen op het gebied van levensstandaard / inkomen, onderwijs en gezondheidszorg van groot belang te zijn. Samengevat luidt het antwoord op de centrale onderzoeksvraag: Er is een aantoonbaar elkaar wederzijds positief versterkende relatie tussen onderwijs en gezondheid. Bovendien zijn condities als degelijk onderwijs en een goede gezondheid noodzakelijke voorwaarden voor economische ontwikkeling en daarmee ook voor de algemene menselijke ontwikkeling.

De beschrijvende analyse van ontwikkeling in Sub-Sahara Afrika in Hoofdstuk 3 toont aan dat, ondanks de significante vooruitgang die is geboekt de afgelopen tien jaar, het ontwikkelings-tempo van veel Afrikaanse landen nog steeds relatief laag is. De meeste Afrikaanse landen bezuiden de Sahara zijn slechts in beperkte mate in staat de doelstellingen die door de Verenigde Naties in 2000 zijn vastgelegd in de Millennium Development Goals te realiseren. Dit mag evenwel niet leiden tot de conclusie dat er geen resultaat geboekt is, of dat de MDG's "oneerlijk" zijn voor veel Afrikaanse landen, zoals eerder wordt uiteengezet in Hoofdstuk 2. Zonder deze doelstellingen is het niet mogelijk meetbare ontwikkelingsdoelen te formuleren en daarop ontwikkelingsbeleid te baseren. De MDG's zijn dan ook bedoeld als een overkoepelend instrument en ijkpunt voor alle landen bij het nastreven van de daarin geformuleerde ontwikkelingsdoelen.

De analyse in Hoofdstuk 4 maakt gebruik van de gegevens welke zijn gepresenteerd in Hoofdstuk 3. Door middel van een aanvullende econometrische analyse wordt het bestaan aangetoond van positieve relaties tussen gezondheid en educatieve aspecten, en omgekeerd, die elkaar wederzijds versterken. In het onderliggende econometrische model is een aanpassing meegenomen om rekening te houden met evidente afwijking van het als optimaal beschouwde ontwikkelingstraject. De gebruikte indicatoren zijn: het sterftecijfer voor kinderen onder de 5 jaar (dit is van invloed op de kwantificering van gezondheidsprestaties), het al dan niet voltooien van de basisschool (dit is van invloed op de 
kwantificering van onderwijsprestaties). Het is echter onduidelijk wat de relatie van deze twee indicatoren is m.b.t. de economische ontwikkeling gemeten naar het BBP per hoofd van de bevolking, de consumptie-uitgaven per capita en het primaire energieverbruik per capita. De resultaten laten echter duidelijk zien dat ontwikkelingsbeleid gericht op het bevorderen van zowel onderwijs als de gezondheidszorg in het algemeen, een positiever effect zal hebben op de algehele ontwikkeling van een land, dan ontwikkelingsbeleid gericht op het bevorderen van scholing of de gezondheid van individuen.

Dit resultaat roept de vraag op welke beleidsmatige keuzes van belang zijn, in het bijzonder voor lokale beleidsmakers, om onderwijsprestaties te stimuleren en tevens de gezondheidstoestand van de bevolking te verbeteren. Omdat de politieke situatie in ieder afzonderlijk Afrikaans land verschillend is, is het hier niet de bedoeling om gedetailleerde beleidsmaatregelen te schetsen. In plaats daarvan onderzoekt Hoofdstuk 5 een macroeconomische benadering voor het maken van beleidskeuzes, door het in kaart brengen van de optimale verdeling van de overheids bestedingen gerelateerd aan duurzame ontwikkeling, en gemeten als overheidsuitgaven gekoppeld aan de afzonderlijke componenten van de Human Development Index. De efficient development portfolio approach die hier wordt ontwikkeld is gebaseerd op de "optimale portefeuille theorie" van Markowitz. De uitkomsten hiervan laten zien dat in de meeste Afrikaanse landen de overheidsbegroting op dit punt niet efficiënt wordt ingezet. Deze inefficiënties zijn meestal het gevolg van te weinig bestedingen op het gebied van gezondheidszorg en onderwijs. Een herverdeling van de overheidsuitgaven tot circa 20 procent van het overheidsbudget in de richting van deze twee uitgavencategorieën is dan ook aan te bevelen.

Hoofdstuk 6 vormt een aanvulling op de voorgaande hoofdstukken door de onderlinge relatie tussen de verschillende ontwikkelingsaspecten te onderzoeken vanuit een lange termijn perspectief vormgegeven binnen het kader van een endogeen groeimodel. De resultaten van de voorgaande hoofdstukken onderstrepen het belang van zowel gezondheidszorg als onderwijs bij de beoordeling van de mate van welzijn van de bevolking van een land. Het groeimodel ontwikkeld in Hoofdstuk 6 integreert deze bevindingen in één van de standaardmodellen van de endogene groeitheorie, onder andere door verschillende aspecten van gezondheidszorg en onderwijs op te nemen in de welvaartsfunctie naast de standaardcomponent, i.e. consumptie per hoofd van de bevolking. In het model wordt eveneens rekening gehouden met het feit dat de productie van gezondheids- en onderwijsdiensten de inzet van alternatief aanwendbare middelen vergt. Een belangrijke uitkomst van dit model is dat, ondanks het feit dat gezondheidszorg, onderwijs en economische groei weliswaar substituten zijn op de korte termijn, maar ze zijn tevens complementen op de lange termijn.

Dit proefschrift toonde in de voorgaande hoofdstukken de werkingsprincipes van de verschillende kwantitatieve modellen aan. Deze modellen worden geschikt geacht om duurzame ontwikkeling te beoordelen, niet alleen in het Afrikaanse continent maar ook in andere regio's. De belangrijkste boodschap van dit proefschrift is dat gezondheidszorg en onderwijs belangrijke determinanten zijn van economische ontwikkeling en groei. Desondanks wordt kennelijk in veel Afrikaanse landen het belang van de bijdragen van investeringen in onderwijs en gezondheidszorg aan de afzonderlijke componenten van de HDI stelselmatig onderschat. Voor de lange termijn leidt dit tot een structureel lager tempo van de welvaartsgroei, omdat gezondheids-, onderwijs- en groeiprestaties onlosmakelijk aan elkaar zijn verbonden. 


\section{Curriculum Vitae}

Kirsten S. Wiebe, born 1982 in Münster, Germany, studied Econometrics and Operations Research at Maastricht University (Bachelor of Science 2005, Master of Science 2006), and spent one semester abroad at the Handelshögsskolan vid Göteborgs Universitetet in Gothenburg, Sweden (focus on international and environmental economics). She has been working as a volunteer in Kinshasa, Democratic Republic of the Congo, in 2006, where she has also been an election observer. Since 2007, she is a researcher at the Institute of Economic Structures Research (GWS mbH) in Osnabrück, Germany, where she also continued working next to participating in the $\mathrm{PhD}$ programme "Economics and policy studies of technical change" at UNU-MERIT. During her PhD studies she received several scholarships - next to the MERIT foundation fellowship - to participate in summer schools, e.g. the First Jerusalem Summer School on Economic Growth organized by the Minerva Center for Economic Growth at the Hebrew University of Jerusalem or the Summer School on " $R$ " organized by the European Science Foundation Quantitative Methods in the Social Sciences 2 project.

Her research interests are mainly quantitative in the fields of sustainable development, environmental, energy and resource economics, input-output analysis and global economic modeling. She presented her research at different international conferences such as the International Conference on Economic Policy Modeling (Ecomod 2010, 2011 and 2012), the INFORUM World Conference or the First World Sustainability Forum. Her research on an environmentally extended multiregional input-output model is published in several international peer-reviewed journals (Economic Systems Research, Journal of Industrial Ecology and Global Environmental Change). 



\section{UNU-MERIT Dissertation series}

2012

73. Julio Miguel Rosa - Organizational Strategies, Firms' Performance and Spatial Spillovers. The Canadian Case in Research and Development.

xx. Johannes Wilhelmus Marie Boels Joseph Schumpeter, honderd jaar economische ontwikkeling. Een historisch-theoretische beschouwing.

\section{1}

72. Daniel Vertesy - Interrupted Innovation: Emerging economies in the structure of the global aerospace industry.

71. Tina Saebi - Successfully managing alliance portfolios: an alliance capability view.

70. Nora Engel - Tuberculosis in India - A case of innovation and control.

69. Evans Mupela - Connectivity and growth in Sub-Saharan Africa: The role of communication satellites

68. Nantawan Kwanjai - Cross cultural intelligence amid intricate cultural webs - A tale of the UnDutchables in the land of 1002 smiles

67. Lina Sonne - Innovation in Finance to Finance Innovation: Supporting pro-poor entrepreneur-based innovation

\section{0}

66. Fernando Santiago - Human Resources Management Practices and Learning for Innovation in Developing Countries: Pharmaceutical Firms in Mexico

65. Zakaria Babutsidze - Essays on Economies with Heterogenous Interacting Consumers

64. Bertha Vallejo - Learning and Innovation Under Changing Market Conditions: The Auto Parts Industry in Mexico

63. Donatus Ayitey - Technical Change, Competitiveness and Poverty Reduction: A Study of the Ghanaian Apparel Industry

62. Sergey Fillipov - Multinational Subsidiary Evolution: Corporate Change in New EU Member States

61. Asel Doranova - Technology Transfer and Learning under the Kyoto regime; Exploring the Technological Impact of CDM projects in developing countries

\section{9}

60. Alexis Habiyaremye - From Primary Commodity Dependence to Diversification and Growth: Absorptive Capacity and Technological Catch Up in Botswana and Mauritius.

59. Yoseph Getachew - The Role of Public Capital in Economic Development

58. Sandra Leitner - Embodied Technological Change and Patterns of Investment in Austrian Manufacturing

57. Semih Akçomak - The Impact of Social Capital on Economic and Social Outcomes
56. Abraham Garcia - The Role of Demand in Technical Change

55. Saurabh Arora - Coherence in sociotechnical systems: a network perspective on the innovation process

\section{8}

54. Rutger Daems - Medicines for the developing world

53. Johannes Hanel - Assessing Induced Technology - Sombart's Understanding of Technical Change in the History of Economics

52. Rifka Weehuizen - Mental Capital: the economic significance of mental health

51. Danielle Cloodt - The relationship between R\&D partnership formation, social embeddedness and innovative performance

50. Sabine Fuss - Sustainable Energy Development under Uncertainty

\section{7}

49. Tobias Kronenberg - Reconciling Environmental Conservation with Economic Prosperity: The Feasibility of Double Dividends in the Short and Long Run

48. Viktoria Kravtsova - Assessing the Impact of Foreign Direct Investment in Transition Economies

47. Suhail Sultan - The Competitive Advantage of Small and Medium Sized Enterprises: The Case of Jordan's Natural Stone Industry

\section{6}

46. Bulat Sanditov - Essays on Social Learning and Imitation

45. Mamata Parhi - Dynamics of New Technology Diffusion: A Study of the Indian Automotive Industry

44. Andreas Reinstaller - Social structures and the innovation process: Their role in the demand of firms and consumers

43. Rose Kiggundu - Innovation systems and development : the journey of a Beleaguered Nile Perch Fishery in Uganda

42. Thomas Pogue - The Evolution of Research Collaboration in South African Gold Mining: 1886-1933

41. Geoffrey Gachino - Foreign Direct Investment, Spillovers and Innovation: The Case of Kenyan Manufacturing Industry

40. Önder Nomaler - Technological Change, International Trade and Growth - An Evolutionary, Multi-Agents-Based Modeling Approach 2005

39. Samia Satti Osman Mohamed-Nour Change and Skill Development in the Arab Gulf Countries

38. Elad Harison - Intellectual Property Rights: Economics and Policy Analysis

37. Daniel Dalohoun - The relationship between R\&D partnership formation, social em- 
beddedness and innovative performance: multi-level approach of social embeddedness 36. Müge Ozman - Networks, Organizations and Knowledge

35. Bas Straathof - Product variety and economic growth - The counteracting effects of scale and idiosyncrasy

34. Wilfred Schoenmakers - Knowledge Flows between Multinational Companies: A Patent Data Analysis 33. Myriam Cloodt - Mergers and Acquisitions (M\&As) in High-Tech Industries: Measuring the Post-M\&A Innovative Performance of Companies

2004

32. Paola Criscuolo - R\&D Internationalisation and Knowledge Transfer. Impact on MNEs and their Home Countries

31. Maarten Verkerk - Trust and Power on the Shop Floor

30. Gottfried Leibbrandt - Adoption, harmonization and succession of network technologies across countries

29. Mark Sanders - Skill Biased Technical change - Its Origins, the Interaction with the Labour Market and Policy Implications 2003

28. Nadine Roijakkers - Inter-firm cooperation in high-tech industries: a study of $R \& D$ partnerships in pharmaceutical biotechnology 27. Viki Sonntag - Speed, Scale and Sustainability

26. Masaru Yarime - From End-of-Pipe Technology to Clean Technology

25. Stéphane Malo - The combinatorial Chemistry Revolution - Sustaining a Superior Performance Position through Technological Learning

\section{2}

24. Annelies Hogenbirk - Determinants of Inward Foreign Direct Investment: the Case of the Netherlands

2001

23. John Adeoti - Technology Investment in Pollution Control in Sub-Saharan Africa: The Case of the Nigerian Manufacturing Industry

22. Edward Huizenga - Innovation Management: How Frontrunners Stay Ahead. An Empirical Study on Key Success Factors in the ICT sector

2000

21. Machiel van Dijk - Technological Change and the Dynamics of Industries. Theoretical Issues and Empirical evidence from Dutch Manufacturing

\section{9}

20. Jan Cobbenhagen - Managing Innovation at the Company Level: A Study on Non-SectorSpecific Success Factors

19. Marjolein Caniëls - Regional Growth Differentials: The Impact of Locally Bounded

\section{Knowledge Spillovers} 1998

18. Aldo Geuna - Resource allocation and knowledge production: Studies in the economics of university research

\section{6}

17. Reinoud Joosten - Dynamics, Equilibria, and Values

16. Hugo Kruiniger - Investment, R\&D, and the Financing Decisions of the Firm

\section{5}

15. Hans van Meijl - Endogenous Technological Change: The Case of Information Technology. Theoretical Considerations and Empirical Results

14. René Kemp - Environmental Policy and Technical Change. A Comparison of the Technological Impact of Policy Instruments

13. Rohini Acharya - The Impact of New Technologies on Economic Growth and Trade. A Case Study of Biotechnology

12. Geert Duysters - The Evolution of Complex Industrial Systems. The Dynamics of Major IT Sectors

11. Marjan Groen - Technology, Work and Organisation, A Study of the Nursing Process in Intensive Care Units

\section{4}

10. Huub Meijers - On the Diffusion of Technologies in a Vintage Framework; Theoretical Considerations and Empirical Results

9. Theon van Dijk - The Limits of Patent Protection. Essays on the Economics of Intellectual Property Rights

8. Hans Voordijk - Naar Integrale Logistiek in Bedrijfsketens, Ontwikkelingen in de Bouw 1993

7. Paul Diederen - Technological Progress in Enterprises and Diffusion of Innovations. Theoretical Reflections and Empirical Evidence.

6. Ben Dankbaar - Economic Crisis and Institutional Change. The crisis of Fordism from the perspective of the automobile industry 5. Hanno Roberts - Accountability and Responsibility: The Influence of Organisation Design on Management Accounting

\section{2}

4. Bart Verspagen - Uneven Growth Between Interdependent Economies. An Evolutionary View on Technology Gaps, Trade and Growth 3. Sjoerd Romme - A Self-organization Perspective on Strategy Formation

\section{9}

2. John Spangenberg - Economies of Scale, and Atmosphere in Research Organisations 1988

1. John Hagedoorn - Evolutionary and heterodox innovation analysis: a study of industrial and technological development in process control and information technology 